\title{
TMI-2 Vessel Investigation Project Integration Report
}

RECEIVED

APR 181994

OSTI

Prepared by J. R. Wolf, J. L. Rempe, L. A. Stickler, G. E. Korth, D. R. Diercks, L. A. Neimark, D. W. Akers, B. K. Schuetz, T. L. Shearer, S. A. Chávez, G. L. Thinnes,

R. J. Witt, M. L. Corradini, J. A. Kos

Idaho National Engineering Laboratory EG\&G Idaho, Inc.

Prepared for

U.S. Nuclear Regulatory Commission 


\section{AVAILABILITY NOTICE}

Availability of Reference Materials Cited in NRC Publications

Most documents cited in NRC publications will be available from one of the following sources:

1. The NRC Public Document Room, 2120 L Street, NW., Lower Level. Washington, DC 20555-0001

2. The Superintendent of Documents, U.S. Government Printing Office, Mail Stop SSOP, Washington. DC $20402-9328$

3. The National Technical Information Service, Springfield, VA 22161

Although the listing that follows represents the majority of documents cited in NRC publications, it is not intended to be exhaustive.

Referenced documents available for inspection and copying for a fee from the NRC Public Document Room include NRC correspondence and internal NRC memoranda; NRC bulletins, circulars, information notices, inspection and investigation notices; licensee event reports; vendor reports and correspondence; Commission papers; and applicant and licensee documents and correspondence.

The following documents in the NUREG series are avallable for purchase from the GPO Sales Program: formal NRC staff and contractor reports, NRC-sponsored conference proceedings, international agreement reports, grant publications, and NRC booklets and brochures. Also avallable are regulatory guides, NRC regulations in the Code of Federal Regulations. and Nuclear Regulatory Commission Issuances.

Documents avallable from the National Technical information Service include NUREG-series reports and technical reports prepared by other Federal agencies and reports prepared by the Atomic Energy Commission, forerunner agency to the Nuclear Regulatory Commission.

Doouments avallable from public and special technical libraries include all open literature items, such as books. journal articles. and transactions. Federal Register notices. Federal and State legislation, and congressional reports can usually be obtained from these libraries.

Documents such as theses, dissertations, foreign reports and translations, and non-NRC conference proceedings are available for purchase from the organization sponsoring the publication cited.

Single copies of NRC draft reports are available free, to the extent of supply, upon written request to the Office of Administration. Distribution and Mall Services Section, U.S. Nuclear Regulatory Commission. Washington. DC 20555-0001.

Copies of industry codes and standards used in a substantive manner in the NRC regulatory process are maintained at the NRC Library, 7920 Norfolk Avenue. Bethesda, Maryland. for use by the public. Codes and standards are usually copyrighted and may be purchased from the originating organization or, if they are American National Standards, from the American National Standards Institute, 1430 Broadway, New York, NY 10018.

\section{DISCLAIMER NOTICE}

This report was prepared as an account of work sponsored by an agency of the United States Government. Neither the United States Government nor any agency thereof, or any of their employees, makes any warranty, expressed or implied, or assumes any legal liability of responsibility for any third party's use, or the results of such use, of any information, apparatus, product or process disclosed in this report, or represents that its use by such third party would not infringe privately owned rights. 


\section{DISCLAIMER}

This report was prepared as an account of work sponsored by an agency of the United States Government. Neither the United States Government nor any agency Thereof, nor any of their employees, makes any warranty, express or implied, or assumes any legal liability or responsibility for the accuracy, completeness, or usefulness of any information, apparatus, product, or process disclosed, or represents that its use would not infringe privately owned rights. Reference herein to any specific commercial product, process, or service by trade name, trademark, manufacturer, or otherwise does not necessarily constitute or imply its endorsement, recommendation, or favoring by the United States Government or any agency thereof. The views and opinions of authors expressed herein do not necessarily state or reflect those of the United States Government or any agency thereof. 


\section{DISCLAIMER}

Portions of this document may be illegible in electronic image products. Images are produced from the best available original document. 
NUREG/CR-6197

TMI V(93)EG10

EGG-2734

\section{TMI-2 Vessel Investigation Project Integration Report}

Manuscript Completed: February 1994

Date Published: March 1994

Prepared by J. R. Wolf, J. L. Rempe, L. A. Stickler, G. E. Korth, D. R. Diercks, L. A. Neimark, D. W. Akers, B. K. Schuetz, T. L. Shearer, S. A. Chávez, G. L. Thinnes,

R. J. Witt, M. L. Corradini, J. A. Kos

Idaho National Engineering Laboratory

Managed by the U.S. Department of Energy

EG\&G Idaho, Inc.

Idaho Falls, ID 83415

\section{Prepared for}

Division of Systems Research

Office of Nuclear Regulatory Research

U.S. Nuclear Regulatory Commission

Washington, DC 20555-0001

NRC FIN A6899

Under DOE Contract No. DE-AC07-76ID01570

\section{DISCLAIMER}

This report was prepared as an account of work sponsored by an agency of the United States Government. Neither the United States Government nor any agency thereof, nor any of their employees, makes any warranty, express or implied, or assumes any legal liability or responsibility for the accuracy, completeness, or usefulness of any information, apparatus, product, or process disclosed, or represents that its use would not infringe privately owned rights. Reference herein to any specific commercial product, process, or service by trade name, trademark, manufacturer, or otherwise does not necessarily constitute or imply its endorsement, recommendation, or favoring by the United States Government or any agency thereof. The views and opinions of authors expressed herein do not necessarily state or reflect those of the United States Government or any agency thereof. 



\begin{abstract}
The Three Mile Island Unit 2 (TMI-2) Vessel Investigation Project (VIP) was an international effort that was sponsored by the Nuclear Energy Agency of the Organization for Economic Cooperation and Development. The primary objectives of the VIP were to extract and examine samples from the lower head and to evaluate the potential modes of failure and the margin of structural integrity that remained in the TMI-2 reactor vessel during the accident.
\end{abstract}

This report presents a summary of the major findings and conclusions that were developed from research during the VIP. Results from the various elements of the project are integrated to form a cohesive understanding of the vessel's condition after the accident. 



\section{CONTENTS}

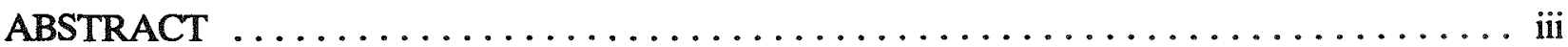

LIST OF FIGURES $\ldots \ldots \ldots \ldots \ldots \ldots \ldots \ldots \ldots \ldots \ldots \ldots \ldots \ldots \ldots \ldots \ldots \ldots \ldots \ldots$

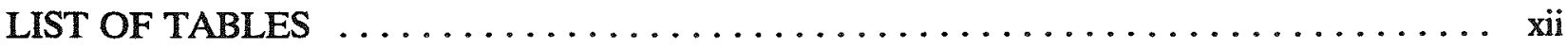

EXECUTTVE SUMMARY $\ldots \ldots \ldots \ldots \ldots \ldots \ldots \ldots \ldots \ldots \ldots \ldots \ldots \ldots \ldots \ldots$ xiii

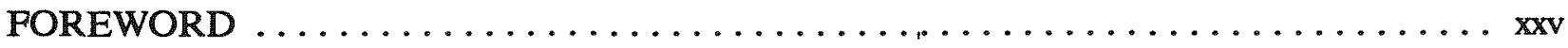

ACKNOWLEDGMENTS $\ldots \ldots \ldots \ldots \ldots \ldots \ldots \ldots \ldots \ldots \ldots \ldots \ldots \ldots \ldots$ xxvii

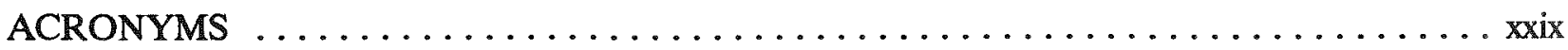

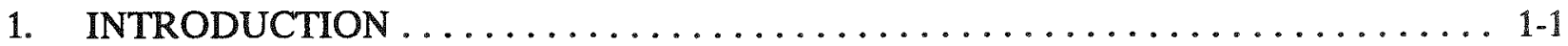

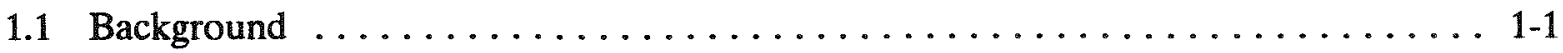

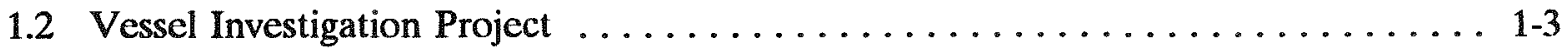

1.3 Vessel Investigation Project Objectives $\ldots \ldots \ldots \ldots \ldots \ldots \ldots \ldots \ldots \ldots \ldots \ldots \ldots \ldots .4$

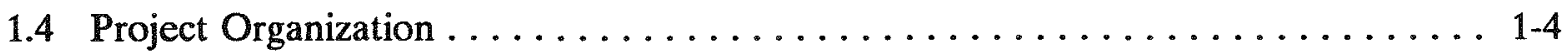

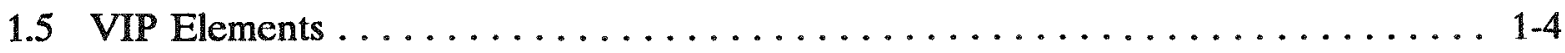

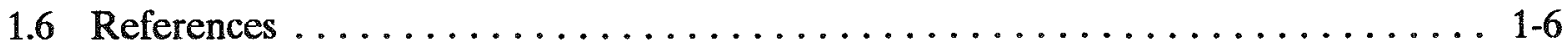

2. REACTOR DESIGN AND ACCIDENT SCENARIO $\ldots \ldots \ldots \ldots \ldots \ldots \ldots .2-1$

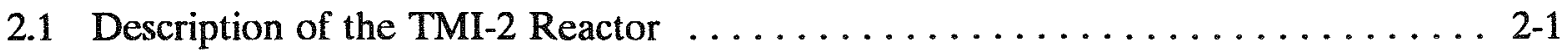

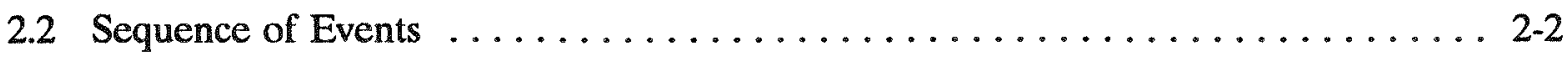

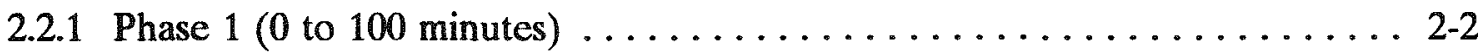

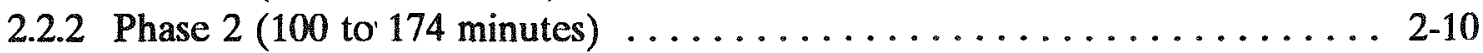

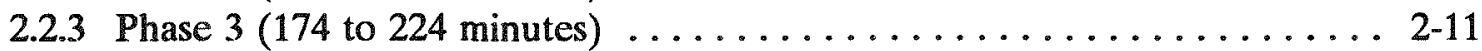

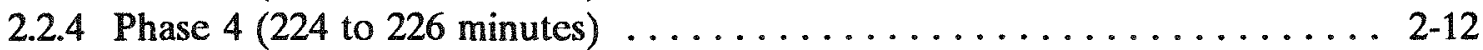

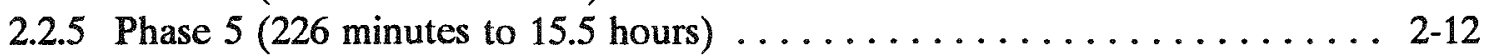

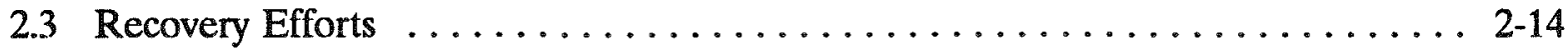

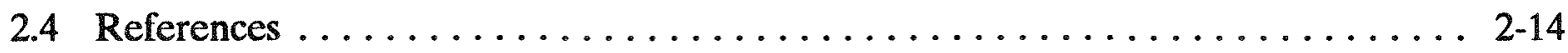


3.1 Sample Selection $\ldots \ldots \ldots \ldots \ldots \ldots \ldots \ldots \ldots \ldots \ldots \ldots \ldots \ldots \ldots \ldots$

3.2 Sample Acquisition $\ldots \ldots \ldots \ldots \ldots \ldots \ldots \ldots \ldots \ldots \ldots \ldots \ldots \ldots$

3.2.1 Nozzle and Guide Tube Cutting Tools . . . . . . . . . . . . . . . 3-2

3.2.2 Vessel Steel Sample Cutting Tool . . . . . . . . . . . . . . . . 3-2

3.3 Description of Samples Removed $\ldots \ldots \ldots \ldots \ldots \ldots \ldots \ldots \ldots \ldots \ldots$

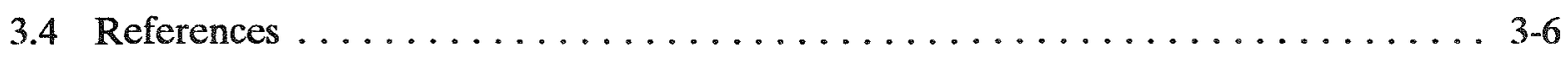

4. METALLURGICAL EXAMINATIONS AND MECHANICAL PROPERTIES ..... 4-1

4.1 Metallurgical Examinations ....................... $4-3$

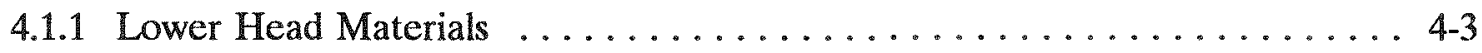

4.1.2 Metallographic Sample Examinations . . . . . . . . . . . . . . 4-4

4.1.3 Hardness Measurements of the TMI-2 Samples ................ $4-8$

4.1 .4 Microstructure of TMI-2 Samples . . . . . . . . . . . . . . 4-8

4.2 Mechanical Properties $\ldots \ldots \ldots \ldots \ldots \ldots \ldots \ldots \ldots \ldots \ldots \ldots \ldots \ldots \ldots$

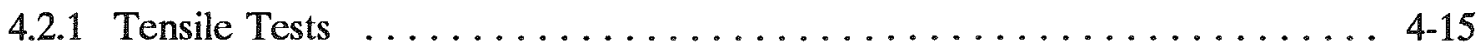

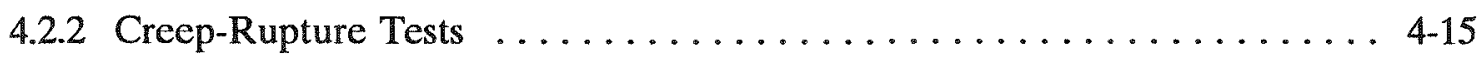

4.2 .3 Impact Tests $\ldots \ldots \ldots \ldots \ldots \ldots \ldots \ldots \ldots \ldots \ldots \ldots \ldots . \ldots \ldots$

4.3 Examination of Cracks in Vessel Cladding $\ldots \ldots \ldots \ldots \ldots \ldots \ldots \ldots \ldots$

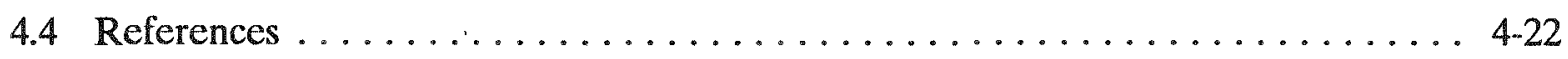

5. COMPANION SAMPLE EXAMINATIONS $\ldots \ldots \ldots \ldots \ldots \ldots \ldots \ldots \ldots \ldots$

5.1 Sample Acquisition $\ldots \ldots \ldots \ldots \ldots \ldots \ldots \ldots \ldots \ldots \ldots \ldots \ldots \ldots \ldots \ldots \ldots \ldots$

5.2 Physical Characterization $\ldots \ldots \ldots \ldots \ldots \ldots \ldots \ldots \ldots \ldots \ldots \ldots \ldots$

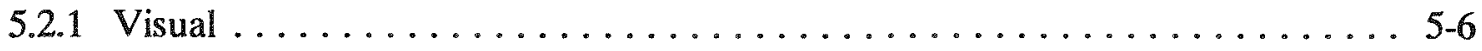

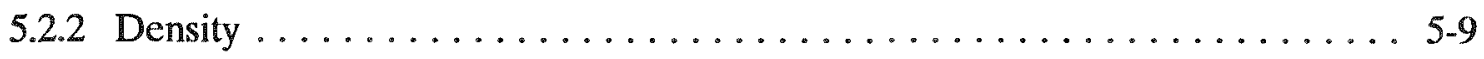

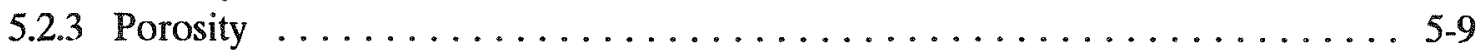

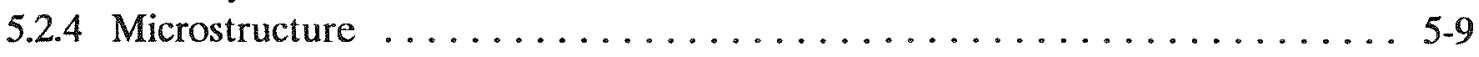

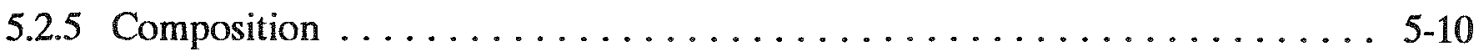




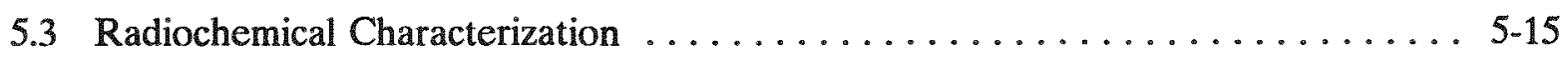

5.3.1 Elemental Composition ....................... $5-15$

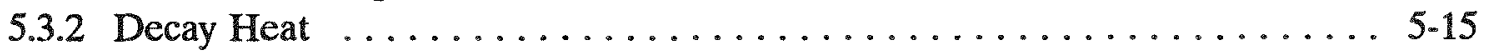

5.4 Input to Margin-to-Failure Analysis $\ldots \ldots \ldots \ldots \ldots \ldots \ldots \ldots \ldots \ldots \ldots \ldots$

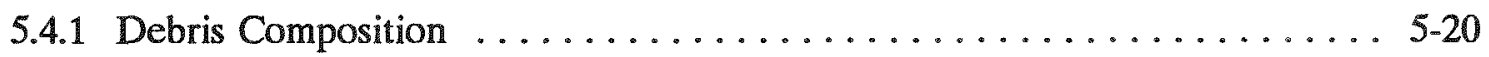

5.4.2 Peak Debris Temperature at Relocation ................ 5-21

5.4 .3 Debris Cooling Rate . . . . . . . . . . . . . . . . . . . . . .

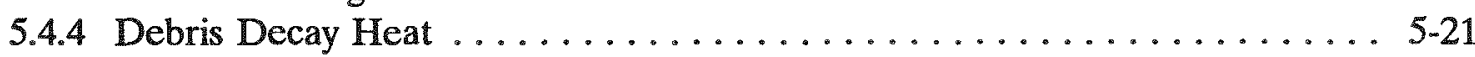

5.5 Summary and Conclusions $\ldots \ldots \ldots \ldots \ldots \ldots \ldots \ldots \ldots \ldots \ldots \ldots \ldots \ldots \ldots \ldots \ldots .21$

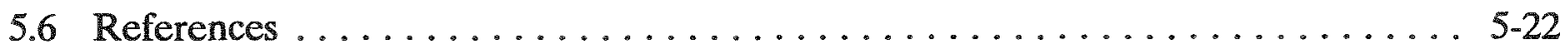

6. EXAMINATION OF NOZZLES AND GUIDE TUBES $\ldots \ldots \ldots \ldots \ldots \ldots \ldots .6$.

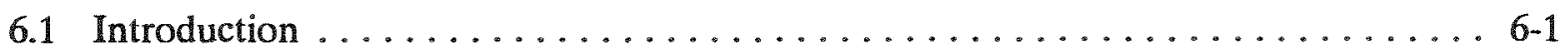

6.2 Sample Preparation and Examination Methodology $\ldots \ldots \ldots \ldots \ldots . . \ldots .6 .2$

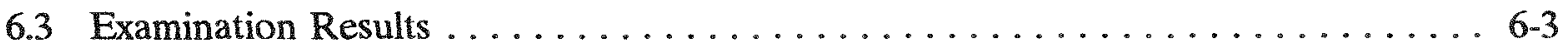

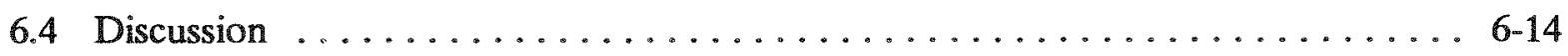

6.4.1 Nature of Nozzle Damage ...................... 6-14

6.4.2 Presence of Control Assembly Materials ................. 6-15

6.4 .3 Temperature Indicators ....................... $6-17$

6.4.4 Penetration of Materials into Nozzles .................. 6.19

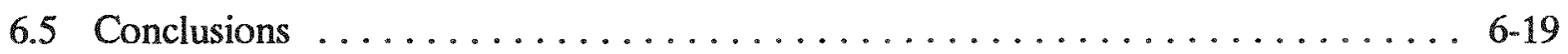

6.6 References ................................ $6-20$

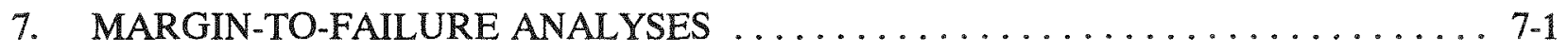

7.1 Input for Margin-to-Failure Analyses $\ldots \ldots \ldots \ldots \ldots \ldots \ldots \ldots \ldots \ldots \ldots \ldots \ldots .3$

7.1.1 Instrumentation Data $\ldots \ldots \ldots \ldots \ldots \ldots \ldots \ldots \ldots \ldots \ldots \ldots \ldots \ldots .3$

7.1.2 Previous TMI Examinations $\ldots \ldots \ldots \ldots \ldots \ldots \ldots \ldots \ldots \ldots \ldots .3$

7.1 .3 TMI-2 VIP Data . . . . . . . . . . . . . . . . .

7.1 .4 Preliminary Analyses ..................

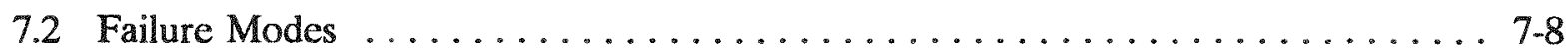


7.3 Analytical Estimates of Vessel Margin to Failure ............... $7-9$

7.3.1 Scoping Analysis for TMI-2 Penetration Tube Weld Failure . . . . . . . . 7-9

7.3.2 Ex-vessel Instrument Tube Failure .................... . 7-10

7.3.3 Global Vessel Rupture . . . . . . . . . . . . . . . . . . . . 7-10

7.3 .4 Localized Vessel Failure ....................... 7-11

7.4 Sensitivity of Results to Debris Cooling and Failure Criterion $\ldots \ldots \ldots \ldots \ldots$

7.4.1 Changes in Debris Internal Energy after Relocation $\ldots \ldots \ldots \ldots \ldots \ldots 7-18$

7.4.2 Slow and Rapid Cooling Analysis ................... 7-19

7.4.3 Debris Configurations to Obtain Required Cooling Rates . . . . . . . . . 7-20

7.4.4 Sensitivity of Results to Failure Criteria $\ldots \ldots \ldots \ldots \ldots \ldots \ldots \ldots \ldots$ 7-22

7.5 Summary and Conclusions $\ldots \ldots \ldots \ldots \ldots \ldots \ldots \ldots \ldots \ldots \ldots \ldots \ldots \ldots$

7.6 References $\ldots \ldots \ldots \ldots \ldots \ldots \ldots \ldots \ldots \ldots \ldots \ldots \ldots \ldots \ldots \ldots$

8. DEBRIS RELOCATION SCENARIO $\ldots \ldots \ldots \ldots \ldots \ldots \ldots \ldots \ldots$

8.1 Introduction $\ldots \ldots \ldots \ldots \ldots \ldots \ldots \ldots \ldots \ldots \ldots \ldots \ldots . \ldots \ldots$

8.2 Initial Events $\ldots \ldots \ldots \ldots \ldots \ldots \ldots \ldots \ldots \ldots \ldots \ldots \ldots \ldots \ldots$

8.3 Relocation to the Lower Head ....................... $8-2$

8.3.1 Movement of Molten Material Through The Vessel ..............8-2

8.3.2 Movement of Molten Debris Through the Core Support Assembly . . . . . . 8-2

8.3.3 Molten Debris Movement on the Elliptical Flow Distributor . . . . . . . . . 8-4

8.3.4 Movement of Molten Debris on the Lower Head . . . . . . . . . . . . . . 8 8-6

8.3 .5 Formation of the Hot Spot $\ldots \ldots \ldots \ldots \ldots \ldots \ldots \ldots . \ldots \ldots$

8.4 Lower Head Cooling $\ldots \ldots \ldots \ldots \ldots \ldots \ldots \ldots \ldots \ldots \ldots$

8.5 Relocation Scenario Conclusions $\ldots \ldots \ldots \ldots \ldots \ldots \ldots \ldots \ldots \ldots$

8.6 References $\ldots \ldots \ldots \ldots \ldots \ldots \ldots \ldots \ldots \ldots \ldots \ldots \ldots \ldots \ldots . \ldots \ldots$

9. CONCLUSIONS $\ldots \ldots \ldots \ldots \ldots \ldots \ldots \ldots \ldots \ldots \ldots \ldots \ldots \ldots \ldots \ldots$ 


\section{LIST OF FIGURES}

ES-1. Location of lower head steel, nozzle, and guide tube samples . . . . . . . . . . xvi

ES-2. Lower head hot spot location $\ldots \ldots \ldots \ldots \ldots \ldots \ldots \ldots \ldots \ldots \ldots \ldots$

1-1. TMI-2 reactor vessel end-state configuration $\ldots \ldots \ldots \ldots \ldots \ldots \ldots \ldots \ldots \ldots \ldots$

2-1. Reactor vessel components $\ldots \ldots \ldots \ldots \ldots \ldots \ldots \ldots \ldots \ldots \ldots \ldots \ldots \ldots \ldots$

2-2. Lower head core support assembly $\ldots \ldots \ldots \ldots \ldots \ldots \ldots \ldots \ldots \ldots \ldots \ldots \ldots$

2-3. Cross section of the reactor vessel and internals $\ldots \ldots \ldots \ldots \ldots \ldots \ldots \ldots \ldots$

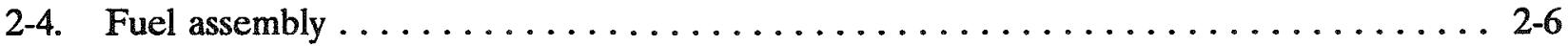

2-5. Schematic of the TMI-2 primary system $\ldots \ldots \ldots \ldots \ldots \ldots \ldots \ldots \ldots$

2-6. Various instrumentation data during the accident $\ldots \ldots \ldots \ldots \ldots \ldots \ldots \ldots$

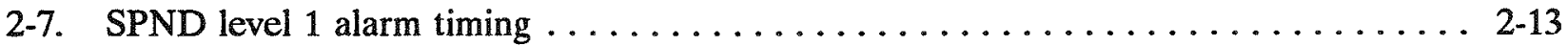

3-1. MDM cutting head $\ldots \ldots \ldots \ldots \ldots \ldots \ldots \ldots \ldots \ldots \ldots \ldots \ldots \ldots \ldots$

3-2. Location of lower head steel, nozzle, and guide tube samples $\ldots \ldots \ldots \ldots \ldots$

4-1. Location of lower head boat samples with respect to core locations . . . . . . . . 4-2

4-2. Schematic of the source of TMI-2 metallographic and mechanical property samples ... 4-2

4-3. Typical as-fabricated microstructure and hardness of TMI-2 lower head material (from $\mathrm{H}-5$ sample) $\ldots \ldots \ldots \ldots \ldots \ldots \ldots \ldots \ldots \ldots \ldots \ldots \ldots$

4-4. Diagram of time/temperature observations of A533B pressure vessel steel clad with type $308 \mathrm{~L}$ stainless steel $\ldots \ldots \ldots \ldots \ldots \ldots \ldots \ldots \ldots \ldots \ldots \ldots \ldots \ldots$

4-5. Hardness profiles of samples F-10, G-8, E-8, and E-6 compared to the as-fabricated

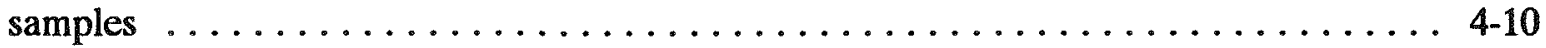

4-6. Thermal contour map of peak temperatures constructed as best estimate based on results of the metallographic examinations of the boat samples $\ldots \ldots \ldots \ldots \ldots \ldots$. $\ldots$-10

4-7. Microstructure and hardness profile of sample $\mathrm{F}-10 \ldots \ldots \ldots \ldots \ldots$

4-8. Microstructure and hardness profile of sample $E-8, \ldots \ldots \ldots \ldots \ldots \ldots \ldots$

4-9. Lower head temperatures in the vicinity of the E-6 and E-8 samples showing estimated thermal gradients through the thickness $\ldots \ldots \ldots \ldots \ldots \ldots \ldots \ldots . \ldots 4$ 
4-10. Tensile and yield strengths of TMI-2 lower head material compared with Japanese National Research Institute for metals data for other heats of A533B steel . . . . 4 4-17

4-11. Stress versus time to rupture data from creep tests conducted on TMI-2 lower head material compared with Larson-Miller time-temperature correlation best-fit curves ...

4-12. Impact energy versus test temperature data from Charpy $V$-notch impact tests on specimens from TMI-2 lower head material

4-13. Cross section through principal crack in sample E-6 .

5-1. Depth of hard layer of solidified debris (Contour lines designate distance between a "hard stop" from probe tests and the bowl-shaped lower head) $\ldots \ldots \ldots \ldots \ldots \ldots \ldots$. . .

5-2. TMI-2 lower head, cross section of hard debris, row $10 \ldots \ldots \ldots \ldots \ldots$

5-3. TMI-2 lower head, cross section of hard debris, row $12 \ldots \ldots \ldots \ldots \ldots$

5-4. Locations from which companion samples were taken (numbers are MPR sample identification designations) $\ldots \ldots \ldots \ldots \ldots \ldots \ldots \ldots \ldots \ldots \ldots \ldots \ldots$

5-5. Sample collected from the southeast quadrant (sample 1-9; total sample weight is $2,436 \mathrm{~g}$ g)

5-6. Sample collected from the northwest quadrant (sample 1-10; total sample weight is

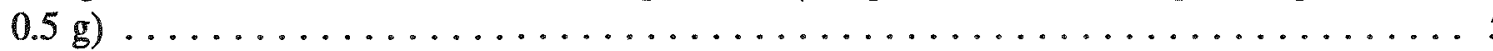

5-7. Sample collected from the southwest quadrant (sample 1-11; total sample weight is

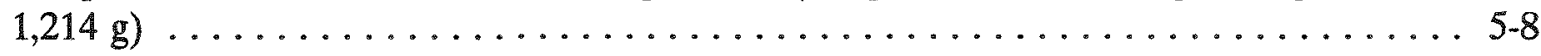

5-8. Sample collected from the northeast quadrant (sample 1-12; total sample weight is

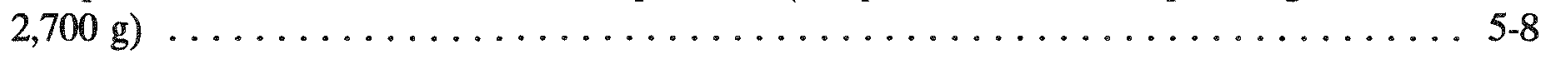

5-9. Cross-sectional views of sample $1-11-\mathrm{R} \ldots \ldots \ldots \ldots \ldots \ldots \ldots \ldots \ldots \ldots$

5-10. SEM backscattered electron image of two phase region (sample 1-9-A, Area 2) ... . 5-13

5-11. Photocomposite of microstructure in sample $1-11-\mathrm{R} / \mathrm{T} \ldots \ldots \ldots \ldots \ldots$

5-12. Comparison of TMI-2 decay heat to decay heat from a full burnup core $\ldots \ldots \ldots \ldots 5-20$

6-1. Grid map of TMI-2 core showing locations of nozzles examined $\ldots \ldots \ldots \ldots-4$

6-2. Typical incore nozzle with seal and retaining weld $\ldots \ldots \ldots \ldots \ldots \ldots$

6-3. Lower head area and incore instrument guide tubes $\ldots \ldots \ldots \ldots \ldots$

6-4. Full-length view of the $\mathrm{R}-7$ nozzle $\ldots \ldots \ldots \ldots \ldots \ldots \ldots \ldots \ldots$ 
6-5. Elevation view of nozzle segment M-9 $\ldots \ldots \ldots \ldots \ldots \ldots \ldots \ldots \ldots \ldots \ldots \ldots \ldots \ldots$

6-6. Full-length view of the $\mathrm{K}-11$ nozzle $\ldots \ldots \ldots \ldots \ldots \ldots \ldots \ldots \ldots \ldots \ldots \ldots \ldots \ldots$

6-7. Top view of nozzle E-7 $\ldots \ldots \ldots \ldots \ldots \ldots \ldots \ldots \ldots \ldots \ldots .6 .6 \ldots \ldots$

6-8. Segment of guide tube $\mathrm{K}-5 \ldots \ldots \ldots \ldots \ldots \ldots \ldots \ldots \ldots \ldots \ldots \ldots \ldots \ldots \ldots \ldots \ldots .12$

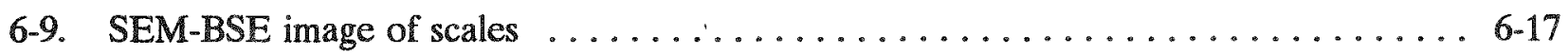

7-1. Flow diagram of margin-to-failure analyses $\ldots \ldots \ldots \ldots \ldots \ldots \ldots \ldots \ldots \ldots \ldots \ldots \ldots \ldots$

7-2. Cold-leg temperatures during the TMI-2 accident $\ldots \ldots \ldots \ldots \ldots \ldots \ldots \ldots \ldots \ldots \ldots$

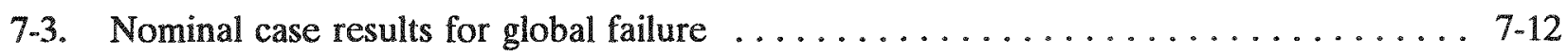

7-4. Lower-bound case results for global failure $\ldots \ldots \ldots \ldots \ldots \ldots \ldots \ldots \ldots \ldots \ldots$

7-5. Damage rate and accumulated damage versus time in the hot spot case for localized

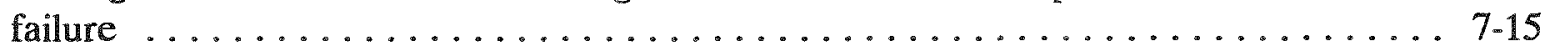

7-6. Distributions of $100 \%$ damaged ligaments in the hot spot case for localized failure . . 7-17

7-7. Comparison of results for cases with a hot spot on $50 \%$ and $62.5 \%$ nominal case heat

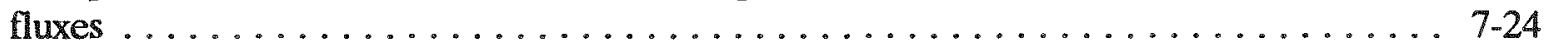

7-8. Distribution of ligaments experiencing tertiary creep at various times for the $62.5 \%$ nominal case with a hot spot $\ldots \ldots \ldots \ldots \ldots \ldots \ldots \ldots \ldots \ldots \ldots \ldots \ldots \ldots \ldots \ldots \ldots .25$

7-9. Comparison of results with and without rapid cooling for a $6.25 \%$ nominal case with

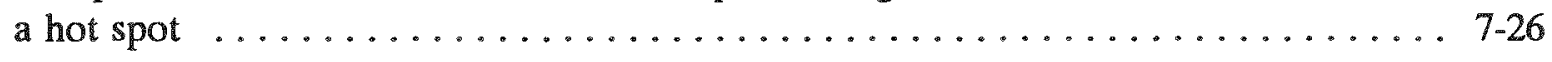

7-10. Comparison of results for rapid cooling on various nominal heat fluxes with a hot spot

8-1. Reactor vessel internal structures $\ldots \ldots \ldots \ldots \ldots \ldots \ldots \ldots \ldots \ldots . . \ldots \ldots$

8-2. Fuel debris profile inside core former (laid flat) $\ldots \ldots \ldots \ldots \ldots \ldots \ldots \ldots .3$

8-3. TMI-2 core support assembly $\ldots \ldots \ldots \ldots \ldots \ldots \ldots \ldots \ldots \ldots \ldots . \ldots \ldots$

8-4. Solidified material in core support assembly $\ldots \ldots \ldots \ldots \ldots \ldots \ldots . \ldots . \ldots . . .6$

8-5. Solidified material in the elliptical flow distributor $\ldots \ldots \ldots \ldots \ldots \ldots \ldots . .6$

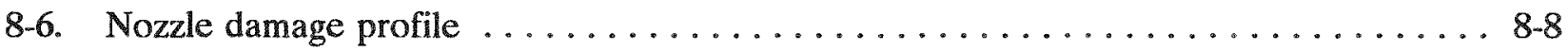

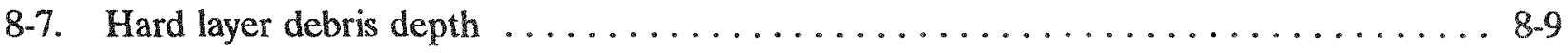


8-8. End state hard and loose layer debris configuration $\ldots \ldots \ldots \ldots \ldots \ldots \ldots$

8-9. TMI-2 lower head cross section of hard debris, row $7 \ldots \ldots \ldots \ldots \ldots \ldots$

8-10. TMI-2 lower head cross section of hard debris, row $6 \ldots \ldots \ldots \ldots \ldots \ldots$

8-11. TMI-2 lower head cross section of hard debris, row $5 \ldots \ldots \ldots \ldots \ldots \ldots \ldots$

8-12. Lower head hot spot and nozzle/guide tube locations $\ldots \ldots \ldots \ldots \ldots \ldots \ldots \ldots$

\section{LIST OF TABLES}

2-1. TMI-2 design data $\ldots \ldots \ldots \ldots \ldots \ldots \ldots \ldots \ldots \ldots \ldots \ldots \ldots \ldots \ldots . \ldots \ldots$

2-2. Reactor component materials $\ldots \ldots \ldots \ldots \ldots \ldots \ldots \ldots \ldots \ldots \ldots \ldots \ldots$

4-1. Laboratories participating in metallographic examination and mechanical properties testing of TMI-2 samples $\ldots \ldots \ldots \ldots \ldots \ldots \ldots \ldots \ldots \ldots \ldots \ldots \ldots$

4-2. Fabrication history of the TMI-2 and midland pressure vessel lower heads $\ldots . \ldots .4-4$

4-3. Results of metallographic examinations of TMI-2 lower head samples ........ 4-11

4-4. Lower head temperatures in the vicinity of samples E-6 and E-8 showing thermal gradients through the thickness $\ldots \ldots \ldots \ldots \ldots \ldots \ldots \ldots \ldots \ldots \ldots \ldots \ldots$

5-1. TMI-2 bulk sample weights and densities $\ldots \ldots \ldots \ldots \ldots \ldots \ldots \ldots \ldots$

5-2. TMI-2 lower plenum individual sample weights and densities $\ldots \ldots \ldots \ldots \ldots$

5-3. TMI-2 lower plenum sample porosities $\ldots \ldots \ldots \ldots \ldots \ldots \ldots \ldots \ldots \ldots \ldots$

5-4. TMI-2 reactor core composition $\ldots \ldots \ldots \ldots \ldots \ldots \ldots \ldots \ldots \ldots \ldots \ldots \ldots \ldots$

5-5. Average debris composition by quadrant $\ldots \ldots \ldots \ldots \ldots \ldots \ldots \ldots \ldots \ldots$

5-6. Radionuclide retention in the debris bed $\ldots \ldots \ldots \ldots \ldots \ldots \ldots \ldots \ldots$

6-1. ANL nozzle segment lengths, elevations, and fuel penetration depths $\ldots \ldots \ldots \ldots$. . . 6 -7

6-2. INEL nozzle segment lengths, elevations, and fuel penetration depths $\ldots \ldots \ldots \ldots$

7-1. Vessel thermal response calculation results $\ldots \ldots \ldots \ldots \ldots \ldots \ldots \ldots$ 


\section{EXECUTIVE SUMMARY}

\section{Introduction}

On March 28, 1979, a severe accident occurred in the Three Mile Island Unit 2 (TMI-2) pressurized water reactor, which resulted in a partial melting of the core, significant cladding oxidation, and a significant release of fission products from the fuel. Later investigations concluded that at least $45 \%$ of the core had melted and approximately $19,000 \mathrm{~kg}$ of molten core material relocated and came to rest on the lower head of the reactor vessel.

In order to develop a comprehensive understanding of the accident, several research programs were established. The initial program was jointly sponsored by the General Public Utilities Nuclear (GPUN) Corporation, the Electric Power Research Institute (EPRI), the U.S. Nuclear Regulatory Commission (NRC), and the U.S. Department of Energy (DOE). Collectively, this group was known as GEND. Under the GEND program, GPUN was responsible for ongoing plant cleanup operations, while the DOE was responsible for providing transportation and interim storage of the core until permanent disposition was decided. The DOE also supported an extensive research program, the TMI-2 Accident Evaluation Program, whose objective was to develop a consistent understanding of the accident and to ensure that these results are available for resolution of severe accident issues. An additional research program was formed under the auspices of the Committee on the Safety of Nuclear Installations of the Organization for Economic Cooperation and Development (OECD). Under this program, a number of OECD countries and the Commission of the European Communities' Joint Research Centre participated in the Accident Evaluation Program by performing detailed examinations of samples of fuel debris.

\section{Formation of the Vessel Investigation Project}

When the GEND research program was originally established, it was not expected that a significant amount of molten material had relocated to the lower head. As a result, further study of the implications associated with the relocation of fuel and a potentially damaged lower head was not included in the GEND program work scope. Once it was realized that molten fuel had relocated to the lower head, the NRC proposed that the important safety questions raised by a potentially damaged lower head be further investigated through a joint international cooperative program under the sponsorship of the Nuclear Energy Agency (NEA) of the OECD. During initial discussions concerning the formation of the Vessel Investigation Project (VIP), it became clear that countries which operated nuclear power reactors needed to further increase their overall understanding of the TMI-2 accident. This would best be accomplished through joint international participation in an additional TMI-2 research program. As a result, the OECD "Project To Investigate The Three Mile Island 2 Reactor Pressure Vessel," commonly called the TMI-2 VIP, was established. The signatories to the formal VIP agreement are Belgium, Finland, France, Germany, Italy, Japan, Spain, Sweden, Switzerland, the United Kingdom, and the United States.

Control of the VIP was vested in a Management Board, which consisted of one member designated by each signatory. A Program Review Group was formed to act as the technical 
advisor to the Management Board and to make recommendations to the $\mathrm{NRC}$, which acted as the Operating Agent for the project. The Operating Agent had the responsibility for implementing the project activities in accordance with the project agreement and the directions of the Management Board.

\section{Objectives of the VIP}

As described in the formal project agreement, the objectives of the VIP were to:

Jointly carry out a study to evaluate the potential modes of failure and the margin to failure of the TMI-2 reactor vessel during the TMI-2 accident. The condition and properties of material extracted from the lower head of the TMI- 2 reactor pressure vessel will be investigated to determine the extent of damage to the lower head by chemical and thermal attack, the thermal input to the vessel, and the margin of structural integrity that remained during the TMI-2 accident.

The project objectives were realized through a combination of several major elements, which included extraction of samples from the lower head, examinations performed on the extracted material, and analytical calculations directed towards a better understanding of the vessel's margin to failure. The vessel steel, nozzle, and guide tube samples extracted from the lower head as part of the VIP, along with previously molten debris samples removed during the GEND defueling program, provided the material for the examinations performed by various project members. The condition and properties of these materials were examined to determine the extent of damage to the lower head during the accident. Results of the examinations were used to assist in quantifying potential reactor vessel failure modes, to determine the temperatures that the lower head experienced during the accident, and to develop physical and mechanical property data to support and validate the analysis effort.

In the area of analysis, scoping calculations and sensitivity studies were performed in an effort to quantify the margin to failure for different reactor vessel failure modes and to identify which modes had the smallest margin to failure during the accident. The examination data and analytical results would also be available for future studies after the conclusion of the VIP.

\section{Sample Acquisition}

The initial phase of the VIP was devoted to developing the techniques and hardware necessary for removing the steel, nozzle, and guide tube samples. Removing the samples from the lower head of the TMI-2 vessel was a unique challenge that required the development of specialized cutting tools. Under the direction of MPR Associates, Inc., different types of tooling were developed for each of the three type of samples (vessel nozzle penetrations, guide tubes, and vessel steel), which were extracted from the lower head. In order to meet schedule requirements, the sample removal techniques had to be selected prior to the removal of the hard debris layer. After the hard debris layer had been removed, a clear view of the lower head itself was obtained for the first time, and it was discovered that several nozzles and guide tubes had been damaged during the accident. The sample removal effort was further complicated by the fact that all operations were performed from the top of the reactor vessel through a $45-\mathrm{cm}$-wide, 
$300-\mathrm{cm}$-long slot that was $12 \mathrm{~m}$ above the area of interest. The vessel was also filled with water that had a typical visibility of 2 to $3 \mathrm{~m}$. Special lighting and underwater cameras were used during all sample extraction activities.

The vessel steel extraction effort was particularly challenging since it was required that the vessel not be breached. The removal technique selected was an electrical discharge machining method referred to as metal disintegration machining (MDM). The MDM process was carried out through the removal of conductive material in small bits by melting them away with a small electric arc between the electrodes and the works piece. The MDM process makes and breaks electrical arcs by moving the cutting head electrode into and away from the work material. A variety of different samples could be obtained simply by changing the electrode size and shape.

The second phase of the project entailed the actual extraction of vessel steel and nozzle samples from the lower head itself. A 30-day vessel access window was available to the VIP in which to remove as many samples as possible. This window extended from January 30,1990 , when the lower head defueling was completed, to March 1, 1990.

Under the direction of MPR Associates, Inc., 15 prism-shaped metallurgical "boat samples" were cut out of the vessel lower head along with 14 incore nozzle stubs and two incore instrument guide tube sections. The vessel steel samples, which typically extended approximately halfway through the thickness of the lower head, came from different locations of the lower head, including the areas where significant nozzle damage was observed. Specifically, steel samples were removed from lower head locations D-10, E-6, E-8, E-11, F-5, F-10, G-8, H-4, H-5, H-8, K-7, K13, L-9, M-8, and M-11, as shown in Figure ES-1. The samples from locations H-5, H-8, D-10, and $\mathrm{E}-11$ were removed after the vessel nozzles at these locations had been severed as close to the lower head as possible. The steel samples were typically $152-178 \mathrm{~mm}$ long, 64-89 $\mathrm{mm}$ wide, and 64-76 mm thick. Nozzle samples were removed from locations D-10, E-7, E-11, G-5, L-6, H-5, H-8, H-9, K-11, K-12, L-11, M-9, M-10, R-7.

The removal of the lower head debris that was to become known as the companion samples was part of the overall defueling effort of the TMI-2 reactor vessel and was not part of the VIP. However, the examinations that were performed on the companion samples were formally part of the VIP effort.

\section{Examinations and Results}

\section{Vessel Steel}

Argonne National Laboratory (ANL) in the United States coordinated the metallographic examinations and mechanical property tests of the vessel steel samples. All the lower head steel samples were visually examined, decontaminated, sectioned, and sent to eight of the member countries for testing. The participants that examined the vessel steel samples were Belgium, Italy, Finland, France, Germany, Spain, the United Kingdom, and the United States. Examinations performed by the project participants included tensile, creep, and Charpy V-notch impact tests, microhardness measurements, micro and macro photography, and chemical composition. The primary purpose of these tests was to determine the lower head steel's mechanical properties over the temperature range experienced during the accident. Optical metallography and hardness tests 


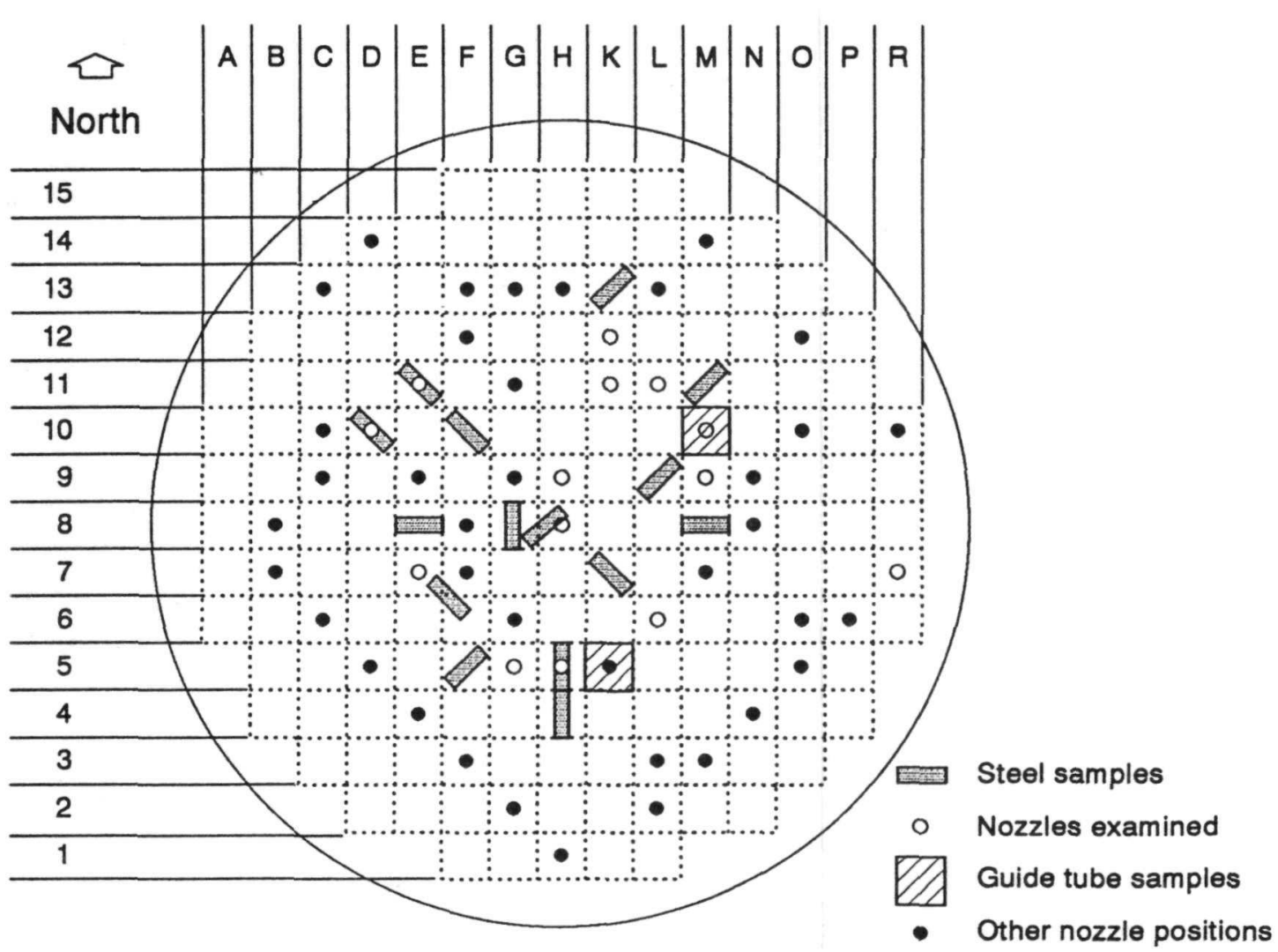

Figure ES-1. Location of lower head steel, nozzle, and guide tube samples.

were performed in order to estimate the maximum temperature various portions of the lower head reached during the accident.

The integrated results of the wide range of inspections, mechanical property determinations, and metallographic examinations of the lower head vessel samples revealed several important and previously unknown facts relating to the degree of thermal attack on the lower head. During the sample removal effort, tears or cracks were found in the cladding of the vessel around nozzles E-6, G-8, and to a lesser extent at F-10. Vessel steel samples containing these cracks were analyzed by ANL. After completion of the examinations, these cracks were attributed to hot tearing of the cladding, down to but not into the base metal. This resulted from differential thermal expansion between the stainless steel cladding and the carbon steel vessel that occurred during vessel cooling. Metallographic examinations of vessel samples E-6, E-8, F-10, and G-8 indicated that the portion of the lower head from which these samples were taken reached temperatures between 1,075 and $1,100^{\circ} \mathrm{C}$ during the accident.

These measurements, along with the cladding tears, indicated the presence of a localized hot spot where the temperature was considerably higher than the surrounding region of the lower head. At the hot spot location, peak temperatures $5 \mathrm{~cm}$ into the 14.2-cm-thick vessel wall (the cladding thickness is included) were estimated to be $100 \pm 50^{\circ} \mathrm{C}$ lower than the peak vessel inner surface temperatures. Portions of H-8 and F-5 that were adjacent to the hot spot reached temperatures in excess of the $727^{\circ} \mathrm{C}$ ferrite-austenite transformation temperature for the low alloy 
A533B pressure vessel. Measurements on sample M-11, which was relatively far from the hot spot, suggested that a portion of this sample also exceeded $727^{\circ} \mathrm{C}$ within a few millimeters of the surface. Tempering of the bainite in samples from locations H-4, H-5, M-8, and L-9 indicated that the temperature of these samples probably approached, but did not exceed, $727^{\circ} \mathrm{C}$. There was no evidence to suggest that any other vessel steel samples reached or exceeded $727^{\circ} \mathrm{C}$.

Overall, these examinations revealed that the localized hot spot covered a $1 \mathrm{~m} \times 0.8 \mathrm{~m}$ region on the lower head that was approximately elliptical in shape. The hot spot was also located in the area where visual observations made during the defueling process indicated that the most severe nozzle damage had occurred. Figure ES-2 shows the location of the hot spot in relation to the steel, nozzle, and guide tube samples. Furthermore, the presence of control assembly material $(\mathrm{Zr}, \mathrm{Ag}, \mathrm{Cd}$, and $\mathrm{In})$ within the cladding tears and intergranularly on the surface of some sample locations indicated the presence of debris containing metallic material that was already present on the lower head when the major relocation took place at 224 minutes after the initial reactor scram.

The steel examinations were also able to provide data on the cooling rate of the lower head hot spot. Microstructural and hardness observations, in the as-received state for samples E-6 and E-8, reflected the austenitizing heat treatment and the subsequent relatively rapid cooling of this material during the accident. Cooling rates were estimated to have been in the range of 10 to $100^{\circ} \mathrm{C} / \mathrm{min}$ through the transition temperature. By comparing results of the TMI-2 lower head sample examinations with results from similar metallurgical examinations of heat-treated samples from an equivalent steel, it was determined that samples F-10, G-8, E-6, and E-8 may have remained at their peak temperature for as long as 30 minutes prior to being cooled.

Mechanical property tests performed on the vessel steel samples produced a wealth of high temperature mechanical property data, which not only provided information on the present condition of the lower head, but also provided input to the margin-to-failure analysis. Creep tests performed at 600 and $700^{\circ} \mathrm{C}$ indicated no significant differences in behavior between samples that exceeded a maximum temperature of $727^{\circ} \mathrm{C}$ and those that did not. Tensile tests for specimens which exceeded $727^{\circ} \mathrm{C}$ showed significantly higher strengths at room temperature and at $600^{\circ} \mathrm{C}$ when compared to those that did not exceed $727^{\circ} \mathrm{C}$. These tensile tests at lower test temperatures further confirmed the hardness measurements that the material from the hot spot had been austenitized and subsequently cooled rapidly.

\section{Nozzles}

The nozzle and guide tube specimens were removed from the vessel by being cut off as close to the lower head as possible. Several nozzles (F-8, E-9, G-6, and G-9) were melted off almost flush with the vessel and could not be removed. Nozzles were successfully removed from locations D-10, E-7, G-5, L-6, E-11, H-5, H-8, H-9, K-11, K-12, L-11, M-9, M-10, and R-7 (see Figure ES-1). Incore guide tube samples were obtained from locations K-5 and M-10.

After the nozzle and guide tube were removed from the vessel, all nozzle and guide tube samples were shipped to the Idaho National Engineering Laboratory (INEL) in the United States, and six were then shipped to ANL for examination. Examinations included micro and macro photography, optical metallography, scanning electron microscope measurements, gamma 


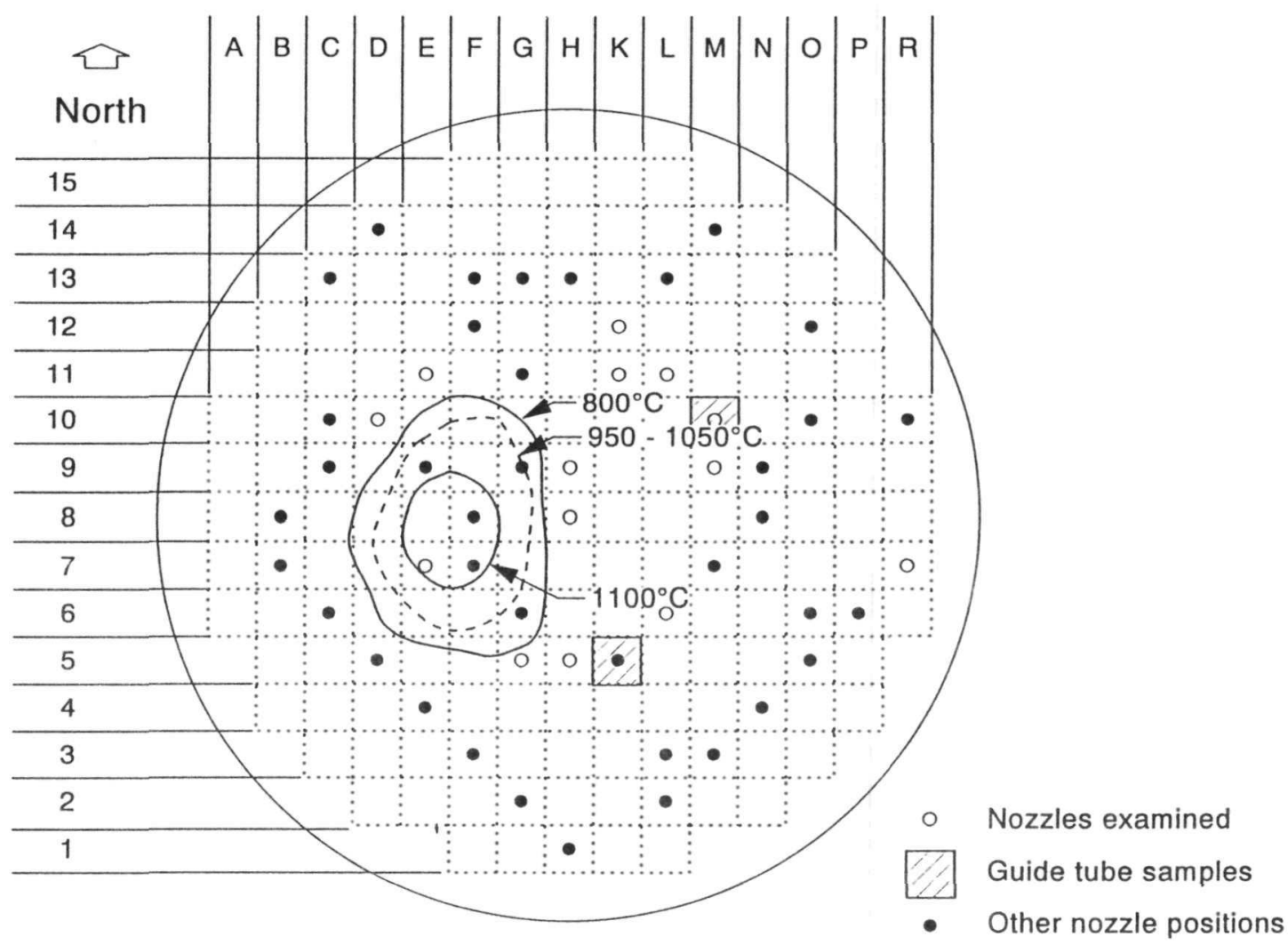

Figure ES-2. Lower head hot spot location.

M958 jw-0o93.05

scanning, melt penetration measurements, and microhardness. There were two primary purposes for these examinations. First, these examinations would help to determine the extent of nozzle degradation to evaluate the thermal challenge to the lower head. Second, they would provide information on the movement of molten fuel onto and across the lower head during the relocation. Portions from selected INEL nozzles and guide tubes were later sent to CEA Saclay, France, where similar examinations were performed.

Examinations performed on the nozzles and guide tubes, conducted primarily at ANL, also provided significant insights into the accident. Damage to nozzles $\mathrm{M}-9, \mathrm{H}-5$, and $\mathrm{H}-8$ indicated that their end-state condition was caused by molten core material coming in contact with the nozzles at an elevation ranging from 140 to $270 \mathrm{~mm}$ above the lower head. Surface scale found on the nozzles below their melt-off points suggested that this molten material flowed on top of a crust of preexisting solidified fuel debris that had been cooled below its solidus temperature.

During the examinations, it was estimated that nozzle temperatures varied widely as a function of location and elevation above the lower head. They ranged from $1,415^{\circ} \mathrm{C}$, which is the Inconel 600 nozzle liquidus temperature, at an elevation of $140 \mathrm{~mm}$ from the lower head surface for nozzle $\mathrm{H}-5$, to $1,000^{\circ} \mathrm{C}$ at an elevation of $64 \mathrm{~mm}$ for nozzle $\mathrm{H}-8$. The penetration of fuel debris downward into the nozzles was probably influenced by the temperature of the fuel at the time of entry, debris composition (and hence its fluidity), and the temperature of the nozzle itself. 
Temperature was found to greatly affect the nozzle's ability to solidify fuel and also the degree of interaction between the debris and the nozzle. This interaction controlled trapping of fuel in the Cr-oxide matrix.

Examination results also indicated the presence of $\mathrm{Zr}$ and $\mathrm{Ag}-\mathrm{Cd}$ on nozzle surfaces, which interacted with the material. The presence of this material indicated that control rod material had relocated prior to the primary fuel relocation. The early movement of control material to the lower head was substantiated by the presence of control assembly material, which was found in the cladding tears at locations E-6 and F-10. However, the examinations were unable to determine the quantity of these materials that had relocated.

\section{Companion Samples}

The debris samples examined as part of the VIP were known as companion samples since they came from the same hard layer that was in contact with the lower head. Hence, they were "companions" to the lower head steel samples. Results of the companion sample examinations made it possible to determine the debris composition and the lower head decay heat load. During the defueling process, it was discovered that the hard layer was indeed extremely hard and had to be broken into pieces for removal. However, there was virtually no adherence of the material to the lower head itself.

The primary constituents of the companion samples were uranium, zirconium, and oxygen $(\mathrm{U}, \mathrm{Zr}) \mathrm{O}_{2}$ with only small percentages $(<1 \mathrm{wt} \%)$ of other structural materials such as iron, nickel, and chromium. Control rod materials such as silver, indium, and cadmium were present in low $\left(<0.5 \mathrm{wt} \%\right.$ ) concentrations. The average sample debris density was $8.4 \pm 0.6 \mathrm{~g} / \mathrm{cm}^{3}$ with an average porosity of $18 \pm 11 \%$. Overall, the examinations indicated that the companion samples were relatively homogeneous with relatively, small variations in composition and density.

Based on the debris composition, it is quite probable that the molten material reached temperatures greater than $2,600^{\circ} \mathrm{C}$ in the central core region prior to relocation. It is not known what the temperature of the debris was when it reached the lower head. However, data suggest that the material reached the lower head in a molten state and that portions of the debris cooled slowly over an extended period of time.

Radiochemical examinations indicated that the primary radionuclides retained in the debris bed were medium and low volatile constituents. Almost all of the radiocesium, radioiodine, and radioactive noble gases volatilized from the molten core before it relocated to the lower head. Knowledge of the retained fission products is critical to calculating the debris decay heat and the resulting heat load on the lower head. Decay heat calculations indicated an overall heat load of $0.13 \pm 20 \% \mathrm{~W} / \mathrm{g}$ of debris when the relocation occurred at 224 minutes after scram and $0.096 \pm$ $20 \% \mathrm{~W} / \mathrm{g}$ at 600 minutes after scram. At the time of relocation, the total decay heat load was approxinately $2.47 \mathrm{MW}$ for the estimated $19,000 \mathrm{~kg}$ of material that relocated to the lower head.

There are two limitations inherent in the companion sample examinations that must be considered when evaluating this data. First, there is no detailed information on the exact sample location. Because the hard layer had to be broken into pieces during sample acquisition, location information was limited to only identifying from which quadrant the sample was acquired. 
Second, the total mass of all the companion samples examined was less than $7 \mathrm{~kg}$ compared with a total mass of $19,000 \mathrm{~kg}$ of molten material that relocated to the lower head. Even though every effort was made to select representative samples, and examination results were consistent for the samples tested, only a very small portion of the debris was actually analyzed.

\section{Margin-to-Failure Analyses}

The final element of the VIP, a margin-to-failure analysis effort, was performed to investigate mechanisms having the potential to threaten the integrity of the reactor vessel and to help improve understanding of events that occurred during the accident. Analyses addressed mechanisms that could result in lower head penetration tube and vessel failures. Specific failure modes examined were instrument tube rupture, tube ejection, localized vessel failure, and global vessel failure. Because of considerable uncertainty in the input parameters, analyses relied upon methods with closed-form or simplified numerical solution techniques so that a larger number of cases could be evaluated.

Margin-to-failure calculations included structural and thermal response analyses that provide input to the failure analyses. Calculations relied upon three major sources of VIP examination data: (a) nozzle examination data for characterizing melt composition and penetration distances within instrument tubes, (b) companion sample examination data for characterizing debris properties (such as decay heat and material composition), and (c) vessel steel examination data for characterizing peak vessel temperatures, duration of peak temperatures, and vessel cooling rate. Analyses were coordinated with the experimental efforts to ensure that needed input data were provided.

The margin-to-failure analyses provided significant insights into potential failure mechanisms of the TMI-2 lower head. Results of these calculations eliminated tube rupture and tube ejection as potential failure mechanisms during the accident. Melt penetration results indicated that ceramic melt did not penetrate below the lower head, which effectively eliminated ex-vessel tube rupture as a failure mechanism. Analyses also indicate that the instrument tube weld would remain intact even if the peak reactor coolant system (RCS) pressure was conservatively assumed to occur at the same time that the hot spot formed. As a result, tube ejection was also eliminated as a potential failure mechanism.

The thermal response of the vessel during and after melt relocation was investigated considering lower-bound, upper-bound, and best-estimate values for input parameters, such as debris decay heat, debris-to-coolant heat transfer coefficient, debris-to-vessel contact resistance, and vessel-to-containment heat transfer coefficient. Analyses were also performed to investigate the manner in which molten material relocated to and impinged upon the lower head considering appropriate ranges for input parameters.

Jet impingement calculations indicated that the amount of breakup occurring as melt relocated to the lower plenum was insignificant. Calculations also indicate that the magnitude and duration of hot spot temperatures estimated in TMI-2 vessel examinations could not have been caused by an impinging jet. Rather, hot spot temperatures were due to a sustained heat load from debris on the lower head. 
The potential for the vessel to experience a global failure was evaluated for temperature distributions obtained from thermal analyses with best-estimate and lower-bound input assumptions. For temperature distributions obtained with either lower-bound or best-estimate input parameters, global failure due to creep rupture was predicted to occur within approximately 2 hours after debris relocation because of the sustained high vessel temperatures when the RCS was repressurized. This rise in RCS pressure occurred when the plant operators closed the block valve for the power operated relief valve (PORV) at 320 minutes.

Localized vessel failure analyses indicated that the time to vessel failure was reduced when a localized hot spot was superimposed upon the calculated best-estimate temperatures. However, these localized calculations also indicated that it is possible to withstand the $1,100^{\circ} \mathrm{C}$ hot spot temperatures for the 30 -minute time period inferred from the vessel steel examinations, provided that the rest of the vessel remained relatively cool.

Taken together, the localized and global vessel failure calculations indicated that the background vessel steel temperature behavior, which is highly dependent on the heat load from the relocated debris in the lower head, was key to predicting failure from either of these mechanisms. Cool background vessel temperatures have the potential to reduce structural damage and preclude global vessel failure even at high pressure and in the presence of a localized hot spot.

Thermal and structural analyses results were dominated by input assumptions based upon companion sample examination data, which suggest that the debris experienced relatively slow cooling. However, differences between analysis results and data from the vessel steel examinations indicate that the entire lower head cooled within the first 2 hours after debris relocation.

An energy balance that considered coolant mass flows entering and exiting the vessel indicated that the debris cooled in the time period between relocation and vessel repressurization. TMI-2 data are not sufficient to determine the exact mechanisms that caused the debris to cool within the first two hours. However, results of thermal response calculations indicate that the debris cooled in the lower plenum even though rapid cooling was not evident from companion sample examinations. Although the magnitude of cooling required was decreased when a stressbased damage failure criterion was replaced with a mechanical instability failure criterion, calculational results indicate that cooling occurred in order for results to be consistent with metallurgical examination data. For example, if such cooling were not considered, the vessel temperatures would not have experienced the rapid cooling rates observed in the metallurgical examinations. Furthermore, analyses indicate that a vessel subjected to peak hot spot temperatures on nominal-case background heat fluxes could not survive the 30-minute time period estimated in metallurgical examinations. Thus, analyses indicate that cooling must be considered in order to obtain results consistent with TMI-2 VIP examinations.

Although there are insufficient data to quantitatively determine the exact mechanisms that caused this cooling, scoping calculations were performed to investigate possible mechanisms that could provide this cooling. In these analyses, it was assumed that the simultaneous presence of cracks and gaps within the debris provides multiple pathways for steam release (e.g., water may travel down along the gap and boil up through cracks). Results indicate that a minimal volume of 
cooling channels within the debris and a minimal size gap between the debris and the vessel could supply the cooling needed to obtain vessel temperatures and cooling rates determined in metallurgical examinations. Such cooling is not currently considered in severe accident analysis models.

The large uncertainty in methods for predicting vessel failure precluded an accurate assessment of the margin to failure during the TMI-2 event. Two areas of uncertainty, the amount of cooling that occurred within the debris and the criterion used for predicting vessel failure, were investigated with additional sensitivity studies. Results indicate that these uncertainties limit the ability of current severe accident analysis models to predict debris behavior and vessel response during a severe accident. Because of these uncertainties, results of the margin-to-failure analysis should be viewed as providing insight into areas such as assessing what failure mechanisms were plausible during the TMI-2 event, identifying the failure mode with the smallest margin during the TMI-2 event, and emphasizing areas in which additional research is needed in severe-accident analysis.

\section{Lower Head Relocation Scenario}

Due to the complex nature of the interactions that took place during the accident, and to the limited data available from the TMI-2 plant instrumentation, a definitive relocation scenario that accounts for both the molten fuel movement onto and across the lower head, and the formation of the hot spot cannot be determined. However, results from the VIP were used to develop a much better understanding of the relocation phenomena, of molten fuel movement down to and across the lower head, and of the damage patterns that developed.

Visual observations indicated that the large holes (e.g., $20 \mathrm{~cm} \times 7 \mathrm{~cm}$ ) burned in the core former wall at the $\mathbb{R}-7$ core location provided the primary pathway that allowed the majority of the molten material to flow into the lower core support assembly, down through this structure, through holes in the elliptical flow distributor (EFD) plate, and onto portions of the lower head.

The minimal amount of damage on the EFD suggests that the first material that reached the EFD (and subsequently the lower head) was probably cooler than the material that followed later in the flow. Some of this material solidified on the EFD and formed plugs in the flow holes, while the remaining material was diverted by the plugged holes and dropped onto the lower head from several different locations around the periphery of the EFD.

As the initial cooler material fell onto the lower head from several different locations around the periphery of the EFD, the material effectively formed a cup-shaped basal crust structure that served to insulate the lower head. It is postulated that when this material reached the lower head, the combination of the heat sink provided by the nozzles and the vessel lower head itself, along with insufficient thermal energy in the molten flow, made it possible for a thick crust to rapidly build up. The rapid buildup of this crust resulted in the formation of an insulating layer that covered much of the lower head and also formed around many nozzles. Wherever the lower head and nozzles were covered by this insulating debris layer, they were protected from thermal damage. 
When hotter molten material dropped onto the lower head, it flowed across the top of the insulating debris layer and began to fill up the cup-shaped structure that initially formed on the lower head. It was this hotter material, which flowed across the top of the insulating crust, that was responsible for the damage to the nozzles. The pattern of nozzle damage indicates that multiple flow paths occurred and that the movement of molten material onto and across the lower head was not one massive unified flow.

The pattern of nozzle damage is thought to have occurred because as later portions of the lava-like flow moved over the top of the insulating debris layer, newly exposed molten fuel came in contact with the nozzles at elevated levels. These nozzles were melted at an elevation that is thought to be representative of the bottom of the molten fuel flow. Since the molten material flowed on top of the existing debris layer, this height is also representative of the thickness of insulating material that protected the lower head and the lower portions of many nozzles.

The nozzle examinations also provided insights into what caused the localized hot spot on the TMI-2 lower head. One possible explanation is based on the pattern of nozzle degradation and damage. As the viscous lava-like flow moved across the vessel towards the location where the hot spot occurred, the insulating crust became progressively thinner. This is consistent with the observation that the deepest debris was found on the lower head at locations away from the hot spot. A thinning crust was also indicated by data from the nozzle examinations, which show that more of the nozzle length was melted (i.e., the remaining nozzle stubs were shorter) in the area of the hot spot. The region where the most severe nozzle damage occurred was consistent with the location of the hot spot and indicated that the insulating layer was thinnest in this area.

\section{Conclusions}

Through the efforts of the VIP signatories who supported the project, numerous significant contributions were made that dramatically increased the understanding of both the extent of damage to the vessel lower head and the margin of structural integrity that remained in the vessel during the TMI- 2 accident. The principal results and conclusions from this project are summarized below.

- Vessel steel examinations indicated that a localized hot spot on the lower head developed in the region of samples E-6, E-8, F-10, and G-8. In this region, the maximum temperature of the ferritic steel base metal near the interface with the stainless steel cladding was approximately $1,100^{\circ} \mathrm{C}$. The steel may have remained at this temperature for as long as $\mathbf{3 0}$ minutes before cooling occurred. Temperatures $5 \mathrm{~cm}$ into the 14.2-cm-thick vessel wall (the thickness includes the cladding) were estimated to be $100 \pm 50^{\circ} \mathrm{C}$ lower than the peak surface temperatures. With the exception of an indication of a partial transformation very near the surface of sample M-11, there is no evidence that lower head temperatures away from the hot spot exceeded the $727^{\circ} \mathrm{C}$ transformation temperature.

- Nozzle examinations and post-accident visual examinations indicated that the major lower head relocation flow path for molten material was from the northeast and southeast quadrants of the vessel lower head towards the hot spot location.

xxiii 
- Large margins to failure existed throughout the TMI-2 event for the failure mechanisms of tube rupture and tube ejection. In fact, calculational results indicated that tube rupture and ejection can essentially be eliminated as potential failure mechanisms.

- Analyses results indicated that a localized effect, such as a hot spot, can shorten the overall vessel failure times due to creep rupture. However, by itself, it is unlikely to cause vessel failure for the temperatures and pressures that occurred in the vessel during the TMI-2 accident.

- Without modeling enhanced cooling of the debris and lower head, margin-tofailure scoping calculations indicated that lower head temperature distributions and durations based on data from companion sample examinations would have resulted in vessel failure when the reactor system was repressurized by plant operators at about 300 minutes.

- Even though a definitive scenario describing the relocation of molten fuel and the formation of a localized hot spot cannot be determined, there is considerable evidence that indicated that the lower head was insulated by a debris layer containing both ceramic and metallic material. The hot spot formed in a location where this layer had insufficient thickness to effectively insulate the lower head from the molten flow. 


\section{FOREWORD}

The contents of this report were developed as part of the Three Mile Island Unit 2 Vessel Investigation Project. This project is jointly sponsored by eleven countries under the auspices of the Nuclear Energy Agency of the Organization for Economic Cooperation and Development. The twelve sponsoring organizations are:

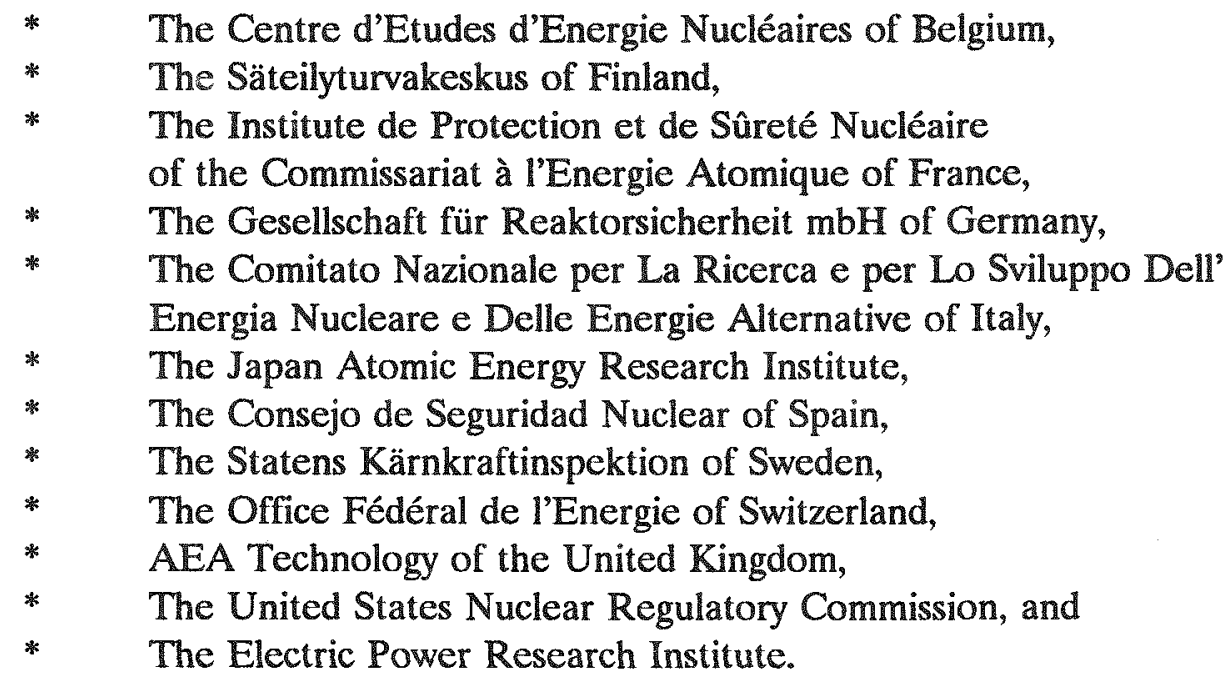

The primary objectives of the Nuclear Energy Agency (NEA) are to promote cooperation between its Member governments on the safety and regulatory aspects of nuclear development, and on assessing the future role of nuclear energy as a contributor to economic progress.

This is achieved by:

- encouraging harmonisation of governments' regulatory policies and practices in the nuclear field, with particular reference to the safety of nuclear installations, protection of man against ionising radiation and preservation of the environment, radioactive waste management, and nuclear third party liability and insurance;

- keeping under review the technical and economic characteristics of nuclear power growth and of the nuclear fuel cycle, and assessing demand and supply for the different phases of the nuclear fuel cycle and the potential future contribution of nuclear power to overall energy demand;

- developing exchanges of scientific and technical information on nuclear energy, particularly through participation in common services;

- setting up international research and development programmes and undertakings jointly organized and operated by OECD countries.

In these and related tasks, NEA works in close collaboration with the International Atomic Energy Agency in Vienna, with which it has concluded a Cooperation Agreement, as well as with other international organizations in the nuclear field. 



\section{ACKNOWLEDGMENTS}

The contents of this report were developed as part of the Three Mile Island Unit 2 Vessel Investigation Project. This project is jointly sponsored by 11 countries under the auspices of the Nuclear Energy Agency of the Organization for Economic Cooperation and Development. The individuals and organizations who have contributed to this project are the following:

Belgium

Mr. P. Dejonghe

Mr. W. Vandermeulen

Study Centre for Nuclear

Energy, SCK/CEN

Finland

Mr. C. Ottosson

Finnish Centre for Radiation and Nuclear Safety

Mr. R. Pelli

Technical Research Centre of Finland

France

Mr. J. Duco

Mr. M. Gomolinski

CEA/FAR

Mr. P. Soulat

Mr. F. Le Naour

CEA/CEN

Mrs. M. Trotabas

CEA/DRN

\section{Germany}

Dr. M. Banaschik (Chairman, Management Board)

GRS

Dr. D. Sturm

MPA

Dr. H. Schulz

GRS
Italy

Mr. P. Milella

Mr. G. Saponaro

ENEA/DISP

Japan

Dr. S. Kawasaki

Mr. K. Hashimoto

Mr. I. Kobayashi

JAERI

Spain

Mr. J. Bros

TECNATOM S.A.

Dr. J. Figueras

CSN

Dr. R. Monroy

UNIDAD

Dr. P. Veron

Equipos Nucleares S.A.

Sweden

Mr. K. Pettersson

Swedish Nuclear Power

Inspectorate

Switzerland

Dr. S. Chakraborty

Swiss Federal Nuclear Safety Inspectorate

Mr. H. Njo

Nuclear Safety Inspectorate

\section{United Kingdom}

Dr. S. Kinnersly

AEA Technology, Winfrith

Dr. J. Hudson (Chairman, Program Review Group)

AEA Technology, Harwell

Dr. B. Turland

AEA Technology, Culham

\section{United States}

Mr. E. Beckjord

Dr. A. Rubin (NRC Project Manager)

Mr. C. Serpan

Dr. E. Hackett

Dr. R. Van Houten

Mr. M. Mayfield

U.S. Nuclear Regulatory

Commission

Mr. W. Pasedag

Mr. S. Armour

U.S. Department of Energy

Dr. M. Merilo

EPRI

Secretariat

Mr. K. Stadie

Dr. N. McDonald

Ms. K. Leigh

Dr. P. Reyners

Mr. J. Stronsnider

Dr. A. Milier

Dr. G. McPherson 



\section{ACRONYMS}

$\begin{array}{ll}\text { AEP } & \text { Accident Evaluation Program } \\ \text { ANL } & \text { Argonne National Laboratory } \\ \text { CSA } & \text { core support assembly } \\ \text { DOE } & \text { U.S. Department of Energy } \\ \text { dph } & \text { disintegrations per hour } \\ \text { DPH } & \text { diamond pyramid hardness } \\ \text { EFD } & \text { elliptical flow distributor } \\ \text { EDS } & \text { energy dispersive x-ray spectroscopy } \\ \text { EPRI } & \text { Electric Power Research Institute } \\ \text { GEND } & \text { GPUN-EPRI-NRC-DOE } \\ \text { GPUN } & \text { General Public Utilities Nuclear } \\ \text { HAZ } & \text { heat-affected zone } \\ \text { HPI } & \text { high pressure injection } \\ \text { ICP } & \text { inductively coupled plasma } \\ \text { INEL } & \text { Idaho National Engineering Laboratory } \\ \text { JAERI } & \text { Japanese Atomic Energy Research Institute } \\ \text { LOCA } & \text { loss-of-coolant accident } \\ \text { MDM } & \text { metal disintegration machining } \\ \text { NRC } & \text { U.S. Nuclear Regulatory Commission } \\ \text { NRIM } & \text { National Research Institute for Metals } \\ \text { OECD } & \text { Organization for Economic Cooperation and Development } \\ \text { PORV } & \text { power operated relief valve } \\ \text { PWR } & \text { pressurized water reactor } \\ \text { RCS } & \text { reactor coolant system } \\ \text { SEM } & \text { scanning electron microscopy } \\ \text { SPND } & \text { self-powered neutron detector } \\ \text { SRM } & \text { source range monitor } \\ \text { TMI-2 } & \text { Three Mile Island Unit 2 } \\ \text { VIP } & \text { Vessel Investigation Project } \\ \text { WDS } & \text { wavelength dispersive x-ray spectroscopy } \\ \end{array}$

xxix 



\title{
TMI-2 Vessel Investigation Project Integration Report
}

\section{INTRODUCTION}

\author{
J. R. Wolf, Idaho National Engineering Laboratory
}

The primary objective of the Vessel Investigation Project (VIP) was to assess the damage that occurred to the lower head of the Three Mile Island Unit 2 (TMI-2) pressure vessel and to evaluate the margin of structural integrity that remained during the accident. The purpose of this report is to provide a technical summary of results and conclusions from the VIP.

\subsection{Background}

On March 28, 1979, the TMI-2 pressurized water reactor underwent a prolonged, smallbreak loss-of-coolant accident that resulted in severe damage to the reactor core. This accident, the most severe to occur in a commercial pressurized water reactor, resulted in extensive oxidation of the fuel cladding, a partial melting of the reactor core, and significant release of fission products from the fuel. The progression of the TMI- 2 accident was mitigated by the injection of emergency cooling water.

Although significant amounts of krypton and xenon were released during the accident, indicating some fuel failure, extensive core damage was not confirmed until 1982. The end-state configuration of the core, as determined by closed-circuit television investigation, revealed a central cavity in the upper portion of the core approximately $1.5 \mathrm{~m}$ above a loose debris bed. ${ }^{1}$ Below the loose debris layer, a previously molten region existed, which was contained by partly or fully metallic crust layers. ${ }^{2}$ Overall, at least $45 \%$ (62 metric tonnes) of the core had melted. ${ }^{3}$ Video examinations also indicated that approximately $19,000 \mathrm{~kg}$ (19 metric tonnes) of molten material had relocated into the lower plenum, much of which came to rest on the lower head of the reactor vessel. ${ }^{4}$ The end-state condition of the TMI-2 reactor vessel and core is shown in Figure 1-1.

As more information was obtained concerning the extent of damage to the TMI-2 reactor, it was determined that complete cleanup of the reactor would take years and would require the cooperation of both private industry and government agencies. As a result, an organization named GEND was formed, which includes General Public Utilities Nuclear Corporation (GPUN), the Electric Power Research Institute (EPRI), the U.S. Nuclear Regulatory Commission (NRC), and the U.S. Department of Energy (DOE). GEND provided technical and financial assistance to the owner of the TMI-2 reactor, GPUN, which was responsible for ongoing plant cleanup operations. DOE was responsible for providing transportation and interim storage of the core until permanent disposition was decided. DOE also supported an extensive research program, the TMI-2 Accident Evaluation Program (AEP), whose objective was to develop a consistent understanding of the accident and to ensure that research results were available for resolution of severe accident issues. 


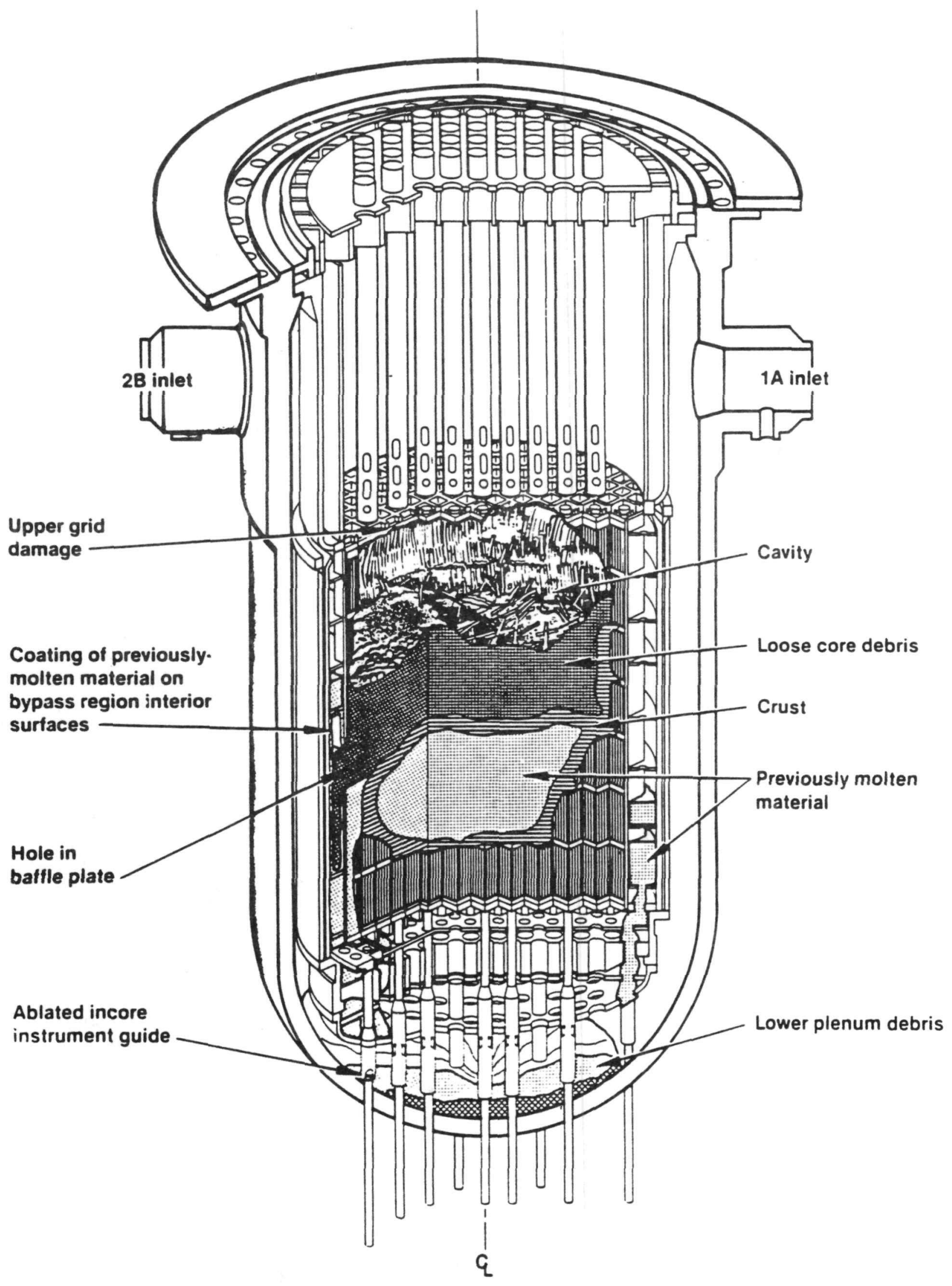

Figure 1-1. TMI-2 reactor vessel end-state configuration. 
An additional research program was formed under the auspices of the Committee on the Safety of Nuclear Installations of the Organization for Economic Cooperation and Development (OECD). Under this program, a number of OECD countries and the Commission of the European Communities' Joint Research Centre participated in the AEP by performing detailed examinations of fuel debris samples.

The Accident Evaluation Program was focused primarily on core damage progression and the mechanisms that controlled fission product behavior. ${ }^{5}$ However, observations made during the latter portions of the defueling effort indicated that the accident progressed even further than was envisioned when the Accident Evaluation Program was established. ${ }^{6}$ Molten core materials were found to have moved laterally through the east-side core baffle and former plates and into the core bypass region between the core former wall and the core barrel. Visual observation also indicated the presence of a large hole approximately $0.6 \mathrm{~m}$ wide and $1.5 \mathrm{~m}$ high extending across the lower portion of three core former plates. The 0.019 -m-thick vertical core former plates and sections of three $0.032-\mathrm{m}$-thick horizontal baffle plates were melted in this region. Molten material from the core region flowed through this hole and into the upper core support assembly. Loose debris was found in the area behind the baffle plates and extended completely around the core region. It was estimated that $4,200 \mathrm{~kg}$ of core debris were located in the upper core support region. Closed-circuit television pictures taken of the lower plenum indicated evidence of thermal damage to instrument structures in the lower plenum and around flow holes in the elliptical flow distributor. It was estimated that $19,000 \mathrm{~kg}$ (19 metric tonnes) of material relocated to the lower head.

Even though the Accident Evaluation Program successfully accomplished its objectives, results obtained during the latter phases of the program indicated that gaps still remained in the understanding of the TMI-2 accident. In particular, the vital issue of lower-head integrity needed to be further investigated.

\subsection{Vessel Investigation Project}

In October 1987, the NRC proposed that a joint international cooperative program be formed that would be sponsored by the Nuclear Energy Agency (NEA) of the Organization for Economic Cooperation and Development. ${ }^{7}$ This program would conduct further investigations because of the implications of important safety questions raised by molten fuel relocation and a potentially damaged lower head. A steering committee was established to determine if there was sufficient interest from the OECD member countries to warrant formation of such a program. The OECD efforts culminated in June 1988 with the completion of the final draft of the Agreement to Investigate the Three Mile Island-2 Reactor Pressure Vessel. Signatories to the project, commonly called the Vessel Investigation Project (VIP) included Belgium, Finland, France, Germany, Italy, Japan, Spain, Sweden, Switzerland, the United Kingdom, and the United States. 


\subsection{Vessel Investigation Project Objectives}

As described in the original 1988 project agreement and the 1991 protocol amending the original agreement, the objectives of the VIP were to:

Jointly carry out a study to evaluate the potential modes of failure and the margin to failure of the TMI-2 reactor vessel during the TMI-2 accident. The condition and properties of material extracted from the lower head of the TMI-2 pressure vessel will be investigated to determine the extent of damage to the lower head by chemical and thermal attack, the thermal input to the vessel, and the margin of structural integrity that remained during the accident. ${ }^{8}$

The project objectives were realized through a combination of several major activities that included extraction of vessel steel, nozzle, and guide tube samples from the lower head region; examinations of the extracted material; and analytical studies directed towards a better understanding of the vessel's margin to failure.

\subsection{Project Organization}

The management and organization of the VIP was defined in the formal agreement establishing the project. Overall control and direction of the VIP was vested in a Management Board, which consisted of one member designated by each of the signatories. The primary function of the management board was to approve the overall VIP workscope and budget, including the allocation of tasks among the signatories.

A Program Review Group was also formed, which consisted of one member designated by each signatory. The primary function of the Program Review Group was to act as the technical advisor to the Management Board for both ongoing activities and future work. The Program Review Group was also chartered to provide technical advice and recommendations to the VIP Operating Agent and the NRC, which was responsible for implementing project objectives in accordance with the project agreement and directions from the Management Board.

\subsection{VIP Elements}

VIP objectives were realized through the completion of several key elements, which included sample material identification and extraction, examination of the extracted material, and analyses to determine the structural integrity that remained in the vessel. Steel samples extracted from the lower head, along with nozzles, guide tubes, and previously molten debris, formed the basis of the examinations that were performed by various project members.

The condition and properties of these materials were examined to determine the extent of damage to the lower head during the accident. The results of these examinations were used to assist in quantifying potential reactor vessel failure modes, to determine the temperatures experienced by the lower head during the accident, and to develop physical and mechanical property data to support the analysis effort. In the area of analysis, scoping calculations and sensitivity studies were performed in an effort to quantify the margin to failure for different reactor failure modes and to identify which modes had the smallest margin to failure during the accident. 


\subsection{References}

1. Quick Look Inspection: Report on the Insertion of a Camera into the TMI-2 Reactor Vessel Through a Leadscrew Opening, GEND-030, Vol. 1 and 2, EG\&G Idaho, Inc., March/April 1983.

2. E. L. Tolman, R. P. Smith, M. R. Martin, R. K. McCardell, and J. M. Broughton, TMI-2 Core Bore Acquisition Summary Report, EGG-TMI-7385, Rev. 1, EG\&G Idaho, Inc., February 1987.

3. J. M. Broughton, P. Kuan, D. A. Petti, and E. L. Tolman, "A Scenario of the Three Mile Island Unit 2 Accident," Nuclear Technology, 87, No. 1, August 1989, p. 34.

4. J. P. Adams and R. Smith, TMI-2 Lower Plenum Video Data Summary, EGG-TMI-7429, EG\&G Idaho, Inc., July 1987.

5. E. Tolman et al., TMI-2 Accident Evaluation Program, EGG-TMI-7048, EG\&G Idaho, Inc., February 1986.

6. J. L. Anderson and J. J. Sienicki, "Thermal Behavior of Molten Corium During the Three Mile Island Unit 2 Core Relocation Event," Nuclear Technology, 87, 1989, p. 283.

7. Proposal For a Joint Undertaking to Investigate Material From the Lower Head of the Three Mile Island Pressure Vessel, TMI(88)2, OECD-NEA-TMI-2, October 1987.

8. Agreement on the OECD Project to Investigate the Three Mile Island-2 Pressure Vessel, OECD Document EN/S/1480, July 1988. 



\title{
2. REACTOR DESIGN AND ACCIDENT SCENARIO
}

\author{
L. A. Stickler, Idaho National Engineering Laboratory \\ 2.1 Description of the TMI-2 Reactor
}

Three Mile Island Unit 2 was a pressurized water reactor designed and manufactured by Babcock \& Wilcox, Inc. (Table 2-1; Figures 2-1, 2-2, and 2-3). ${ }^{1}$ The core contained 177 fuel assemblies arranged in a square lattice to approximate the shape of a cylinder. All fuel assemblies were identical in construction and mechanically interchangeable to any core location. A basic fuel assembly consisted of 208 fuel rods, 16 control rod guide tubes, one instrumentation tube assembly, eight spacer grids, and two end fittings (Figure 2-4). The spacer grids and end fittings formed a structural cage to arrange and maintain the rods and tubes in a $15 \times 15$ array. The center position in the assembly was reserved for the instrumentation assembly. Control rod guide tubes were placed in 16 locations throughout the array. The cross sectional view in Figure 2-4 shows the positions of the instrument and control rod guide tubes within the array.

The core contained 93.1 metric tonnes of fuel. The fuel was designed for a maximum local burnup of $55,000 \mathrm{MWd} / \mathrm{mtU}$. At the time of the accident, the burnup ranged from 900 to $6,000 \mathrm{MWd} / \mathrm{mtU}^{2}$ The fuel was sintered, low-enriched uranium dioxide in the shape of cylindrical pellets with $92.5 \%$ theoretical density. The pellets were encapsulated in zircaloy- 4 tubing and sealed by zircaloy -4 end caps, welded at each end. A fuel rod consists of the cladding, fuel pellets, end caps, and fuel support components (Table 2-2).

The reactor coolant system (RCS) consisted of the reactor vessel, two vertical once-through steam generators, four shaft-sealed reactor coolant pumps, an electrically heated pressurizer, and interconnecting piping. The system was arranged with two heat transport loops, each with two pumps and one steam generator. Figure 2-5 shows an isometric view of the TMI-2 coolant system. The coolant not only served as a heat transport medium, but also as a solvent for boron poison and as a moderator.

Core reactivity was controlled with control rod assemblies and boron dissolved in the coolant. It was also controlled with burnable poison rod assemblies added for the first fuel cycle. A control rod was composed of a silver-indium-cadmium alloy, which acted as a neutron absorber. Each of the 68 burnable poison rod assemblies consisted of 16 burnable rods. Sintered $\mathrm{Al}_{2} \mathrm{O}_{3}-\mathrm{B}_{4} \mathrm{C}$ pellets served as the poison. The burnable poison was clad in cold-worked zircaloy-4 tubing and zircaloy-4 upper and lower end pieces.

There were 52 instrument assemblies in the core. Each assembly contained seven selfpowered neutron detectors (SPNDs), one gamma-compensating background detector, and one type $\mathrm{K}$ chromel-alumel core exit thermocouple. In addition to incore instrumentation, three source range monitors, which were located outside the reactor vessel, provided a means for monitoring reactor operation. 
Table 2-1. TMI-2 design data.

\begin{tabular}{ll}
\hline Reactor & Data \\
\hline Design heat output & $2272 \mathrm{MWt}$ \\
Vessel coolant inlet temperature & $292^{\circ} \mathrm{C}$ \\
Vessel coolant outlet temperature & $320^{\circ} \mathrm{C}$ \\
Core coolant outlet temperature & $321^{\circ} \mathrm{C}$ \\
Average core fuel temperature & $649^{\circ} \mathrm{C}$ \\
Core operating pressure & $15 \mathrm{MPa}$ \\
\hline Core and Fuel Assemblies & Number \\
\hline Fuel assemblies in core & 177 \\
Fuel rods per fuel assembly & 208 \\
Control rod guide tubes per assembly & 16 \\
Incore instrument positions per fuel assembly & 1 \\
\hline
\end{tabular}

\subsection{Sequence of Events}

The TMI-2 accident scenario can be divided into five phases, beginning with reactor scram. Phase 1 encompasses the loss of coolant period from 0 to 100 minutes. The core heatup period, from 100 to 174 minutes, defines Phase 2. Phase 3 extends from 174 to 224 minutes. Core relocation between 224 and 226 minutes comprises Phase 4. Phase 5 extends from 226 minutes to 15.5 hours. The early phases of the accident were inferred from interpretation and analysis of instrumentation data, the end-state core configuration, and previous severe accident research results. The accident scenario up to the time of core relocation at 224 minutes has been extensively analyzed and reviewed. However, the sequence of events that took place within the vessel during core relocation are not well defined. Section 8 describes a postulated relocation scenario.

Instrumentation traces of several monitoring devices during the course of the accident are shown in Figure 2-6. Data shown in the figure, from the top down, include source and intermediate range count rate, reactor coolant pump operation, reactor coolant flow, high pressure injection pump operation, reactor coolant outlet temperature, core flood injection, reactor coolant inlet temperature, PORV block valve operation, and reactor coolant pressure.

\subsubsection{Phase 1 ( 0 to 100 minutes)}

This phase was characterized by a loss of primary system coolant. A reduction in feedwater to the steam generator caused the coolant to expand and initially increased the RCS pressure. The pilot-operated relief valve (PORV) opened when the pressure reached $15.7 \mathrm{MPa}$, with reactor scram occurring when the pressure reached $16.3 \mathrm{MPa}^{3}$ The PORV failed to close as the RCS pressure decreased, initiating a small-break loss-of-coolant accident (LOCA). Emergency core cooling was reduced by operators who thought that the pressurizer liquid level indicated a nearly full RCS, while coolant continued to be lost from the PORV. After the initial decrease in 


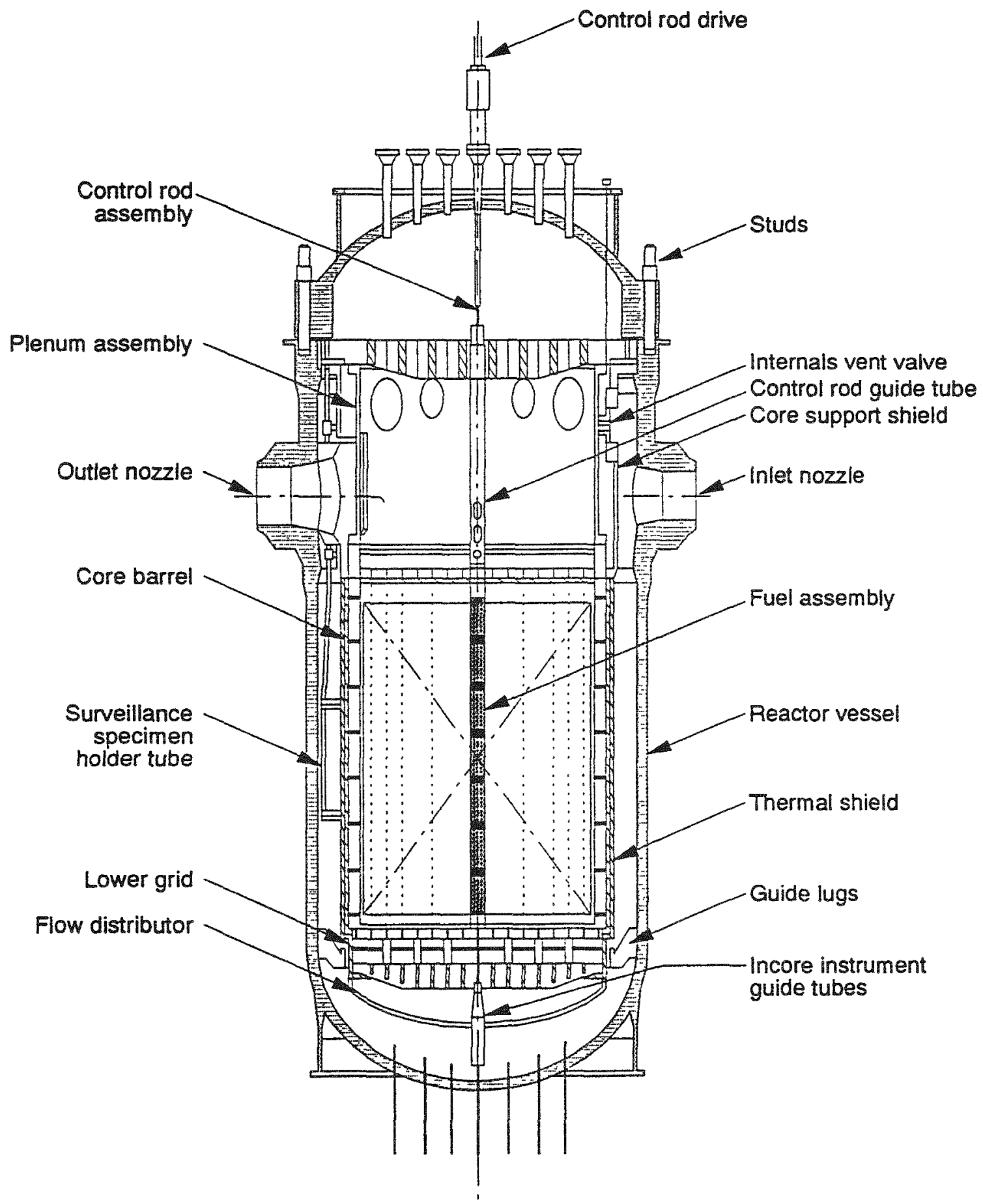

Figure 2-1. Reactor vessel components. 


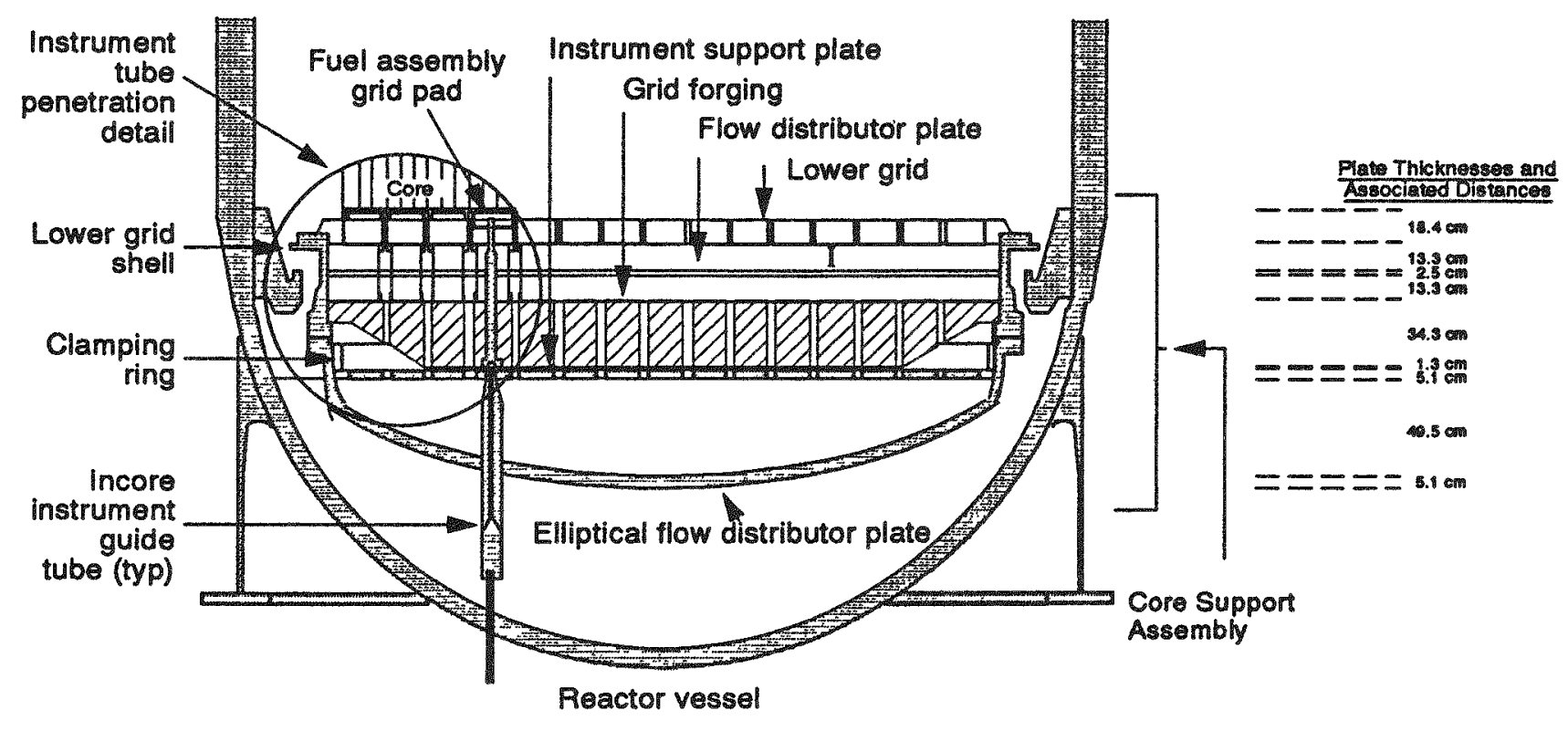

Figure 2-2. Lower head core support assembly.

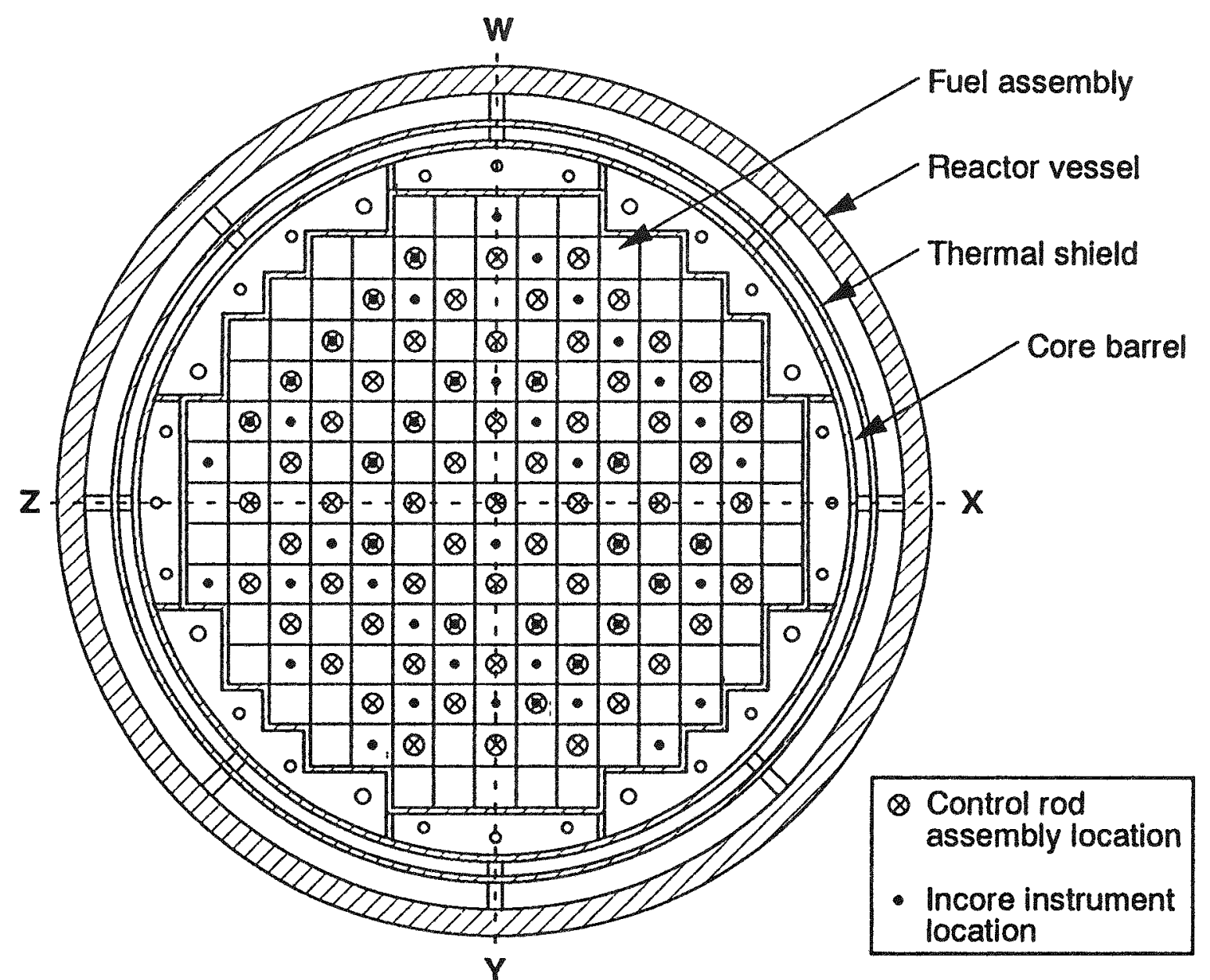

Figure 2-3. Cross section of the reactor vessel and internals. 


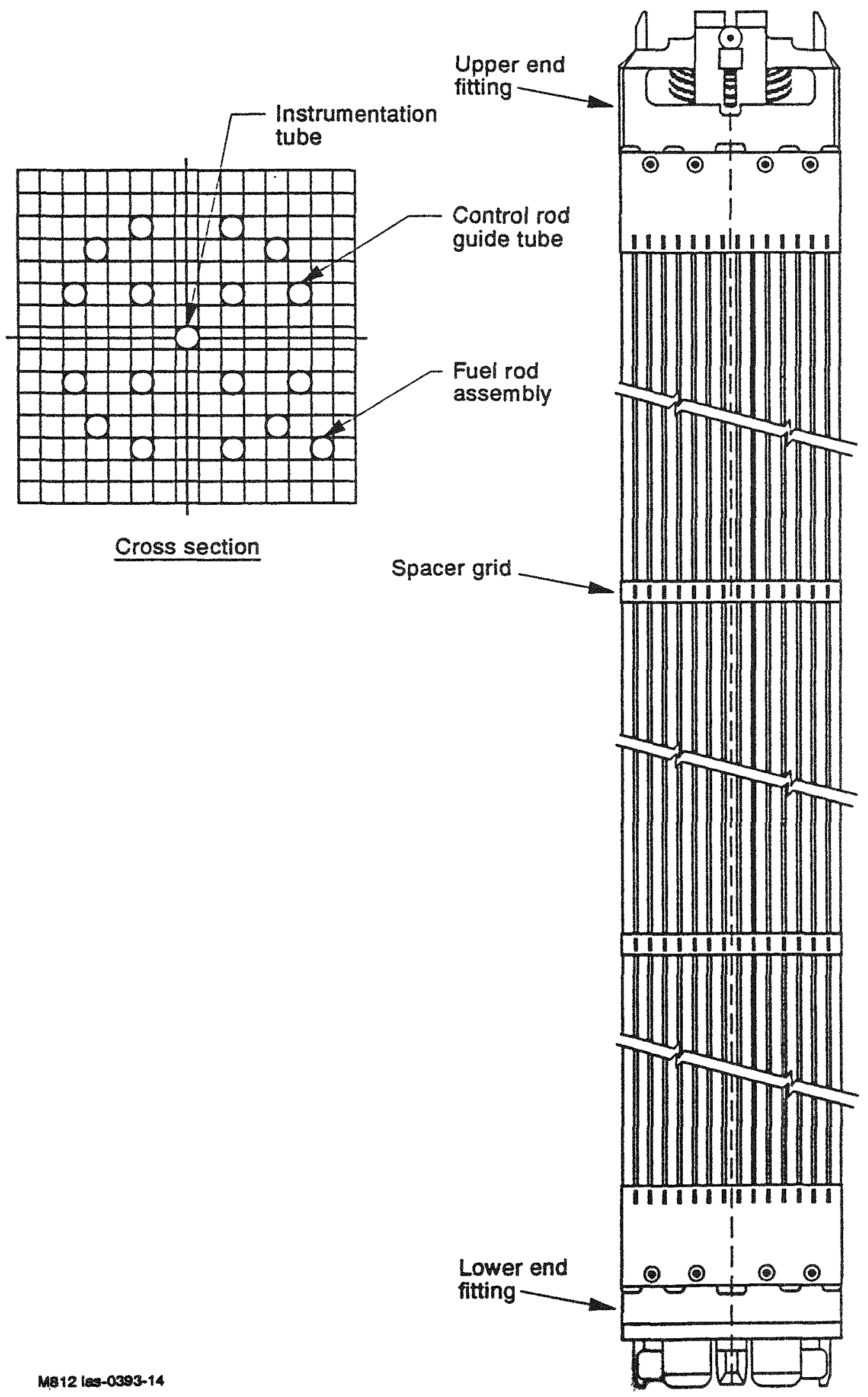

Figure 2-4. Fuel assembly. 
Table 2-2. Reactor component materials.

\begin{tabular}{|c|c|c|}
\hline Area & Component & Material \\
\hline \multirow[t]{3}{*}{ Fuel rod (208) } & Fuel & $\mathrm{UO}_{2}$ sintered pellets \\
\hline & Cladding & Zircaloy-4 \\
\hline & Ceramic spacer & $\mathrm{ZrO}_{2}$ \\
\hline \multirow[t]{10}{*}{ Fuel assembly (177) } & Control rod & $\mathrm{Ag}-\mathrm{In}-\mathrm{Cd}$ \\
\hline & Control rod cladding & SS-304 \\
\hline & Control rod guide tube (16) & Zircaloy-4 \\
\hline & Instrumentation tube & Zircaloy-4 \\
\hline & End fittings (2) & SS castings \\
\hline & Spacer grid strips (8) & Inconel-718 \\
\hline & Spacer sleeve (7) & Zircaloy-4 \\
\hline & Burnable poison rods & $\mathrm{Al}_{2} \mathrm{O}_{3}-\mathrm{B}_{4} \mathrm{C}$ \\
\hline & Burnable poison rod cladding & Zircaloy-4 \\
\hline & Axial power shaping rods & $\mathrm{Ag}-\mathrm{In}-\mathrm{Cd}$ \\
\hline \multirow[t]{4}{*}{ Pressure vessel } & Vessel & SA533B \\
\hline & Cladding & $\mathrm{SS}$ or $\mathrm{Ni}-\mathrm{Cr}-\mathrm{Fe}$ \\
\hline & Instrumentation nozzles (52) & Inconel-600 \\
\hline & Instrument guide tubes (52) & SS-304 \\
\hline
\end{tabular}




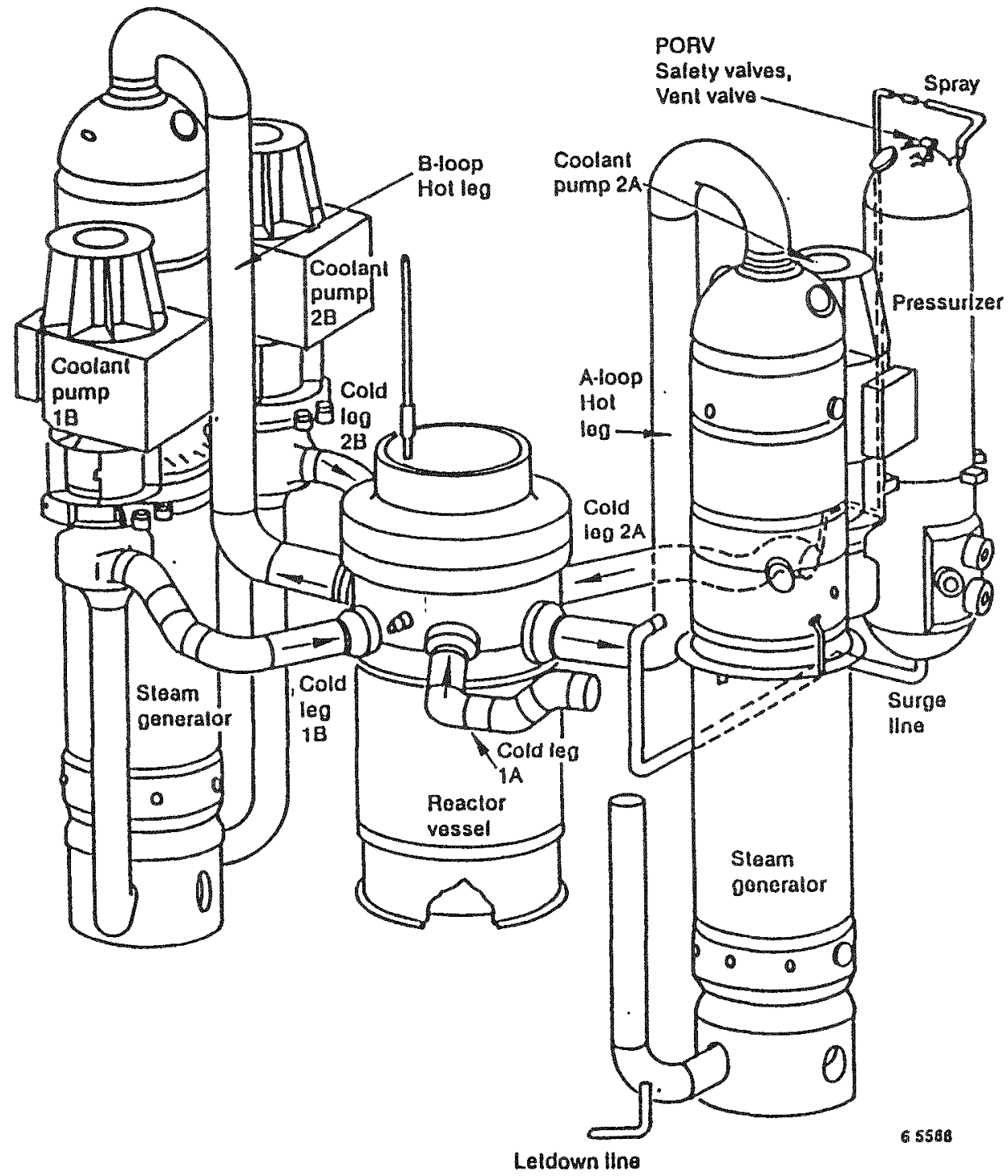

Figure 2-5. Schematic of the TMI-2 primary system. 

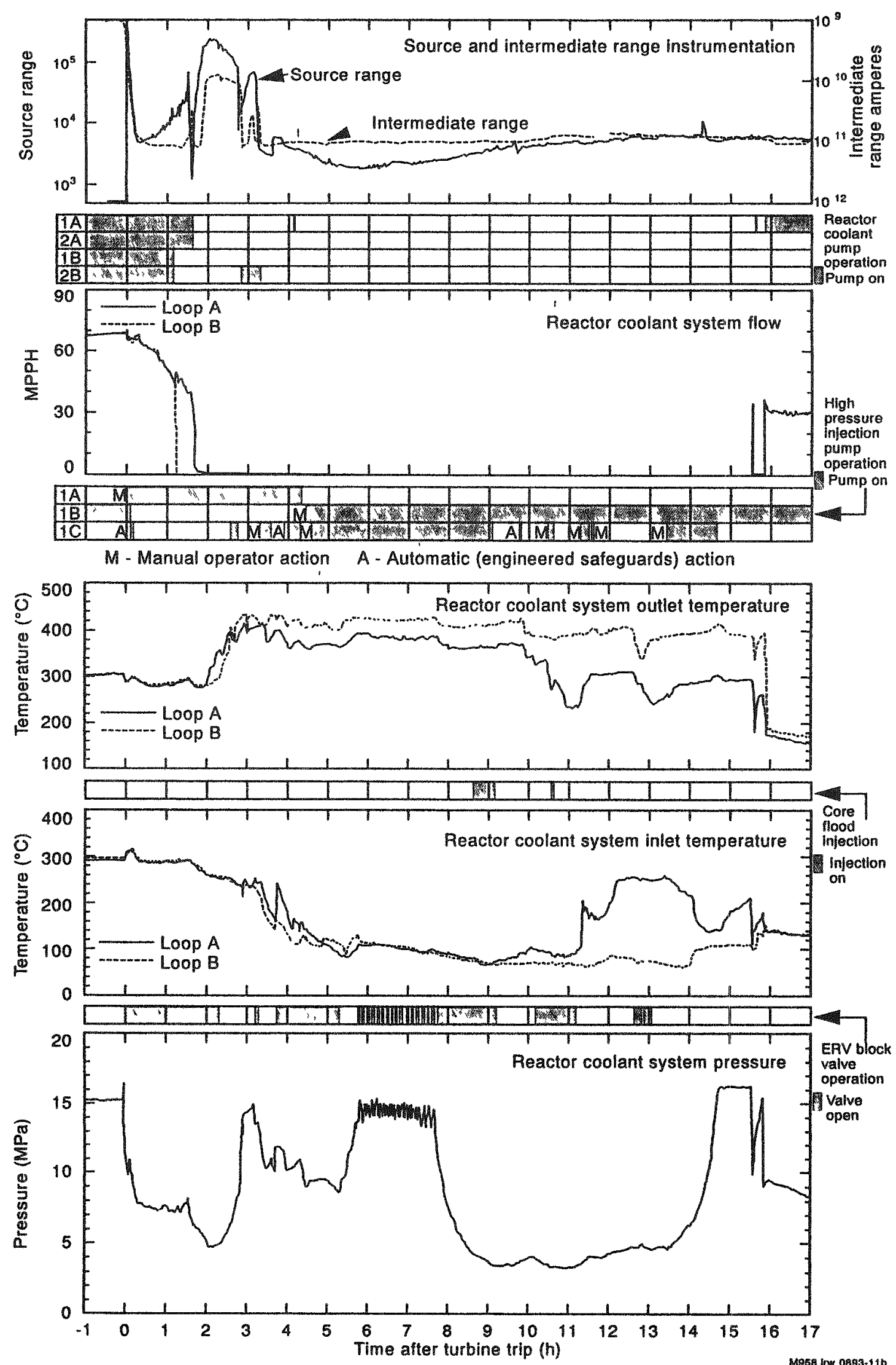

Figure 2-6. Various instrumentation data during the accident. 
RCS pressure, the system pressure remained at approximately $7 \mathrm{MPa}$ (Figure 2-6). The coolant void fraction increased over the next hour, due to loss of coolant through the PORV and continued decay heat generation by the fuel. The void fraction increased to such an extent as to cause cavitation in the reactor pumps. At approximately 73 minutes, the two pumps in the $B$ loop were shut off, resulting in loss of heat removal by the B loop steam generator. At approximately 100 minutes, the A loop pumps were shut off, and forced convective cooling of the core was terminated. Pump operation timing is shown in Figure 2-6. Prior to the A loop pump shutdown, the two-phase forced flow of coolant, which covered the core, had been sufficient to prevent core heatup.

\subsubsection{Phase 2 (100 to 174 minutes)}

After pump termination at 100 minutes, liquid in the two-phase coolant mixture drained from the upper regions of the cooling system into the reactor vessel. The liquid level in the reactor vessel decreased because makeup to the primary cooling system was insufficient to compensate for coolant loss through the PORV. Initial core uncovery was estimated to have occurred between 114 and 120 minutes resulting in temperature increases at the top of the core. The upper regions of the core would have heated to temperatures between 827 and $927^{\circ} \mathrm{C}$, causing the cladding to balloon and rupture. Cladding failure, which results in the release of gaseous fission products, was substantiated by significant increases in containment radiation levels starting at 140 minutes. The pressurizer block valve upstream of the PORV was closed by reactor operators about this time (Figure 2-6), terminating coolant loss and the release of fission products to the containment structure.

Incore self-powered neutron detector output and RCS pressure indicated that core temperatures continued to increase between 150 and 165 minutes. Subsequent analysis of SPND output indicated that temperatures probably reached $1,077^{\circ} \mathrm{C} .{ }^{4}$ Continued core degradation caused the RCS pressure to increase approximately $5.5 \mathrm{MPa}$ between 150 and 174 minutes, (Figure 2-6). Oxidation of zircaloy cladding produced large quantities of hydrogen, which reduced the heat transferred to the secondary system in the steam generator, and caused the core temperatures to rise to levels that would melt control rods and fuel rod cladding.

During this period, interactions between melted cladding and structural materials resulted in eutectic material flowing down through the central region of the core until it reached the liquid/steam interface where it solidified, forming the lower supporting crust. Analysis revealed that the lower crust was a $\mathrm{Zr}$-Ag-In-Fe-Ni metallic mixture. ${ }^{5}$ Zircaloy cladding and Inconel grid spacers most likely formed the first eutectics. Stainless steel control rod cladding would melt when temperatures exceeded $1,427^{\circ} \mathrm{C}$. The cladding may also have been breached due to interactions between the stainless steel cladding and molten zircaloy, since the materials form relatively low temperature eutectics. After cladding failure, molten $\mathrm{Ag}$-In-Cd control material with a melting temperature of $827^{\circ} \mathrm{C}$ would flow down into the crust. Increased fuel rod temperatures would eventually lead to fuel melting.

A lower crust surrounded standing fuel columns and blocked coolant channels between fuel rods in the central region of the core, gradually progressing out to the periphery of the core. Complete blockage of the central core region occurred by 174 minutes. The blockage caused a diversion of steam to the periphery of the core, increasing heat transfer at the periphery of the 
crust. The presence of the lower crust limited interactions between the coolant and molten materials, reducing oxidation and hydrogen production. During this period of core oxidation and molten core and structural material relocation, the coolant liquid level was near the second fuel assembly spacer grid location. The presence of intact rod stubs below the lower crust indicated that core coolant levels around $0.5 \mathrm{~m}$ were maintained throughout the accident. A region of partially molten metallic and ceramic material was consolidated on top of the crust. Peak temperatures within this region may have reached the melting temperature of the fuel, approximately $2,830^{\circ} \mathrm{C}$, with the average about 2,330 to $2,530^{\circ} \mathrm{C} .6,7$

The dominant release mechanism for the volatile fission products during initial core heatup was diffusion of gaseous fission products through the fuel matrix. Sensitivity calculations with varying material properties and core temperatures indicate that the core diffusional release of the volatile fission products such as krypton, xenon, and cesium, could range from 0 to nearly $45 \%{ }^{8}$ Individual locations within the core could have experienced total release. However, due to the low burnup of the core at the time of the accident, the fission product level within the fuel was relatively low compared to that of an older core.

\subsubsection{Phase 3 (174 to 224 minutes)}

Beginning at 174 minutes, the $2 \mathrm{~B}$ coolant pump was operated for approximately 19 minutes and represented the first significant addition of coolant to the reactor vessel since the A-looppump shutdown at 100 minutes. This coolant injection rapidly repressurized the reactor system (Figure 2-6). Core exit thermocouples above peripheral fuel assemblies indicated that the core was cooled at the time of the $2 \mathrm{~B}$ pump transient. Source range monitor (SRM) count rate showed a large decrease (Figure 2-6) at the time of coolant injection, although the rate was still above the nominal count rate for a water-filled undamaged core. The injection may have caused some quenching and fragmentation of oxidized fuel and control rods in the top half of the core. Over the course of the accident, fragmented debris was circulated through the coolant system via the operation of the pumps, eventually settling on the lower head. Coolant flow through the central region of molten core material was nonexistent due to blockages.

High-temperature steam and hydrogen caused oxidation, melting, and ablation of the upper support grid, but upper plenum structures above the core did not receive significant damage. Metallurgical examinations of control rod drive leadscrews ${ }^{9}$ identified structural temperatures above the grid plate of approximately $930^{\circ} \mathrm{C}$ at the center of the core, approximately $730^{\circ} \mathrm{C}$ near the periphery of the core, and about $430^{\circ} \mathrm{C}$ across the core at the hot leg outlet elevation. These data were consistent with the existence of a single axisymmetric convection cell confined to the upper plenum and core. Hence, the energy generated by the core was not transferred uniformly to upper plenum structures.

Decay heat from the core evaporated coolant, decreasing the level of liquid in the reactor vessel. At 200 minutes, the liquid level stood at approximately $2 \mathrm{~m}^{10}$ The decreased coolant level was substantiated by reheated peripheral incore thermocouples, which increased SRM responses at levels above those recorded at 174 minutes. Steam production from 192 to 197 minutes indicated that heat transferred away from the core was less than nominal core decay power. ${ }^{11}$ Degraded core heatup calculations indicated that a pool of molten material formed in the center of the consolidated region and increased in size during this period. ${ }^{7}$ The low thermal 
diffusivity of the large region of consolidated material would have prevented the interior from cooling, even if the vessel had been filled with water.

At 200 minutes, the high pressure injection system was operated for 17 minutes, transferring emergency cooling water to the vessel (Figure 2-6). The reactor vessel was refilled with water by approximately 207 minutes. ${ }^{10,12}$ Much of the water that filled the reactor vessel came from drainage of the pressurizer coolant as the RCS pressure decreased. Water began to penetrate and eventually quench the upper debris bed. Quenching of the debris bed was estimated to have taken about 25 minutes, ${ }^{13}$ with quenching completed by 230 minutes.

Although the core was estimated to have been covered with coolant, little coolant flowed through the consolidated core region; as a result, this region continued to heat up. ${ }^{7}$ This hypothesis was substantiated by estimates of the RCS steam production between 200 and 217 minutes. The steam production rate was less than what it would have been if all the core décay heat generation had been transferred to the water. ${ }^{12}$

Fission product release was dominated by the thermal and hydrodynamic behavior of molten debris, by the volatility of the fission products, and by dynamics of bubble formation, coalescence, and mobility. ${ }^{8}$ Calculations indicate a rapid release of volatile fission products due to the formation of large buoyant bubbles from smaller coalescing fission gas bubbles. The large gas bubbles would have been trapped inside the crust until crust failure. Medium and low volatile fission products were estimated to have remained as oxides or metallic phases in the melt. Little release was expected due to the low vapor pressure and small mole fraction of materials within the pool.

\subsubsection{Phase 4 (224 to 226 minutes)}

Some control material and quenched, fuel-bearing ceramic material apparently relocated to the lower head prior to 224 minutes. However, the majority of the ceramic material that was deposited on the lower head relocated from the core to the lower head beginning 224 minutes after reactor scram. Debris relocation was completed in approximately 120 seconds. The relocation was substantiated by a sharp increase in pressure and by the increase in SRM count rate (Figure 2-6). The SPND alarm signals originated from locations P6 and R7 during relocation as shown in Figure 2-7. Details of the postulated relocation scenario are presented in Section 8.

\subsubsection{Phase 5 (226 minutes to 15.5 hours)}

The pressure rise between 224 and 240 minutes indicated that steam generation was significant for at least 15 minutes. The pressurizer block valve was repeatedly cycled between 320 and 480 minutes, in an attempt to establish RCS flow (Figure 2-6). Cycling of the valve resulted in the transfer of coolant to the containment building. SRM data indicate that molten debris may have continued to relocate to the lower head between 230 minutes and 15.5 hours (Figure 2-6), although in quantities much smaller than the initial relocation event. Reformed thermocouple junctions embedded in the debris indicate that temperatures exceeding $730^{\circ} \mathrm{C}$ existed within the debris bed for three days following the accident. ${ }^{14}$ At 15.5 hours, one of the A-loop primary coolant pumps was restarted, forcing coolant to flow through the core. 


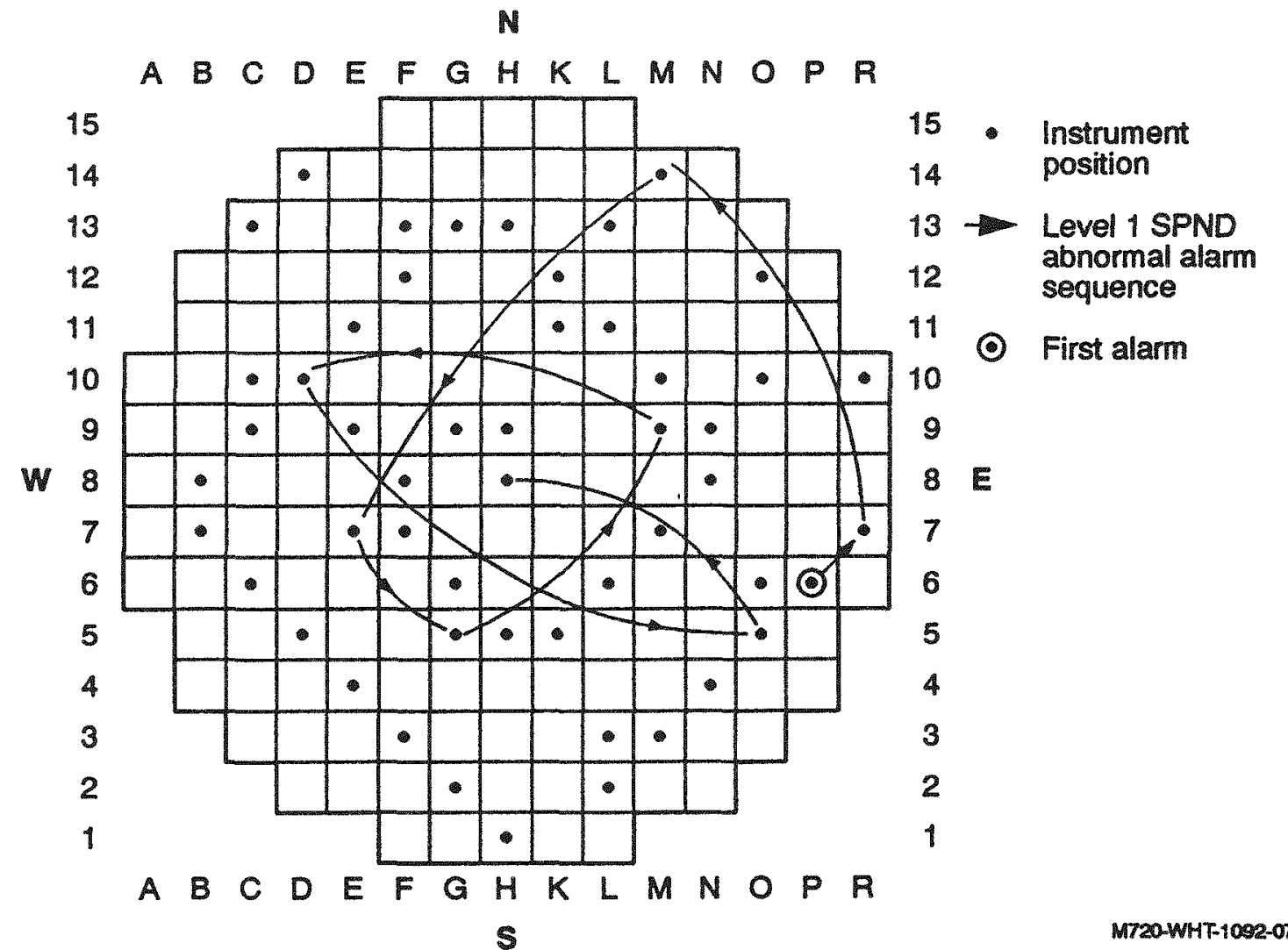

Figure 2-7. SPND level 1 alarm timing. 


\subsection{Recovery Efforts}

Upon failure of the PORV to close during the early stage of Phase 1, the RCS pressure continued to decrease. Operators responded by increasing makeup flow to $30 \mathrm{~L} / \mathrm{sec}$. At 8 minutes, operators opened block valves, permitting auxiliary feedwater injection into the steam generator secondary sides. Although the RCS pressure was approximately $7 \mathrm{MPa}$, the operators decreased makeup flow and increased letdown flow in response to a high indicated pressurizer level. The pressurizer block valve upstream of the opened PORV was closed at about 140 minutes during Phase 2.

At 174 minutes, during Phase 3, the reactor system was repressurized by the 19-minute operation of the $2 \mathrm{~B}$ coolant pump. Emergency core cooling was injected for 17 minutes, starting at 200 minutes. The vessel was refilled with water by approximately 207 minutes. The upper debris bed was eventually quenched at about 230 minutes by the emergency cooling water. At 220 minutes, the pressurizer block valve was opened.

The pressurizer block valve was cycled between 320 and 480 minutes in an attempt to establish flow through the reactor coolant system in the final phase of the accident. Operators tried to establish stable cooling by either natural or forced circulation of coolant through the steam generators, or by using the decay heat removal system. ${ }^{15}$ Numerous attempts were made to remove heat via the steam generators in a 5-hour period after closure of the block valve at 140 minutes. These attempts were unsuccessful due to the presence of a large amount of hydrogen trapped in the reactor coolant system. During the next 4 hours, operators reduced pressure in the coolant system in an attempt to remove heat through the low pressure decay heat removal system. A large quantity of hydrogen was vented from the coolant system during depressurization. Core flood tanks injected some water to the reactor vessel; however, the RCS pressure remained too high to initiate the decay heat removal system. Enough hydrogen was vented during depressurization to resume operation of one of the pumps in the A-loop steam generator 15.5 hours after reactor scram, thus establishing heat removal from the reactor vessel.

\subsection{References}

1. Three Mile Island Nuclear Station Unit 2, License Application FSAR docket number 50320 (73 through 82), Metropolitan Edison Co., Reading, PA, 1974.

2. B. G. Schnitzler and J. B. Briggs, TMI-2 Isotope Inventory Calculations, EGG-PBS-6798, EG\&G Idaho, Inc., August 1985.

3. E. L. Tolman et al., TMI-2 Accident Scenario Update, EGG-TMI-7489, December 1986.

4. D. J. N. Taylor, "TMI SPND Interpretation," Proceedings of the First International Information Meeting on the TMI-2 Accident, Germantown, MD, October 1985, CONF-8510166.

5. D. W. Akers and R. K. McCardell, "Core Materials Inventory and Behavior," Nuclear Technology, 87, 1989. 
6. D. W. Golden, N. Ohnishi, and A. Takizawa, "SCDAP/RELAP5 Simulation of the Three Mile Island Unit 2 Accident," Nuclear Technology, 87, 1989.

7. R. L. Moore, D. W. Golden, and E. L. Tolman, "Three Mile Island Unit 2 Degraded Core Heatup and Cooldown Analysis," Nuclear Technology, 87, 1989.

8. D. A. Petti, J. P. Adams, J. L. Anderson, and R. R. Hobbins, "Analysis of Fission Product Release Behavior from the Three Mile Island Unit 2 Core," Nuclear Technology, 87, 1989.

9. K. Vinjamuri, D. W. Akers, and R. R. Hobbins, Examination of H8 and B8 Leadscrews from Three Mile Island Unit 2, GEND-INF-052, EG\&G Idaho, Inc., September 1985.

10. Y. Nomura and J. L. Anderson, "Analysis of Refill Phenomena During the Three Mile Island Unit 2 Accident," Nuclear Technology, 87, 1989.

11. J. M. Broughton, P. Kuan, D. A. Petti, and E. L. Tolman, "A Scenario of the Three Mile Island Unit 2 Accident," Nuclear Technology, 87, No. 1, August 1989, p. 34.

12. R. Henry et al., "Core Relocation Phenomenology," Proceedings of the First International Information Meeting on the TMI-2 Accident, Germantown, MD, October 1985, CONF-8510166.

13. P. Kuan, TMI-2 Core Debris Bed Coolability, EGG-TMI-7150, EG\&G Idaho, Inc., March 1986.

14. T. L. Van Witbeck et al., Three Mile Island Unit 2 Annotated Sequence of Events, March 28 , 1979, GPU-TDR-044, GPU Nuclear, Inc., February 6, 1981.

15. Nuclear Safety Analysis Center, Analysis of Three Mile Island Unit 2 Accident, NSAC-80-1, Electric Power Research Institute, Palo Alto, CA, March 1980. 


\title{
3. SAMPLE SELECTION AND ACQUISITION
}

\author{
J. R. Wolf, Idaho National Engineering Laboratory
}

During the formative stages of the VIP, the lower head was still covered with a hard layer of previously molten material topped by a layer of loose debris. This debris layer obscured the lower head from direct observation and made it impossible to determine, ahead of time, which vessel samples should be acquired. In order to properly plan the extraction efforts, criteria were developed to help prioritize which samples would be removed first. Steel, nozzle, and guide tube samples from the vessel would be identified after the lower head had been defueled and the condition of the head itself observed.

\subsection{Sample Selection}

Since it was possible to remove only a small number of samples, it was imperative that the extracted samples provide the maximum amount of data possible. After a careful review of data from visual observations and mechanical probing of the debris bed, it was decided that samples from a variety of locations throughout the vessel lower head would best satisfy the VIP objectives. ${ }^{1}$ The areas included the following:

- The area towards the radial center of the lower head where the hard layer of debris was thickest

- The area directly beneath the postulated primary relocation path of molten material to the lower head

- The area in the north sector of the lower head where a wall of consolidated material similar to a lava flow was observed

- In an area where no core debris existed to act as a control sample

- Areas discussed above that contain an instrument penetration.

These extraction criteria provided an excellent framework for the later identification of individual steel and nozzle samples.

\subsection{Sample Acquisition}

GPUN completed the process of defueling of the reactor vessel and the lower head on January 30, 1990. A 30-day window was then available for the VIP sample acquisition effort. During this time period, as many samples as possible were removed from the vessel. Under the direction of MPR Associates, Inc., 15 prism-shaped metallurgical "boat samples" were cut from the vessel lower head along with 14 incore nozzle stubs and two incore instrument guide tube sections. These samples were removed between January 30 and March 1, 1990.

Removing the samples from the lower head of the TMI-2 vessel was a unique challenge that required the development of specialized cutting tools. Different types of tooling were developed 
for each of the three types of samples (nozzle, guide tube, and vessel steel). Sample removal was complicated by the fact that all operations were performed from the top of the reactor vessel through a $0.45-\mathrm{m}$-wide, $3.0-\mathrm{m}$-long slot that was $12 \mathrm{~m}$ above the area of interest. The vessel was also filled with water that had a typical visibility of 2 to $3 \mathrm{~m}$. Special lighting and underwater cameras were used during all sample extraction activities. ${ }^{2}$

The removal of the lower head debris that was to become known as the companion samples was part of the overall defueling effort of the TMI-2 reactor vessel and was not part of the VIP. However, the examinations that were performed on the companion samples were formally part of the VIP effort.

\subsubsection{Nozzle and Guide Tube Cutting Tools}

The nozzle cutting tool was an underwater hydraulic motor mounted on the end of a long pipe. Commercially available abrasive saw blades ranging from 20 to $41 \mathrm{~cm}$ in diameter were attached to the motor and used to cut the nozzles. During the cutting process, the pipe section of the tool was placed over an adjacent nozzle to counter reaction forces that occurred during the cutting process.

Cutting the guide tubes was more complicated than cutting the nozzles (since the guide tube pieces had been stored on the vessel shield wall during the defueling operation). When the elliptical flow distributor was cut up into sections and removed from the vessel, each section had several guide tubes attached. During the guide tube cutting process, each section was placed in a tank of water to prevent airborne contamination and to provide radiation shielding. After the section was placed in the water tank, a modified pipe cutting tool was attached to the guide tube, which was then severed from the flow distributor. The cutting tool was similar in design to strapon tools that cut and prepare pipe sections for welding.

Even though these tools were relatively simple in design, they underwent extensive development testing and full mockup testing with all delivery systems to verify design functions and capabilities. These tests ensured that the tools would operate reliably during the actual sample removal process at TMI-2.

\subsubsection{Vessel Steel Sample Cutting Tool}

The vessel steel samples were the most difficult to extract. In the initial planning for the vessel steel sample removal task, three potential approaches were considered: trepanning, abrasive saws, and electrical discharge machining. The electrical discharge machining was found to best meet the constraints imposed on the removal effort by providing as large a sample as possible and not breaching the vessel wall.

The type of electrical discharge machining ultimately used is referred to as metal disintegration machining (MDM). The MDM process consists of removing conductive material in small bits by melting them away with a small electric arc between the electrodes and the works piece. During operation, the MDM process makes and breaks electrical arcs by moving the cutting head electrode into and away from the work material. 
Between May 1988 and December 1989, the MDM system underwent an extensive development and qualification process prior to actual use in the TMI-2 vessel. Proof-of-principle tests were conducted to verify that the MDM technique would work given that it had never been used for this type of application. Functional prototype testing was followed by final qualification testing in a mock-up that was as representative of the actual TMI-2 environment as possible. Both water chemistry and vessel pressure were simulated to match conditions that would be encountered during the actual cutting process.

The MDM cutting head used for removing the VIP lower head samples had two graphite electrodes attached to hydraulic cylinders and slide on tracks mounted at angles. This setup was able to successfully cut samples with an included angle of 60 degrees. The same type of cutting head arrangement was used to remove samples both in open areas of the vessel and at incore penetrations. Special seal plugs were developed and installed in the penetrations prior to cutting. A sketch of the MDM cutting head is shown in Figure 3-1.

\subsection{Description of Samples Removed}

During the period between January 30 and March 1, 1990, 15 metallurgical samples, 14 incore nozzle stubs, and two incore guide tube sections were removed. Steel samples were removed from lower head locations D-10, E-6, E-8, E-11, F-5, F-10, G-8, H-4, H-5, H-8, K-7, K13, L-9, M-8, and M-11. The samples were typically 152-178 mm long, $64-89 \mathrm{~mm}$ wide, and 64-76 mm thick. Nozzle samples were removed from locations D-10, E-7, E-11, G-5, H-5, H-8, H-9, K-11, K-12, L-6, L-11, M-9, M-10, and R-7. Steel samples from D-10, E-11, H-5, and H-8 were removed after the vessel nozzles at those locations had been severed as close to the lower head as possible. During the sample removal process, it was noted that several nozzles (E-9, F-7, F-8, G-6, and G-9) had sustained such severe damage that the remaining stubs were too short to cut. Guide tubes were removed from locations K-5 and M-10. The vessel steel, nozzle, and guide tube samples extracted were located throughout the vessel and allowed the VIP objectives described in Section 1.3 to be met. Sample locations are shown in Figure 3-2.

After the steel samples were removed from the vessel, they were sent to Argonne National Laboratory (ANL) in the United States. ANL coordinated the metallographic examinations and mechanical tests that were performed by VIP members. A detailed description of the steel examinations and their results is contained in Section 4.

The nozzle and guide tube samples were sent to the Idaho National Engineering Laboratory (INEL) and to ANL in the United States for examination. Portions from selected INEL nozzles and guide tubes were later sent to CEA Saclay, France, where additional examinations were performed. Detailed discussions of the nozzle and guide tube examinations and results are contained in Section 6.

During the sample removal effort, tears or cracks were found in the cladding of the vessel around nozzle E-7, and subsequently in the samples from G-8 and F-10. These cracks were analyzed by ANL and were attributed to stresses associated with the thermal gradient in the thickwalled carbon steel vessel during the heating and cooling phases of the accident. 


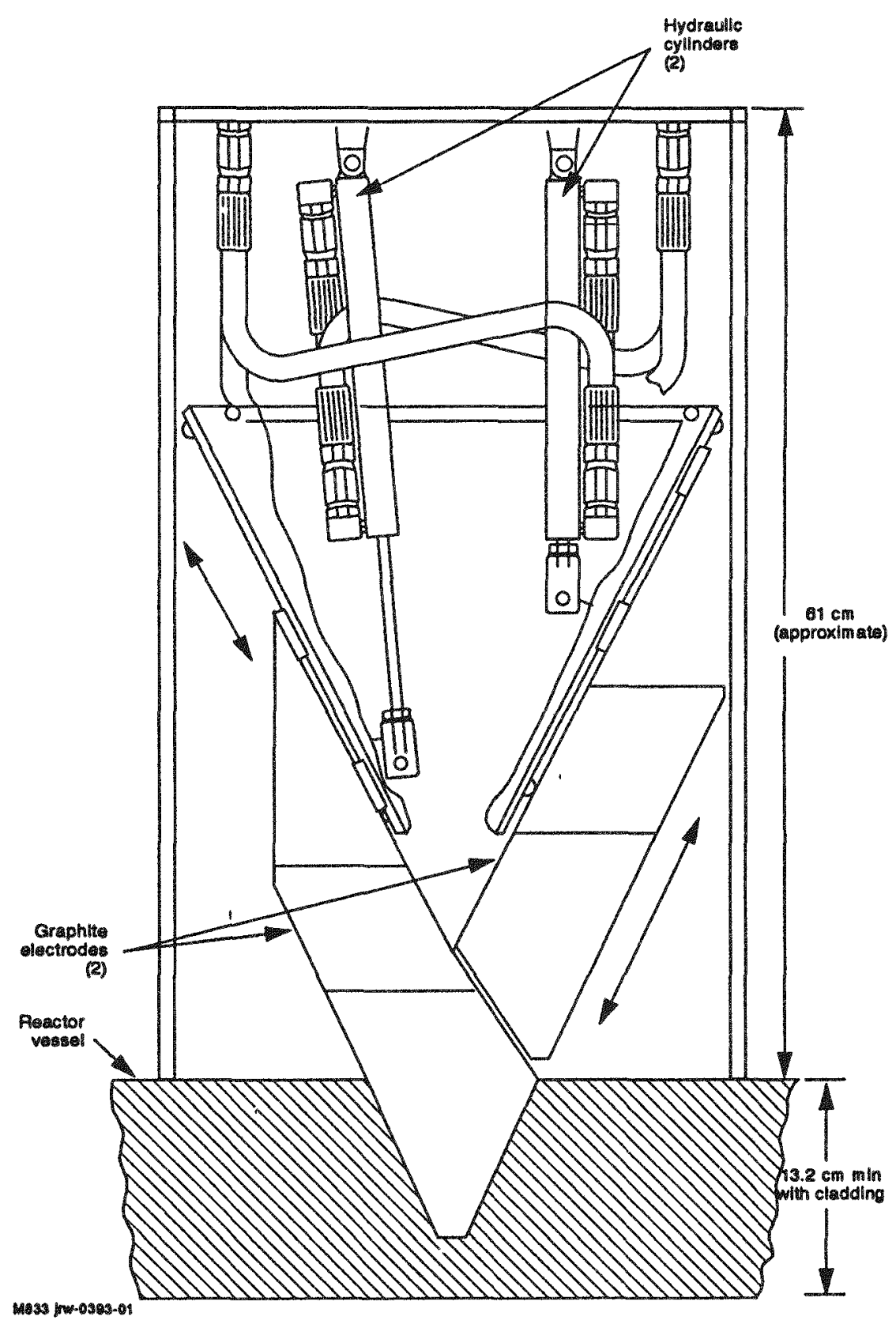

Figure 3-1. MDM cutting head. 


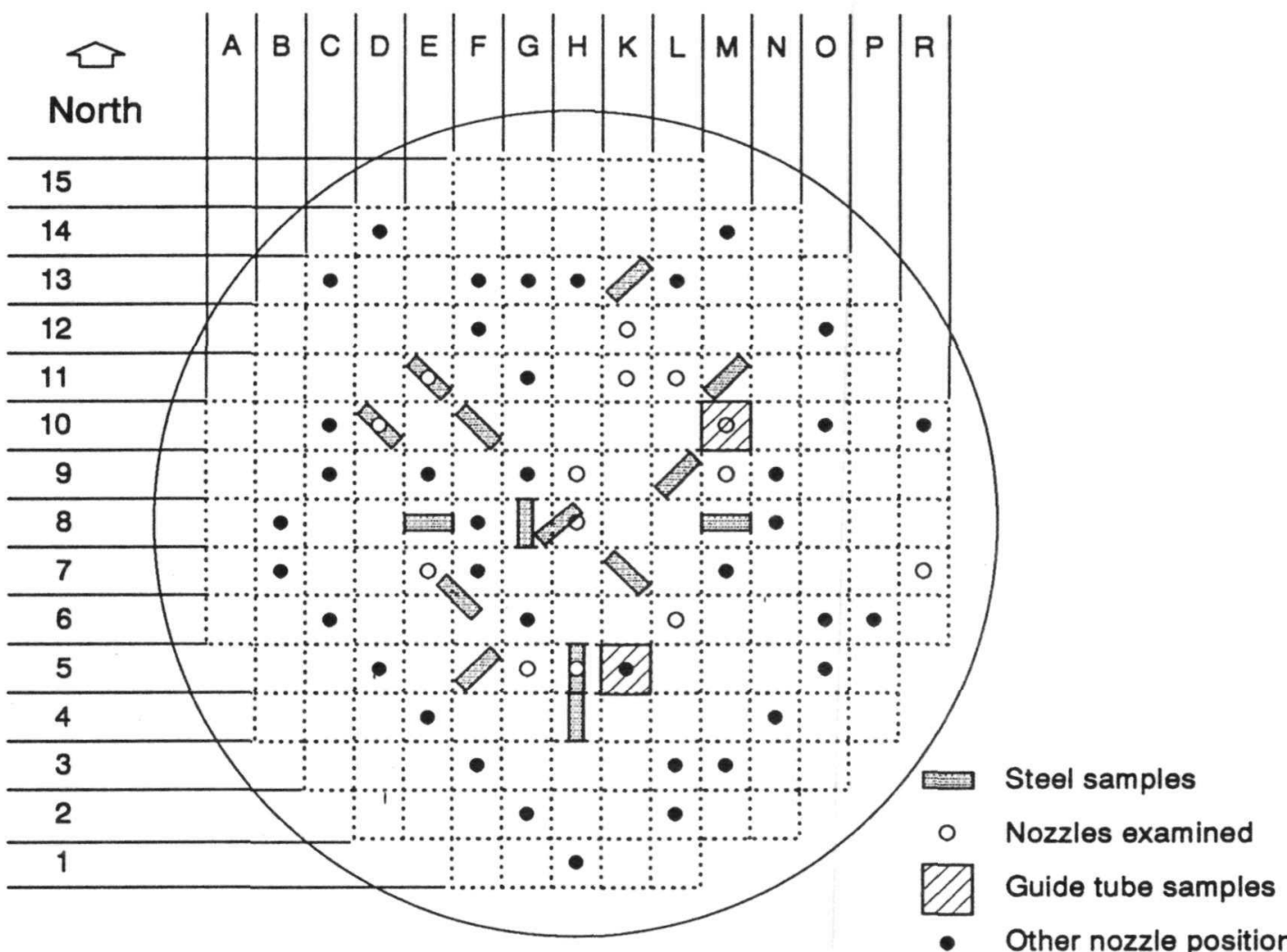

$\operatorname{mos} i m$

Figure 3-2. Location of lower head steel, nozzle, and guide tube samples. 


\subsection{References}

1. Proposed OECD Project On The Three Mile Island Pressure Vessel Lower Head Sample Examination, TMI V(88)4, OECD-NEA-TMI-2 Vessel Investigation Project, March 1988.

2. MPR Associates, Inc., Phase 4 Status Report: Removal of Test Specimens from the TMI-2 Reactor Vessel Bottom Head, Project Summary, MPR-1195, October 1, 1990. 


\title{
4. METALLURGICAL EXAMINATIONS AND MECHANICAL PROPERTIES
}

\author{
G. E. Korth, Idaho National Engineering Laboratory \\ D. R. Diercks and L. A. Neimark, Argonne National Laboratory
}

The relocation of $19,000 \mathrm{~kg}$ of molten core debris onto the lower head of the reactor pressure vessel caused a considerable threat to the integrity of the pressure vessel. The molten debris had the potential of melting or considerably weakening the lower head, which is comprised of 136-mm-thick A533B pressure-vessel steel with 5-mm type 308L stainless steel clad. The lower head did not melt or fail by tensile overload from the internal pressure, but contained the debris as it cooled. This indicates that the temperature of the lower head was considerably below $1,495^{\circ} \mathrm{C}$, the temperature where this steel starts to melt, but may have been well within the regime where failure by short-term creep could have occurred.

To determine the post-accident condition of the lower head steel, samples were removed for examination. Fifteen prism-shaped steel samples were removed by metal disintegration machining techniques from the lower head of the TMI-2 reactor pressure vessel following the defueling operation. These "boat samples" were triangular, with the apex penetrating approximately 50 to $60 \mathrm{~mm}$ into the $141-\mathrm{mm}$-thick lower head. This technique of removal allowed the lower head material to be examined without breaching the vessel. The locations from which samples were removed are shown in Figure 4-1. Mechanical properties and metallographic examinations were performed on the samples. The objective of the metallurgical examinations was to determine, to the extent possible, the thermal history (especially the peak temperatures reached) of the lower pressure vessel head during the accident. The mechanical property tests provided the strength and deformation behavior of the lower head material at the accident temperatures. The information from these two investigations was used in the margin-to-failure assessment discussed in Section 7.

In order to assess the thermal history imposed on the lower head by the accident and to determine the mechanical properties, the boat samples were sectioned into metallurgical and mechanical property specimens as illustrated schematically in Figure 4-2. ANL was responsible for the sectioning of the samples, performing some of the material examinations and mechanical property tests, and distributing the metallurgical sections and test specimens to the participating laboratories for testing and examination. Those laboratories participating in metallurgical and/or mechanical properties measurements are listed in Table 4-1, which includes references for the reporting documents from the various participating laboratories. The INEL acted as the lead laboratory for the metallurgical examinations.

Cladding cracks were observed in three of the lower head samples, namely E-6, G-8, and F-10, during initial examinations conducted at ANL prior to sectioning. Cladding cracks were also detected at location G-6 in the TMI-2 lower head, but no sample was removed from this location. Metallographic and scanning electron microscopy examinations were conducted on samples E-6 and G-8 in some detail to characterize the nature and extent of the cracking. The results of these examinations are also summarized here. 


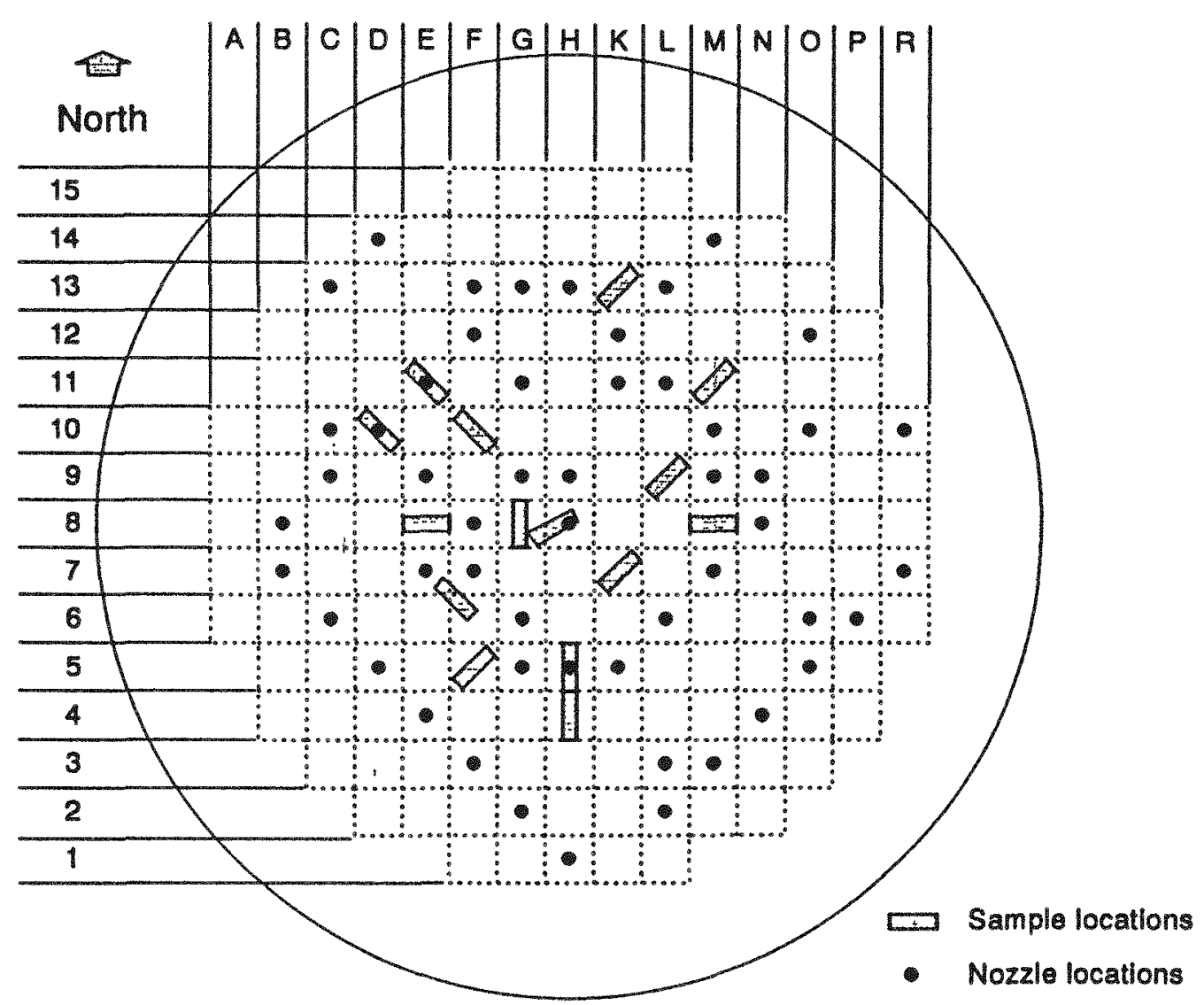

Figure 4-1. Location of lower head boat samples with respect to core locations.

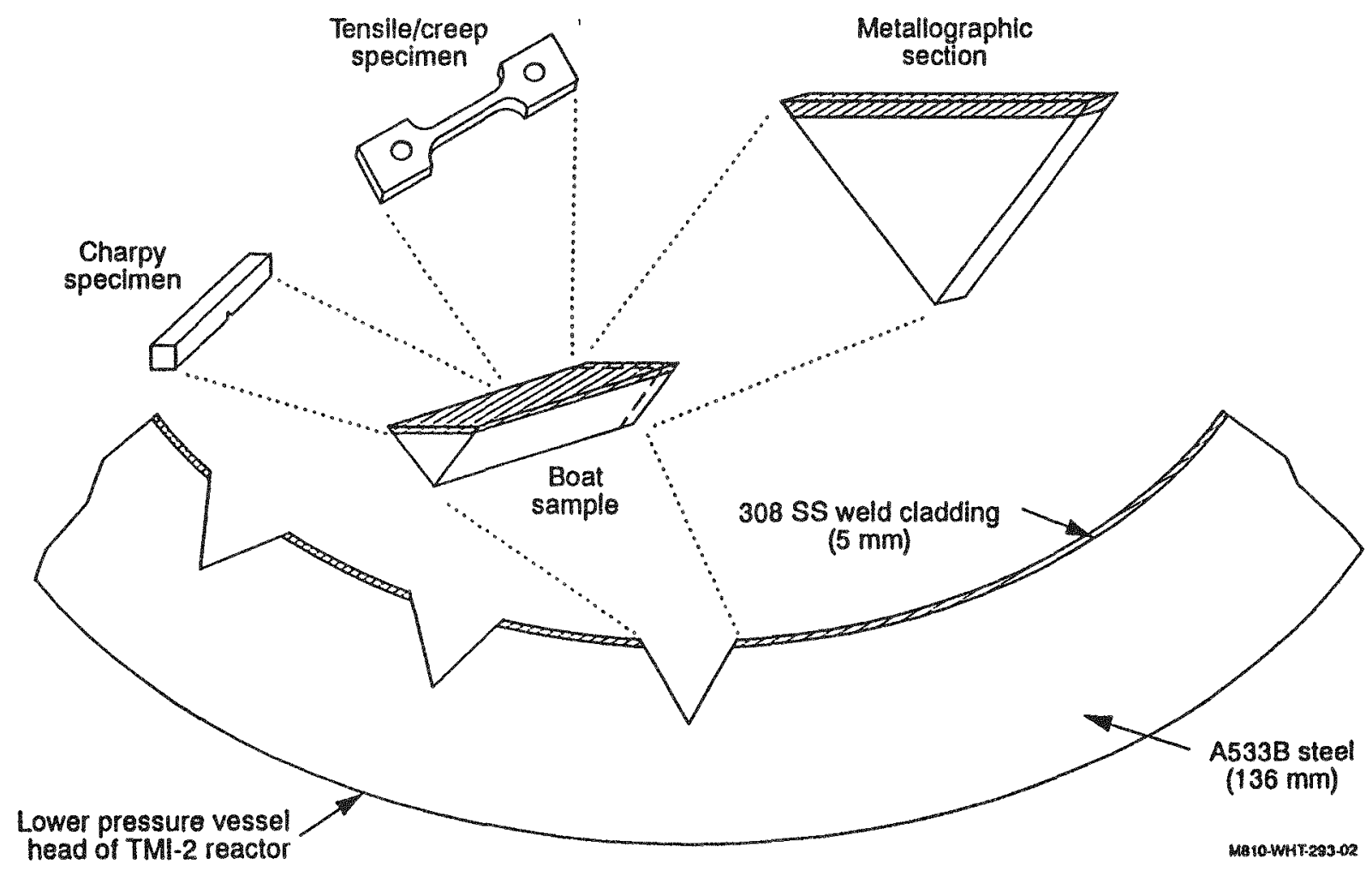

Figure 4-2. Schematic of the source of TMI-2 metallographic and mechanical property samples. 
Table 4-1. Laboratories participating in metallographic examination and mechanical properties testing of TMI-2 samples.

\begin{tabular}{ccccc}
\hline $\begin{array}{c}\text { U.S. or } \\
\text { OECD } \\
\text { laboratory }\end{array}$ & $\begin{array}{c}\text { Number of } \\
\text { metallographic/hardness } \\
\text { specimens }\end{array}$ & $\begin{array}{c}\text { Number of } \\
\text { tensile tests }\end{array}$ & $\begin{array}{c}\text { Number of } \\
\text { creep tests }\end{array}$ & $\begin{array}{c}\text { Number of } \\
\text { impact tests }\end{array}$ \\
\hline ANL & $1-3$ & 7 & 14 & 0 \\
Belgium $^{4}$ & 15 & 8 & 10 & 0 \\
Finland $^{5}$ & 3 & 0 & 0 & 0 \\
France $^{6}$ & 2 & 6 & 6 & 0 \\
FRG $^{7}$ & 3 & 0 & 0 & 0 \\
INEL $^{8}$ & 9 & 0 & 0 & 0 \\
Italy $^{9}$ & 15 & 0 & 0 & 27 \\
Spain $^{10-12}$ & 3 & 6 & 9 & 0 \\
UK $^{13}$ & 3 & 0 & 0 & 0 \\
\hline
\end{tabular}

\subsection{Metallurgical Examinations}

\subsubsection{Lower Head Materials}

The TMI-2 pressure-vessel lower head was fabricated from A533B low-alloy ferritic steel and clad with type $308 \mathrm{~L}$ austenitic stainless steel for corrosion protection. The fabrication history of the vessel is shown in Table 4-2. Since the amount of material extracted from the TMI-2 vessel was limited, archive A533B steel was also obtained from the abandoned Midland reactor, which had never been put into service. The Midland reactor pressure vessel was of the same vintage as the TMI- 2 vessel, was built by the same contractor, and had a very similar fabrication history, which is also shown in Table 4-2. The Midland material was plentiful and provided a valuable resource for studying properties and accident-simulated thermal response of lower head material.,2

The majority of the vessel was weld clad using submerged arc welding, in which consumable SS wire electrodes (either six wires or one wire) are fused to the base metal while submerged in a pool of molten flux. The welding head is stationary, and the work piece (vessel) is rotated and translated on a "positioner" to control the welding process. A circular region (approximately 200 to $300 \mathrm{~mm}$ in diameter) could not be clad with this process; it was clad using shielded metal arc welding process. Before the TMI-2 vessel was put into service, it was retrofitted with heavier instrument nozzles, which penetrated the lower head. The original Inconel 600 nozzles (made from 3/4-in. schedule 160 pipe) were not heavy enough and were subject to failure due to flowinduced vibration. The nozzles were cut off just above the internal surface of the lower head, and new, heavier ( 50 -mm diameter at the base) nozzles were welded to the old nozzle stubs and to the lower head. This weld repair was not necessary with the Midland vessel since the problem 
Table 4-2. Fabrication history of the TMI-2 and midland pressure vessel lower heads.

\begin{tabular}{lcc}
\hline & $\begin{array}{c}\text { TMI-2 reactor } \\
\text { lower head }\end{array}$ & $\begin{array}{c}\text { Midland reactor } \\
\text { lower head }\end{array}$ \\
\hline Initial plate thickness & $137 \mathrm{~mm}(5.375 \mathrm{in})$. & $162 \mathrm{~mm}(6.375 \mathrm{in})$. \\
Forming operation & hot pressed & 87 pressed \\
Austenitizing temperature & $871-899^{\circ} \mathrm{C}$ & $571-899^{\circ} \mathrm{C}$ \\
Austenitizing time & $5.5 \mathrm{hr}$ & $5.5 \mathrm{hr}$ \\
Cooling method & brine quench & brine quench \\
Tempering temperature & $649-677^{\circ} \mathrm{C}$ & $649-663^{\circ} \mathrm{C}$ \\
Tempering time & $5.5 \mathrm{hr}$ & $5.5 \mathrm{hr}$ \\
Cooling method & air cooled & brine quench \\
Finishing operation & none [minimum final & ID and OD machined to \\
& thickness $=127 \mathrm{~mm}(5 \mathrm{in})]$. & $127 \mathrm{~mm}(5 \mathrm{in}$.$) minimum$ \\
I.D. weld cladding & thickness \\
Cladding thickness & $4.8 \mathrm{~mm}(3 / 16 \mathrm{~L}$ in. & ER308L \\
Stress relief temperature & $607^{\circ} \mathrm{C}$ & $4.8 \mathrm{~mm}(3 / 16 \mathrm{in})$. \\
Stress relief time & $50 \mathrm{hr}$ & $607^{\circ} \mathrm{C}$ \\
\hline
\end{tabular}

was detected before the smaller nozzles were installed and the heavier nozzles were installed directly by cutting V-grooves into the lower head and welding the nozzles directly to the lower head.

The weld cladding described above and the fabrication history shown in Table 4-2 left their "thermal signature" on the lower head. This as-fabricated condition existed before the molten core debris relocated during the accident and left further thermal alterations. The typical asfabricated condition (microstructure and hardness) as found in the TMI-2 and Midland lower head material is illustrated in Figure 4-3. A heat-affected zone (HAZ) of 7 to $12 \mathrm{~mm}$ is observed in the A533B steel directly adjacent to the stainless steel weld clad. The first 2 to $3 \mathrm{~mm}$ of the HAZ is made up of enlarged, partially decarburized grains, and the remainder of this HAZ band is comprised of refined grains that reached temperatures above the ferrite-austenite transformation temperature of $727^{\circ} \mathrm{C}$ from the welding operation and were then quenched due to the massive heat sink provided by the remaining material thickness. This austenitizing and quenching can result in grain refinement and undoubtedly explains the hardening in the band, which could be a martensitic transformation, a Hall-Petch effect from grain refinement, or both. Beyond the $\mathrm{HAZ}$ band, tempered bainite is observed uniformly throughout the remaining thickness. Any further thermal exposure equal to or greater than $727^{\circ} \mathrm{C}$ altered this as-fabricated structure and created a new thermal signature, which was used to determine the thermal history caused by the accident.

\subsubsection{Metallographic Sample Examinations}

Participating laboratories used three different methods of examination to assess the thermal history of the samples: (a) hardness, (b) microstructure, and (3) thermally induced metallurgical modifications of the weld clad interface. The interfacial modifications were mainly a result of 


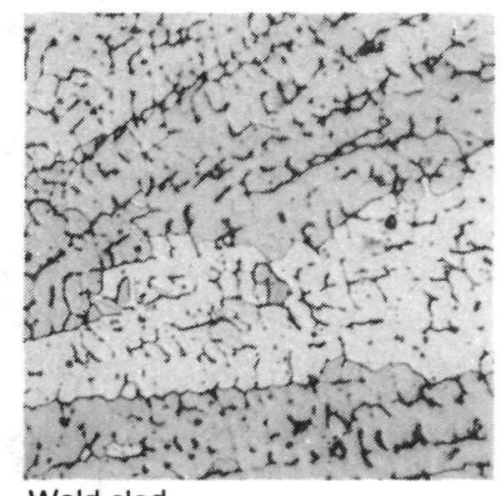

Weld clad

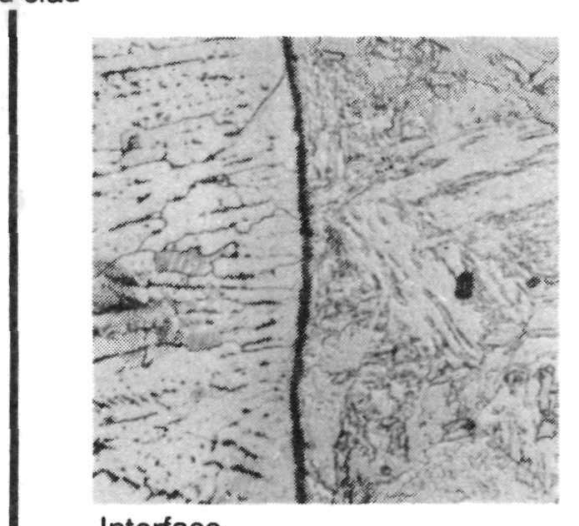

Interface

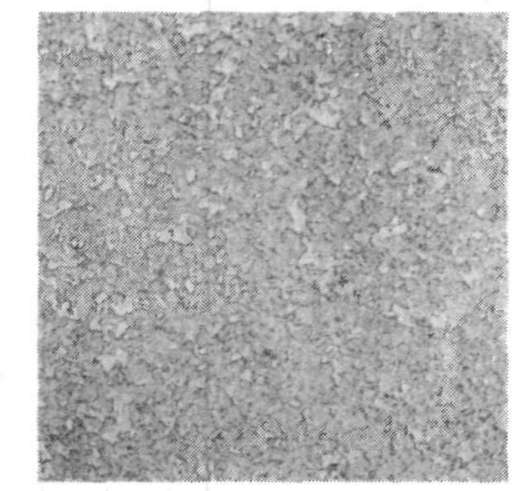

Haz band
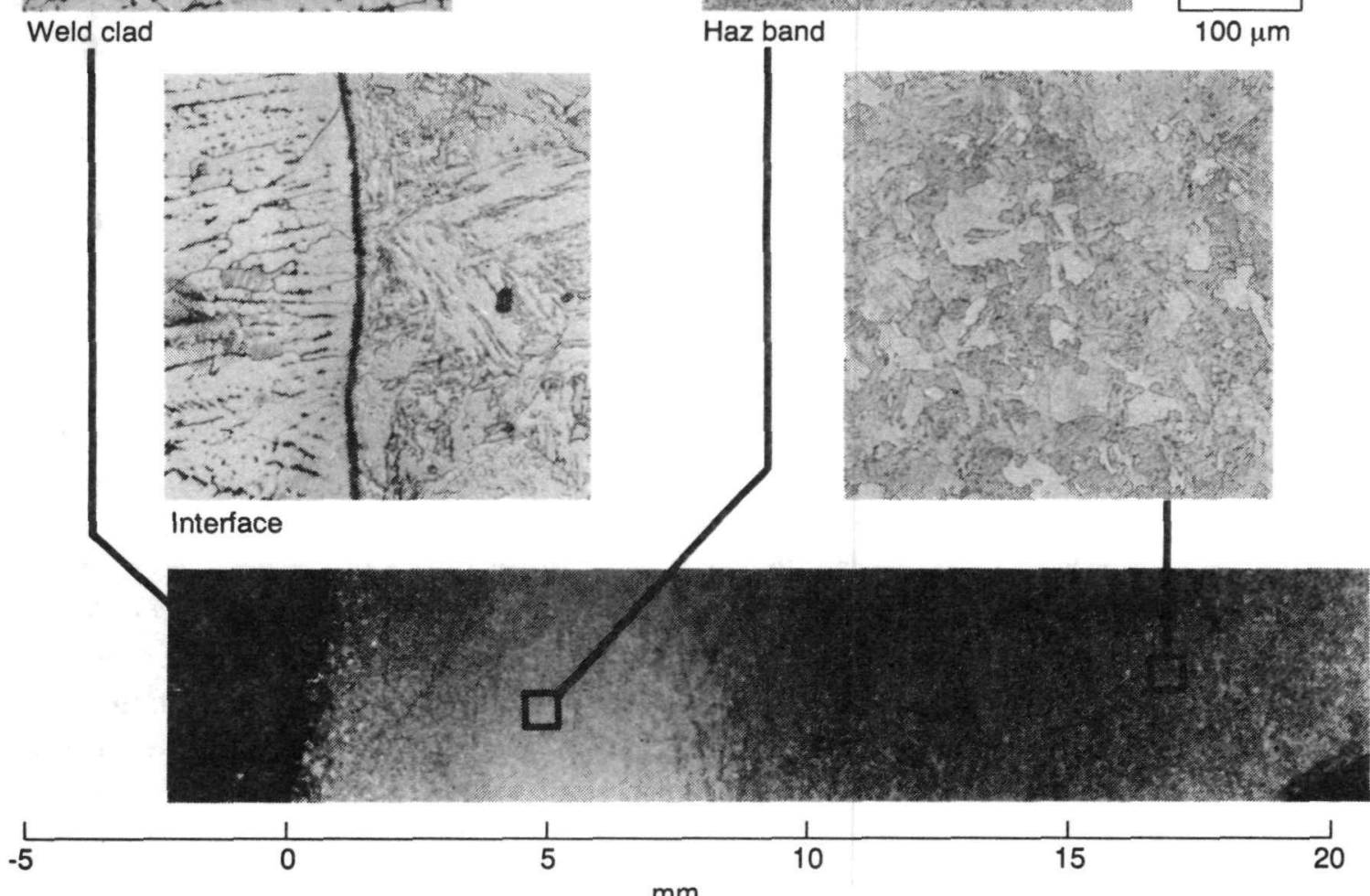

$\mathrm{mm}$

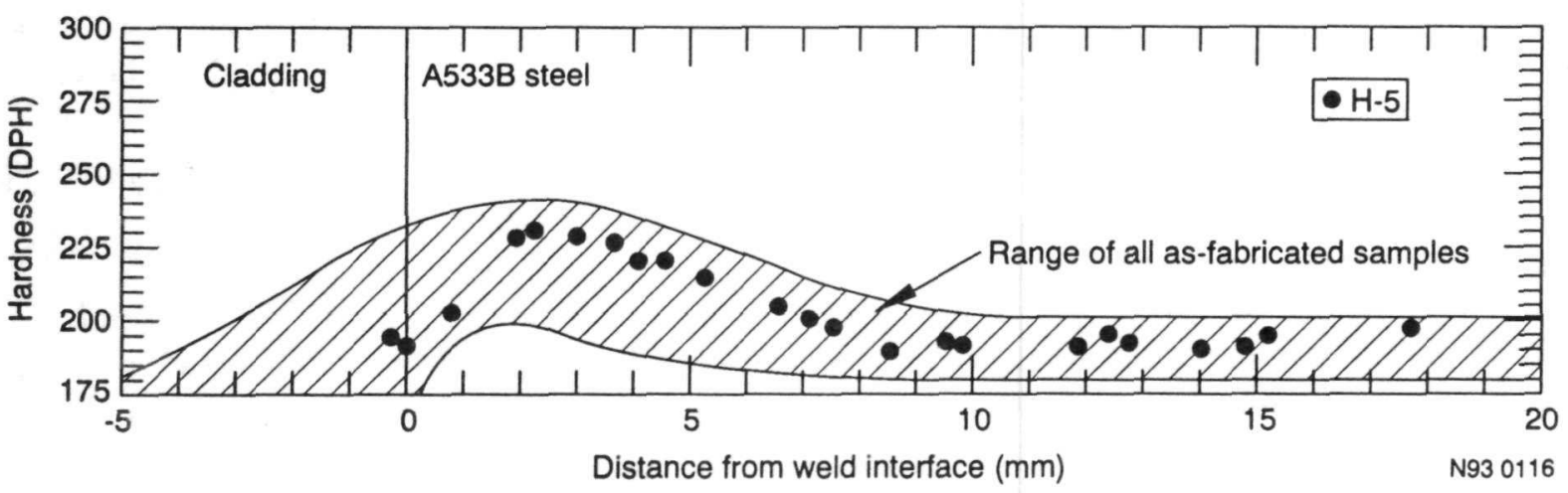

Figure 4-3. Typical as-fabricated microstructure and hardness of TMI-2 lower head material (from H-5 sample). 
carbon diffusion from the A533B steel (C 0.25\%) into the 308L stainless steel clad (C = $0.035 \%$ max.). Typical hardness profiles were taken of the samples from the weld cladding to the bottom tip of the triangular piece. The microstructure was examined using standard optical metallographic practices. Electron microscopy (both scanning and transmission) were used by some laboratories in their examinations.

Standards with known thermal histories were prepared from Midland archive material and later from actual as-fabricated TMI-2 material. These accident-simulated standards provided a means for comparing a similar material with a known thermal history to TMI-2 material with an unknown thermal history. Initially, standards were prepared to determine the effect of cooling rate through the austenite-ferrite transition temperature range, which affects the hardness. Then, several laboratories prepared standards from Midland archive material with maximum temperatures that ranged from 700 to $1,300^{\circ} \mathrm{C}$ and with dwell times at peak temperatures of one minute to two hours. The heatup rate was controlled at $40^{\circ} \mathrm{C} / \mathrm{min}$, and the cooling rate following the dwell period was 1 or $50^{\circ} \mathrm{C} / \mathrm{min}$. Finally, as unknown thermal histories were narrowed down, an additional set of standards was prepared from some actual TMI-2 lower head material determined to be in the as-fabricated condition. These small sections of TMI-2 material were heat-treated at $950,1,000,1,050$, and $1,100^{\circ} \mathrm{C}$ for dwell times of 10,30 , and 100 minutes and provided the final basis for comparison to determine the thermal history of the lower head due to the accident.

As the standards were prepared and examined, various metallurgical observations revealed a step-wise process that could be used in determining the thermal histories of the TMI-2 samples. A diagram (shown in Figure 4-4) was constructed, which illustrates the metallurgical changes with time and temperature of the Midland and TMI-2 lower head A533B steel with a 308L stainless weld clad. Since the vessel was stress relieved at $607^{\circ} \mathrm{C}$ after the weld cladding, no thermal effects from the accident could be detected at or below this temperature and, therefore, the diagram shows only metallurgical observations for temperatures above this point. The lowest temperature indicator, above the stress relief temperature, was the ferrite-austenite transformation, which starts at $727^{\circ} \mathrm{C}$ and is complete by $-830^{\circ} \mathrm{C}$. Variations in the typical as-fabricated hardness profile will be evident when this threshold is exceeded. The next indicator is the dissolution or dissipation of a dark feathery band at the interface; this occurs between 800 and $925^{\circ} \mathrm{C}$, depending on the time. The next indicator of increasing temperature is the appearance of small equiaxed grains, which formed in the A533B steel adjacent to the interface at temperatures between 850 and $900^{\circ} \mathrm{C}$ and disappeared between 1,025 and $1,100^{\circ} \mathrm{C}$ as they were consumed by grain growth in the low alloy steel. The dissolution of the dark feathery band and the formation of the equiaxed grains are believed to be associated with carbon diffusion into the stainless steel cladding. The dark feathery band appears to be some sort of carbide that disperses as the carbon diffuses into the stainless steel. The equiaxed grains, which are not typical for a low alloy steel, appear to be devoid of cementite, due to a loss of carbon into the stainless steel. Grain growth in the A533B steel becomes significant above approximately 950 to $1,075^{\circ} \mathrm{C}$, depending on the time involved. The highest temperature indicator shown on the diagram is the change in morphology of the 8ferrite islands in the stainless steel cladding. In the approximate range of 975 to $1,000^{\circ} \mathrm{C}$ at 100 minutes or 1,100 to $1,125^{\circ} \mathrm{C}$ at 10 minutes, the 8 -ferrite islands begin to lose their slender branch-like morphology and become spherical in shape. This spheroidizing of the 8 -ferrite islands is believed to be due to the dissolution of $\mathrm{M}_{23} \mathrm{C}_{6}$ carbides, which decorate the ferrite-austenite boundaries and stabilize their shape. When the carbides dissolve, the 8 -ferrite becomes more 


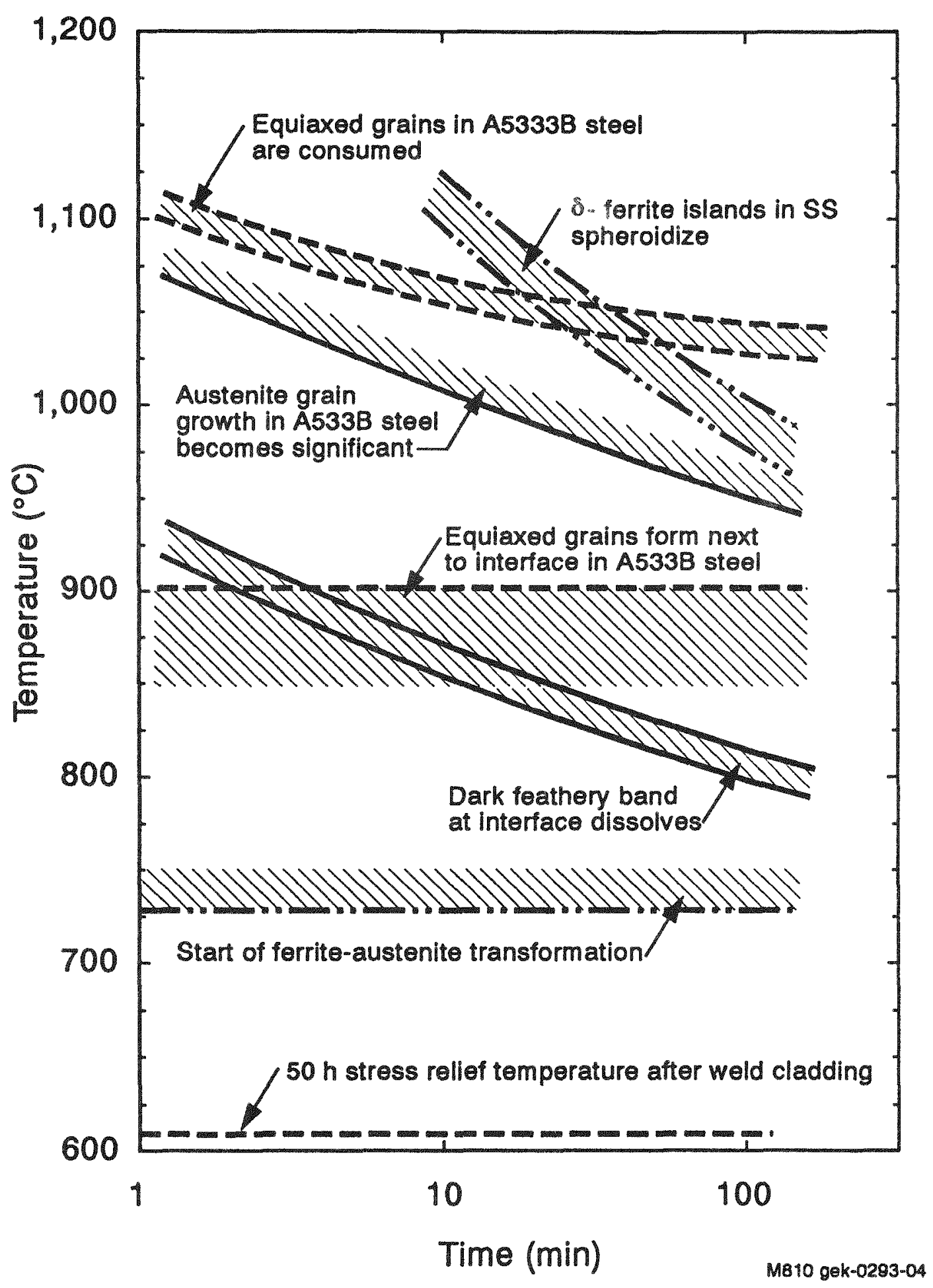

Figure 4-4. Diagram of time/temperature observations of A533B pressure vessel steel clad with type $308 \mathrm{~L}$ stainless steel. 
spherical to minimize surface energy. There was also evidence that some of the 8 -ferrite was consumed into the austenitic matrix after exposures above $1,000^{\circ} \mathrm{C}$ since there was a net loss of 8 ferrite after cooling. Researchers in the Federal Republic of Germany ${ }^{7}$ and Spain ${ }^{10}$ observed that 8 -ferrite in the cladding of non-affected samples was 4 to $5 \%$, but only $1.4 \%$ in E-8.

\subsubsection{Hardness Measuremente of the TMl-2 Samples}

The hardness profiles of most of the TMI-2 samples had the typical characteristic profile of as-fabricated material as shown in Figure 4-3, but the hardness profiles from Samples E-6, E-8, F-10, and G-8 were markedly different than all other samples, as shown in Figure 4-5. The characteristic hardness profile through the HAZ band had risen sharply in these four samples to much higher levels and was then sustained throughout the full sample depth. Heat-affected bands from the weld cladding were not evident in these four samples, but were completely eliminated by the thermal effects of the accident.

Two other samples (H-8 and F-5) also showed anomalies in the hardness profiles. Hardness measurements of H-8 in a longitudinal direction (parallel to the inside surface of the lower head) on several strips remaining after the tensile specimens were cut showed a hardness increase as the end closest to G-8 was approached. This observation indicates that the ferrite-austenite transformation temperature was reached on the end of H-8 nearest to G-8. The hardness profile of F-5, as measured by some of the participating laboratories, showed some deviation from the typical weld cladding $\mathrm{HAZ}$ effects, which indicates that temperatures in the vicinity of this sample slightly exceeded the $727^{\circ} \mathrm{C}$ threshold.

The final hardness of the TMI-2 samples is not only a strong indicator that the A533B steel transformation temperature of $727^{\circ} \mathrm{C}$ was exceeded during the accident, but also allows some bounds on the cooling rate back through the phase change. To achieve the same hardness values on standards as observed in Samples E-6, E-8, F-10, and G-8, the cooling rate had to be in the range of 10 to $100^{\circ} \mathrm{C} / \mathrm{min}$. Studies with the Midland material showed that if the cooling rate had been in the vicinity of $1^{\circ} \mathrm{C}$ /min or less, then the final hardness would have been approximately the same as that of the as-fabricated parent metal. Therefore, hardness measurements would not have been very helpful in determining the thermal history due to the accident-they would only reveal that the hardness peak from the $\mathrm{HAZ}$ band from the weld cladding was eliminated. However, the final hardness values for $\mathrm{E}-8, \mathrm{~F}-10, \mathrm{G}-8$, and $\mathrm{E}-6$ are consistent with cooling rates $210^{\circ} \mathrm{C} /$ min and any peak temperature above $800^{\circ} \mathrm{C}$. Therefore, hardness values of the TMI-2 samples are indicative of two things: (a) whether or not the material had exceeded the transformation temperature, and (b) if it had, some bounds on the cooling rate. However, hardness values are not very conclusive as to the peak temperatures that may have been reached even though some trends were observed by ANL and France. From just the hardness measurements, it was concluded that F-5 and one end of H-8 slightly exceeded $727^{\circ} \mathrm{C}$ and E-6, E-8, F-10, and G-8 exceeded $830^{\circ} \mathrm{C}$. Microstructure examinations were used to assess peak temperatures after an initial screening was performed with hardness measurements.

\subsubsection{Microstructure of TMI-2 Samples}

To further assess the thermal history of the four samples clearly showing thermal effects above the ferrite-austenite transformation temperature, microstructural indicators as illustrated in 
Figure 4-4 were employed. Examinations of the microstructure of E-6, E-8, F-10, and G-8 showed that the feathery carbide band had dissipated at the A533B steel/weld cladding interface in all four samples. Austenitic grain growth was evident in all four samples, with E-6 and E-8 showing the most pronounced effect. F-10 revealed that a small remnant of the cementite-devoid equiaxed small ferrite grains were still present, but none were evident in the other three. Spheroidization of the 8 -ferrite islands in the weld cladding was not readily detected in F-10, was partially observed in G-8, and was fairly complete in E-6 and E-8. By applying the above microstructural observations and meticulous comparisons with the standards of known thermal history, the lead laboratory for metallurgical examinations (INEL) determined peak temperatures and time at temperature of areas near the weld clad interface (within $2.5 \mathrm{~mm}$ ). They were estimated as follows:

- $\quad$ E-6 and E-8: $1,075-1,100^{\circ} \mathrm{C}$ for about 30 minutes

- F-10 and G-8: $1,040-1,060^{\circ} \mathrm{C}$ for about 30 minutes.

Examinations at ANL and some of the OECD partner laboratories for different sections of these same boat samples are consistent with the INEL conclusions. A summary of the conclusions on temperatures from all the participating laboratories is shown in Table 4-3. United Kingdom researchers showed evidence that $\mathrm{M}-11$ also slightly exceeded the $727^{\circ} \mathrm{C}$ transformation temperature, but that determination was not confirmed by the other five laboratories examining different sections of the M-11 boat sample. Based on the above observations and conclusions, a thermal contour map of peak temperatures was constructed as shown in Figure 4-6. The hardness profile and microstructure of two of the thermally altered samples, F-10 and E-8, are shown in Figures 4-7 and 4-8.

The temperature gradient through the thickness of the lower vessel head wall was estimated by two methods. First, since the high level of hardness of the four affected samples persisted to the full depth of the boat samples $(50 \mathrm{~mm}$ from the inside surface and $45 \mathrm{~mm}$ from the weld clad interface; see Figure 4-5), it could be concluded that the temperature at that depth was greater than the $727^{\circ} \mathrm{C}$ transformation temperature. Secondly, based on the assumption from the microstructure comparisons that the thermal excursion on the lower head due to the accident was on the order of $\mathbf{3 0}$ minutes, prior austenite grain size at the bottom-most tip of the heat-affected samples was compared with the prepared standards given the 30 -minute heat treatments. The results of this comparison indicated that the temperature $50 \mathrm{~mm}$ from the inside surface $(45 \mathrm{~mm}$ from the stainless steel/low alloy steel interface) was approximately $50-150^{\circ} \mathrm{C}$ lower than the peak temperatures determined previously for the region near the interface. There is a fair amount of uncertainty in the gradient estimate because only average prior austenite grain size was used for the determination, and that measurement cannot be made with precision due to local size segregations. Also, the assumption that 30 minutes was the actual time at peak temperatures $50 \mathrm{~mm}$ into the thickness may be in error. Another uncertainty regarding the use of grain size for time/temperature determinations was reported by Italy ${ }^{14}$ wherein they showed that final grain size could be affected by differential thermal strain. Although this effect is not great, it adds somewhat to the uncertainty of using grain size exclusively as a determining factor to estimate the thermal gradient through the thickness.

In spite of the uncertainties, several other labs also estimated thermal gradients for E-6 and E-8. ANL estimates the temperature of E-6 at $50 \mathrm{~mm}$ below the interface to be $900-1000^{\circ} \mathrm{C} .^{3}$ 


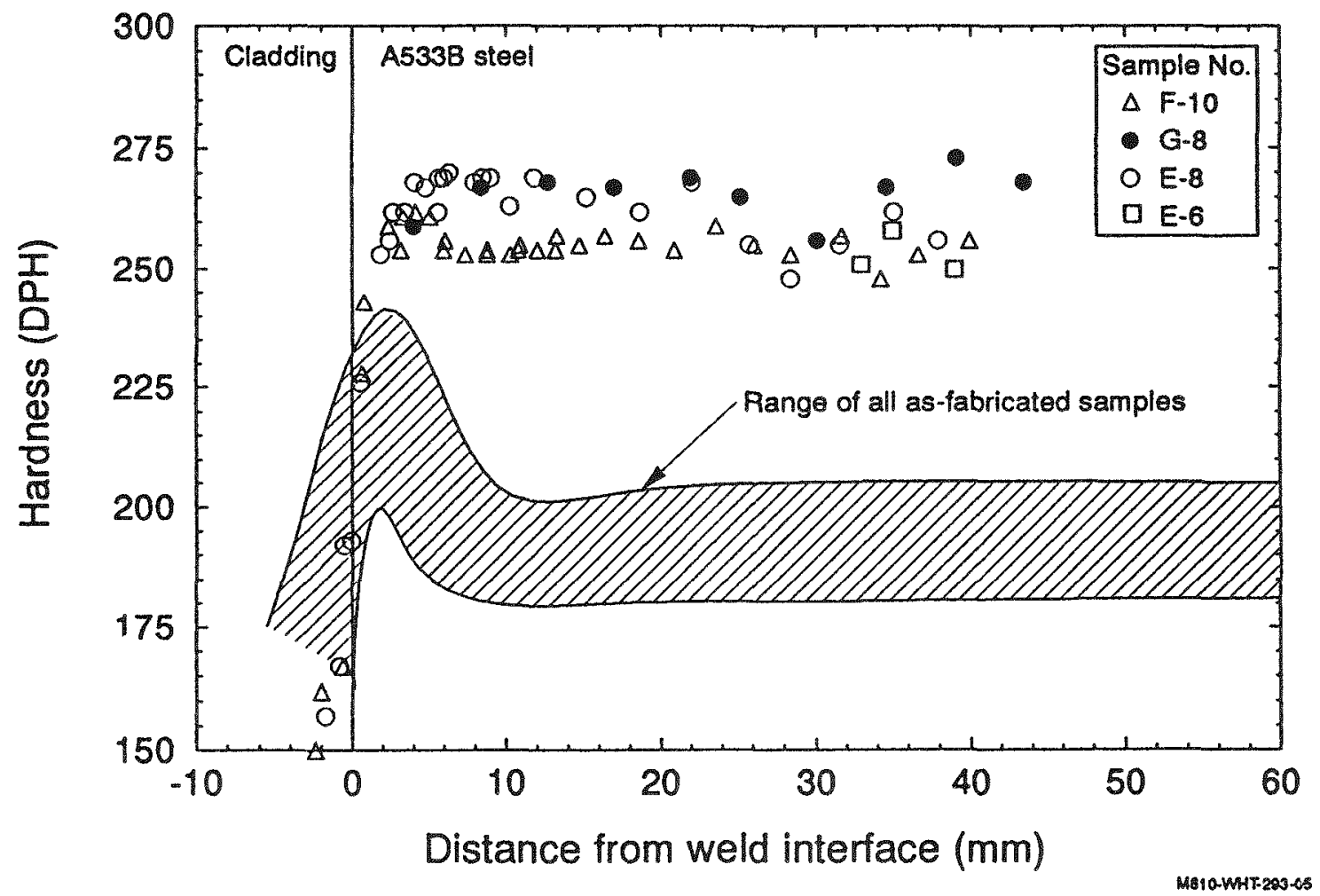

Figure 4-5. Hardness profiles of samples F-10, G-8, E-8, and E-6 compared to the as-fabricated samples.

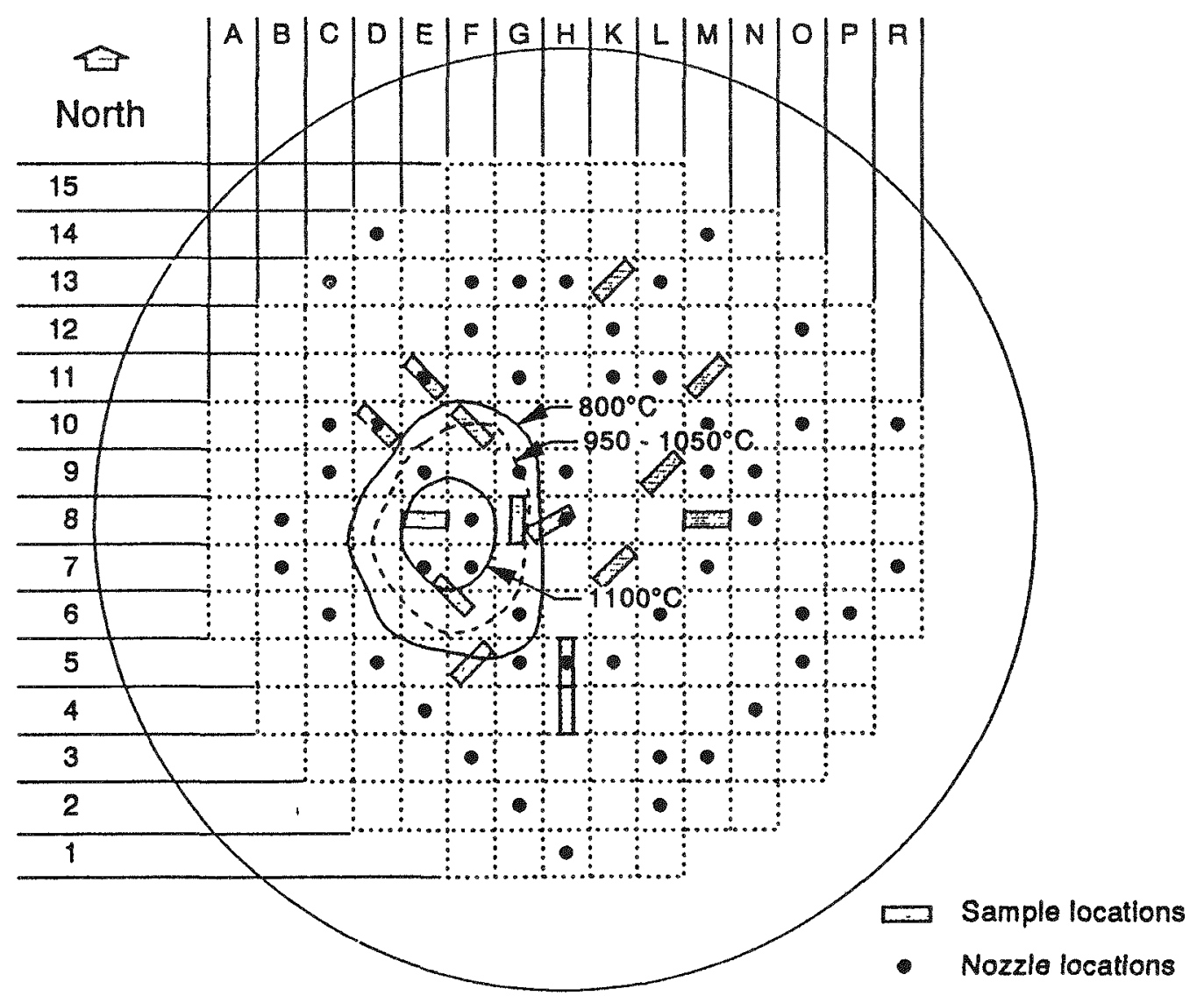

Figure 4-6. Thermal contour map of peak temperatures constructed as best estimate based on results of the metallographic examinations of the boat samples. 
Table 4-3. Results of metallographic examinations of TMI-2 lower head samples.

\begin{tabular}{|c|c|c|}
\hline Sample No. & $\begin{array}{l}\text { Country or } \\
\text { laboratory }\end{array}$ & $\begin{array}{l}\text { Maximum temperature during accident } \\
\qquad\left({ }^{\circ} \mathrm{C}\right)\end{array}$ \\
\hline \multirow[t]{3}{*}{ D-10 } & Italy & $<727$ \\
\hline & ANL & $<727$ \\
\hline & INEL & $<727$ \\
\hline \multirow[t]{2}{*}{ E-6 } & ANL & $1000-1100$ \\
\hline & INEL & $1075-1100$ \\
\hline \multirow[t]{7}{*}{ E-8 } & Belgium & $>727$ \\
\hline & Finland & 1100 in cladding; 950 at $34 \mathrm{~mm}$ below clad interface \\
\hline & France & $1000-1100$ \\
\hline & FRG & $>850($ probably $>1000)$ \\
\hline & Spain & $>1000$ \\
\hline & ANL & $1000-1100$ \\
\hline & INEL & $1075-1100$ \\
\hline \multirow[t]{2}{*}{$\mathrm{E}_{-11}$} & ANL & $<727$ \\
\hline & INEL & $<727$ \\
\hline \multirow[t]{6}{*}{$\mathrm{F}-5$} & Belgium & $>727$ to a depth of $20-30 \mathrm{~mm}$ below clad \\
\hline & FRG & $730-850$ to a depth of $-15 \mathrm{~mm}$ below clad \\
\hline & UK & $>727$ to a depth of $15 \mathrm{~mm}$ below clad; \\
\hline & $A T T$ & -727 to a depth of $\sim 40 \mathrm{~mm}$ \\
\hline & ANL & $<727$ \\
\hline & INEL & $<727$ \\
\hline \multirow[t]{3}{*}{$\mathbf{F}-10$} & UK & $>727$ \\
\hline & ANL & $900-1000$ \\
\hline & INEL & $1040-1060$ \\
\hline \multirow[t]{2}{*}{ G.8 } & ANL & $1000-1100$ \\
\hline & INEL & $1040-1060$ \\
\hline \multirow[t]{5}{*}{$\mathrm{H}-4$} & FRG & $<727$ \\
\hline & Italy & $<727$ \\
\hline & UK & $<727$ (possibly near 727 ) \\
\hline & ANL & $<727$ \\
\hline & INEL & $<727$ \\
\hline \multirow[t]{4}{*}{$\mathrm{H}-5$} & FRG & $<727$ \\
\hline & UK & $<727$ (possibly near 727 ) \\
\hline & ANL & $<727$ \\
\hline & INEL & $<727$ \\
\hline \multirow[t]{2}{*}{$\mathrm{H}-8$} & ANL & $<727$ \\
\hline & INEL & $<727$ on one end; $>727$ on the other end \\
\hline
\end{tabular}


Table 4-3. (continued).

\begin{tabular}{lcl}
\hline Sample No. & $\begin{array}{c}\text { Country or } \\
\text { laboratory }\end{array}$ & \multicolumn{2}{c}{$\begin{array}{c}\text { Maximum temperature during accident } \\
\left({ }^{\circ} \mathrm{C}\right)\end{array}$} \\
\hline K-7 & FRG & $<727$ \\
& Spain & $<727$ \\
UK & $<727$ \\
& ANL & $<727$ \\
INEL & $<727$ \\
K-13 & Belgium & $<727$ \\
& FRG & $<727$ \\
& UK & $<727$ \\
& ANL & $<727$ \\
INEL & $<727$ \\
& France & $<727$ \\
& FRG & $<727$ \\
& UK & $<727$ (possibly near 727) \\
& ANL & $<727$ \\
& INEL & $<727$ \\
M-8 & FRG & $<727$ \\
& UK & $<727$ (possibly near 727) \\
& ANL & $<727$ \\
& INEL & $<727$ \\
& France & $<727$ \\
M-11 & FRG & $<727$ \\
& Spain & $<727$ \\
& UK & 2727 to a depth of a few mm below clad; \\
& & $<727$ in remainder \\
& ANL & $<727$ \\
& INEL & $<727$ \\
\hline
\end{tabular}



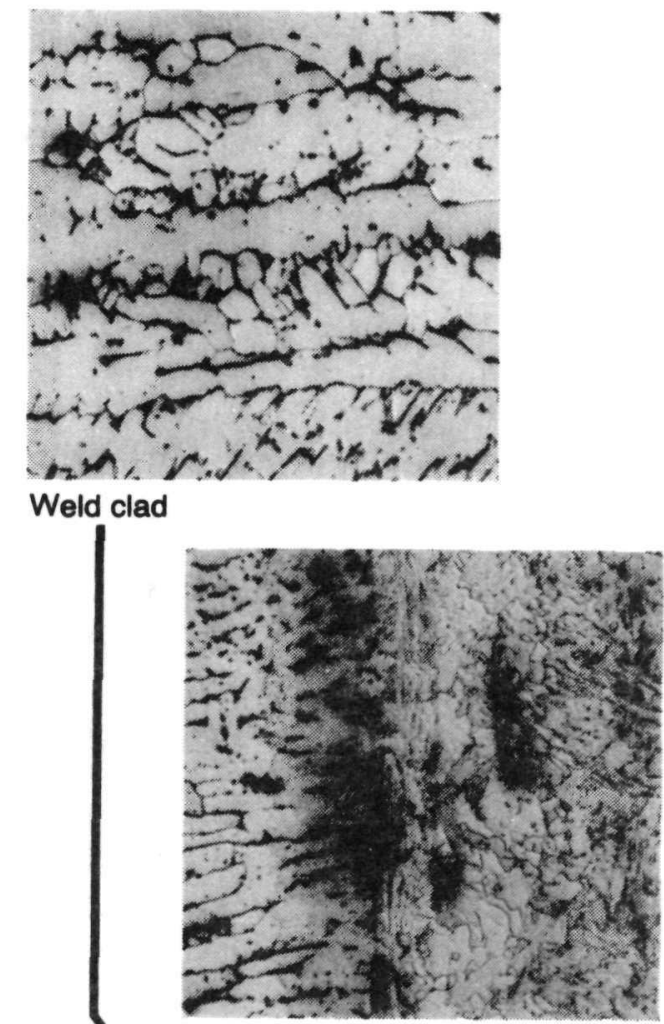
Interface

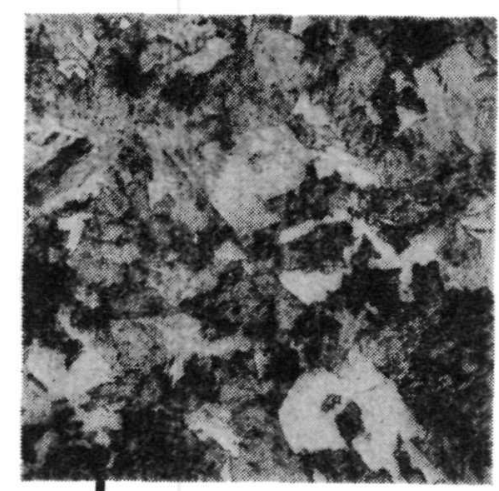

$100 \mu \mathrm{m}$
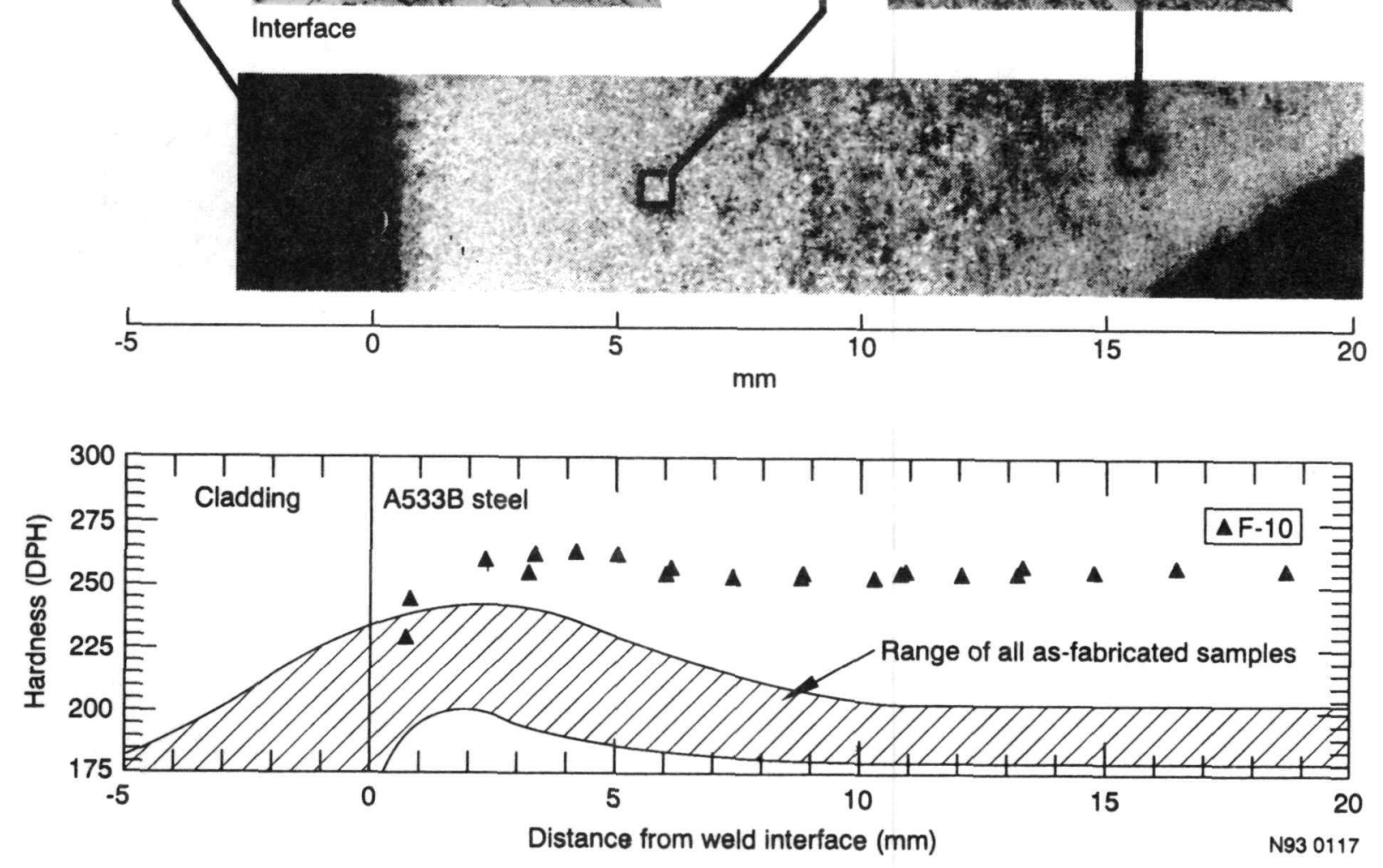

Figure 4-7. Microstructure and hardness profile of sample F-10. 


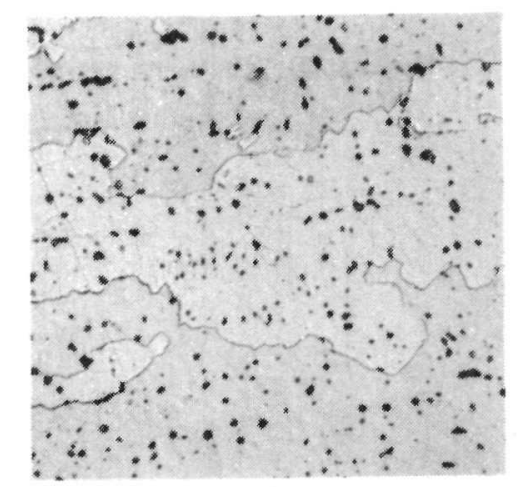

Weld clad

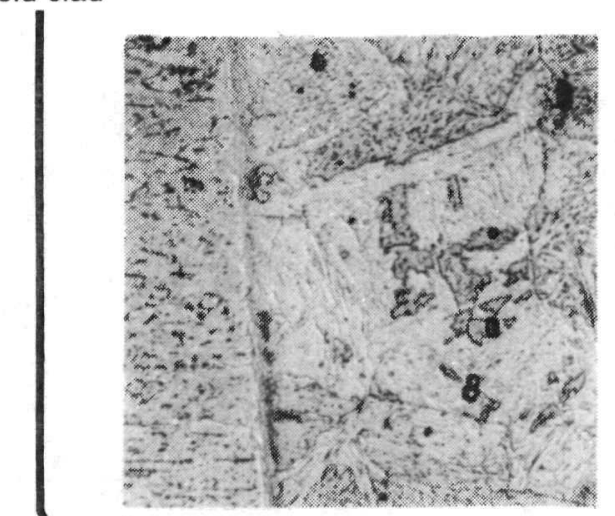
Interface
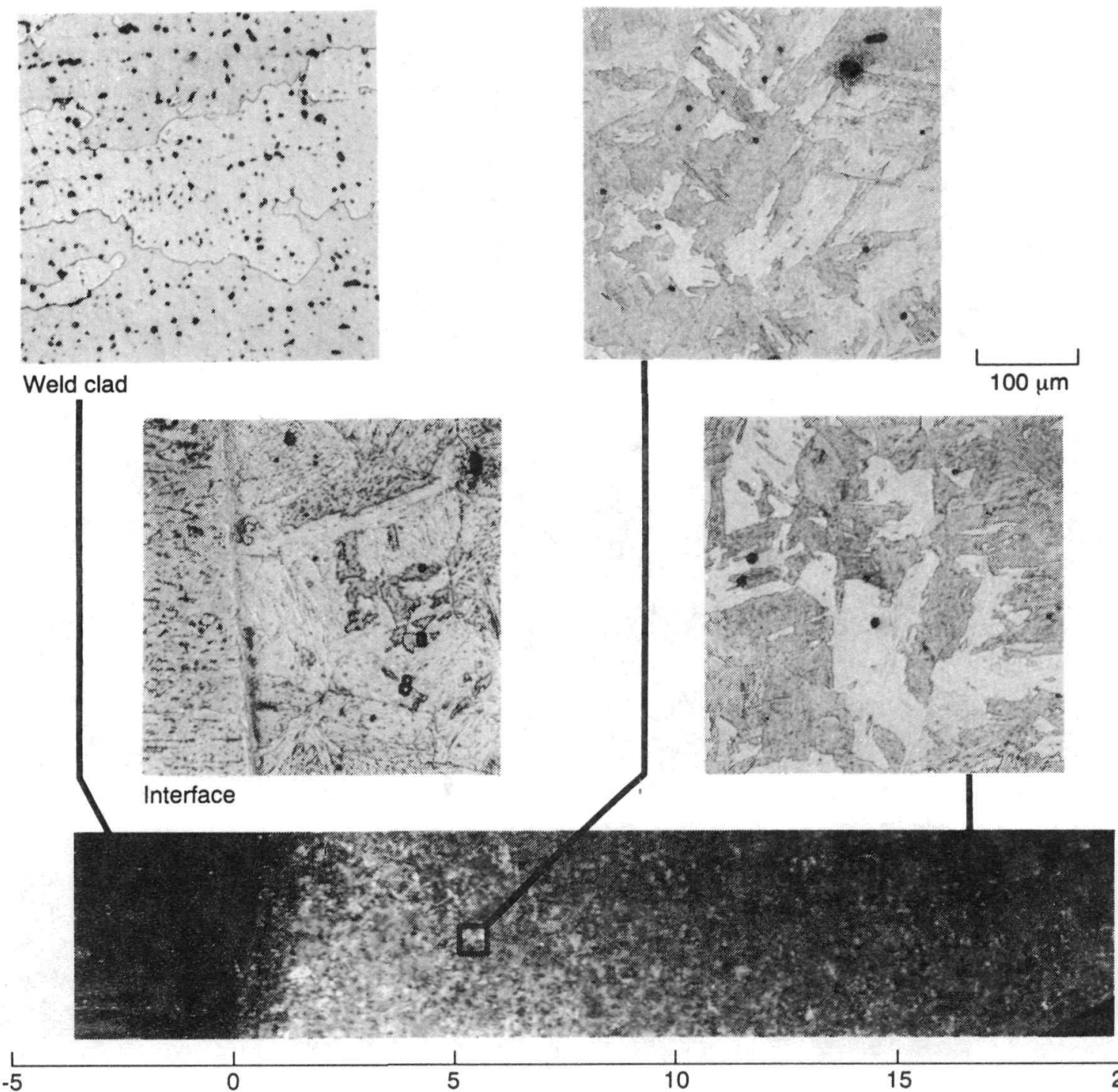

$\mathrm{mm}$

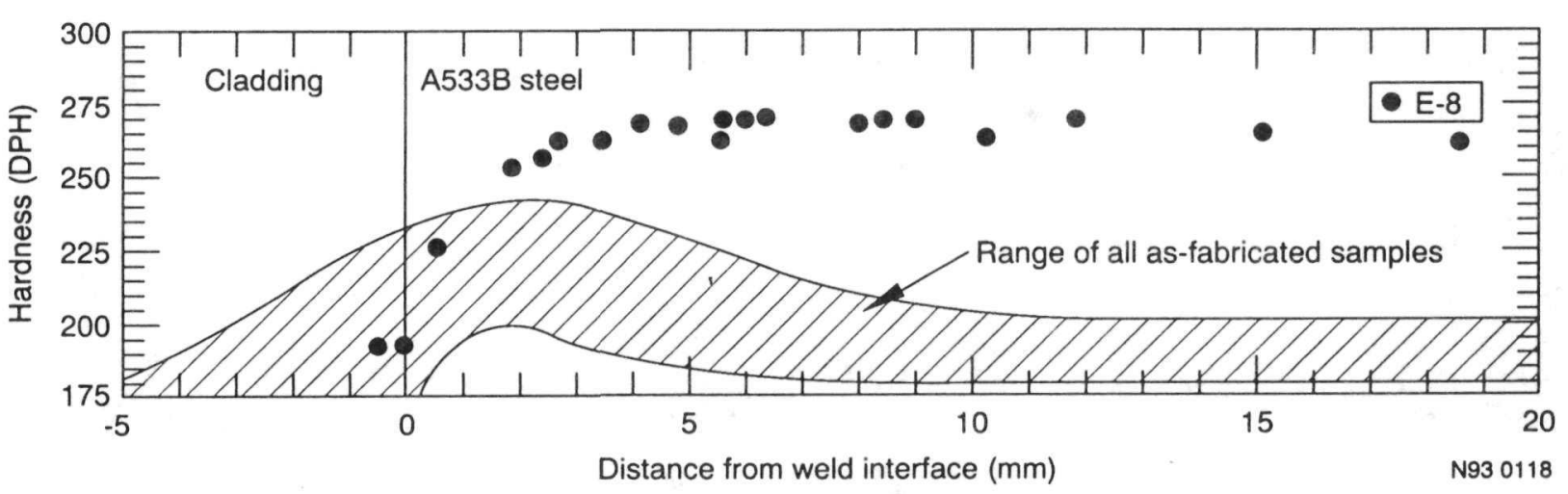

Figure 4-8. Microstructure and hardness profile of sample E-8. 
Finland researchers also made an estimate of the thermal gradient from a section of $\mathrm{E}-8$, wherein they estimated a temperature of $1,050^{\circ} \mathrm{C}$ for about 20 minutes in the base metal $2 \mathrm{~mm}$ from the clad interface, slightly less than $1,000^{\circ} \mathrm{C}$ at $21 \mathrm{~mm}$, and $950^{\circ} \mathrm{C}$ for 30 minutes at $34 \mathrm{~mm}$ from the interface. $^{5}$

The Japan Atomic Energy Research Institute (JAERI) examined microstructural changes in 308 stainless steel overlay of Midland archive material heat treated up to $1,420^{\circ} \mathrm{C}$, and estimated the peak temperatures by comparing their data with TMI-2 microstructures reported by other laboratories. By these comparisons, JAERI estimated that the maximum temperatures did not exceed $1,100^{\circ} \mathrm{C}$ at $\mathrm{E}-6,1,050^{\circ} \mathrm{C}$ at $\mathrm{E}-8$, and $1,000^{\circ} \mathrm{C}$ at $\mathrm{F}-10$ locations, respectively. Table $4-4$ lists the estimated temperatures versus depth for material in the vicinity of E-6 and E-8, and Figure 4-9 illustrates these data graphically, ignoring the fact that estimates were based on different times (from 15 to 30 minutes). Assuming a linear gradient (which may not be true for a transient situation), the gradient appeared to be between 2 and $4^{\circ} \mathrm{C} / \mathrm{mm}$ for the ANL, INEL, and Finland data. Observations by ANL and MPR Associates, Inc. indicate that the weld clad did not melt during the accident. ANL observed microstructure in the clad that showed interpass weld structure was still present in sample E-6. ${ }^{3}$ MPR Associates, Inc. reported, "The general surface of the vessel lower head looked to be in extremely good condition. Lines from the original clad weld application were visible." 15

\subsection{Mechanical Properties}

Mechanical property tests were conducted from TMI-2 material to determine the tensile, creep-rupture, and impact properties of the lower pressure vessel head steel. Tensile test were conducted at room temperature, $600,700,800,900,1,000,1,100$, and $1,200^{\circ} \mathrm{C}$. Creep-rupture tests were performed at $600,700,800,900,1,000,1,100$, and $1,200^{\circ} \mathrm{C}$, and Charpy V-Notch tests from -20 to $300^{\circ} \mathrm{C}$. Further details of the test specimens and mechanical property tests are listed for each individual test in an ANL report. ${ }^{3}$ Appendix B of that same ANL report also shows the strain-time behavior for most of the creep tests.

\subsubsection{Tensile Tests}

Yield and ultimate strength of the TMI-2 material as a function of test temperature is shown in Figure 4-10. Japanese National Research Institute for Metals (NRIM) data ${ }^{16}$ are also shown in the figure for comparison and to fill in the temperature region between 24 and $600^{\circ} \mathrm{C}$ where TMI-2 material was not tested. The TMI-2 data from samples not thermally altered by the accident merge well with the NRIM data for five heats of A533B steel. However, TMI-2 material from E-6 and E-8 showed significant strength increases when tested at room temperature and showed moderate increases when tested at $600^{\circ} \mathrm{C}$. This increase in strength is consistent with the increase in hardness that was observed in these same two samples.

\subsubsection{Creep-Rupture Tests}

The stress-rupture data of the creep tests were fitted to two different time-temperature correlations: the Larson-Miller parameter ${ }^{17}$ and the Manson-Haferd parameter. ${ }^{18}$ The stressrupture data of the TMI-2 VIP creep tests were supplemented with lower temperature data from 
Table 4-4. Lower head temperatures in the vicinity of samples E-6 and E-8 showing thermal gradients through the thickness.

\section{Temperature}

$\left({ }^{\circ} \mathrm{C}\right)$

\begin{tabular}{ccccc}
$\begin{array}{c}\text { Distance from clad interface } \\
(\mathrm{mm})\end{array}$ & JAERI & INEL & ANL & $\begin{array}{c}\text { Finland } \\
(\text { VTT })\end{array}$ \\
\hline-5 & - & - & - & 1,100 \\
0 & $1,050-1,100$ & $1,075-1,100$ & $1,000-1,100$ & - \\
2 & - & - & - & 1,050 \\
21 & - & - & - & 1,000 \\
30 & - & - & - & - \\
34 & - & $937-1,037$ & - & 950 \\
45 & - & - & $900-1,000$ & - \\
50 & - &
\end{tabular}




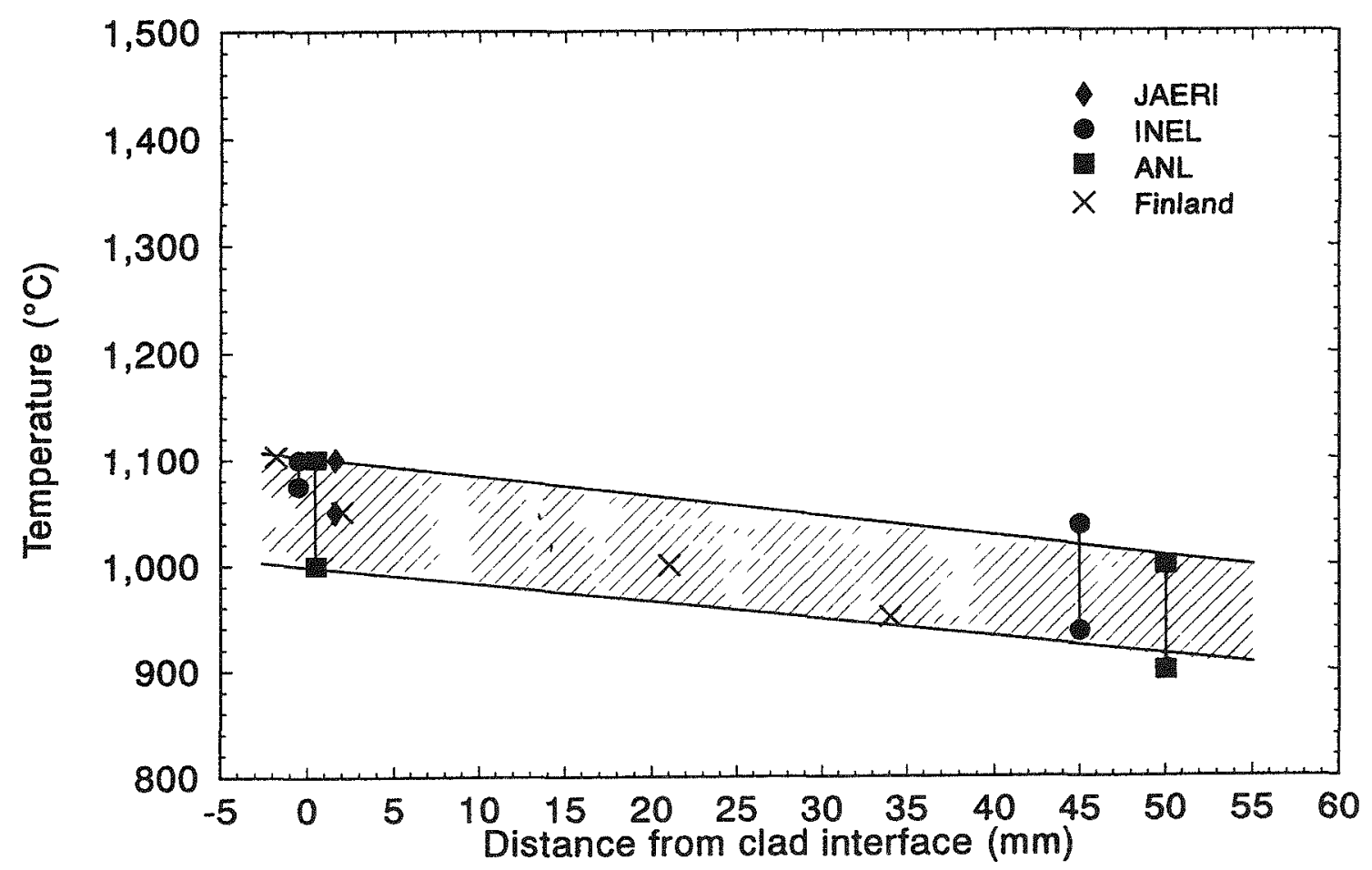

Z021 gek-1093-02

Figure 4-9. Lower head temperatures in the vicinity of the E-6 and E-8 samples showing estimated thermal gradients through the thickness.

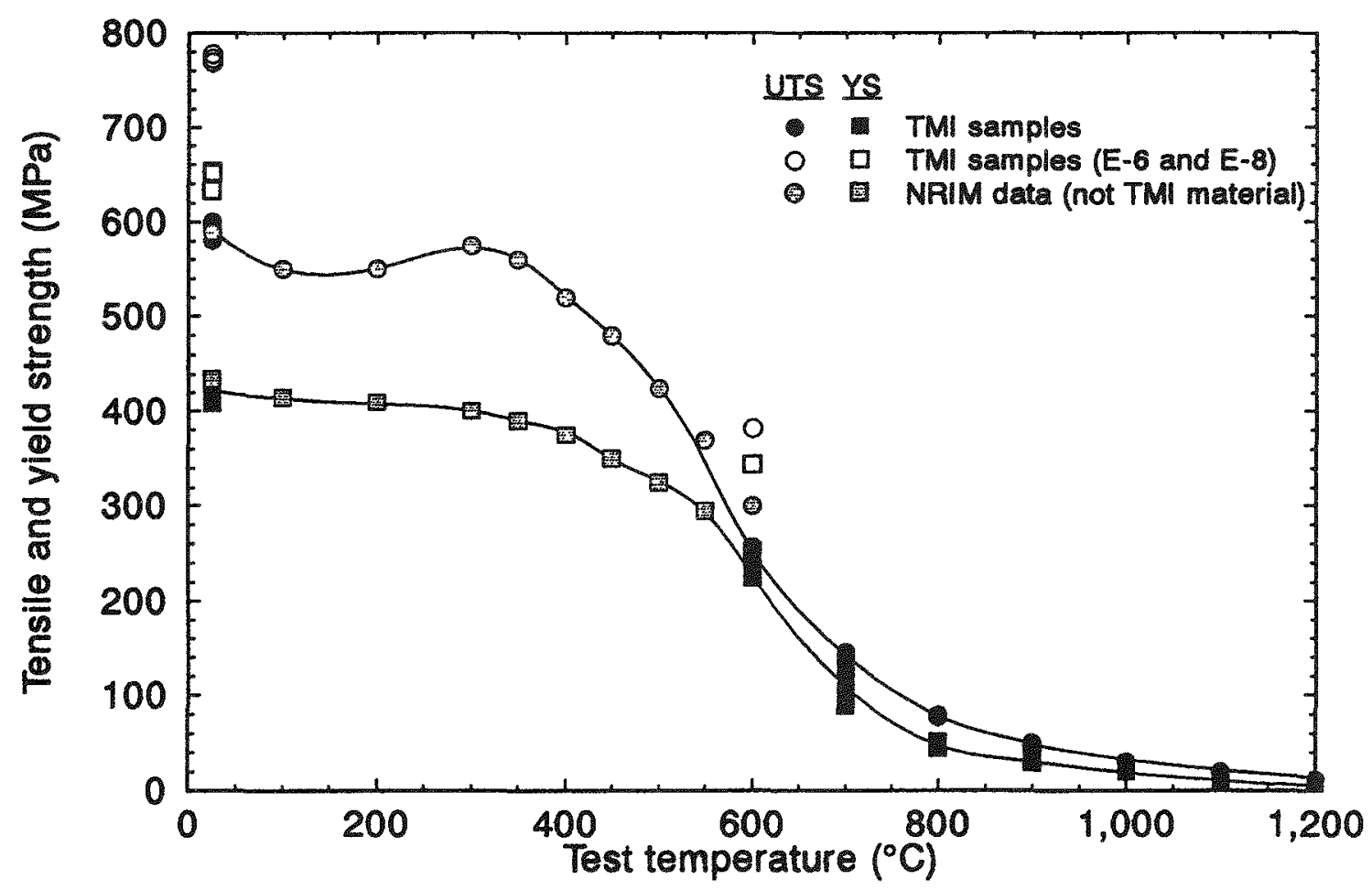

Mato 201-0293-10

Figure 4-10. Tensile and yield strengths of TMI-2 lower head compared with Japanese National Research Institute for metals data for other heats of AsanB steel. 
other published sources ${ }^{16,19}$ and fit to the Larson-Miller parameter. Figure 4-11 shows the stress/time-to-rupture test data compared to the Larson-Miller parameter, which was used in the margin-to-failure analysis. Only the data shown in Figure 4-11 were used in the curve fitting analysis. There were several other creep-rupture tests conducted as part of this program but were omitted in the curve fitting for the following reasons. Specimens, which were cut from boat samples that had exceeded the $727^{\circ} \mathrm{C}$ transformation temperature during the accident, and then tested at temperatures below the transformation temperature $\left(600-700^{\circ} \mathrm{C}\right)$, exhibited markedly different creep strain-time behavior as well as atypical yield and ultimate strength. These tests were omitted from the data base used for the curve fitting, as were the three $1,100^{\circ} \mathrm{C}$ creeprupture tests due to their inconsistent behavior compared to themselves and adjacent temperature tests at 1,000 and $1,200^{\circ} \mathrm{C}$. The best-fit equations for the Larson-Miller parameter are listed below. Time to rupture was found from the known stress and temperature.

For $450 \leq \mathrm{T}<577^{\circ} \mathrm{C}$ :

$L M P=55.847-11.492 \log (\sigma)$

$t_{p}=10^{[L M P(1000) / T-25]}$

For $577 \leq \mathrm{T}<1,200^{\circ} \mathrm{C}$ :

$L M P=30.014-12.127 \log (\sigma)+5.1831[\log (\sigma)]^{2}-1.83939[\log (\sigma)]^{3}$

$t_{p}=10^{[L M P(1000) / T-11]}$

where

$L M P=$ Larson-Miller parameter

$\sigma \quad=$ effective stress (ksi)

$t_{r}=$ time to rupture $(\mathrm{hr})$

$T=$ temperature $(\mathbb{R})$ (English units were used to be consistent with historical data).

\subsubsection{Impact Tests}

The Charpy V-notch impact data were obtained by Italy on specimens from four boat samples: D-10, H-4, E-11, and F-10. Of these four, only F-10 had been thermally altered by the accident. The adsorbed impact energy to fracture is plotted as a function of test temperature as shown in Figure 4-12. Test specimens for which the maximum temperature did not exceed $727^{\circ} \mathrm{C}$ all show similar behavior, but the data from F-10 exhibited a marked change. The F-10 material shows a significantly higher ductile-to-brittle transition temperature (from 20 to approximately $70^{\circ} \mathrm{C}$ ) as well as a lower upper-shelf energy value (dropped from 170 to $120 \mathrm{~J}$ ). These differences reflect the reduced ductility and impact resistance of this material produced by the high temperatures and relatively rapid cooling associated with the accident. 


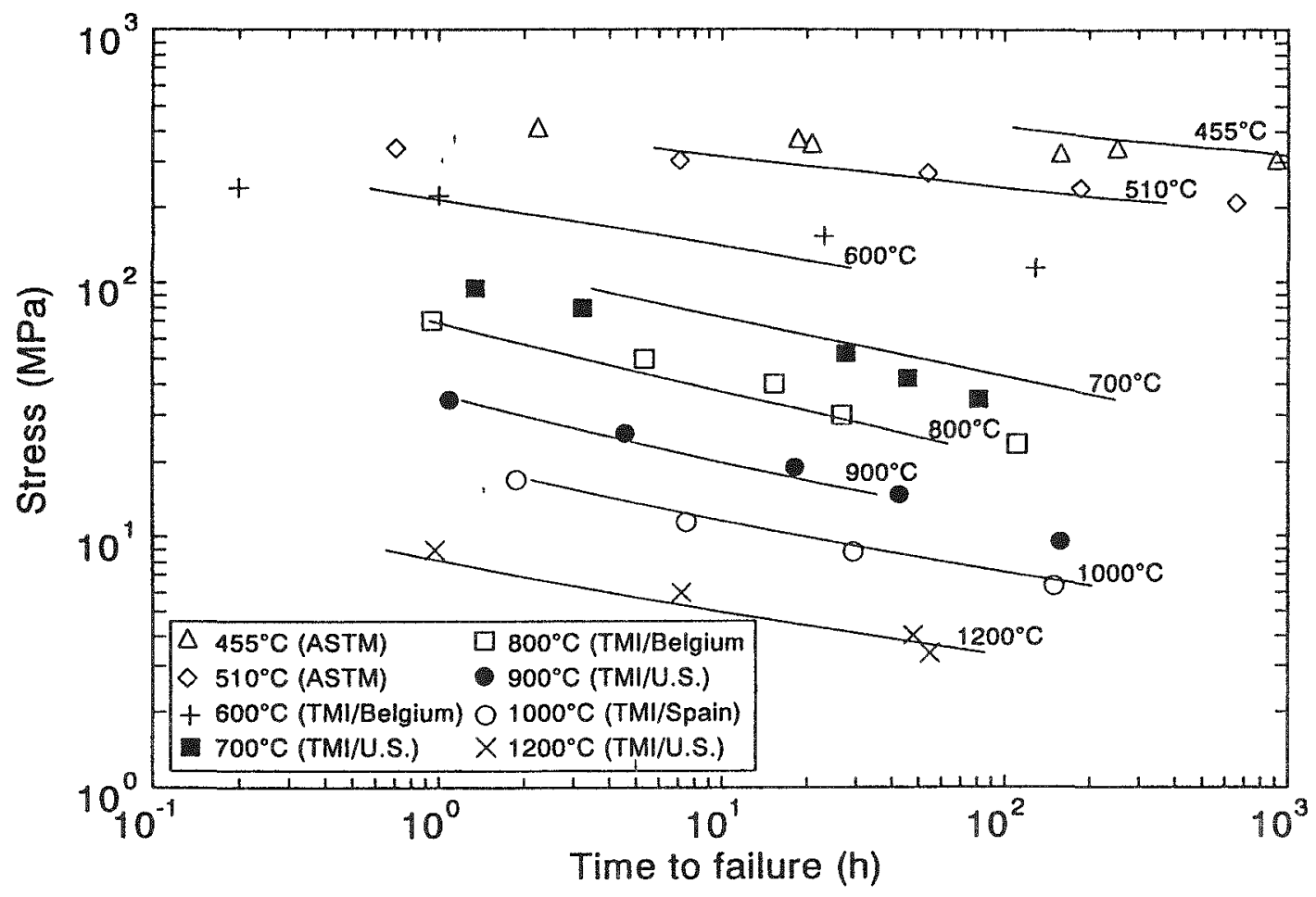

M958 jow-0893-10

Figure 4-11. Stress versus time to rupture data from creep tests conducted on TMI-2 lower head material compared with Larson-Miller time-temperature correlation best-fit curves.

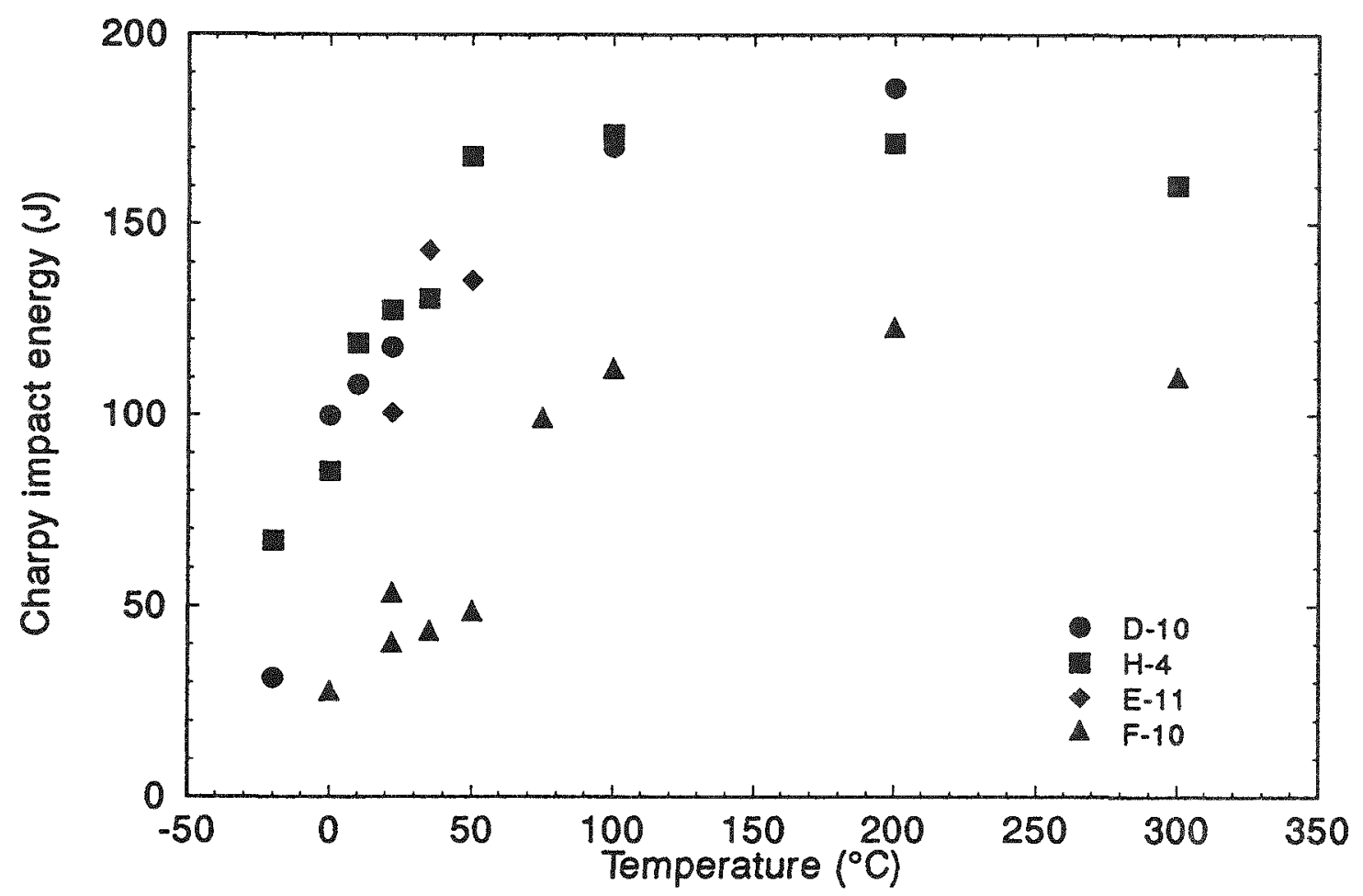

M810 20-0293-12

Figure 4-12. Impact energy versus test temperature data from Charpy V-notch impact tests on specimens from TMI-2 lower head material. 


\subsection{Examination of Cracks in Vessel Cladding}

Results of the metallographic examinations through the cracks in samples E-6 and G-8 indicated that the cracking originated in and was essentially limited to the Type 308L stainless steel cladding used on the vessel. A cross section through the principal crack in E-6 is shown in Figure 4-13. Penetration into the A533 vessel steel was only superficial $(-3 \mathrm{~mm})$. This was also the case for the two cracks examined form the G-8 sample, where the maximum penetration was somewhat greater $(\sim 6 \mathrm{~mm})$.

The rent nature of the 308L stainless steel within the crack of E-6, which was also typical of the G-8 crack, is evidence of the elevated-temperature ductility of the Type $308 \mathrm{~L}$ weldment and the hot tearing along interdendritic boundaries that resulted in the cracks. The hot tearing would have been caused by the thermal stresses when this hot spot area cooled rapidly at approximately $10-100^{\circ} \mathrm{C} /$ minute.

The scanning electron microscopy examination of the materials found in the E-6 and G-8 cracks revealed evidence of molten material that was present at, or shortly after, formation of the cracks. The principal constituents of this material, which appeared to be layered on the exposed crack surfaces, were $\mathrm{Fe}, \mathrm{Cr}$, and $\mathrm{Ni}$, together with $\mathrm{Sn}, \mathrm{In}, \mathrm{Ag}$, and $\mathrm{Cd}$ in combinations as second phases or discrete metallic particles within the general oxidized matrix. The appearance of the material indicated that it was not a surface oxidation product, but had once been molten and was interacting with the cladding in a solid/liquid reaction. These elements are the essential constituents of the Zircaloy-shrouded, stainless-steel-clad Ag-In-Cd control rods. The extensive gray structure in the root of the crack, however, was principally the Fe oxidation product of A533 vessel steel laced with a solidified Sn-In phase. Fuel particles were found only on top of the oxidized layers or as minor constituents of the layers. The absence of significant quantities of fuel in the cracks indicated that the massive fuel flow to the lower head was not the source of the solidified material in the cracks.

Inclusions of $\mathrm{Ag}$-Cd were found in numerous intergranular tears on the surface and well into the cladding $(-4 \mathrm{~mm})$. It is quite likely that interdendritic penetration of these materials as liquids contributed to the hot tearing of the cladding. Copper was also found in the cladding, next to the cracks, suggesting the causative agent for the hot tearing.

These observations on the superposition of core materials in the cladding and in cladding cracks suggest that the control-assembly materials were already on the lower head when the massive fuel flow from the core region arrived. Because the control assembly materials would have reached the lower head as solids, they apparently were remelted by the fuel flow, resulting in intergranular penetration of the cladding by $\mathrm{Ag}-\mathrm{Cd}$, which probably contributed to the hot tearing during the subsequent rapid cooling. 


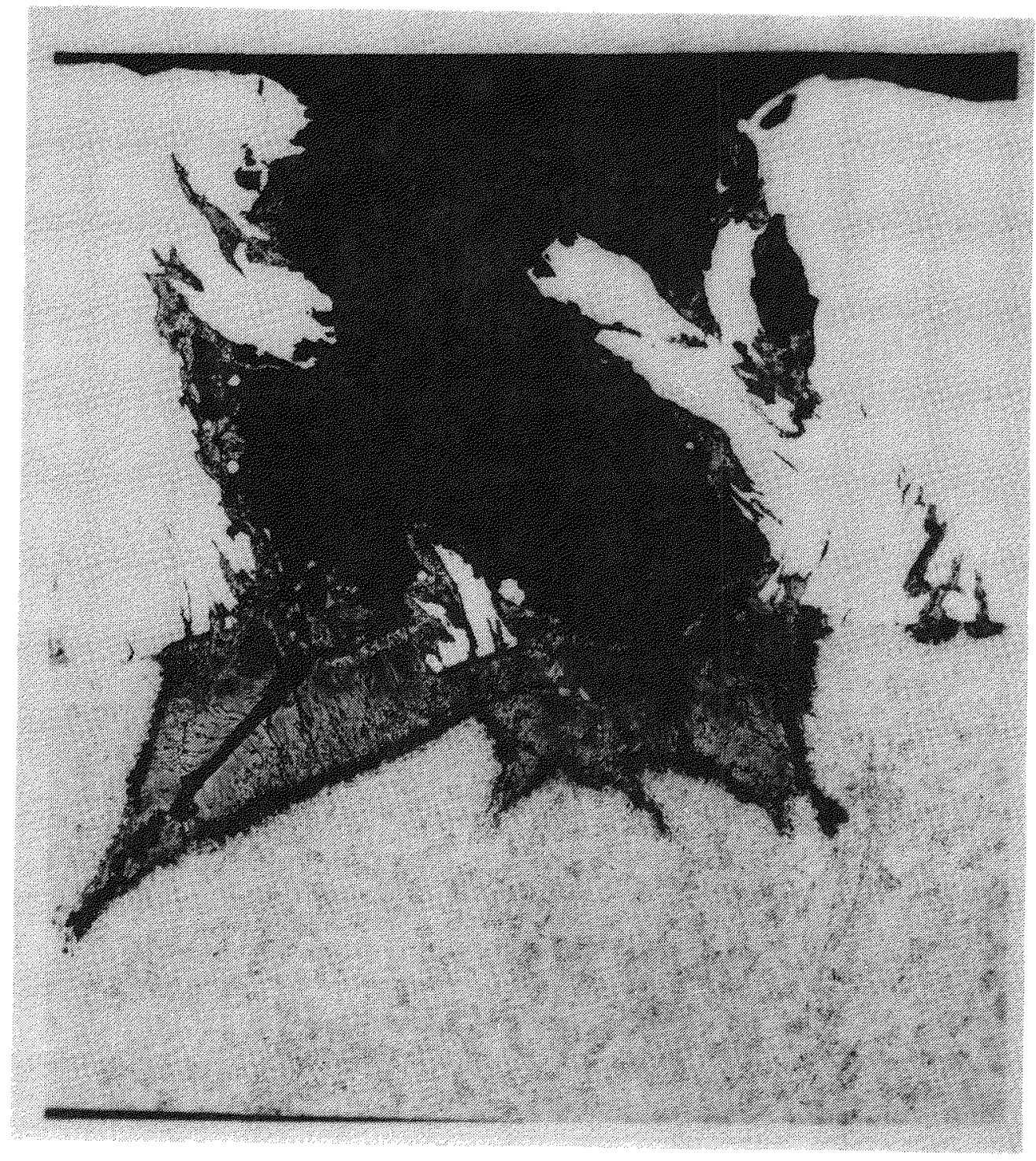

Figure 4-13. Cross section through principal crack in sample E-6. 


\subsection{References}

1. D. R. Diercks, TMI-2 Vessel Investigation Project (VIP) Metallurgical Program, Progress Report January-September 1989, NUREG/CR-5524, Vol. 1, ANL-90/2, Argonne National Laboratory, March 1990.

2. D. R. Diercks, TMI-2 Vessel Investigation Project (VIP) Metallurgical Program, Progress Report October 1989-June 1990, NUREG/CR-5524, Vol. 2, ANL-90-34, Argonne National Laboratory, November 1990.

3. D. R. Diercks and L. A. Neimark, Results of Mechanical Tests and Supplementary Metallographic Examinations of the TMI-2 Lower Head Samples, Argonne National Laboratory, TMI V(93)AL02, OECD-NEA-TMI-2 Vessel Investigation Project, June 1993.

4. W. Vandermeulen and W. Hendrix, Examination Report of the Samples of the TMI-2 RPV Received by SCK/CEN (Belgium), SCK/CEN, Mol, March 1992.

5. Reijo Pelli, Metallographic Examination of TMI-2 RPV Lower Head Sample E-8 and the Archive Material of Midland Reactor, TMI V(92)SF01, OECD-NEA-TMI-2 Vessel Investigation Project, VTT Technical Research Centre of Finland, Espoo, April 1992.

6. F. Le Naour, CEA Contribution to the TMI-2 Vessel Material Investigation Project, N.T. SRMA 92-1956, Centre d'Etudes de Saclay, May 1992.

7. H. Ruoff, K. H. Katerbau, and D. Sturm, Metallographic Examination of TMI-2 Lower Pressure Vessel Head Samples, TMI V(91)DO01, OECD-NEA-TMI-2 Vessel Investigation Project, Staatliche Materialprüfungsanstalt, Stuttgart, September 1991.

8. G. E. Korth, Metallographic and Hardness Examinations of TMI-2 Lower Pressure Vessel Head Samples, TMI V(92)EG01, OECD-NEA-TMI-2 Vessel Investigation Project, EG\&G Idaho, Inc., January 1992.

9. P. P. Milella and F. Bigagli, Charpy V Testing of Specimens of the TMI-2 Vessel Lower Head, TMI V(92)I01, OECD-NEA-TMI-2 Vessel Investigation Project, ENEA, Rome, May 1992.

10. L. Pedrero and P. Veron, Metallographic Investigation of TMI-2 Lower Pressure Vessel Head Samples, TMI V(92)EO02, OECD-NEA-TMI-2 Vessel Investigation Project, Equipos Nucleares S. A., Maliaño, April 1992.

11. A. Ballesteros, TMI-2 Vessel Investigation Project Creep Tests, TMI V(92)EO04, OECDNEA-TMI-2 Vessel Investigation Project, TECNATOM, Madrid, February 1992.

12. E. López Rincón, Testing of Lower Head Specimens in Spain (Tensile Results), TMI V(92)EO01, OECD-NEA-TMI-2 Vessel Investigation Project, CIAT, Madrid, May 1992. 
13. J. M. Titchmarsh and R. Coode, AEA-Technology Examinations of TMI-VIP Lower Head Samples, TMI V(91)UK2, OECD-NEA-TMI-2 Vessel Investigation Project, AEA Technology, Harwell, September 1991.

14. M. Beghini, P. P. Milella, and E. Vitale, "Temperature and Plastic Strain Effects on Metallurgical Properties of A533Gr.B Steel," TMI V(92)I02, OECD-NEA-TMI-2 Vessel Investigation Project, University of Pisa (Italy) and ENEA DISP (Rome), May 12-13, 1992, PRG Review Meeting, Idaho Falls, ID.

15. MPR Associates, Inc., Phase 4 Status Report: Removal of Test Specimens from the TMI-2 Reactor Vessel Bottom Head, Project Summary, MPR-1195, October 1, 1990.

16. National Research Institute for Metals, Data Sheets on the Elevated-Temperature Properties of 1.3 Mn-0.5 Mo-0.5 Ni Steel Plates for Boilers and Other Pressure Vessels (SBV 2), NRIM Creep Data Sheet No. 18B, Tokyo, 1987.

17. F. R. Larson and J. Miller, "A Time-Temperature Relationship for Rupture and Creep Stresses," Transactions of the ASME, 78, July 1952, pp. 765-775.

18. S. S. Manson and A. M Haferd, NACA Tech. Note 2890, March 1953.

19. G. V. Smith, Evaluations of the Elevated Temperature Tensile and Creep-Rupture Properties of C-Mo, Mn-Mo, and Mn-Mo-Ni Steels, ASTM Data Series Publication DS47, Metal Properties Council, American Society for Testing and Materials, 1971. 



\title{
5. COMPANION SAMPLE EXAMINATIONS
}

\author{
D. W. Akers and B. K. Schuetz, Idaho National Engineering Laboratory
}

As part of the Vessel Investigation Project, examinations of companion samples were performed to (a) assess the physical and radiochemical properties of the debris adjacent to the vessel lower head, (b) assess the potential for interactions between the molten core materials and the lower head, and (c) provide information needed for the vessel margin-to-failure analysis effort.

This section summarizes results of the physical and radiochemical examinations performed on the companion samples and the analysis of these data as required for interpretation of the data. A more detailed description of companions sample examination results may be found in Reference 1. Section 5.1 of this report describes how the companion samples were acquired from the vessel lower head, their approximate location in the debris bed, and sample designations. Results from examinations to characterize the physical characteristics of the companion sample debris are reported in Section 5.2, and results from examinations to determine radiochemical properties of the debris are presented in Section 5.3. Section 5.4 summarizes companion sample data obtained for the margin-to-failure analyses. Major conclusions from the companion sample examinations are presented in Section 5.5.

\subsection{Sample Acquisition}

As part of the defueling efforts, all of the loose debris upon the lower head was removed, revealing a variable topography of solidified debris (the companion material) upon the lower head. Results from probing examinations performed on February 15, 1989 (see Reference 2) were used to obtain the topographical map of the debris height shown in Figure 5-1. The contour lines in Figure 5-1 represent the depth of the hard debris, that is, the difference between the "hard stop" from the probe tests and the bowl-shaped lower head, rather than the surface contour of the hard layer. Figures 5-2 and 5-3 illustrate cross-sectional views through this hard layer at row 10 and row 12. As indicated in Figure 5-1, the maximum depth of this hard layer was approximately $46 \mathrm{~cm}$. Probe data indicates that this larger depth occurred within the central region of the core, near locations K-8 through K-10.

During the defueling process, it was discovered that the solidified layer was extremely hard and monolithic. This solidified layer was broken up by a $136-\mathrm{kg}$ (300-lb) slid hammer, which was dropped from an elevation of $6.1 \mathrm{~m}(20 \mathrm{ft})$. However, once broken into pieces, it was found that there was virtually no adherence of this material to the lower head itself. Furthermore, the resulting pieces of debris appeared fairly uniform in composition (no metallic layer was observed).

Bulk companion samples were acquired from the southeast, southwest, northeast, and northwest quadrants of the reactor vessel (see Figure 5-4). As noted in Figure 5-4, samples are designated according to the quadrant from which they were taken: 1-9 for samples from the southeast quadrant; 1-10 for samples from the northwest quadrant; 1-11 for samples from the southwest quadrant; and 1-12 for samples from the northeast quadrant. Within this section, individual pieces of samples from each quadrant are further designated by a letter. For example, samples 1-11-C and 1-11-D both come from the southwest quadrant. As indicated in Table 5-1, 


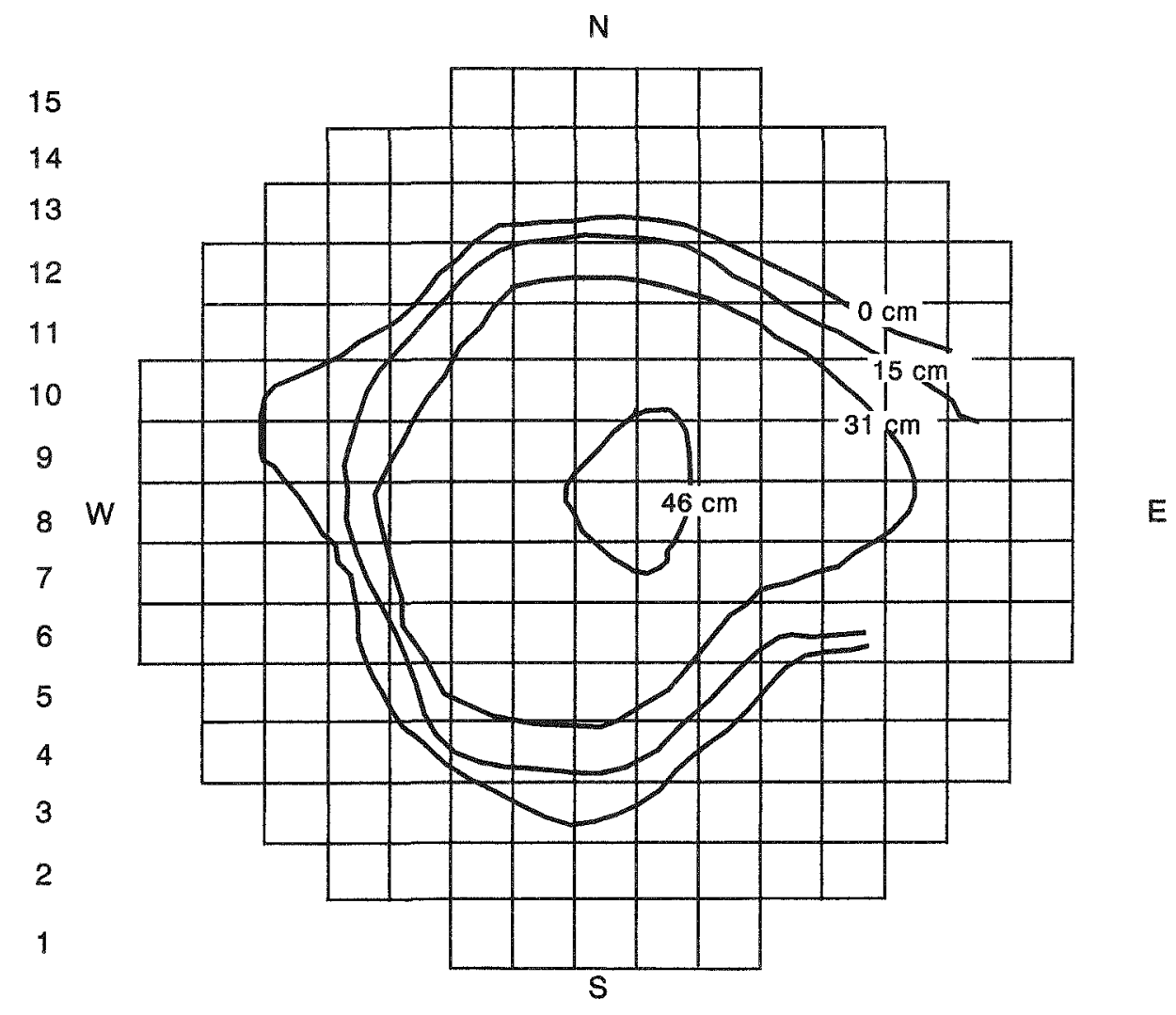

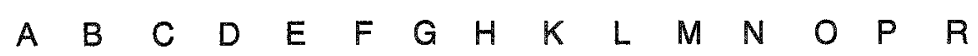

M919 : 1 r-0793-13

Figure 5-1. Depth of hard layer of solidified debris (Contour lines designate distance between a "hard stop" from probe tests and the bowl-shaped lower head). 

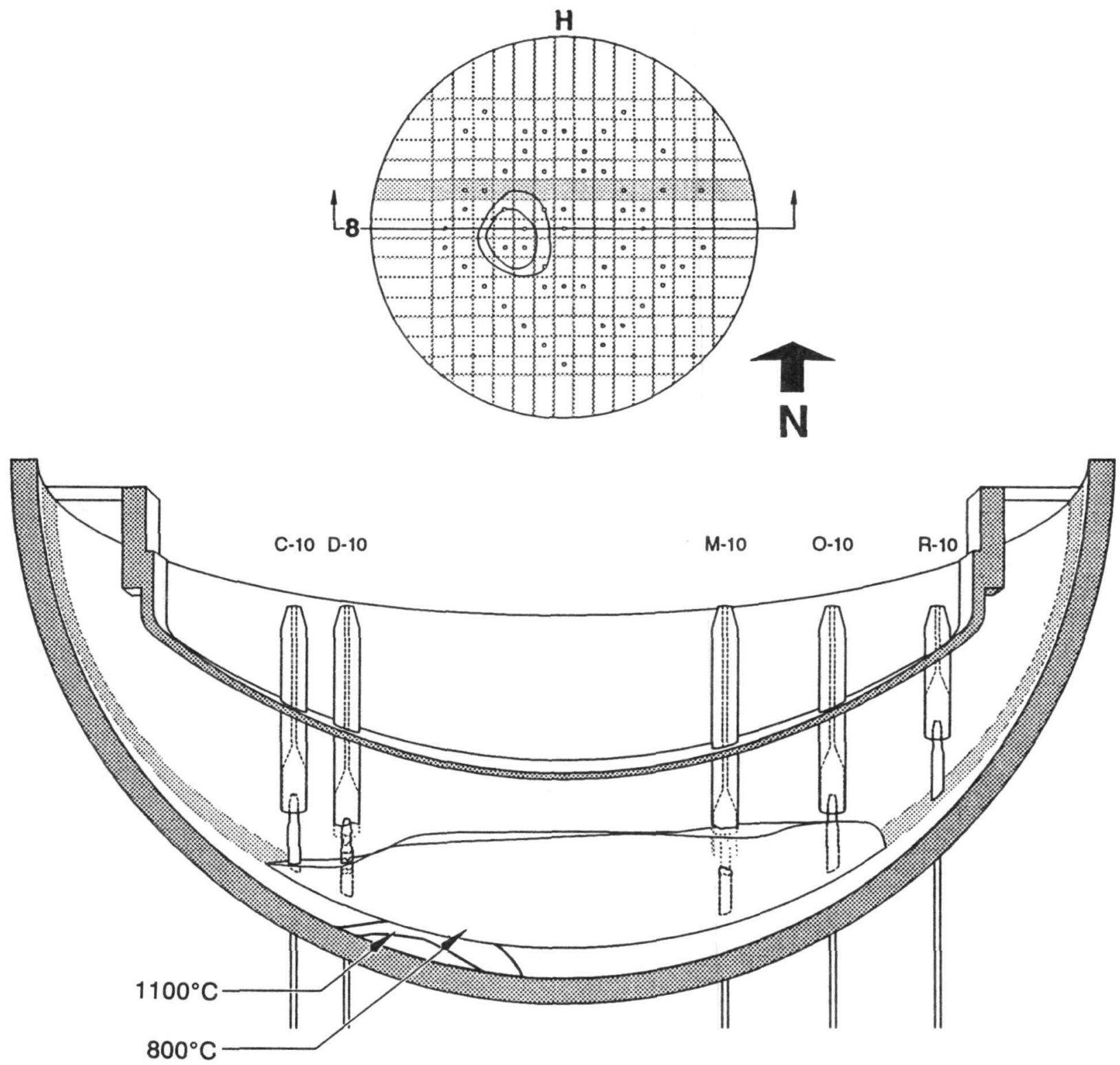

Y93 0390

Figure 5-2. TMI-2 lower head, cross section of hard debris, row 10. 



Y930391

Figure 5-3. TMI-2 lower head, cross section of hard debris, row 12. 
N

15
14
13
12
11
10
9
8
7
6
5
4
3
2
1

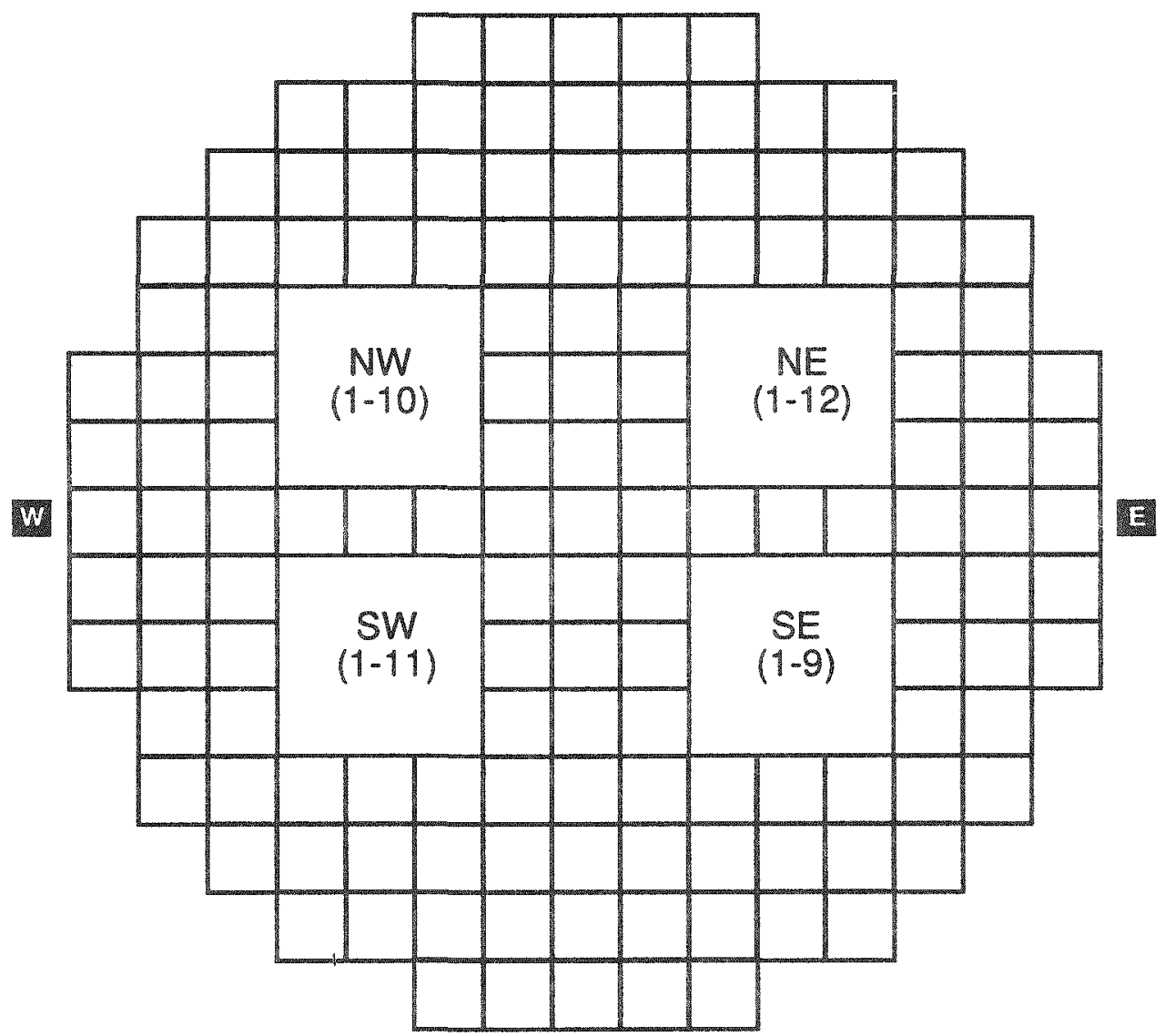

S

A B C D D E F G H K L M $N O A$ O P $R$

W920096

Figure 5-4. Locations from which companion samples were taken (numbers are MPR sample identification designations). 
Table 5-1. TMI-2 bulk sample weights and densities.

\begin{tabular}{cccc}
\hline Sample Number & $\begin{array}{c}\text { Location } \\
\text { (quadrant) }\end{array}$ & $\begin{array}{c}\text { Weight } \\
(\mathrm{g})\end{array}$ & $\begin{array}{c}\text { Density } \\
\left(\mathrm{g} / \mathrm{cm}^{3}\right)\end{array}$ \\
\hline $1-9$ & Southeast & 2,436 & 9.4 \\
$1-10$ & Northwest & 0.5 & 6.9 \\
$1-11$ & Southwest & 1,214 & 8.6 \\
$1-12$ & Northeast & 2,700 & 8.2 \\
\hline
\end{tabular}

much less debris was obtained from the northwest quadrant of the reactor vessel. During the removal of the loose layer in the northwest quadrant, almost all the hard layer was also removed. This left little debris still attached to the lower head when the companion samples were gathered. Hence, examinations focussed primarily on samples from the southeast, southwest, and northeast quadrants.

\subsection{Physical Characterization}

Nondestructive examinations of the companion samples included visual examinations, photography, sample weights, bulk density, and individual particle densities. Figures 5-5 through 5-8 show the bulk companion samples from which individual particles were selected for examination. All companion samples were composed of large pieces of broken-up debris except companion sample 1-10 (see Figure 5-6) from the northwest quadrant. This sample was composed of fine particulate debris and was not considered to be representative of the companion sample material. In retrospect, it is suspected that sample 1-10 was material that did not get removed during attempts to remove loose debris (see Section 5.1).

Eleven individual particle samples from the lower plenum were selected for destructive examinations. The examinations that were performed included optical metallography, scanning electron microscopy (SEM) analysis with energy dispersive $x$-ray spectroscopy (EDS) and wavelength dispersive $\mathrm{x}$-ray spectroscopy (WDS) analysis, bulk elemental analysis, and radionuclide content. Five of the 11 samples were from the primary relocation pathway in the southeast quadrant of the reactor (samples 1-9-A. 1-9-B. 1-9-C, 1-9-F, and 1-9-G). Three samples were from the principal damage region in the southwest quadrant of the reactor (samples 1-11-R, 1-11-C, and 1-11-D), and the remaining three samples were from the northeast quadrant of the reactor vessel head (samples 1-12-R, 1-12-C, and 1-12-D). These samples were sectioned and prepared for metallographic examination, after which representative samples were obtained for $\mathrm{SEM} /$ microprobe examinations and radiochemical analysis.

\subsubsection{Visual}

Visual examinations indicate that the samples were composed primarily of previously molten ceramic material, and possibly included small amounts of metallic material. The samples were generally dull grey in appearance, although some areas were yellow (lighter areas in Figures 5-5 through 5-8). 


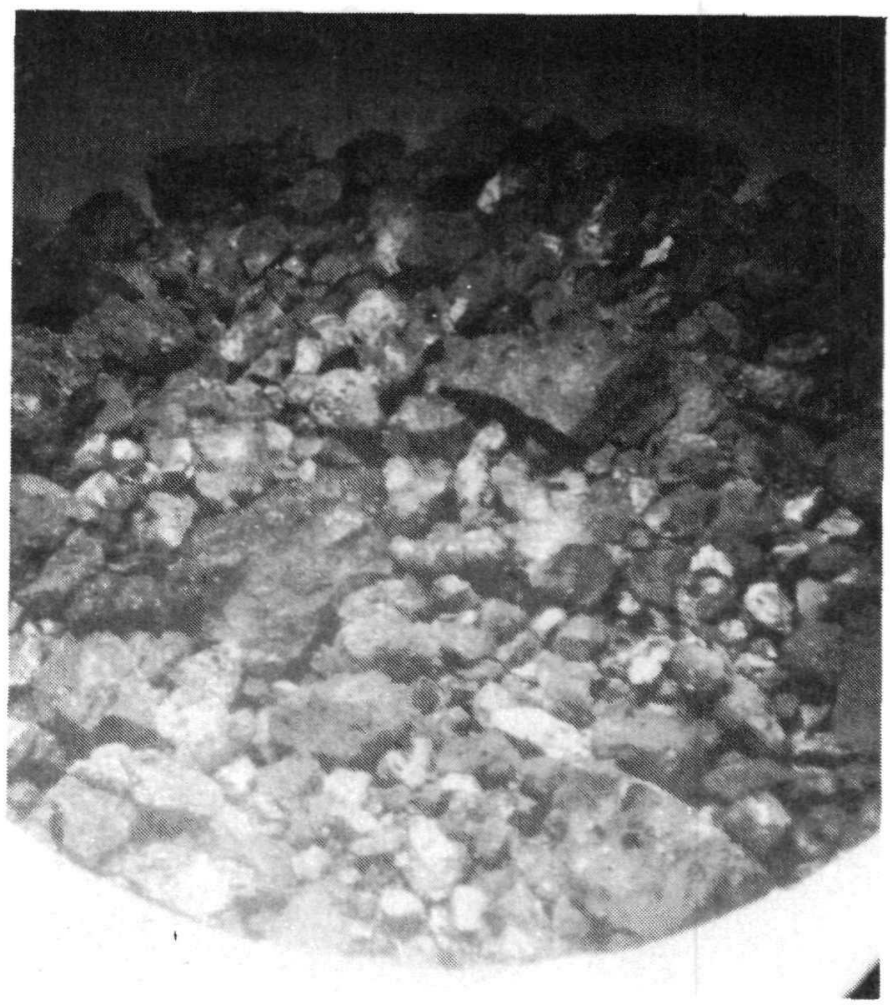

Figure 5-5. Sample collected from the southeast quadrant (sample 1-9; total sample weight is $2,436 \mathrm{~g}$ ).

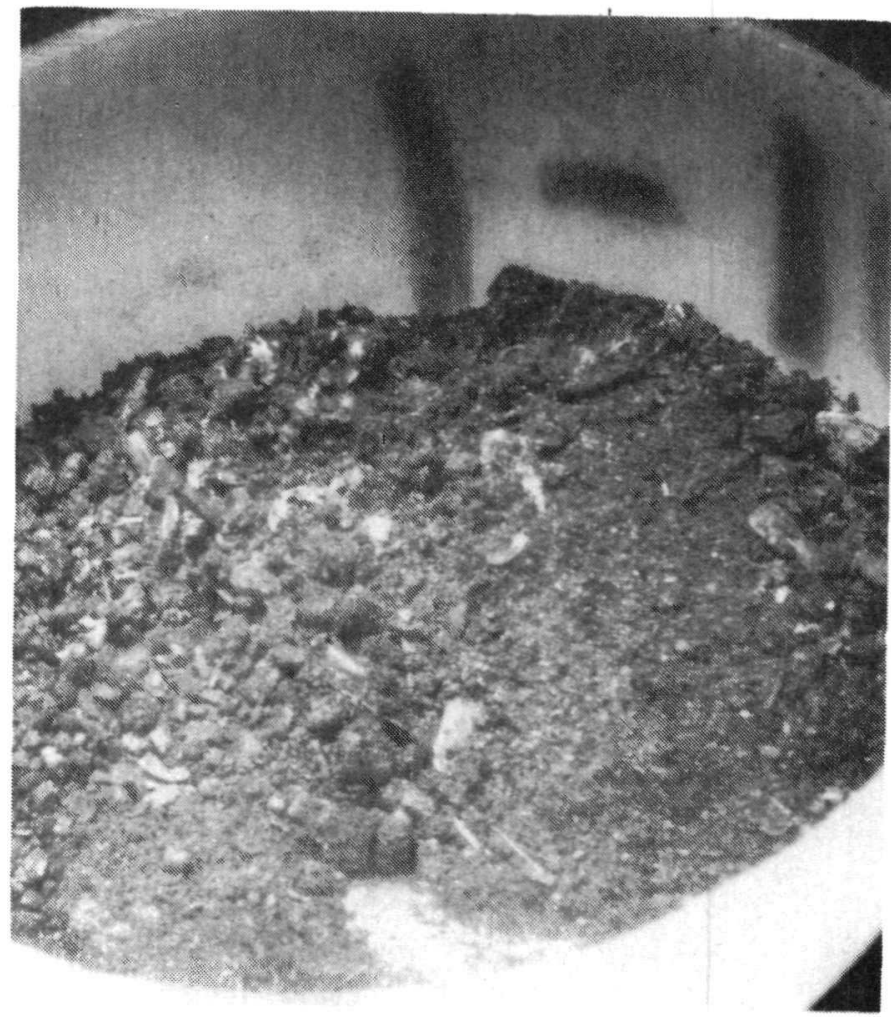

Figure 5-6. Sample collected from the northwest quadrant (sample 1-10; total sample weight is $0.5 \mathrm{~g})$. 


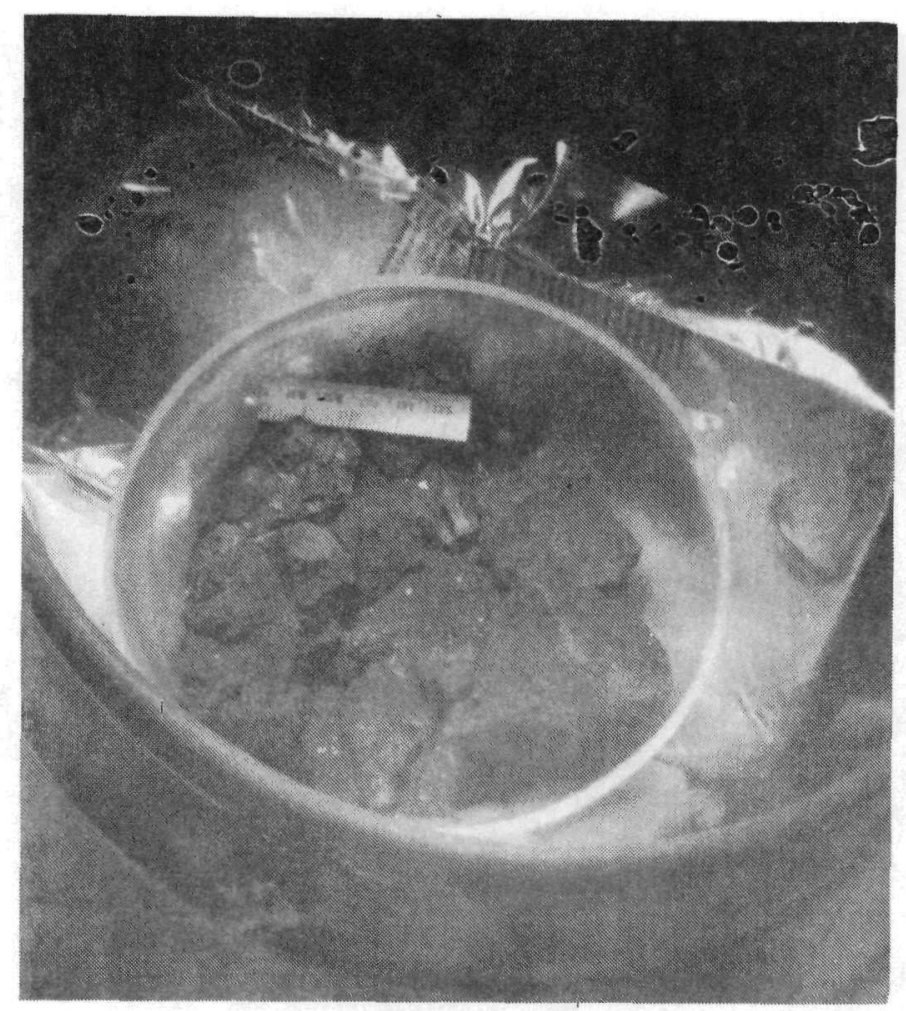

Figure 5-7. Sample collected from the southwest quadrant (sample 1-11; total sample weight is $1,214 \mathrm{~g})$.

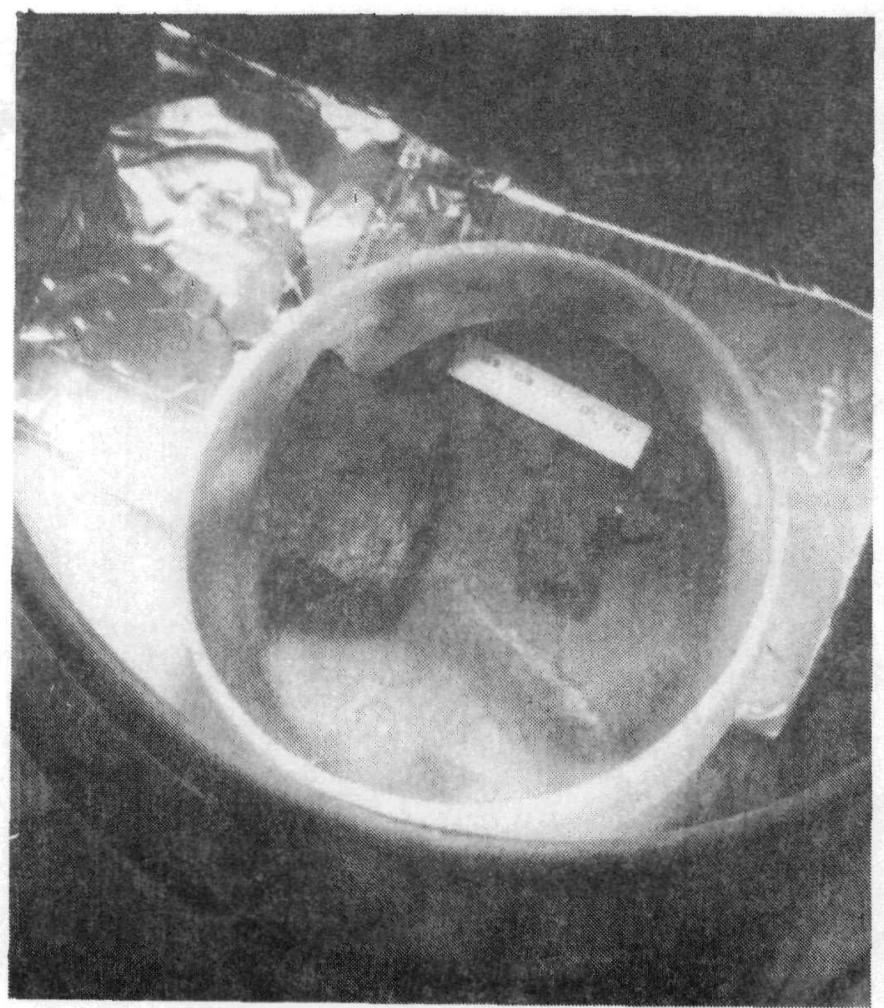

Figure 5-8. Sample collected from the northeast quadrant (sample 1-12; total sample weight is $2,700 \mathrm{~g})$. 


\subsubsection{Density}

Density measurements were performed on entire companion samples from each quadrant and from individual pieces of companion samples from each quadrant using the standard immersion method. Table 5-1 lists the location, total weight, and density of the total companion sample from each quadrant. Densities ranged from 6.0 to $9.4 \mathrm{~g} / \mathrm{cm}^{3}$. An average density for the companion samples is estimated to be $8.7 \pm 0.4 \mathrm{~g} / \mathrm{cm}^{3}$. The low density of the sample taken from the northwest quadrant was excluded from this average due to the sample's small size and its noticeable difference in physical form. Table 5-2 shows the weight and density of individual particles from several quadrants. Densities of these samples ranged from 7.45 to $9.40 \mathrm{~g} / \mathrm{cm}^{3}$, with an average value of $8.4 \pm 0.6 \mathrm{~g} / \mathrm{cm}^{3}$. The measured densities are consistent with samples composed primarily of $(\mathrm{U}, \mathrm{Zr}) \mathrm{O}_{2}$ with a large proportion of $\mathrm{UO}_{2}$. Examination of the elemental analysis results, discussed below in Section 5.3, indicates that the composition of all samples is similar. Hence, differences in sample density are primarily attributed to differences in debris porasity.

\section{2 .3 Porosity}

Table 5-3 lists porosity data for individual particle samples from the three quadrants of the lower head where most of the debris was obtained. The porosity was determined using optical methods on polished metallographic specimens. The approximate average porosities of samples from the southeast, southwest, and northeast quadrants are $21 \pm 7 \%, 18 \pm 14 \%$, and $17 \pm 9 \%$, respectively. However, these data can be misleading due to several high values and the range of observed porosities. The average porosity for all samples is $18 \pm 11 \%$, which suggests a very broad range of porosities in the debris.

\subsubsection{Microstructure}

Sample 1-11-R was sectioned to provide longitudinal and transverse cross-section views through the sample, and these views were labeled 1-11-R/L and 1-11-R/T. As indicated in Figure 5-9, interconnected porosity was observed in the longitudinal view of this sample. This interconnected porosity was observed in many of the samples and may be caused by bubbling of steam or structural material vapors through the molten pool. ${ }^{a}$ The presence of this interconnected porosity in the companion samples suggests that the debris was molten while on the lower head, and that it remained molten for a sufficient period of time to allow bubble coalescence.

The morphology of the material surrounding the pores was discernable only on the scanning electron microscope. As indicated in Figure 5-10, SEM examinations indicate that the material surrounding the pores within samples was composed of two phases, a light, uranium-rich $(\mathrm{U}, \mathrm{Zr}) \mathrm{O}_{2}$ phase and a dark, zirconium-rich $(\mathrm{Zr}, \mathrm{U}) \mathrm{O}_{2}$ phase. Away from the porous regions, the singlephase regions consisted of uranium-rich $(\mathrm{U}, \mathrm{Zr}) \mathrm{O}_{2} \cdot \mathrm{UO}_{2}-\mathrm{ZrO}_{2}$ phase diagrams indicate that the presence of two-phase $(\mathrm{U}, \mathrm{Zr}) \mathrm{O}_{2}$ and $(\mathrm{Zr}, \mathrm{O})_{2}$ structures corresponds to material that underwent a gradual cooldown rather than a rapid quench.

a. Private communication with L. A. Neimark, Argonne National Laboratory, Argonne, IL, May 13, 1992. 
Table 5-2. TMI-2 lower plenum individual sample weights and densities.

\begin{tabular}{ccc}
\hline Sample & $\begin{array}{c}\text { Weight } \\
(\mathrm{g})\end{array}$ & $\begin{array}{c}\text { Density } \\
\left(\mathrm{g} / \mathrm{cm}^{3}\right)\end{array}$ \\
\hline $1-9-\mathrm{R}$ & 51.81 & 9.40 \\
$1-9-\mathrm{F}$ & 14.90 & 7.45 \\
$1-9-\mathrm{G}$ & 12.10 & 8.07 \\
$1-11-\mathrm{R}$ & 52.23 & 8.62 \\
$1-11-\mathrm{C}$ & 49.50 & 8.39 \\
$1-11-\mathrm{D}$ & 76.40 & 8.30 \\
$1-12-\mathrm{R}$ & 47.16 & 8.18 \\
$1-12-\mathrm{C}$ & 45.50 & 9.29 \\
$1-12-\mathrm{D}$ & 15.20 & 7.60 \\
\hline
\end{tabular}

\subsubsection{Composition}

Analyses were performed for key elements in the principal components of the TMI-2 core. Table 5-4 lists the elemental composition of each of the core constituents (see Reference 3). By summing up the masses of each element within the core, an average composition of the TMI-2 core was estimated assuming that the core was homogeneously mixed (including the end fittings). These values are also listed in Table 5-4. Note that these average values include the oxygen content of the uranium but exclude the oxygen that might be present because of the oxidation of zircaloy and structural materials.

In-depth SEM analyses were performed to characterize the composition of companion samples 1-11-R/T, 1-9-A, and 1-9-B, which appeared to be representative of the debris bed. EDS analyses were performed and WDS dot maps were developed to assess the composition of specific phases within the samples. Dot maps were generated for the following core constituents: $U, O$, $\mathrm{Zr}, \mathrm{Ag}, \mathrm{Al}, \mathrm{Cd}, \mathrm{Cr}, \mathrm{Fe}, \mathrm{In}, \mathrm{Mn}, \mathrm{Mo}, \mathrm{Nb}, \mathrm{Ni}, \mathrm{Sn}$, and some fission products. Reference 1 presents a discussion of the regions examined and shows dot maps of the elements for which significant results were obtained.

Areas of interest that were examined include the edge of large pores, metallic inclusions, secondary phases, and pores without secondary phases. As previously discussed, each sample is composed of a homogeneous $(\mathrm{U}, \mathrm{Zr}) \mathrm{O}_{2}$ matrix with relatively low concentrations of $\mathrm{Al}, \mathrm{Sb}$, and $\mathrm{Sn}$ and a zirconium-rich secondary phase around pores and at grain boundaries. ${ }^{b}$ Results from these

b. Aluminum is found in Inconel-718 that is used in spacer grid strips, tin is contained within Zircaloy that is found in fuel cladding and in other fuel assembly components, and Antimony-125 is a fission product from U-235 (see Table 5-4). 
Table 5-3. TMI-2 lower plenum sample porosities. ${ }^{a}$

\begin{tabular}{ccl}
\hline Sample & $\begin{array}{c}\text { Porosity } \\
(\%)\end{array}$ & \multicolumn{1}{c}{ Remarks } \\
\hline $1-9-\mathrm{A}$ & 29.2 & Holes/cracks \\
$1-9-\mathrm{B} 1$ & 10.8 & Holes/cracks \\
$1-9-\mathrm{B} 2$ & 19.5 & Holes/cracks \\
$1-9-\mathrm{F}$ & 27.0 & Holes/halftone \\
$1-9-\mathrm{G}$ & 17.3 & Original macro \\
$1-11-\mathrm{C}$ & 7.6 & Holes/halftone \\
$1-11-\mathrm{D}-\mathrm{A}$ & 20.5 & Original photo \\
$1-11-\mathrm{R} / \mathrm{L}$ & 21 & Fine holes not resolved \\
$1-11-\mathrm{R} / \mathrm{T}$ & 7.0 & Low magnification (halftone) \\
$1-11-\mathrm{R} / \mathrm{T}$ & 5.7 & Large holes only \\
$1-11-\mathrm{D}-\mathrm{B}$ & 47.5 & Mottled stringers not included \\
$1-12-\mathrm{R}$ & 9.5 & Low magnification (halftone) \\
$1-12-\mathrm{R}$ & 19.8 & Halftone \\
$1-12-\mathrm{R}$ & 22.0 & Original photo \\
$1-12-\mathrm{C}$ & 5.7 & Stringers \\
$1-12-\mathrm{D}$ & 31.7 & Original photo \\
\hline
\end{tabular}

a. Reference 1 provides additional information related to the particular photographs from , which porosity measurements were made.

b. Halftones are report-quality photographs that may not contain the level of detail of the original photographs. Some smaller porosity may not be apparent from the optical analysis. Comparisons indicate that the difference in porosity between halftones and originals is $1-2 \%$. 


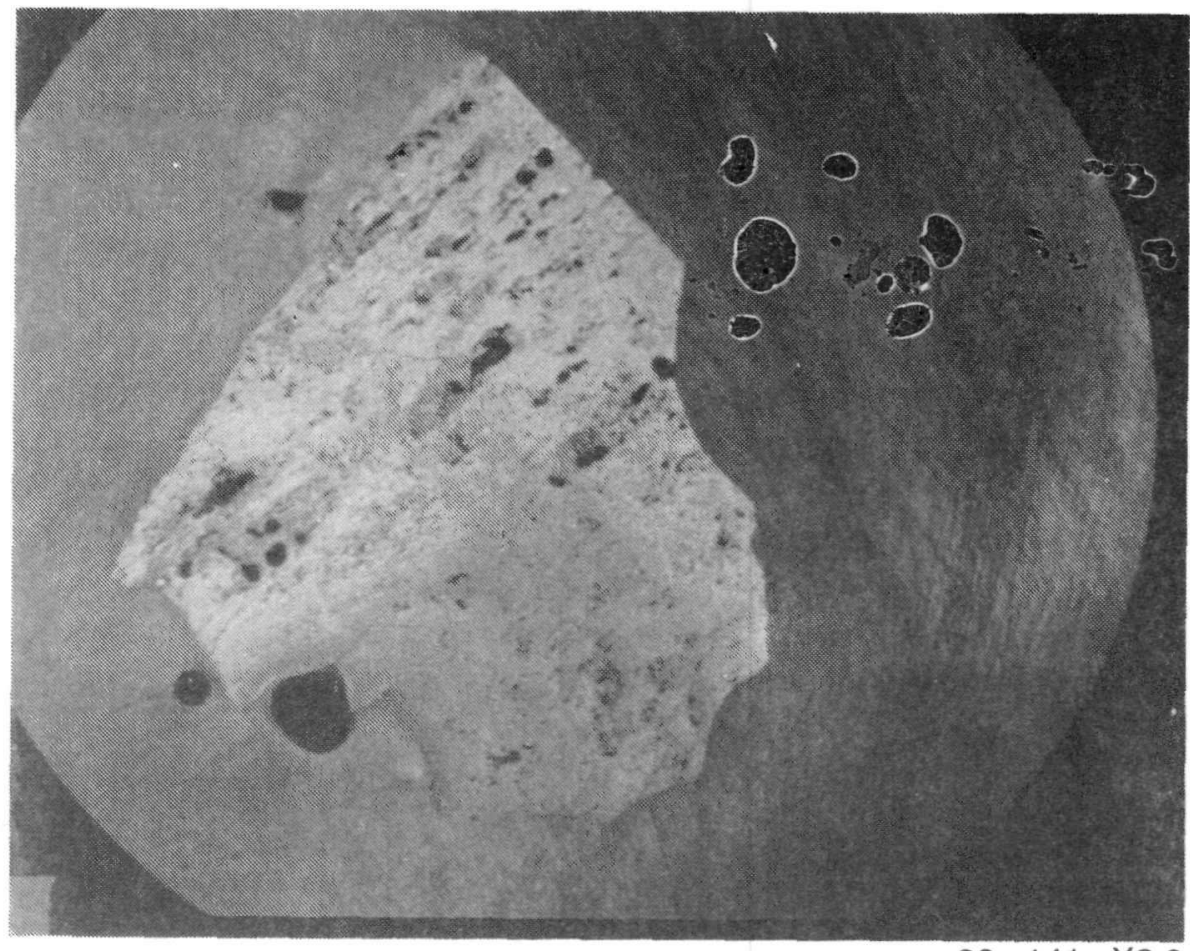

$90 \mathrm{~m} 141 \times 2.9$

(a) Longitudinal section (sample 1-11-R/L)

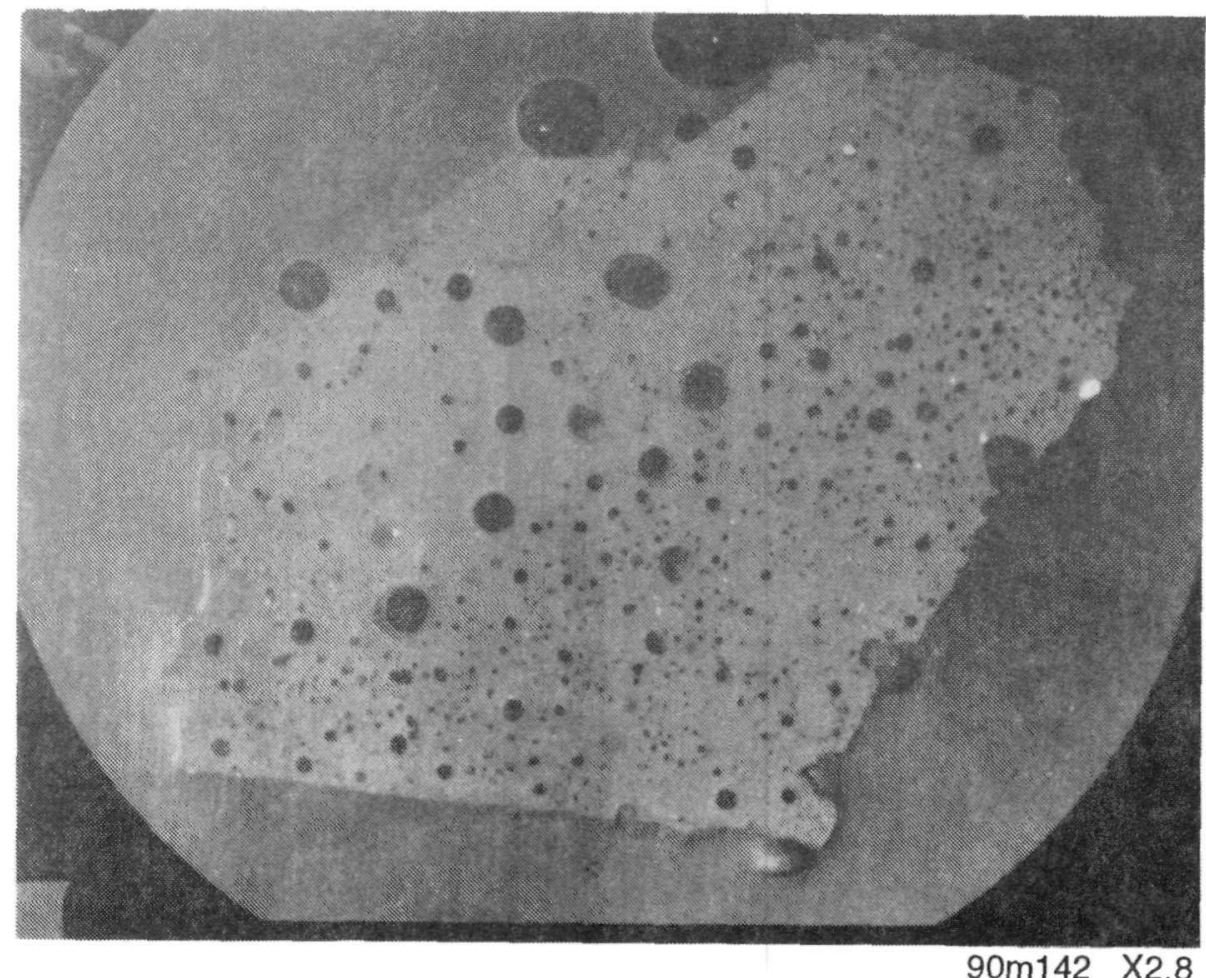

(b) Transverse section (sample 1-11-R/T)

Figure 5-9. Cross-sectional views of sample 1-11-R. 


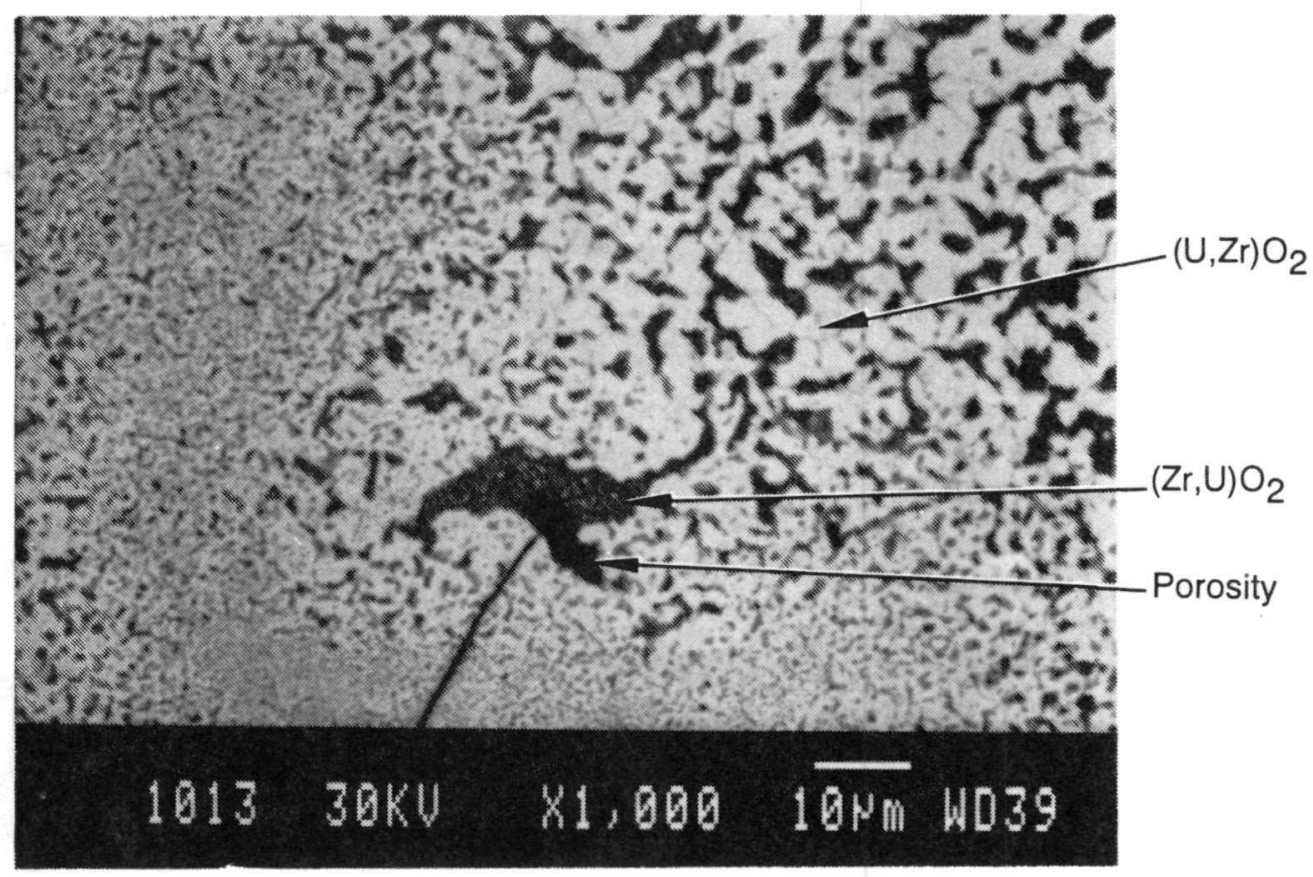

Figure 5-10. SEM backscattered electron image of two phase region (sample 1-9-A, Area 2). 
Table 5-4. TMI-2 reactor core composition. ${ }^{4}$

\begin{tabular}{|c|c|c|c|c|}
\hline \multirow[b]{2}{*}{$\begin{array}{l}\text { Material } \\
\text { (weight) }\end{array}$} & \multirow[b]{2}{*}{ Elements } & \multirow[b]{2}{*}{ Wt.\% } & \multicolumn{2}{|c|}{ Average Core Composition } \\
\hline & & & Element & $\begin{array}{c}\text { Composition } \\
\text { (wt. \%) }\end{array}$ \\
\hline $\begin{array}{l}\mathrm{UO}_{2} \\
(94,029 \mathrm{~kg}) \\
(531.9 \mathrm{~kg})\end{array}$ & $\begin{array}{l}\mathrm{U}-235^{\mathrm{a}} \\
\mathrm{U}-238^{\mathrm{a}} \\
0\end{array}$ & $\begin{array}{r}2.265 \\
85.882 \\
11.853\end{array}$ & $\begin{array}{l}\mathrm{U} \\
\mathrm{Zr} \\
\mathrm{O} \\
\mathrm{Fe}\end{array}$ & $\begin{array}{c}65.8 \\
18.0 \\
8.5 \\
3.0\end{array}$ \\
\hline $\begin{array}{l}\text { Zircaloy-4 } \\
(23,177 \mathrm{~kg}) \\
(125 \mathrm{~kg})^{\mathrm{b}}\end{array}$ & $\begin{array}{l}\mathrm{Zr}^{\mathrm{a}} \\
\mathrm{Sn}^{\mathrm{a}} \\
\mathrm{Fe}^{\mathrm{a}} \\
\mathrm{Cr}^{\mathrm{a}} \\
\mathrm{O}\end{array}$ & $\begin{array}{c}97.907 \\
1.60 \\
0.225 \\
0.125 \\
0.095\end{array}$ & $\begin{array}{l}\mathrm{Ag} \\
\mathrm{Cr} \\
\mathrm{Ni} \\
\mathrm{In} \\
\mathrm{Sn} \\
\mathrm{Al}\end{array}$ & $\begin{array}{l}1.8 \\
1.0 \\
0.9 \\
0.3 \\
0.3 \\
0.2\end{array}$ \\
\hline $\begin{array}{l}\text { Type-304 stainless steel } \\
(676 \mathrm{~kg}) \text { and unidentified } \\
\text { stainless steel }(3960 \mathrm{~kg}) \\
(16.8 \mathrm{~kg})^{\mathrm{b}}\end{array}$ & $\begin{array}{c}\mathrm{Fe}^{\mathrm{a}} \\
\mathrm{Cr}^{\mathrm{a}} \\
\mathrm{Ni}^{\mathrm{a}} \\
\mathrm{Mn}^{\mathrm{a}} \\
\mathrm{Si}^{\mathrm{a}} \\
\mathrm{N} \\
\mathrm{C} \\
\mathrm{Co}\end{array}$ & $\begin{array}{c}68.635 \\
19.000 \\
9.000 \\
2.000 \\
1.000 \\
0.130 \\
0.080 \\
0.080\end{array}$ & $\begin{array}{l}\mathrm{B} \\
\mathrm{Cd} \\
\mathrm{Mn} \\
\mathrm{Nb}\end{array}$ & $\begin{array}{c}0.1 \\
0.1 \\
0.8 \\
0.04\end{array}$ \\
\hline $\begin{array}{l}\text { Inconel-718 } \\
(1211 \mathrm{~kg}) \\
(6.8 \mathrm{~kg})^{\mathrm{b}}\end{array}$ & $\begin{array}{c}\mathrm{Ni}^{\mathrm{a}} \\
\mathrm{Cr}^{\mathrm{a}} \\
\mathrm{Fe}^{\mathrm{a}} \\
\mathrm{Nb}^{\mathrm{a}} \\
\mathrm{Mo}^{\mathrm{a}} \\
\mathrm{Ti}^{\mathrm{a}} \\
\mathrm{Al}^{\mathrm{a}} \\
\mathrm{Co}^{\mathrm{a}} \\
\mathrm{Si}^{\mathrm{a}} \\
\mathrm{Mn}^{\mathrm{a}} \\
\mathrm{N} \\
\mathrm{Cu}\end{array}$ & $\begin{array}{r}51.900 \\
19.000 \\
18.000 \\
5.553 \\
3,000 \\
0.800 \\
0.600 \\
0.470 \\
0.200 \\
0.200 \\
0.130 \\
0.100\end{array}$ & & \\
\hline $\begin{array}{l}\text { Ag-In-Cd } \\
(2749 \mathrm{~kg}) \\
(43.6 \mathrm{~kg})^{b}\end{array}$ & $\begin{array}{l}\mathrm{Ag}^{\mathrm{a}} \\
\mathrm{In}^{\mathrm{a}} \\
\mathrm{Cd}^{\mathrm{a}}\end{array}$ & $\begin{array}{r}80.0 \\
15.0 \\
5.0\end{array}$ & & \\
\hline $\begin{array}{l}\mathrm{B}_{4} \mathrm{C}-\mathrm{Al}_{2} \mathrm{O}_{3} \\
(626 \mathrm{~kg}) \\
(0 \mathrm{~kg})^{\mathrm{b}}\end{array}$ & $\begin{array}{c}\mathrm{Al}^{\mathrm{a}} \\
\mathrm{O} \\
\mathrm{B}^{\mathrm{a}} \\
\mathrm{C}\end{array}$ & $\begin{array}{r}34.33^{\mathrm{c}} \\
30.53^{\mathrm{c}} \\
27.50^{\mathrm{a}} \\
7.64^{\mathrm{c}}\end{array}$ & & \\
\hline $\begin{array}{l}\mathrm{Gd}_{2} \mathrm{O}_{3}-\mathrm{UO}_{2} \\
(131.5 \mathrm{~kg}) \\
(\mathrm{O} \mathrm{kg})^{\mathrm{b}}\end{array}$ & $\begin{array}{c}\mathrm{Gd}^{\mathrm{a}} \\
\mathrm{U}^{\mathrm{a}}\end{array}$ & $\begin{array}{l}10.27^{\mathrm{c}} \\
77.72^{\mathrm{c}} \\
12.01^{\mathrm{c}}\end{array}$ & & \\
\hline
\end{tabular}

a. Elements for which inductively coupled plasma (ICP) analysis was performed.

b. Weight of material in a control rod fuel assembly.

c. Data are suspect. 
examinations indicate that all of the samples appear to consist primarily of previously molten $(\mathrm{U}, \mathrm{Zr}) \mathrm{O}_{2}$. Droplets of metallic melt were found only in samples $1-11-\mathrm{R} / \mathrm{L}, 1-11-\mathrm{R} / \mathrm{T}$, and 1-11-D-A (see Figure 5-11). SEM/microprobe examinations indicate that these metallic melts are silver and indium. A secondary ceramic phase was also observed within the $(\mathrm{U}, \mathrm{Zr}) \mathrm{O}_{2}$ matrix of sample 1-11-R/T (see Figure 5-11). SEM/microprobe examinations of this ceramic phase indicate that it was composed primarily of Cr-oxide.

Examination of the secondary phases around pores and in the matrix of the debris indicates that the secondary phases are composed primarily of $(\mathrm{Zr}, \mathrm{U}) \mathrm{O}_{2}$ with greater amounts of $\mathrm{Fe}$ and $\mathrm{Cr}$ present. The fact that there was time during the cooling process for the lower temperature $(\mathrm{Zr}, \mathrm{U}) \mathrm{O}_{2}$ phase to form, as discussed in section 5.2.4, suggests that the molten pool remained at a relatively high temperature for a period of time. However, the presence of the localized concentrations of $\mathrm{Fe}$ and $\mathrm{Cr}$ suggests that there was not a great deal of mixing after the material was deposited on the lower head.

\subsection{Radiochemical Characterization}

Radiochemical analyses were performed on the companion samples to assess bulk composition and radionuclide content. Before the destructive analysis, the intact samples were analyzed via gamma spectroscopy to provide an initial estimate of the gamma-emitting radionuclide content. Then, the samples were dissolved using a pyrosulfate fusion technique in a closed system. Elemental analyses were performed on dissolved samples using inductively coupled plasma spectroscopy techniques. A detailed description of the analysis methods used for the companion sample examinations may be found in Reference 4.

\subsubsection{Elemental Composition}

Elemental analyses were performed for key elements in principal core components (see Table 5-4). Table 5-5 lists the average compositions of the companion samples from the three quadrants of the lower head for which examinations were performed. The average composition for each of the core constituents are repeated in Table 5-5 for comparison. Examination results indicate that the companion material was relatively homogeneous on a macroscopic scale in all of the areas examined.

The total amount of sample weight accounted for in this analysis is between 84 and 88 wt\% of the total sample weight. Within the uncertainties of the analysis, the remaining material is accounted for by the oxidation of the uranium and zirconium present in the samples.

Comparison of the analysis results with the average composition of core constituents indicates that the fuel melt is composed almost entirely of the constituents of a fuel rod and that little contamination by other structural constituents occurred. It is interesting to note that a relatively high fraction of the Indium within a fuel element was found in the companion samples.

\subsubsection{Decay Heat}

The companion sample examination effort included analyses to determine the decay heat within the debris, which was required as input to the margin-to-failure calculational effort. The 


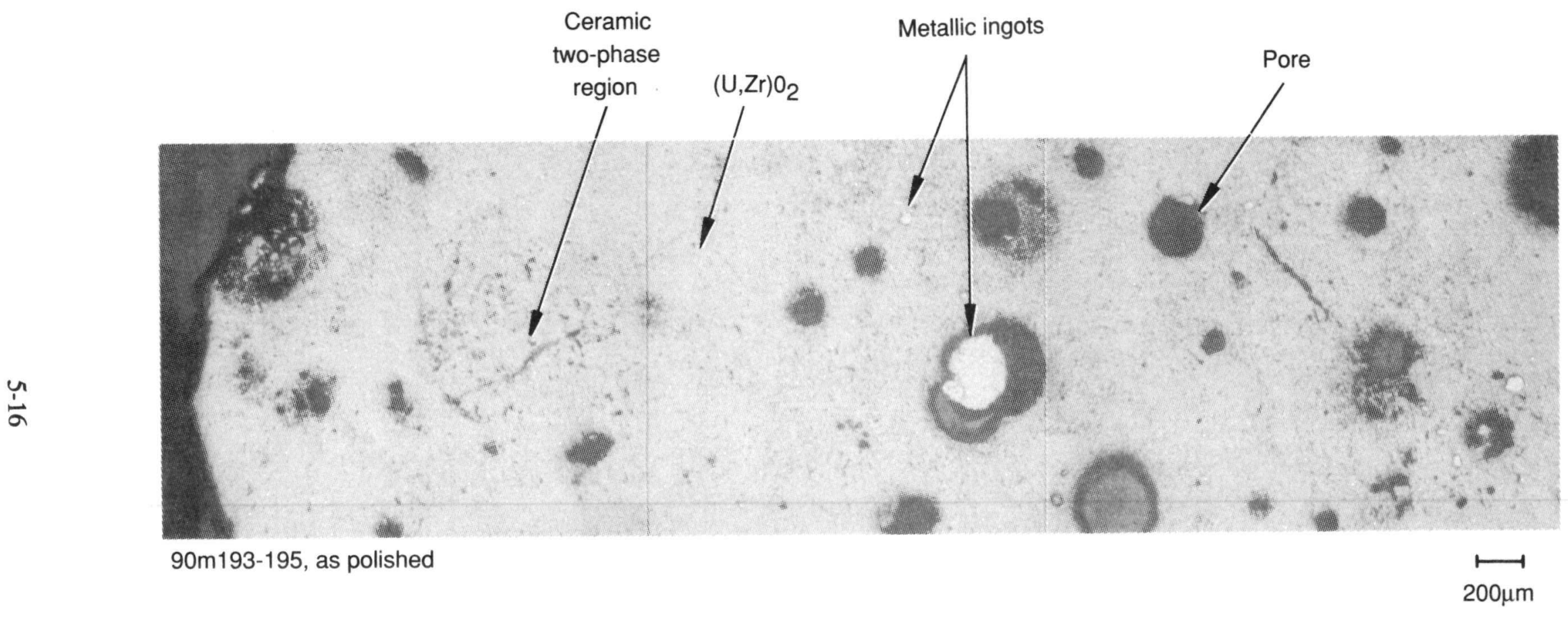

Figure 5-11. Photocomposite of microstructure in sample 1-11-R/T. 
Table 5-5. Average debris composition by quadrant ${ }^{a}(w t \%)$.

\begin{tabular}{|c|c|c|c|c|}
\hline Element & Southeast (1-9) & Southwest (1-11) & Northeast (1-12) & Core average ${ }^{b}$ \\
\hline $\mathbf{U}$ & 72.3 & 70.8 & 68.2 & 65.8 \\
\hline $\mathrm{Zr}$ & 14.1 & 12.0 & 15.2 & 18.0 \\
\hline Sn & $--^{c}$ & $--^{c}$ & $-^{c}$ & 0.3 \\
\hline $\mathrm{Ag}$ & $--^{c}$ & $--^{c}$ & $\ldots$ & 1.8 \\
\hline In & 0.28 & 0.26 & $--^{c}$ & 0.3 \\
\hline $\mathrm{Al}$ & $--^{c}$ & $--^{c}$ & $-^{c}$ & 0.2 \\
\hline $\mathrm{Cr}$ & 0.33 & 0.26 & 0.52 & 1.0 \\
\hline $\mathrm{Fe}$ & 0.74 & 0.53 & 0.93 & 3.0 \\
\hline $\mathrm{Mn}$ & 0.030 & 0.026 & 0.028 & 0.8 \\
\hline Mo & $--^{c}$ & $-^{c}$ & $--^{c}$ & $--^{d}$ \\
\hline $\mathrm{Nb}$ & $--^{c}$ & $--^{c}$ & $-\alpha^{c}$ & 0.04 \\
\hline $\mathrm{Ni}$ & 0.099 & 0.081 & 0.10 & 0.9 \\
\hline Total & $87.8^{\mathrm{e}}$ & $84.3^{\mathrm{e}}$ & $85.1^{\mathrm{e}}$ & 92.14 \\
\hline
\end{tabular}

a. This table presents the average of the examination results obtained from the companion samples; however, because of the small number of samples examined, these data must be used with caution.

b. Based upon data in Table 5-4.

c. Values below the analytical detection limit.

d. Data not available.

e. Total of measurable constituents. Oxygen content was not measured. 
procedure used to determine the decay heat required that the radionuclide concentration within the debris be measured for selected species. These measured concentrations were compared with concentrations predicted in an ORIGEN $2^{5}$ calculation ${ }^{6}$ to verify calculational results. Then, other radionuclide concentrations contributing to the decay heat were obtained from the ORIGEN2 calculation, and calculations were performed to estimate the decay heat from the radionuclide concentration within the debris as a function of time. Results from major steps in this process to estimate the decay heat are presented in Sections 5.3.2.1 and 5.3.2.2.

5.3.2.1 Radionuclide Concentration. The radionuclide content of the lower head debris samples was measured for several key radionuclides using dissolution techniques. Table 5-6 summarizes the normalized radionuclide retentions found in the companion samples. Radionuclide retention percentages reported in Table 5-6 are the ratios of measured retention to the retention predicted by an ORIGEN2 analysis for undamaged fuel. ${ }^{6}$ A ratio of less than 1 indicates that the measured retention is less than the calculated value. Results are discussed below according to the volatility of the chemical group and element.

The high-volatility fission product groups include the noble gases, halogens, alkali metals, and heavy chalcogens. From this group, measurements were made for ${ }^{137} \mathrm{Cs}$. As indicated in Table $5-6$, the volatile ${ }^{137} \mathrm{Cs}$ was measurable in all samples at retentions substantially lower than those predicted with ORIGEN2 for undamaged fuel. However, higher retentions were found in the northeast quadrant (18\%). It is not known why higher levels of this radionuclide, as well as medium- and low-volatile radionuclide concentrations, existed in the northeast region.

The medium-volatility fission products are from the metals, alkaline earths, some of the rare earths, and actinides. Radionuclides from these groups for which measurements were made are ${ }^{125} \mathrm{Sb}$ and ${ }^{90} \mathrm{Sr}$. Strontium-90 is less volatile than Antimony-125 and is expected to be retained by the fuel to the greatest extent. However, the ${ }^{90} \mathrm{Sr}$ data shown in Table 5-6 indicate a range of retentions from 48 to $96 \%$. Thus, some release of this fission product occurred. The low retention of ${ }^{125} \mathrm{Sb}$ in the companion samples probably results from the partition of metallic antimony, unoxidized because of the high potential required to oxidize the element, from the oxidic uranium melt in the upper core region. As a consequence, the melt that relocated to the lower head was low in ${ }^{125} \mathrm{Sb}$ content. In previous core examinations, high concentrations of ${ }^{125} \mathrm{Sb}$ were found in metallic samples from the upper core region. ${ }^{4}$

The low-volatility fission products include elements from the noble metals, the remaining rare earths and actinides, tetravalents, and early transition elements. The radionuclides from this group that were measured are ${ }^{154} \mathrm{Eu}$ and ${ }^{144} \mathrm{Ce}$. The concentrations of ${ }^{144} \mathrm{Ce}$ measured in the companion samples indicate that nearly all of this radionuclide was retained. Considering the uncertainty in the ability to predict ${ }^{154}$ Eu production, data in Table 5-6 also indicate that most of this radionuclide was retained.

5.3.2.2 Decay Heat. Decay heat calculations were performed to estimate the heat generated within the hard layer of debris upon the lower head. These calculations were performed using results from an ORIGEN2 analysis of the TMI-2 core. Burnup was calculated for the TMI-2 reactor core using an analysis model with 1,239 fuel nodes. ${ }^{6}$ Results indicate that the burnup ranged from about $900 \mathrm{MWd} / \mathrm{mtU}$ to $6,000 \mathrm{MWd} / \mathrm{mtU}$ with a core average value of approximately $3,200 \mathrm{MWd} / \mathrm{mtU}$. A benchmark comparison was performed with the measured 
Table 5-6. Radionuclide retention in the debris bed. ${ }^{2}$

\begin{tabular}{cccc}
\hline & \multicolumn{3}{c}{ Radionuclide Retention(\%) } \\
\cline { 2 - 4 } Radionuclide & Southeast (1-9) & Southwest (1-11) & Northeast (1-12) \\
\hline${ }^{90} \mathrm{Sr}$ & 48 & 47 & 96 \\
${ }^{125} \mathrm{Sb}$ & 1.9 & 1.1 & 5.6 \\
${ }^{137} \mathrm{Cs}$ & 3.6 & 1.3 & 18 \\
${ }^{144} \mathrm{Ce}$ & 91 & 85 & 97 \\
${ }^{154} \mathrm{Eu}$ & 83 & 84 & 80
\end{tabular}

a. Retention is calculated based on the uranium content of the sample material as determined from the elemental analysis results.

${ }^{144} \mathrm{Ce}$ (an indicator of burnup) concentrations to determine the actual burnup of the debris on the lower head. This comparison indicated that the debris was at near average burnup. The TMI-2 reactor core was operated for about 96 days of effective full power days of operation.

Although the average burnup of the TMI- 2 core at the time of the accident was relatively low, previous calculations ${ }^{7}$ indicate that the decay heat for a core that had been operated for a considerably longer period of time would not be significantly different for the time periods of concern during the reactor accident. As shown in Figure 5-12, the difference in decay heat for a full burnup equilibrium core at $34 \mathrm{GWd} / \mathrm{mtU}$ and the decay heat for the TMI-2 core with an average burnup of $3.2 \mathrm{GWd} / \mathrm{mtU}$ is negligible for the first 1,000 minutes after reactor scram. Although more volatile fission products would be retained in higher burnup fuel, additional calculations $^{\mathcal{C}}$ that include the effect of volatile release on debris decay heat indicate that the maximum increase in fission product decay power for relocated fuel in a full burnup core would be less than $20 \%$ for time periods of concern during the reactor accident.

Using the methodology described in Reference 8, radionuclide concentrations for other species contributing to debris decay heat were estimated using results from the ORIGEN2 TMI-2 calculation. Based on the radionuclide concentration results discussed above, it was determined that some principal radionuclides should not be included in decay heat calculations. Specifically, the noble gases (primarily $\mathrm{Xe}$ and $\mathrm{Kr}$ ) and the high volatiles (all cesiums and iodines) were removed from the decay heat calculations. These radionuclides were omitted because they would be expected to have volatilized and been released from the fuel before the molten material relocated to the lower head.

c. B. G. Schnitzler, "Fission Product Decay Heat Power for Disrupted Fuel Regions," BGS-08-93, internal INEL memo to J. R. Wolf, October 1, 1993. 


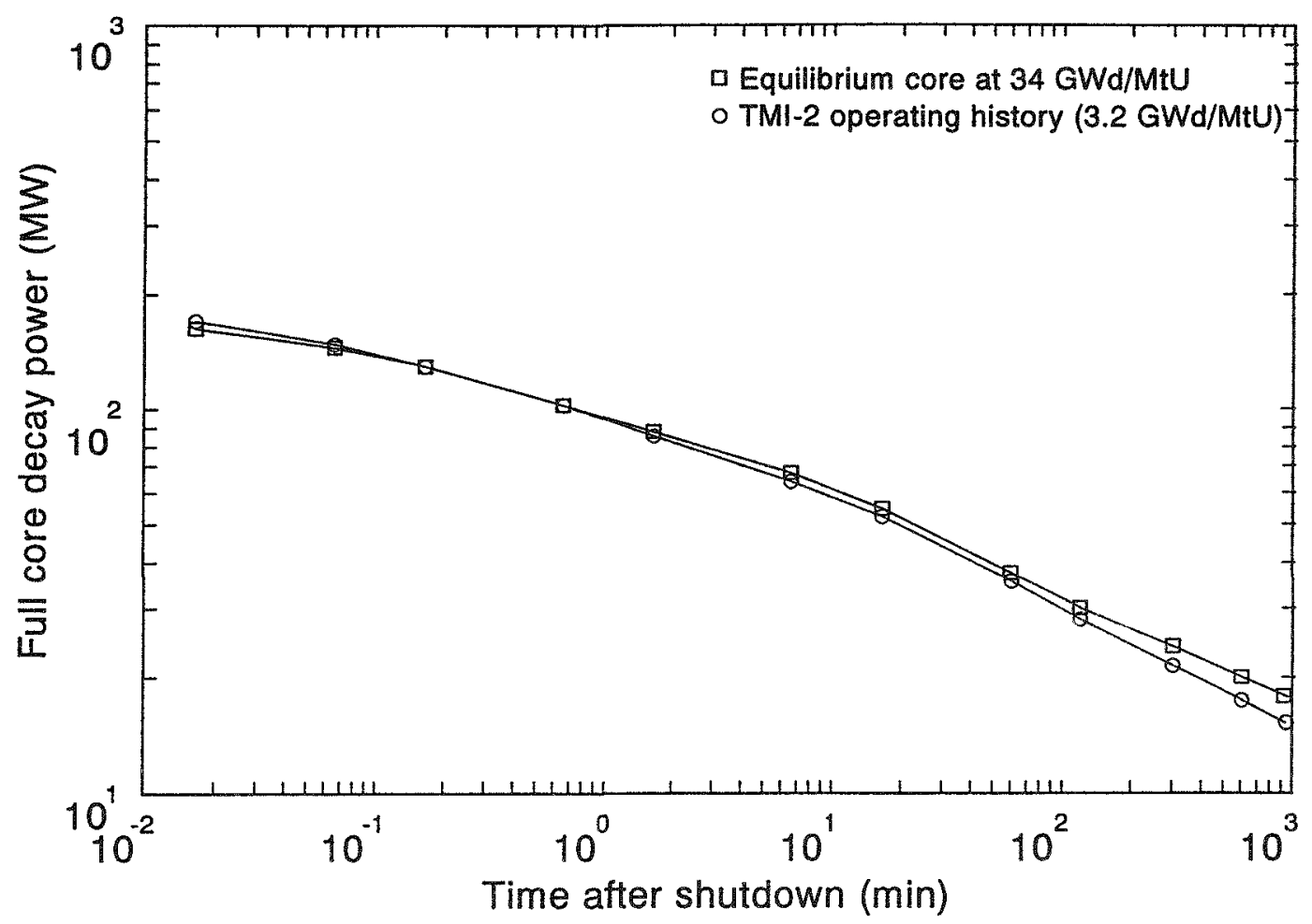

* LA-8041-MS, Revised (March 1980)

Z025 dwz-1093-13a

Figure 5-12. Comparison of TMI-2 decay heat to decay heat from a full burnup core.

Specific decay heats were calculated at 224 minutes after shutdown, which corresponds to the time that the major relocation of debris to the lower head occurred, and at 600 minutes for the later cooldown period. The decay heat produced from the selected radionuclide list is $0.13 \mathrm{~W} / \mathrm{g}$ of debris at 224 minutes and $0.096 \mathrm{~W} / \mathrm{g}$ of debris at 600 minutes after the accident.

\subsection{Input to Margin-to-Failure Analysis}

As discussed at the beginning of Section 5, one of the objectives of the companion sample examinations was to obtain input for the margin-to-failure analyses. In some cases, companion sample data can be used directly as input to the margin-to-failure calculations; in other cases, additional information was required to obtain the desired margin-to-failure analysis input. This section summarizes results from the companion sample examinations that provide input to the margin-to-failure analysis effort.

\subsubsection{Debris Composition}

Radiochemical examination results indicated that the composition of the debris bed is similar for all samples with an average composition of about $70 \mathrm{wt} \% \mathrm{U}, 13.75 \mathrm{wt} \% \mathrm{Zr}$, and $13 \mathrm{wt} \% \mathrm{O}$. This composition accounts for about $97 \mathrm{wt} \%$ of the debris.

Based on the metallography and SEM examination results, the extent of the oxidation of the companion samples can be considered to be almost complete with little or no unoxidized material present other than small quantities of materials such as Ag. These data suggest that the companion debris was fully oxidized with little metallic material present. 


\subsubsection{Peak Debris Temperature at Relocation}

Hofmann" addressed the range of temperatures that might be expected in a severe reactor accident and has shown that the lowest temperatures that might be expected in the dissolution of uranium by zirconium are on the order of $1,760^{\circ} \mathrm{C}$, about $1,000^{\circ} \mathrm{C}$ below the melting point of $\mathrm{UO}_{2}$ $\left(-2,850^{\circ} \mathrm{C}\right)$. However, the companion samples have compositions that are principally $(\mathrm{U}, \mathrm{Zr}) \mathrm{O}_{2}$ (i.e., about $78 \mathrm{wt} \% \mathrm{UO}_{2}$ and $\left.17 \mathrm{wt} \% \mathrm{ZrO}_{2}\right)$ with some secondary $(\mathrm{Zr}, \mathrm{U}) \mathrm{O}_{2}$ phases. Hofmann indicates that a well-mixed (U, $\mathrm{Zr}) \mathrm{O}_{2}$ solid solution, as shown by the metallography and SEM results, would be expected to be found in a peak temperature range between 2,600 and $2,850^{\circ} \mathrm{C}$. Consequently, it is suggested that the peak temperature of the melt that relocated to the lower head was at least $2,600^{\circ} \mathrm{C}$.

\subsubsection{Debris Cooling Rate}

Companion sample examinations provide insight into the debris cooling rate, which is based on the formation of secondary phases around pores and in the matrix material. These secondary phases contain apparent $(\mathrm{Zr}, \mathrm{U}) \mathrm{O}_{2}$ phases with the presence of $\mathrm{Fe}$ and $\mathrm{Cr}$. The formation of these phases would require a finite cooldown period as opposed to an instantaneous quench to allow the phase separation to occur between the $(\mathrm{U}, \mathrm{Zr}) \mathrm{O}_{2}$ and $(\mathrm{Zr}, \mathrm{U}) \mathrm{O}_{2}$ phases. Bart ${ }^{10}$ has suggested that a cooling time between 3 and 72 hours is needed to cause this type of phase separation.

\subsubsection{Debris Decay Heat}

Based upon radionuclide concentrations measured within the companion sample debris, it is estimated that the decay heat within the debris at 224 minutes after shutdown is $0.18 \mathrm{~W} / \mathrm{g}$ of $\mathrm{U}$, and at 600 minutes after shutdown, it is $0.14 \mathrm{~W} / \mathrm{g}$ of $\mathrm{U}$. After conversion of these data to the known debris composition, the decay heat present is $0.13 \mathrm{~W} / \mathrm{g}$ of debris at 244 minutes and $0.096 \mathrm{~W} / \mathrm{g}$ of debris at 600 minutes.

\subsection{Summary and Conclusions}

Examinations were performed on samples from the hard, monolithic layer of debris near the lower head, which are referred to as companion samples. These examinations indicate that the companion samples were relatively homogeneous with relatively small variations in composition and density. The companion samples consisted primarily of previously molten $(\mathrm{U}, \mathrm{Zr}) \mathrm{O}_{2}$ ceramic melt. Small amounts of metallic melt $(<0.5 \%)$ were only observed in samples from the southwest quadrant.

The pores in some of the samples were interconnected and surrounded by microporosity and two-phase structures consisting of uranium-rich $(\mathrm{U}, \mathrm{Zr}) \mathrm{O}_{2}$ and zirconium-rich $(\mathrm{Zr}, \mathrm{U}) \mathrm{O}_{2}$. This interconnected porosity may result from gases percolating up through the melt, which suggests that the debris was molten while on the lower head and that it remained molten for a sufficient period of time to allow bubble coalescence. The presence of two-phase $(\mathrm{U}, \mathrm{Zr}) \mathrm{O}_{2}$ and $(\mathrm{Zr}, \mathrm{U}) \mathrm{O}_{2}$ structures in areas of some samples indicates that these specimens were not rapidly quenched. However, the incomplete phase transformation in these samples suggests that these specimens were not at high temperatures for an extended period of time. 
The microstructure observed in the samples indicated an overall composition that was uranium-rich $(\mathrm{U}, \mathrm{Zr}) \mathrm{O}_{2}$. Radiochemical analyses of the debris indicate that the debris was composed of about $70 \mathrm{wt} \% \mathrm{U}, 13.75 \mathrm{wt} \% \mathrm{Zr}$, and $13 \mathrm{wt} \% \mathrm{O}$. This composition accounts for about $97 \mathrm{wt} \%$ of the debris. The remaining constituents are the elemental constituents of stainless steel and Inconel core components that probably melted during the relocation of debris to the lower head.

The examinations indicate that much of the high-volatile radionuclide content had volatilized out of the debris, leaving primarily medium- and low-volatile components in the debris bed. Decay heat analyses were performed to determine the amount of heat present in the debris bed at the time of relocation (224 minutes after shutdown) and at 600 minutes after reactor shutdown. Calculation results indicate that the retained heat in the lower debris bed was about $0.13 \mathrm{~W} / \mathrm{g}$ of debris at 244 minutes after shutdown and $0.096 \mathrm{~W} / \mathrm{g}$ of debris at 600 minutes after shutdown.

\subsection{References}

1. D. W. Akers, S. M. Jensen, and B. K. Schuetz, Companion Sample Examinations, TMI V(92)EG10, OECD-NEA-TMI-2 Vessel Investigation Project, EG\&G Idaho, Inc., July 1992.

2. A. P. Kelsey, Lower Head Debris Topography, TMI-2 Technical Bulletin TB-89-02, GPU Nuclear Corporation, Project Planning and Analysis Department, Middletown, PA, February 27, 1989.

3. S. M. Jensen et al., Examination of the TMI-2 Core Distinct Components, GEND-INF-082, EG\&G Idaho, Inc., 1987.

4. D. W. Akers et al., TMI-2 Core Bore Examinations, GEND-INF-092, EG\&G Idaho, Inc., January 1990.

5. A. G. Croff, "ORIGEN2--A Revised and Updated Version of the Oak Ridge Isotope Generation and Depletion Code," ORNL-5621, Oak Ridge National Laboratory, July 1980.

6. B. G. Schnitzler and J. B. Briggs, TMI-2 Isotopic Inventory Calculations, EGG-PBS-6798, EG\&G Idaho, Inc., August 1985.

7. T. R. England and W. B. Wilson, TMI-2 Decay Power: LASL Fission Product and Actinide Decay Power Calculations for the President's Commission on the Accident at Three Mile Island, LA-8041-MS, Revised March 1980.

8. C. S. Olsen et al., Examinations of Debris from the Lower Head of the TMI-2 Reactor, GEND-INF-084, EG\&G Idaho, Inc., January 1988.

9. P. Hofmann et al., "Reactor Core Material Interactions at Very High Temperatures," Nuclear Technology, 87, No. 1, August 1989.

10. G. Bart, "TMI-2 Core Sample Evaluation at Paul Scherrer Institute," TMI-2 Examination Results from the OECD-CSNI Program, Vol. 2, EGG-OECD-9168, EG\&G Idaho, Inc., August 1990. 


\title{
6. EXAMINATION OF NOZZLES AND GUIDE TUBES
}

\author{
L. A. Neimark and T. L. Shearer, Argonne National Laboratory \\ D. W. Akers, Idaho National Engineering Laboratory
}

\subsection{Introduction}

Fourteen nozzles and two guide tubes (K-5 and M-10) were removed from the TMI-2 lower head. Six nozzles (in core locations M-9, L-6, H-5, H-8, D-10, and E-11) were examined at ANL, ${ }^{1}$ and eight nozzles (M-10, H-9, L-11, R-7, K-11, K-12, G-5, and E-7) and one guide tube (K-5) were examined at the INEL. In addition, samples from nozzles $\mathrm{E}-7, \mathrm{G}-5$, and $\mathrm{R}-7$ were examined in France at CEA-CEN Saclay. ${ }^{2}$ The nozzles were divided between the two United States laboratories so that both laboratories had comparable samples from all sections of the lower head. A detailed report that presents the results of the examinations has been prepared by ANL. ${ }^{1}$ Although information from the INEL and CEN examinations is also discussed in this section, the bulk of the information discussed in this summary is from the ANL examinations because problems at the INEL hotcell facility limited the scope of work completed there and because the CEA-CEN Saclay examinations were more limited in scope.

The general objectives of the nozzle and guide tube examinations were to determine the temperatures near the lower head; to determine the mechanisms, modes, and extent of nozzle degradation needed to evaluate the challenge to the lower head of the reactor pressure vessel; and to contribute to the understanding of the relocation scenario of fuel to the lower head. The specific objectives of the nozzle and guide tube examinations were the following:

- Determine the nature and extent (axial and radial) of fuel/debris ingress into the nozzles

- Evaluate the nature and degree of chemical and thermal interaction between fuel, debris, and nozzles

- Assess thermal-related metallurgical changes in the nozzle as a function of axial position to evaluate the axial temperature distribution and attempt to quantify temperatures near the vessel

- Determine the position and composition of debris adhering to nozzle surfaces to establish a debris bed depth.

To meet these objectives, a range of examinations was performed on selected nozzle samples to assess the damage to the nozzles and guide tubes. The results of these examinations were evaluated to provide information needed to assess the margin to failure of the reactor vessel. This section discusses the examination methodology, the examination results, and how the results relate to the damage to the reactor vessel and the development of the core relocation scenario. 


\subsection{Sample Preparation and Examination Methodology}

After the nozzle and guide tube samples were removed from the reactor vessel, they were shipped to the INEL for sorting. The nozzles were repackaged in individual containers and shipped to ANL. At each facility, unpacked nozzles were examined visually and photographed to identify notable areas of damage. Photographs were then taken of the entire external surface and of the bottom and top surfaces. In addition, some photographs were taken in stereo because of the complex, three-dimensional nature of the surface.

Following photography, each nozzle section was scanned using gamma spectrometry to assess the distribution of radionuclides present in the nozzle and to identify locations that might contain fuel material. Each nozzle was scanned longitudinally using a collimated intrinsic germanium detector system to assess the distribution of radionuclides along the length of the nozzles. At both laboratories, the distribution of cesium-137 activity was measured because this activity would be expected to be representative of $\mathrm{UO}_{2}$ fuel present in the nozzles. In addition, both cobalt-60 and gross activity profiles were measured at the INEL. The cobalt-60 measurements were performed to assess the location of activated metals that may have been relocated from the reactor core to the lower head.

The locations on each nozzle to be sectioned for further destructive analysis were established based on a combination of the following criteria:

- Top and bottom locations to obtain information on the hottest (sometimes molten) and coldest (nearest the vessel) temperature extremes in a nozzle

- Fuel/nozzle interaction areas (nozzle degradation mechanism)

- Indications from gamma scans of fuel penetration into the nozzle

- Obvious locations of surface layers on a nozzle

- Locations of surface cracking (nozzle degradation mechanism).

After the nozzle sectioning diagrams were developed based on the above criteria, the nozzle segments at ANL were placed in tubes and were vacuum-impregnated with cold-setting epoxy resin. This was done to stabilize loose surface debris, fragile solidified masses, and internal components. Additional vacuum-impregnation was performed at all laboratories during sectioning if significant voids were found and if there was a possibility of material fallout. After the metallographic specimens were sectioned, they were placed in pre-formed Bakelite or other mounts, vacuum-impregnated with epoxy resin, and polished.

After the samples were prepared, microhardness was measured across the face of the mounts. This measurement was performed to assess accident-related thermal effects on the metallurgical characteristics of nozzles and to identify locations for further examination. Usually, five to ten measurements were made from the nozzle surface inward. Hardness measurements that were affected by the surface or internal voids were rejected. Although a surface hardening or a subsequent softening that was attributed to accident-induced annealing could be discerned in some measurement profiles, for purposes of this determination, the population was averaged and 
a standard deviation was reported. This data treatment appears to be adequate to identify qualitative trends in the axial temperature distributions of the nozzles and to provide some insight into quantitative temperatures when compared to limited data from Korth. ${ }^{3}$ Some very low measured values proved to be from areas that were either once molten, had been involved in liquid-metal attack, or were depleted in chromium and thus no longer Inconel 600 . These low values are not representative of a metallurgical state of the Inconel 600 that could be used as a temperature indicator.

Other primary analysis techniques were optical metallography and scanning electron microscopy (SEM) with energy dispersive $x$-ray spectroscopy (EDS) or wavelength dispersive $x$-ray spectroscopy (WDS) analyses. The optical metallography analyses were performed to assess the microstructure of the fuel debris and of the damaged nozzles. The SEM analyses were performed to assess the distribution of elements and the composition of the different phases formed by the interaction of the fuel debris with the nozzle and guide tube material. All SEM/EDS work was performed at ANL with the exception of the analysis of some samples of debris from the surface of INEL nozzles.

\subsection{Examination Results}

Figure 6-1 illustrates the locations of instrument nozzles in the TMI-2 lower head. The six nozzles examined at ANL were from core locations D-10, E-11, H-5, H-8, L-6, and M-9. The nozzles examined at the INEL were from core locations E-7, G-5, M-10, H-9, K-11, K-12, L-11, and R-7. In addition, a guide tube from location K-5 was examined at the INEL. Nozzle samples from locations E-7, G-5, and R-7 were examined at CEA-CEN Saclay. The damage to these nozzles provides a representative sample of the damage that occurred to all nozzles removed from the vessel. Also indicated in Figure 6-1 are nozzles E-9, F-7, F-8, and G-6. These nozzles were so severely damaged that only stubs remained, which were too short to be removed from the vessel. Figure 6-2 shows the typical configuration of nozzles.

Two sample elevations are used in this report, where appropriate, to describe the extent of damage to individual nozzles with reference to the lower head. The primary sample elevation is the distance from the base of the nozzle, which was not usually the elevation cut off during removal from the vessel. The second elevation is the vertical distance from the base of the lowest vessel location (H-8) to the base of the nozzle in question. Figure 6-3 shows the relationship of these reference elevations. The severing of the nozzles from the vessel usually left a stub attached to the vessel. The height of this stub for the ANL nozzles was determined either from the nozzle's companion boat sample that was processed at ANL or from knowledge of the nozzle's dimensions, as shown in Figure 6-2. For nozzles L-6 and M-9, there were no companion boat samples, and the latter method was used. Thus, the reported sample elevation for a given nozzle is the height of the residual stub plus the distance on the nozzle from the cut-off end to the particular elevation. The secondary elevation is the primary elevation plus the elevation from the low-point reference $(\mathrm{H}-8)$ to the base of the particular nozzle.

Tables 6-1 and 6-2 show a summary of data from ANL and INEL, respectively, on the damage to each nozzle, nozzle segment lengths, and relevant elevations. Also tabulated in Tables 6-1 and 6-2 are the fuel penetration distances into each nozzle, as determined by the cesium-137 axial activity profile. The data are provided as the elevation of fuel material above the base of the nozzle. Maximum and minimum values are given for nozzles for which it could 


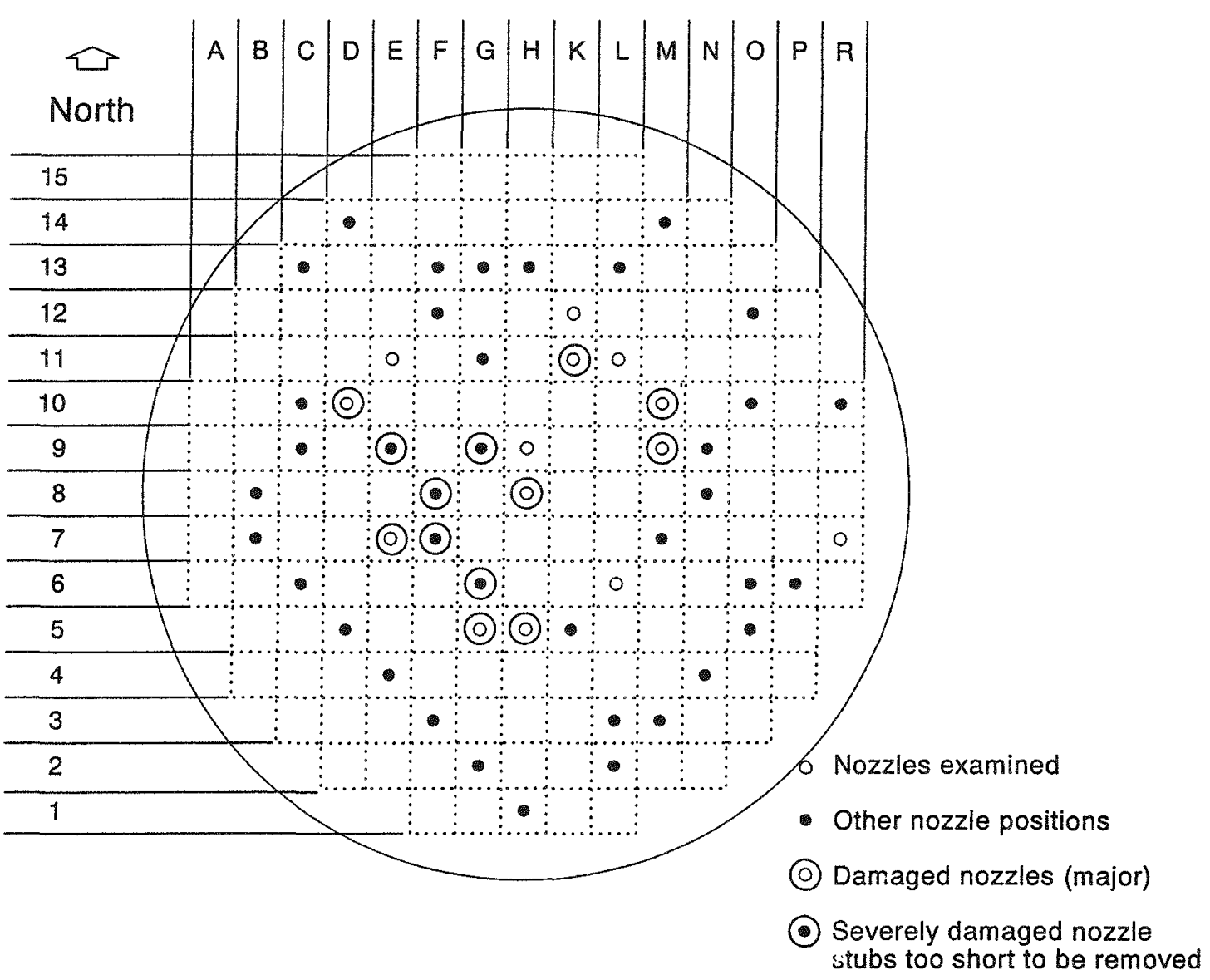

Figure 6-1. Grid map of TMI-2 core showing locations of nozzles examined. 


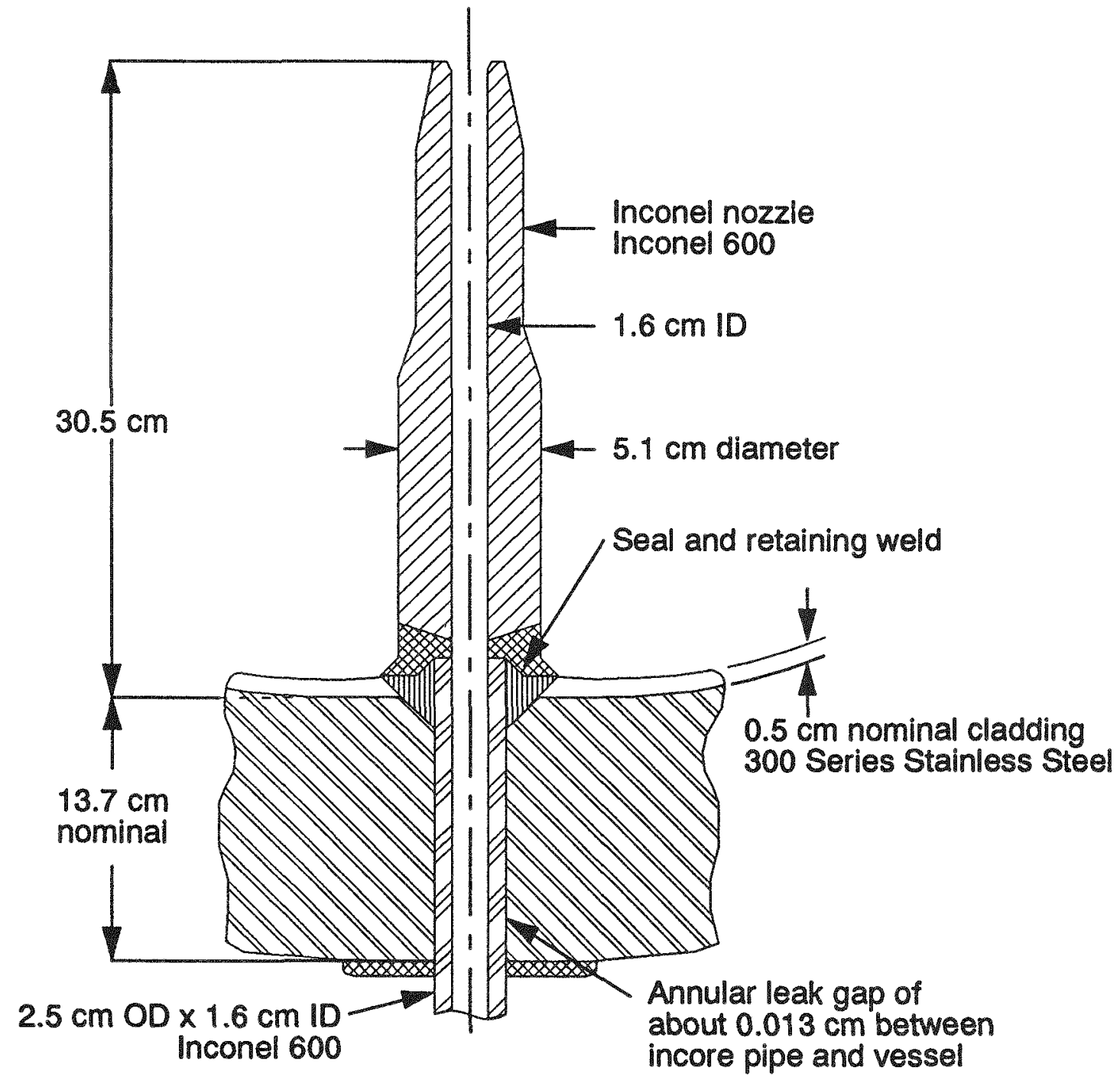

MO30WHT-393-02

Figure 6-2. Typical incore nozzle with seal and retaining weld. 


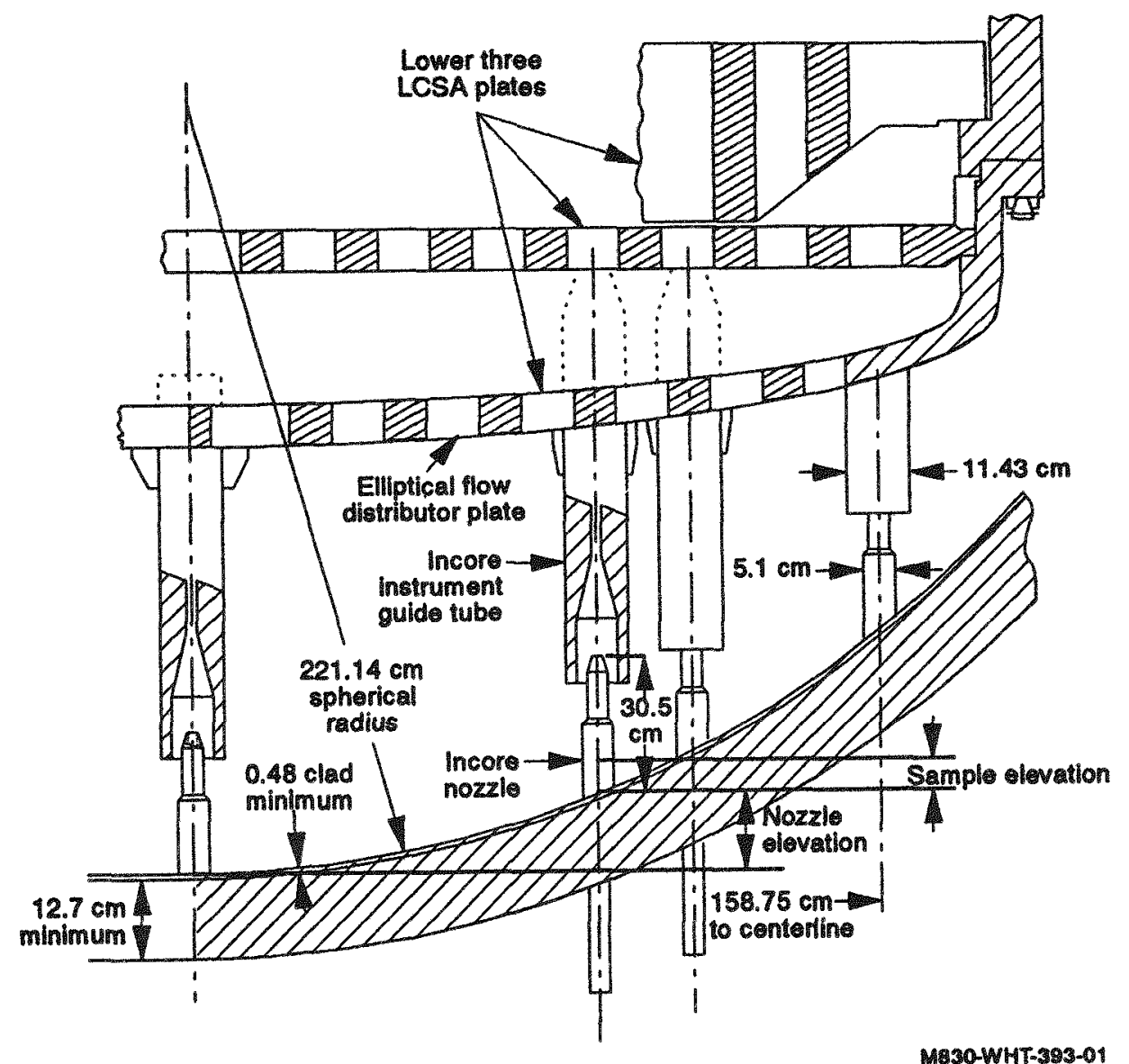

Figure 6-3. Lower head area and incore instrument guide tubes.

not be absolutely concluded that the cesium-137 activity was inside and not on the surface of the nozzle. Gamma-activity profiles were used instead of visual observation of ceramic material in the nozzle cavity because of the possibility that the ceramic material could be a nozzle oxidation product instead of fuel.

Because of the extensive amount of information available from the nozzle and guide tube examinations, only photographs of representative nozzles are shown and discussed in this report. The nozzle photographs being presented are from R-7, M-9, K-11, and E-7 (Figures 6-4 through 6-7) and are ordered from the least damage to the most. An example of an undamaged nozzle is not shown. The K-5 guide tube sample is shown in Figure 6-8.

Figure 6-4 shows the R-7 nozzle where little or no damage occurred to the nozzle; however, the instrument string was melted off and a bulb of previously molten fuel was found attached to the instrument string. The visual examination of the R-7 nozzle shows little damage except for the top edge. The gamma spectroscopy scan results for this sample showed a high activity region near the top of the nozzle; however, the probing examinations indicated that there were no blockages in the nozzle. As a consequence, only the bulb on the instrument string and the top of the nozzle were sectioned for examination. The top bulb proved to be composed of uranium, 
Table 6-1. ANL nozzle segment lengths, elevations, and fuel penetration depths.

\begin{tabular}{|c|c|c|c|c|c|c|c|}
\hline Nozzle & $\begin{array}{l}\text { Elevation of } \\
\text { nozzle base } \\
(\mathrm{mm})\end{array}$ & $\begin{array}{l}\text { Segment length } \\
(\mathrm{mm})\end{array}$ & $\begin{array}{l}\text { Stub length } \\
\quad(\mathrm{mm})\end{array}$ & $\begin{array}{l}\text { Missing top }{ }^{a} \\
\quad(\mathrm{~mm})\end{array}$ & $\begin{array}{l}\text { Elevation of } \\
\text { top of segment }{ }^{b} \\
(\mathrm{~mm})\end{array}$ & $\begin{array}{l}\text { Fuel penetration elevation } \\
\text { above nozzle base } \\
(\mathrm{mm})\end{array}$ & Condition of nozzle \\
\hline M-9 & 119 & 254 & $26^{\mathrm{d}}$ & 25 & 280 & 241 & Top melted off \\
\hline L-6 & 94 & 241 & $64^{\mathrm{d}}$ & 0 & 305 & 75 & Excellent \\
\hline $\mathrm{H}-5$ & 107 & 146 & 0 & 159 & 146 & $\begin{array}{l}89 \max \\
117 \text { min }\end{array}$ & Top melted off \\
\hline $\mathrm{H}-8$ & 0 & 70 & 51 & 184 & 121 & $<64$ & $\begin{array}{l}\text { Ablated in middle; top } \\
\text { portion apparently } \\
\text { melted off }\end{array}$ \\
\hline D-10 & 244 & 235 & $57^{d}$ & 13 & 292 & $\begin{array}{l}55 \max \\
184 \min \end{array}$ & $\begin{array}{l}\text { Heavy debris crust on } \\
\text { one side; oval due to } \\
\text { internal pressurization }\end{array}$ \\
\hline E-11 & 221 & 225 & $77^{\mathrm{d}}$ & 3 & 302 & 204 & $\begin{array}{l}\text { Good, but top end } \\
\text { shows surface melting }\end{array}$ \\
\hline
\end{tabular}

a. Based on measurement from either top taper point or midplane bevel.

b. Referenced to nozzle base.

c. Based only on gamma scans.

d. Calculated as the difference between $305 \mathrm{~mm}$ and the sum of the two known values. Measurements of stub lengths for D-10 and E-11 from photographs were not deemed sufficiently accurate because of the angle of the photos. 
Table 6-2. INEL nozzle segment lengths, elevations, and fuel penetration depths.

\begin{tabular}{cccccccc}
\hline Nozzle & $\begin{array}{c}\text { Elevation of } \\
\text { nozzle base } \\
(\mathrm{mm})\end{array}$ & $\begin{array}{c}\text { Segment length } \\
(\mathrm{mm})\end{array}$ & $\begin{array}{c}\text { Stub length } \\
(\mathrm{mm})\end{array}$ & $\begin{array}{c}\text { Missing top } \\
(\mathrm{mm})\end{array}$ & $\begin{array}{c}\text { Elevation of } \\
\text { top of segment } \\
(\mathrm{mm})\end{array}$ & $\begin{array}{c}\text { Fuel penetration } \\
\text { elevation above cut end } \\
(\mathrm{mm})\end{array}$ & $\begin{array}{c}\text { Short stub extending } \\
\text { Condition of nozzle }\end{array}$ \\
\hline E-7 & $\begin{array}{c}\text { Not available } \\
(\mathrm{NA})\end{array}$ & $\begin{array}{c}12.7-15.9 \\
\text { variable }\end{array}$ & NA & $>203.4$ & $<101.6$ & No blockage & Strom vessel \\
G-5 & NA & 44.5 & NA & $>152.6$ & $<152.4$ & Completely plugged & Stub extending from \\
vessel & No damage & No blockage & Ablated in middle; no \\
damage to top or \\
bottom
\end{tabular}




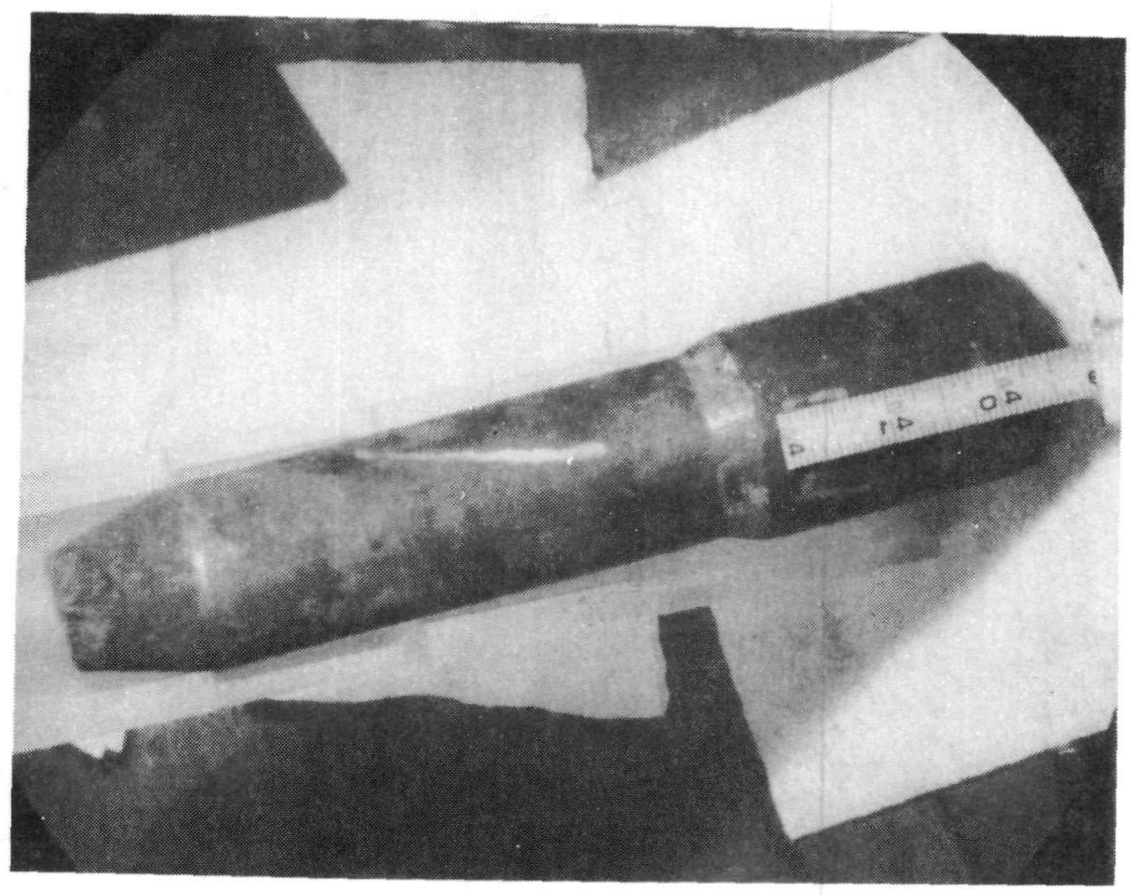

Figure 6-4. Full-length view of the R-7 nozzle. 

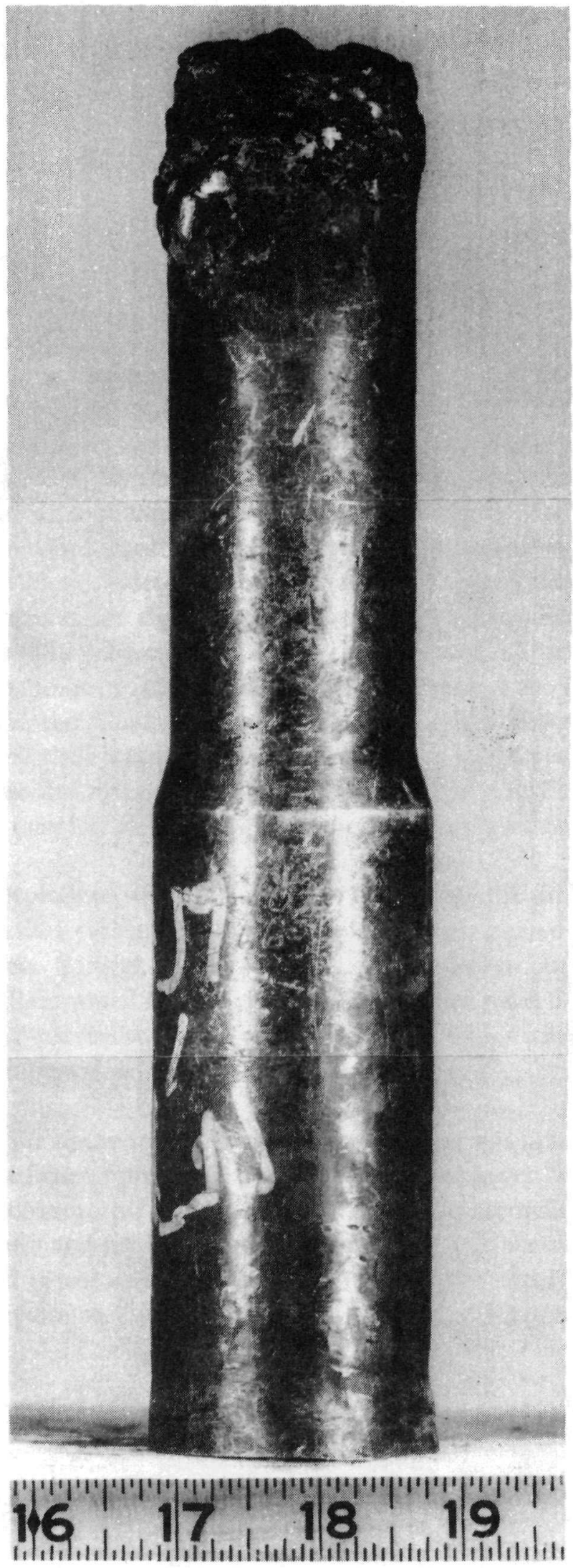

Figure 6-5. Elevation view of nozzle segment M-9. 


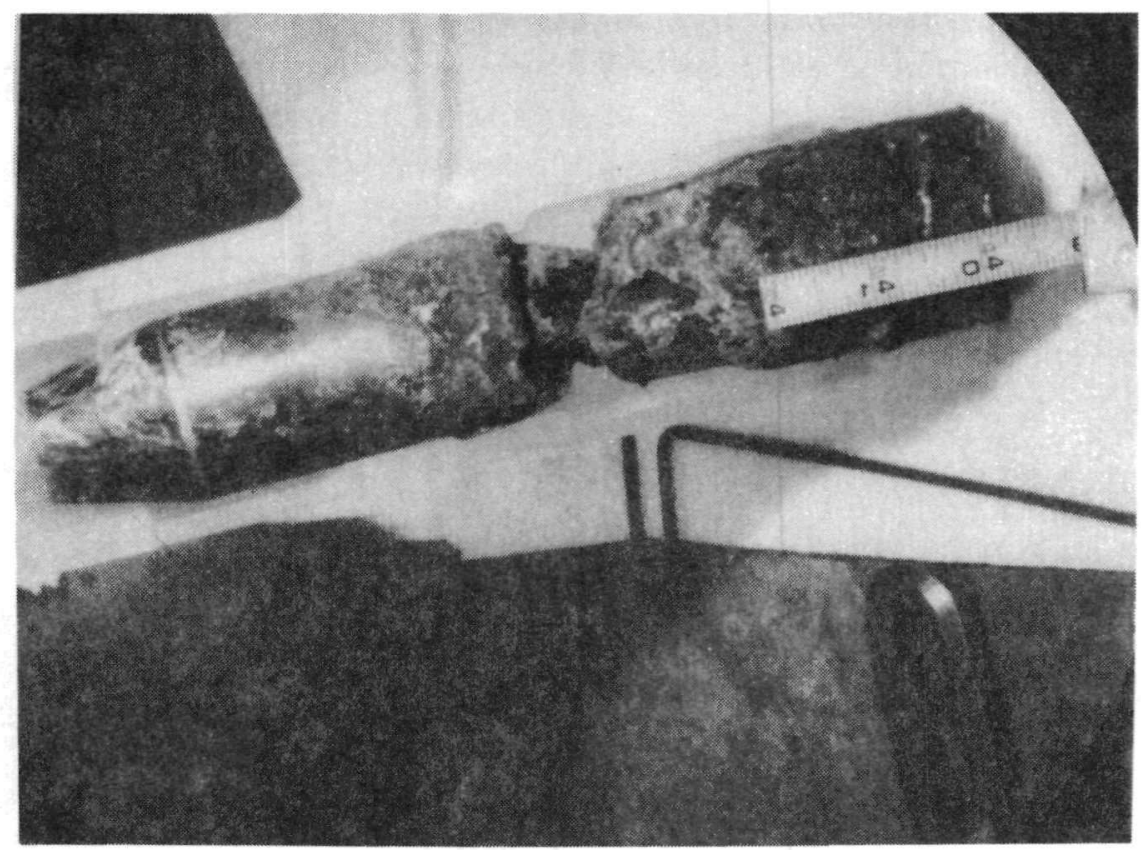

Figure 6-6. Full-length view of the K-11 nozzle.

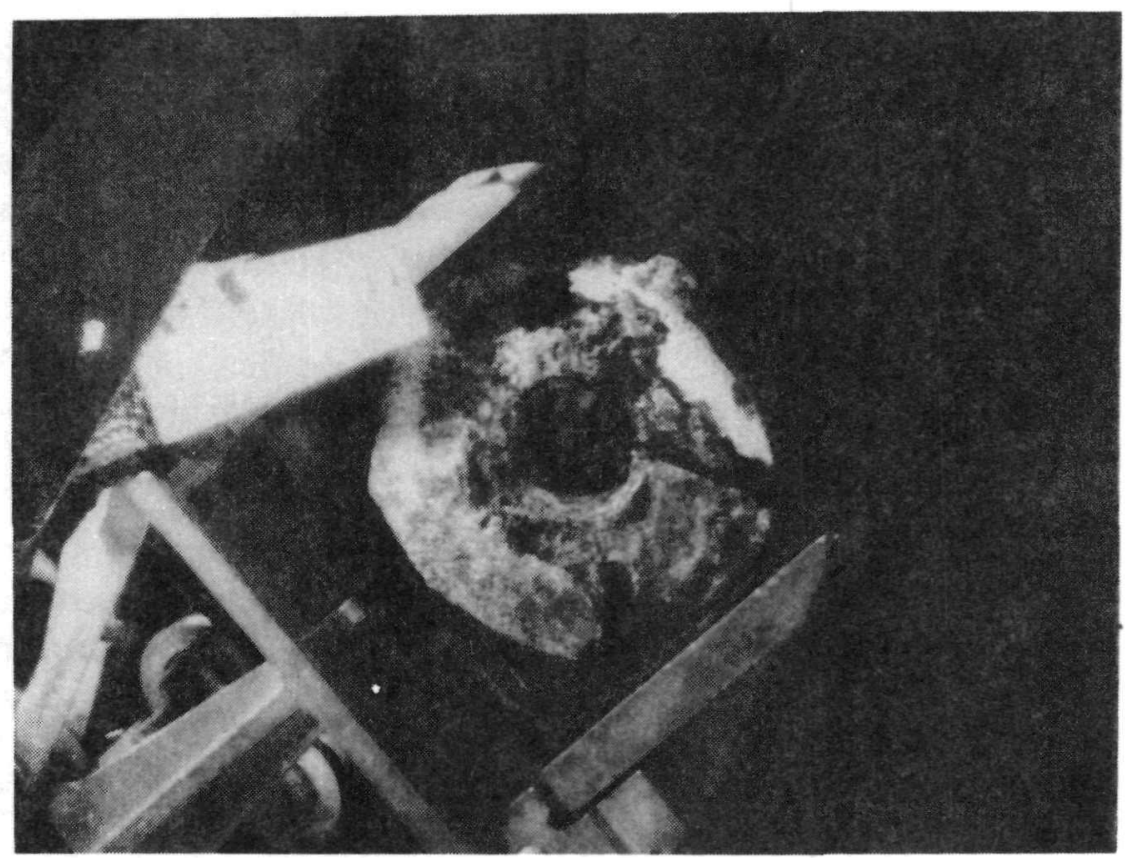

Figure 6-7. Top view of nozzle E-7. 


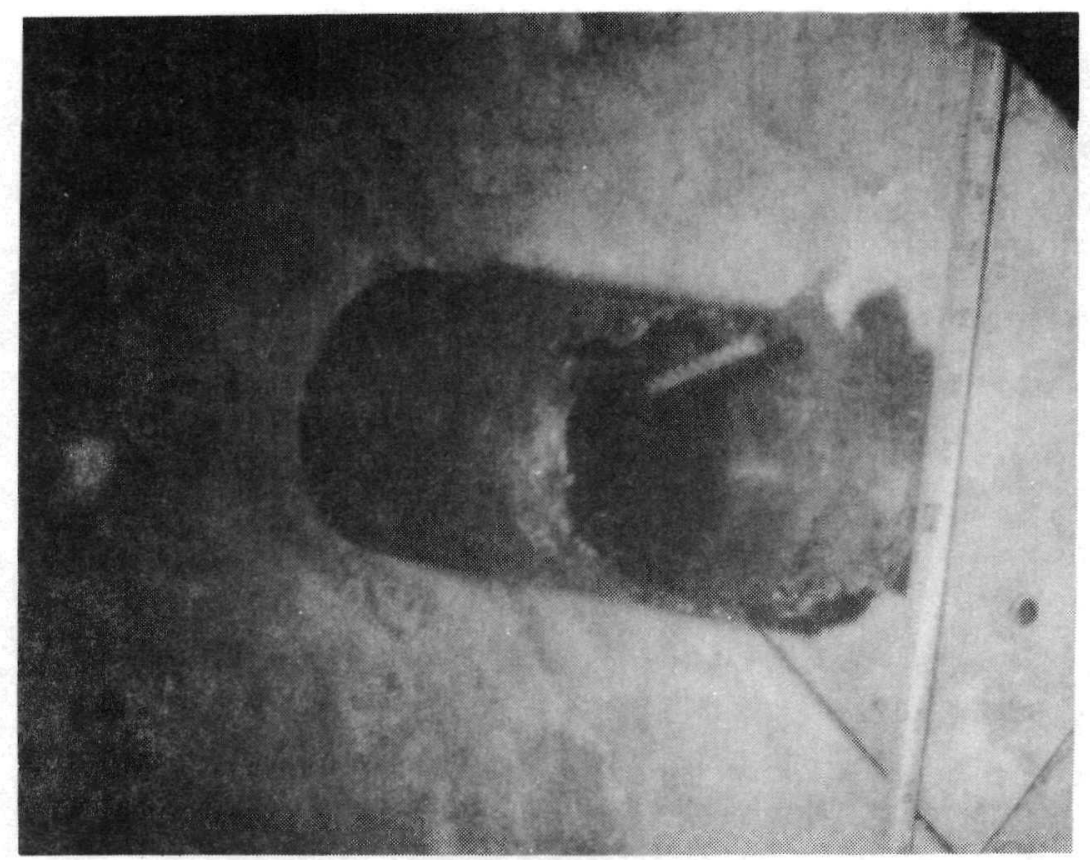

Figure 6-8. Segment of guide tube K-5.

zirconium, and iron-rich phases, which are probably representative of the first material that relocated to the lower head of the reactor vessel (because the R-7 location is where the molten fuel first reached the flow distributor). A quarter section of the bulb was sent to Saclay for examination.

The M-9 nozzle (Figure 6-5) shows the burned-off condition that was observed on the tops of many nozzles with no damage or discoloration at the base of the nozzle and some heat discoloration near the middle. The M-9 nozzle segment was $254 \mathrm{~mm}$ long. Based on a nominal as-fabricated nozzle length of $305 \mathrm{~mm}$ (where the centerline and the slope of base were not considered), a 26-mm stub remained on the vessel after severance. The top $25 \mathrm{~mm}$ of the nozzle had been melted off, and the next $25 \mathrm{~mm}$ show signs of melting, including the initiation of candling. The $25-50 \mathrm{~mm}$ below the melted area appeared to be lightly scaled, whereas the remainder of the nozzle was bright and shiny. As-fabricated vibra-tooled lettering was apparent just below the midplane.

Examination of the M-9 nozzle indicated that the top was totally sealed with molten material, whereas the bottom had no material in the annulus between the instrument string and the nozzle; however, there appeared to be material in the central tube of the instrument string. Melting of the nozzle was restricted to the top $25 \mathrm{~mm}$, but the instrument tube showed signs of melting below that elevation. Vertically oriented voids in the molten nozzle were also found in other once-molten nozzles. The voids are believed to be the result of solidification phenomena, in which spherical voids interlink in a vertical array and surface tension causes the horizontal ligaments to contract and disappear and thus form a continuous longitudinal void. The spherical bubbles, which were closer to the nozzle centerline, would be indicative of rapid cooling, whereas 
the longitudinal bubbles outward from the center would be indicative of a somewhat slower cooling rate. The detailed examination results for this nozzle are discussed in Reference 1.

Figure 6-6 shows the $\mathrm{K}-11$ nozzle and the extensive unique damage to the middle portion of the nozzle (primarily on one side), including a breach through the nozzle wall, with lesser damage to the top and bottom of the nozzle. Measurements of the nozzle length indicated that it was approximately $235 \mathrm{~mm}$ in length. The major damage region extends $-19 \mathrm{~mm}$ from the bottom end to within $76 \mathrm{~mm}$ of the top of the nozzle. Gamma spectroscopy analysis of $\mathrm{K}-11$ indicated the presence of high activity material (e.g., fuel) at locations above the bottom of the nozzle. The fuel locations were $20-63 \mathrm{~mm}, 70-100 \mathrm{~mm}$, and $200-230 \mathrm{~mm}$. Fuel penetration through most of the nozzle is suggested. A probe of the nozzle was performed from both the top and the bottom. Both probes were able to penetrate to the breach near the center of the nozzle.

The E-7 nozzle is shown in Figure 6-7 and is typical of the nozzles that were most extensively damaged. Very little of the E-7 nozzle remained after being removed from the lower head. The length of the nozzle stub is 13 to $16 \mathrm{~mm}$. Gamma spectroscopy was not performed on this nozzle, as it was not deemed necessary for determining sectioning locations. One section of this nozzle was sent to Saclay for examination.

Examination of the K-5 guide tube shown in Figure 6-8 reveals substantial damage to the lower end of the tube. The damaged edges created by melt interaction are misshapen and are slightly twisted outward. The original diameter of the guide tube was about $117 \mathrm{~mm}$. The length of the guide tube on the longest side was $238 \mathrm{~mm}$; on the shortest side, it was determined to be only $149 \mathrm{~mm}$ long. The K-5 guide tube was not gamma scanned or probed because the sample section locations could be determined from visual examination of the guide tube section.

The very bottom of the guide tube was cut transversely, approximately $19 \mathrm{~mm}$ from the bottom of the segment. It was very difficult to section this sample, and MPR Associates, Inc. had indicated that the damaged guide tube material was much harder to cut than the as-fabricated stainless steel. The cause of this hardening is not known because the steel guide tube material, which is nominally single-phase austenitic stainless steel, cannot be hardened by heat treatment.

All of the nozzle or guide samples obtained were subjected to a series of optical and SEM EDS/WDS examinations. Some of the key results of these examinations are listed below:

- The nature of the degradation or melt damage of nozzles G-5, H-5, H-8, M-9, and M-10 indicate that their melt-off was by liquid fuel coming at the nozzles at an elevation ranging from -140 to $270 \mathrm{~mm}$ above the lower head. Surface scale on the nozzles below the melt-offs suggests that the liquid was on top a crust of solidified and partially solidified fuel debris that had been cooled below its solidus by contact with the lower head.

- The fuel debris in and on nozzles D-10 and E-11, which were minimally damaged (i.e., a minor crack at D-10 and minor melting at the top of $\mathrm{E}-11$ ), suggest that these nozzles were at the periphery of the fuel flow, likely on the cooler far side. 
- The pattern of nozzle degradation suggests a fuel flow direction that is consistent with a vessel hot spot at locations E-7-8/F-7-8, which was caused by hot liquid fuel on top of a progressively thinner crust because of decreasing heat transfer to a warming vessel.

- Significant nozzle temperatures ranged from $1,400^{\circ} \mathrm{C}$ (melting) at $140 \mathrm{~mm}$ from the vessel at $\mathrm{H}-5$ (damaged similar to $\mathrm{M}-9$ ), down to $\sim 1,000^{\circ} \mathrm{C}$ (as estimated from materials interation data) at $64 \mathrm{~mm}$ from the vessel at H-8 (also damaged similar to M-9). These temperatures were estimated based on observed material interactions.

- In addition to melting, nozzle degradation mechanisms were ablation by liquid $\mathrm{Zr}$, intergranular penetration by $\mathrm{Zr}$ and $\mathrm{Ag}-\mathrm{Cd}$, chemical interaction with $\mathrm{Al}, \mathrm{Cr}$-depletion caused by extensive oxidation, and internal pressurization causing hot-tearing and nozzle ballooning.

- The presence of significant quantities of $\mathrm{Zr}$ and $\mathrm{Ag}-\mathrm{Cd}$ on the vessel to interact with the nozzles is attributed to the prior deposition at that location of control assembly debris. The depth or nature of such a debris bed could not be confirmed, but the depth is estimated to have been a minimum of $120 \mathrm{~mm}$ at location H-8.

- Fuel debris penetration downward into the nozzles was influenced by the temperature of the fuel at the time of entry, its composition (and hence fluidity), the temperature of the nozzle and its ability to solidify the debris, and the degree of interaction between the fuel and the molten nozzle in entrapping the fuel in $\mathrm{Cr}$-oxide.

\subsection{Discussion}

An assessment of the examination results is presented in this section to provide information that may be used to better understand the relocation event and the margin to failure of the lower head. The following sections discuss the nature of the nozzle damage, the presence of control materials on some samples, nozzle temperature indicators, and the penetration of material into certain nozzles. The results are applicable to the development of the relocation scenario in Section 8 .

\subsubsection{Nature of Nozzle Damage}

The nozzle segments examined fall into essentially two categories: (a) nozzles destructively affected by molten fuel (E-7, G-5, H-5, H-8, K-11, M-9, and M-10), and (b) nozzles thermally affected by fuel debris but outwardly exhibiting little damage (E-11, H-9, K-12, L-6, L-11, and R-7). Nozzle D-10 falls into a middle category that, depending upon interpretation, exhibits both molten fuel effects and thermal damage.

The tops of nozzles H-5 and M-9 were destroyed directly by molten fuel. ${ }^{1}$ The intimate mixing of molten fuel-bearing particles with molten nozzle and instrument string materials is evidence for this conclusion. Only the lower $170 \mathrm{~mm}$ of the remaining $\mathrm{H}-8$ nozzle was received at ANL, and it is not known why the nozzle was severed at the -170 -mm elevation during the accident. However, it may be assumed that the nozzle was melted off in a manner similar to that 
which occurred with nozzles M-9 and H-5, and apparently G-5. The finding of what appears to be porous fuel in the bottom of the H-5 segment supports this conclusion. Although nozzles $\mathrm{D}-10, \mathrm{E}-11$, and $\mathrm{M}-10$ did not melt off as dramatically as did nozzles E-7, G-5, H-5, H-8, and M-9, their tops did melt as evidenced by the metallic debris within the nozzles.

Nozzles L-6, H-5, D-10, and E-11 were found to be covered, in varying degrees, with an Fe(oxide) surface scale that ranged in thickness from a few microns (L-6) to $0.25 \mathrm{~mm}(\mathrm{D}-10)$. The thick crust patches on one side of D-10 are similar in nature (Fe-based), but these patches also contain an abundance of molten Inconel and $\mathrm{Cr}$-oxide, which makes them different in nature but not in source. What is probably a similar scale near the top of M-9 just beneath the melted portion was not examined. These Fe-based scales are different from the porous $\mathrm{Cr}$-based ceramic that was prevalent in the top of the nozzles that melted, $\mathrm{M}-9$ and $\mathrm{H}-5$ (and probably $\mathrm{H}-8$ ). The Fe-based scales are barely adherent to the nozzles and do not appear to have grown from the base metal. Because of its apparently non-nozzle nature, it is believed that the source of the Febased exterior scales and the Fe-based matrix in the top of $\mathbb{E}-11$ was the fuel flow that melted its way through stainless steel structure on the way to the lower head, regardless of its exact path. These Fe-based materials are generally located in temperature regimes that are between that of molten Inconel and that of the very clean nozzle surfaces at the cooler lower elevations. Apparently, chromium is not present in these scales because $\mathrm{Cr}$-oxides are very volatile above $1,000^{\circ} \mathrm{C}$ and would have migrated out of the debris during the movement to the lower head. In contrast, the Cr-oxide that formed at the tops of the nozzles when they were melted by molten fuel stayed in place, indicating very rapid cooling. (Rapid cooling of the molten nozzle tops is also evidenced by a general lack of rundown of fuel-bearing debris in most nozzles, with the noted exception of the exceptionally hot $\mathrm{H}-8$.) The bubbles formed in the remains of $\mathrm{Cr}$-depleted Inconel were likely caused by $\mathrm{Cr}$-oxide vapor, which apparently precipitated into the platelets found in the H-5 microstructure when the vapor could not vent to a free surface.

It was assumed that nozzle $\mathrm{H}-8$ was hour-glass shaped similar to $\mathrm{K}-11$. This may possible be explained by the finding of extensive surface interaction between a $\mathrm{Zr}$-rich phase and the bottom $170 \mathrm{~mm}$ of the nozzle that was received at ANL. The finding of this interaction, which included $\mathrm{Ag}$-Cd inclusions, was a key in concluding that a layer of essentially control assembly material was present on the lower head when the major fuel relocation occurred.

The appearance of the D-10 nozzle surface and the top of R-7 (rough, craggy, and crusty) may be contrasted to the comparatively smoother surface of the necked-down region of H-8 (similar to M-9). Nozzle D-10 was in contact principally with hot fuel at temperatures sufficient to possibly have caused melting on one side. Nozzle H-8, on the other hand, was in contact with $\mathrm{Zr}$, which has a eutectic with $\mathrm{Ni}$ at $961^{\circ} \mathrm{C}$. This lower temperature for liquefaction of $\mathrm{H}-8$ likely caused the severe necking down and smoothing of the surface compared to D-10. An estimate of the minimum depth of the $\mathrm{Zr}$-containing debris on the surface before the fuel flow re-melted would be $\sim 120 \mathrm{~mm}$, the height of the bottom portion of the nozzle segment. A maximum height might be an additional $50 \mathrm{~mm}$, if the ablation was truly hour-glass shaped.

\subsubsection{Presence of Control Assembly Materials}

Four of the six nozzle segments examined at ANL (M-9, L-6, H-5, and H-8) were under control rod assemblies. One, D-10, was beneath an axial power shaping rod that contained 
$914 \mathrm{~mm}$ of $\mathrm{Ag}-\mathrm{In}-\mathrm{Cd}$ clad in stainless steel. The last nozzle, H-5, was beneath a burnable poison rod that contained $\mathrm{Al}_{2} \mathrm{O}_{3}-\mathrm{B}_{4} \mathrm{C}$ pellets clad in Zircaloy. The ANL examinations show that the assemblies containing $\mathrm{Ag}-\mathrm{In}-\mathrm{Cd}$ failed relatively early during the accident and that the debris from these assemblies deposited in some form, probably as solid particulates, on the lower head before the principal fuel flow occurred at 224 minutes.

There is no direct, unequivocal evidence that the postulated control rod debris bed existed on the lower head. Examination of companion material ${ }^{4}$ found no such evidence, either because the sampling of the hard layer of debris in the lower head was random and not site-specific, or because the analytical techniques were too gross to identify what would be a small percentage of the fuel debris. Most, if not all, of such a control rod debris bed would have re-melted when it came in contact with even the basal crust of the fuel flow; possibly, it would have been consumed into it. Therefore, evidence for such a bed would now be, at best, on a microscopic scale.

However, the amount of In found in the companion material is disproportionately high compared with the $\mathrm{Fe}, \mathrm{Ni}$, and $\mathrm{Cr}$ contents (see Table 5-5).

The first evidence that the control materials were on the lower head before the fuel flow arrived was the finding of $\mathrm{Ag}-\mathrm{Cd}$ nodules and $\mathrm{In}-\mathrm{Fe}-\mathrm{Ni}-\mathrm{Zr}$ phases solidified in situ in the vessel cladding cracks in the E-6 and G-8 boat samples. The only fuel present in the cracks was apparently adventitious shards that likely fell in during defueling. Had there not been a control rod debris layer present when the fuel flow occurred, there would be no reasonable explanation for this finding. These materials would not have segregated in that manner from the partially solidified fuel flow.

The overwhelmingly $\mathrm{Zr}$-rich liquid that contained $\mathrm{Ag}-\mathrm{Cd}$ masses and ablated the $\mathrm{H}-8$ nozzle is further evidence for the presence of the control rod debris bed. The $\mathrm{Zr}$ : $\mathrm{U}$ ratio of $\sim 8.5: 1$ was far in excess of the $\mathrm{Zr}: \mathrm{U}$ ratios found in fuel masses that were analyzed. This excess of $\mathrm{Zr}$ would be from the Zircaloy shroud tubes in the control assemblies. The minimum depth of this $\mathrm{Zr}$ containing debris bed was $\sim 120 \mathrm{~mm}$.

The findings of $\mathrm{Ag}$ and $\mathrm{Ag}-\mathrm{Cd}$ inclusions deep beneath the surfaces in most of the nozzles in a form of liquid metal penetration indicates that either there was a layer of control materials adhering to the surface and ready to be melted when contacted by the hot fuel, or there was a thick debris bed up against the nozzle that would yield the same result. That liquid $\mathrm{Ag}-\mathrm{Cd} \mathrm{had}$ penetrated the Inconel nozzles somewhat before nozzle melting occurred is evidenced by the apparently vapor-pressure-derived bubbles in the Inconel that contained $\mathrm{Ag}-\mathrm{Cd}$ and other core debris constituents.

Perhaps the most striking evidence for the superposition of $\mathrm{Ag}-\mathrm{Cd}$ beneath fuel debris is shown in Figure 6-9, where 10- $\mu \mathrm{m}$ particles of $\mathrm{Ag}-\mathrm{Cd}$ are beneath a fuel debris scale on nozzle E-11. The ANL findings for $\mathrm{H}-5$, which was not beneath a control or axial power shaping rod, showed some Ag-Cd in molten masses but only minimally on exterior surfaces and none in the Inconel. The material in the cracks in the boat samples and the $\mathrm{Zr}$ attack of nozzle $\mathrm{H}-8$ is sufficient evidence to conclude that there was a stagnant control material debris bed of some, unfortunately, undetermined depth and breadth. 


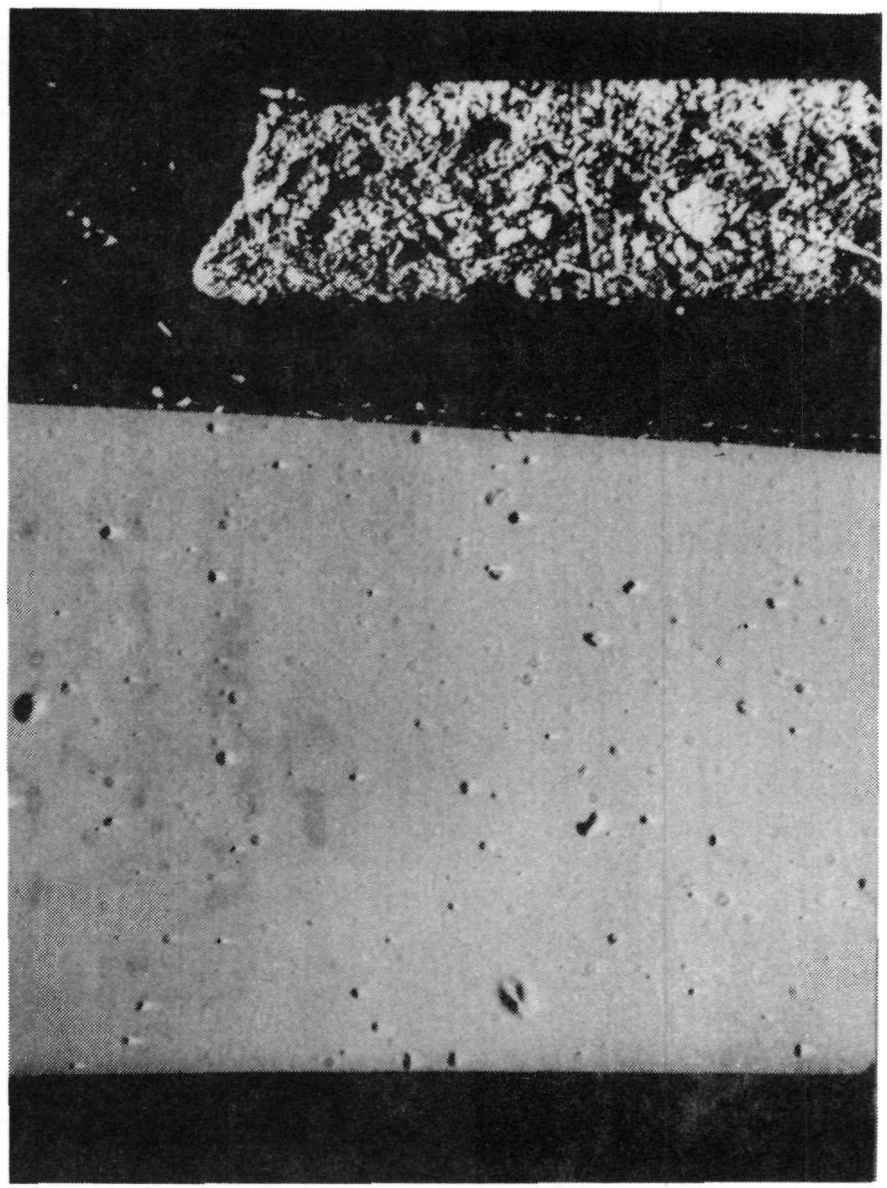

Figure 6-9. SEM-BSE image of scales. White dots along the $10-\mu \mathrm{m}$ inner scale are $\mathrm{Ag}-\mathrm{Cd}$ particles.

\subsubsection{Temperature Indicators}

A principal objective of the nozzle examinations was to provide quantitative data on the temperature of the nozzles in proximity to the vessel. This objective was satisfied only to a limited degree, mainly because of a lack of time-temperature annealing data for archival Inconel 600 . Gleeble tests performed by Korth ${ }^{2}$ on nonarchival Inconel 600 provides insight, but quantification using grain size and hardness data cannot be absolute. The following discussion is an attempt to glean some relative (if not quantitative) information from the ANL examinations.

6.4.3.1 Hardness Measurements. The microhardness measurements on the Inconel 600 nozzles are essentially in qualitative agreement with what was found by observation. The data from $\mathrm{Cr}$-depleted areas should be disregarded because the values do not represent Inconel 600 , only a Ni-Fe alloy of varying composition. Likewise, the value for the hardness of the top of E-11, which partially melted, is inexplicably high and should also be disregarded as not representative. It appears that the nominal hardness of the as-fabricated material is $\sim 200$ diamond pyramid hardness (DPH), considerably higher than the 155-160 DPH range for Korth's material. The most significant data are from $\mathrm{H}-8$, where the hardness $64 \mathrm{~mm}$ from the vessel was 
$133 \mathrm{DPH}$, a value that Korth's data indicate is achieved in 10 minutes at $\sim 1,000^{\circ} \mathrm{C}$. Following this line of reasoning, none of the other nozzles within $70 \mathrm{~mm}$ of the vessel achieved $1,000^{\circ} \mathrm{C}$. It is interesting to note that the $\mathrm{Zr}$ surface ablation of nozzle $\mathrm{H}-8$ would have begun at the $961^{\circ} \mathrm{C} \mathrm{Zr}$ Ni eutectic, a temperature well in keeping with the $1,000^{\circ} \mathrm{C}$ estimated from the hardness measurement.

6.4.3.2 Microstructure. The microstructures at the 77-mm elevation in L-6 and the 25-mm elevation in $\mathrm{H}-5$ show that active grain growth occurred. Korth's data indicate that a temperature of at least $950^{\circ} \mathrm{C}$ was reached. Because the grain size was so large in $\mathrm{H}-5(0.5 \mathrm{~mm})$, the temperature may have been higher, or the time at elevated temperature longer. Grain size and growth kinetics are highly dependent upon metallurgical history. Because Korth's material was not truly archival, this correlation should be viewed with skepticism, particularly because it does not agree with the hardness correlation.

6.4.3.3 Penetration by Ag-Cd. A Ag-Cd alloy with a nominal composition of $80 \mathrm{wt} \% \mathrm{Ag}$ and 20 wt\% $\mathrm{Cd}$, typical of the deposits found, melts at $-860^{\circ} \mathrm{C} ; \mathrm{Ag}$ melts at $960^{\circ} \mathrm{C}$. Liquid penetration occurred only in the upper elevations of the nozzles where such temperatures would be easily achieved. Lack of such penetration nearer the vessel suggests that either the nozzles did not achieve that temperature, save $\mathrm{H}-8$, or there was insufficient $\mathrm{Ag}$ or $\mathrm{Ag}-\mathrm{Cd}$ to penetrate.

6.4.3.4 Miscellaneous Indicators. Qualitatively, a good indicator of the axial temperature profile in a nozzle was the presence and then the relative adherence of the fuel debris scale on the outside nozzle surfaces. For all nozzles except L-6, which has no obvious external scale and apparently was not in a flow path, there is a reasonable correlation between scale location and nozzle hardness. On nozzle D-10, the scale was adherent at the $82-\mathrm{mm}$ elevation, which had a hardness of $161 \mathrm{DPH}$. That hardness is above Korth's breakpoint at $-1,000^{\circ} \mathrm{C}$, where Inconel apparently anneals rapidly and the hardness falls to $\sim 130 \mathrm{DPH}$ or below. With this correlation, it could be subjectively concluded again that only nozzle $\mathrm{H}-8 \mathrm{had}$ a high temperature near the vessel. The temperature of the other nozzles would have been less than $1,000^{\circ} \mathrm{C}$ below the following elevations:

$\begin{array}{ll} & 215 \mathrm{~mm}(\mathrm{M}-9) \\ - & 38 \mathrm{~mm}(\mathrm{H}-5) \\ - & 82 \mathrm{~mm}(\mathrm{D}-10) \\ - & 255 \mathrm{~mm}(\mathrm{E}-11) .\end{array}$

Deriving nozzle temperatures from the condition of the $\mathrm{Zr}$ instrument leads is considerably less direct than using any other indicator because the leads were insulated in $\mathrm{Al}_{2} \mathrm{O}_{3}$ and the radial heat transfer path to the nozzle is impossible to calculate. The observations on $\beta-10-\gamma$ transformations establish only a minimum threshold of $860^{\circ} \mathrm{C}$, which was likely achieved in most nozzles. The $1,200^{\circ} \mathrm{C}$ threshold temperature for the $\mathrm{Zr} / \mathrm{Al}_{2} \mathrm{O}_{3}$ redox reaction would be a good indicator except for the heat transfer issue. It is significant, however, that the 158 -mm elevation in D-10, where this reaction was obvious, is also the elevation where the hardness was the lowest for that nozzle, $124 \mathrm{DPH}$. 


\subsubsection{Penetration of Materials into Nozzles}

The penetration of gamma-active materials downward into the nozzles was estimated from the cesium-137 gamma activity profiles or was measured by probing the nozzle (Tables 6-1 and 6-2). It was assumed that the gamma activity was associated with fission products in fuel and, therefore, the results are reported as "fuel penetration." Metallic debris, essentially molten Inconel from the nozzle, was also found in the nozzles, but not tabulated. Their penetration may be estimated from the as-cut transverse sections of the nozzles. Although some of this debris contained small quantities of fuel, the quantities apparently were insufficient to register in the activity profiles.

Although porous, ceramic-appearing material was seen in the as-cut transverse sections at elevations below the nozzle tops, such as in H-8 and L-6, there seemed to be difficulty in retaining it during the subsequent sectioning operations to form metallographic mounts. This would attest to the friable nature of the material.

Fuel material that was retained at the lower elevations in most cases had two features. First, it appeared to be in the early stages of transformation to U-rich and Zr-rich phases, indicating relatively rapid cooling. Second, it contained $\mathrm{Fe}, \mathrm{Al}$, and $\mathrm{Cr}$ in the grain boundaries, indicating luidity significantly below $2,000^{\circ} \mathrm{C}$. That would aid the fuel's mobility to the elevation where it finally solidified.

In nozzles M-9 and H-5, which melted off, the penetration was shallow, indicating quick melting and relatively rapid cooling, the phase transformations in the fuel areas notwithstanding. It is likely that the melting point of $\mathrm{Cr}$-oxide $\left(\mathrm{Cr}_{2} \mathrm{O}_{3}\right.$ melts at $\left.1,990^{\circ} \mathrm{C}\right)$ dominated the mobility of this material before thermal equilibrium and lower-melting eutectics could form. The phase transformation of the fuel would have occurred below $1,990^{\circ} \mathrm{C}$ while the solidified fuel was trapped in the insulating Cr-oxide.

The fuel in the tops of D-10 and E-11 differed from that in M-9 and H-5 in that it was trapped in an Fe-based matrix rather than in a Cr-based matrix. This reflects two things. First, the Inconel did not readily give up its $\mathrm{Cr}$ to oxidation, probably because the temperature was too

low. Second, the source of the fuel and the Fe-based matrix was probably the same as that of the Fe-based surface scales. That many of the fuel particles were shards and not solidified in situ masses indicates that the fuel flow in this region of the vessel was cooler than the flow that contacted M-9, H-5, and H-8. This is consistent with a scenario that has the fuel flow coming to the vessel hot spot from the east and piling up on the far side against D-10 and E-11. (Note that the surface crust and major heating load was on only one side of D-10.)

\subsection{Conclusions}

Nozzles and guide tubes extracted from the TMI-2 lower head were examined at ANL, INEL, and CEA-CEN Saclay to provide information on their metallurgical state, on interactions with core debris that made its way to the lower head, and on penetration of the core debris into the nozzles. The objectives of the examinations were to determine the temperatures near the lower head; to determine the mechanisms, modes, and extent of nozzle degradation, which would 
help evaluate the challenge to the lower head containment boundary; and to contribute to the generation of a scenario for fuel movement on the lower head.

The results of the examinations indicate that some nozzles were melted off by interaction with molten core debris, whereas others were only thermally affected by contact with core debris, some of which attached itself to nozzle surfaces. The elevations at which the nozzles were melted off suggest that the molten core debris was on top of a crust of solidified material that generally insulated the reactor vessel from the hottest molten debris. The pattern of nozzle degradation was consistent with the location of a hot spot in the vessel at the E-7-8/F-7-8 location as determined by metallurgical examination of the vessel steel samples by others. Based on the severe damage to some nozzles and not to others in relatively close proximity, it can be concluded that the flow of material across the lower head was multi-directional and not unified. The finding of control assembly materials ( $\mathrm{Ag}, \mathrm{Cd}, \mathrm{In}, \mathrm{Zr}, \mathrm{Fe}$, and $\mathrm{Cr}$ without $\mathrm{U}$ ) in the nozzle material and on nozzle surfaces indicates that they were present on the lower head prior to the massive relocation of core debris 224 minutes into the accident.

\subsection{References}

1. L. A. Neimark et al., TMI-2 Instrument Nozzle Examinations at Argonne National Laboratory, TMI V(93)AL01, OECD-NEA-TMI-2 Vessel Investigation Project, February 1993.

2. M. Trotabas, M. Perrot, and P. Winter, "TMI-2 Instrument Nozzle and Guide Tube Examinations at Saclay," Presentation to the TMI-2 Project Review Group, Bethesda, MD, November 12-13, 1992, TMI V(92)FO01, OECD-NEA-TMI-2 Vessel Investigation Project, CEA/DRN/DMT 93/479.

3. G. Korth, Presentation to the Project Review Group, Idaho Falls, ID, May 12-13, 1992, TMI V(92)EG03, OECD-NEA-TMI-2 Vessel Investigation Project, EG\&G Idaho, Inc.

4. D. Akers, S. M. Jensen, and B. K. Schuetz, Companion Sample Examinations, EGG-OECD-9810, EG\&G Idaho, Inc., April 1992. 


\title{
7. MARGIN-TO-FAILURE ANALYSES
}

\author{
J. L. Rempe, L. A. Stickler, S. A. Chávez, \\ and G. L. Thinnes, Idaho National Engineering Laboratory \\ R. J. Witt, M. L. Corradini, and J. A. Kos, University of Wisconsin-Madison
}

As part of the TMI-2 VIP, a margin-to-failure analysis effort was performed to increase understanding of the events that occurred during the TMI-2 accident. Calculations were performed to consider four failure mechanisms: tube rupture, tube ejection, global vessel failure, and localized vessel failure. A flow diagram for the margin-to-failure analysis effort is shown in Figure 7-1. In this figure, the scoping calculations for failure mechanisms are shown in bold ellipses. Unshaded shapes in Figure 7-1 indicate which analyses were completed. Note that several analyses for evaluating phenomena, such as jet impingement, melt penetration distance, vessel thermal response, and weld failure were required as input to the failure analyses. As indicated by the shaded boxes in this figure, results from some of these preliminary analyses precluded the need for subsequent analyses. For example, results from melt penetration calculations indicate that molten fuel will not relocate through an instrument tube to locations below the outer surface of the lower head. Hence, reactor coolant system temperatures were applied in subsequent tube rupture analyses, rather than performing an ex-vessel tube temperature analysis.

As indicated in Figure 7-1, calculations relied on data from VIP nozzle, companion sample, and reactor vessel steel "boat sample" examinations. Examination data were used to quantify calculation input and to verify calculation output. As illustrated by margin-to-failure calculation results, companion sample data suggesting slow cooling of the debris were inconsistent with boat sample examination data that showed faster cooling rates. When results that were obtained from input primarily based on companion sample data indicated that vessel failure would occur, it was postulated that debris cooling (not indicated by companion sample data) needed to be modeled. An energy balance based on plant thermal-hydraulic parameters supported the hypothesis of this cooling during the period between debris relocation and vessel repressurization. Hence, calculations were performed to quantify the magnitude of this cooling and the debris configuration required to support this cooling.

The margin-to-failure calculations that were performed as part of the VIP are summarized in this section. Section 7.1 discusses sources of data that were input to the failure analyses and results from preliminary thermal analyses that were input to failure analyses. Possible failure modes of the pressure vessel are described in Section 7.2. Section 7.3 summarizes the results of the initial failure analyses. As discussed in Section 7.3, results from these initial failure analyses illustrate uncertainties in the ability of current models to predict debris behavior and vessel response during a severe accident. Two areas of uncertainty, the amount of cooling that occurred within the debris and the criteria used to predict vessel failure, were investigated with additional sensitivity studies. Section 7.4 summarizes results from these additional sensitivity studies. Major conclusions from the margin-to-failure calculations are summarized in Section 7.5. 


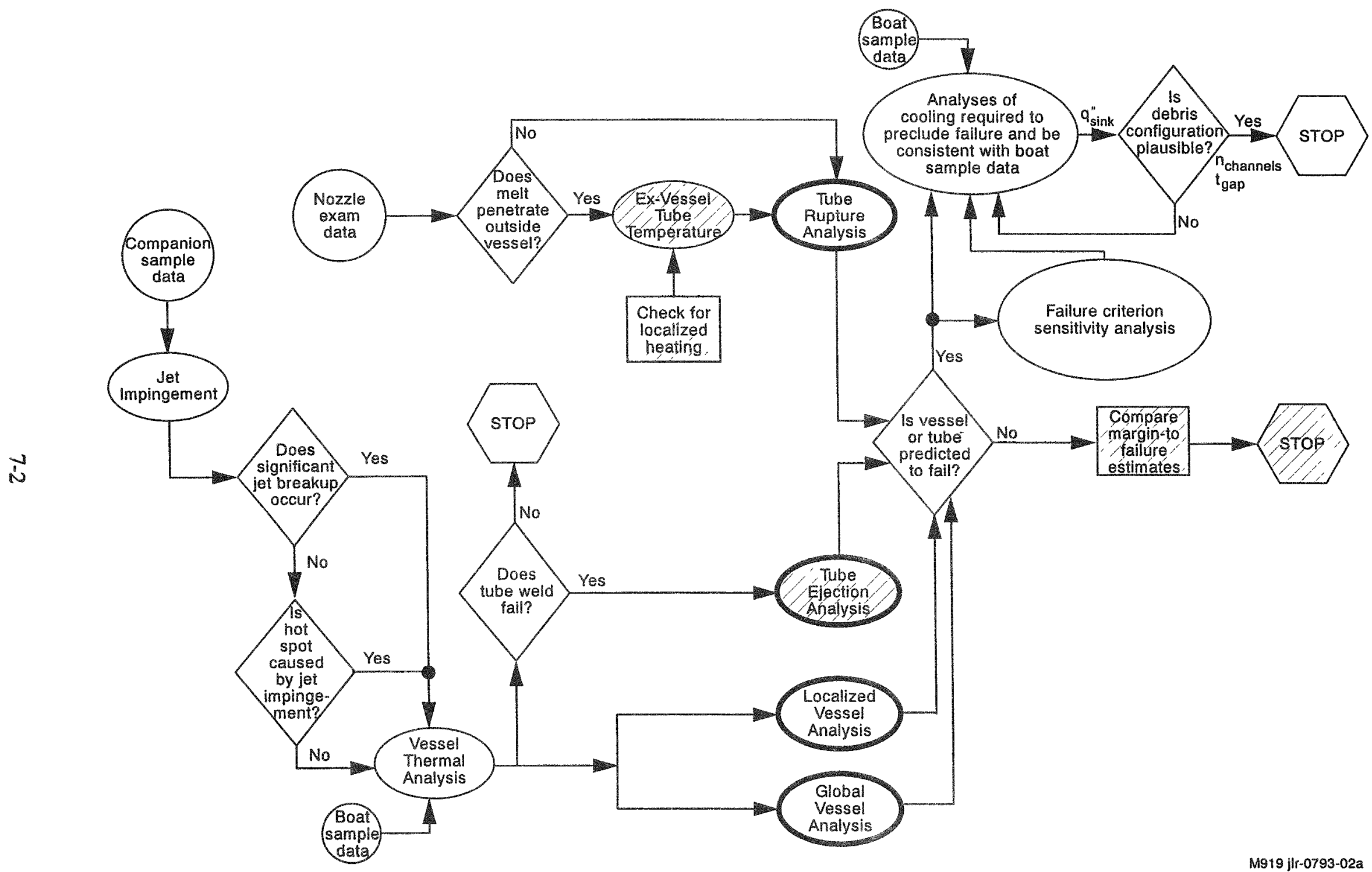

Figure 7-1. Flow diagram of margin-to-failure analyses. 


\subsection{Input for Margin-to-Failure Analyses}

Input data for the margin-to-failure analyses were obtained from various sources. Required data were obtained from plant instrumentation data recorded during the accident, previous TMI-2 examination data, TMI-2 VIP data, various material property data sources, and several preliminary calculations. Material properties used in these calculations are described in Reference 1. Other input data and the source of these data are summarized in this section.

\subsubsection{Instrumentation Data}

Several of the calculations required knowledge of pressure and representative temperatures within the reactor coolant system (RCS) during the accident. Several sources of on-line instrumentation recorded RCS pressure and representative temperatures during the TMI-2 accident. The time-dependent RCS pressure is shown in Figure 2-6 in Section 2. Figure 7-2 shows cold-leg temperatures measured in the $\mathrm{A}$ and $\mathrm{B}$ loops. In addition, margin-to-failure calculations utilized mass flow rates entering and exiting the vessel (letdown, power-operated relief valve flow, high-pressure injection, and makeup). These coolant flow rates and associated uncertainties were quantified using results from previous analyses of plant data. ${ }^{2-5}$

\subsubsection{Previous TMI Examinations}

The end state of the debris on the lower head provided background information for model selection and defining input parameters for margin-to-failure calculations. Clues about the debris end state were obtained from video inspections and wire probing efforts.

Video inspection and probing of the lower head allowed a contour map to be constructed of the debris resting on the lower head (see Figure 5-1). The debris material on the lower head consisted of a hard layer covered by a bed of loose rubble. Hard as well as loose debris, ranging from fine silt to large chunks, could be seen in video tapes. The distribution of the material was neither uniform nor symmetric. Several surface cracks and crevices were present on the surface of the hard layer of debris that relocated to the lower head. Gaps existed between the nozzles and the debris surrounding the nozzles, although it was not possible to verify the existence of gaps between the hard layer of companion sample debris and the lower head. Estimates for the mass of the loose debris and hard layer were obtained based upon views of peripheral flow holes in the flow distributor plate. ${ }^{6}$

\subsubsection{TMI-2 VIP Data}

Margin-to-failure calculations relied primarily upon three major sources of VIP examination data. Metallurgical examination data, which are discussed in Section 4, were used to characterize peak vessel temperatures, the duration of peak temperatures, and vessel cooling rates.

Companion sample examination data, which are discussed in Section 5, were used to characterize debris properties such as decay heat and material composition. Nozzle examination data, which are discussed in Section 6, were used to characterize melt composition attached to nozzles, ablation elevations of nozzles in the vessel, and melt penetration distances within nozzles. 


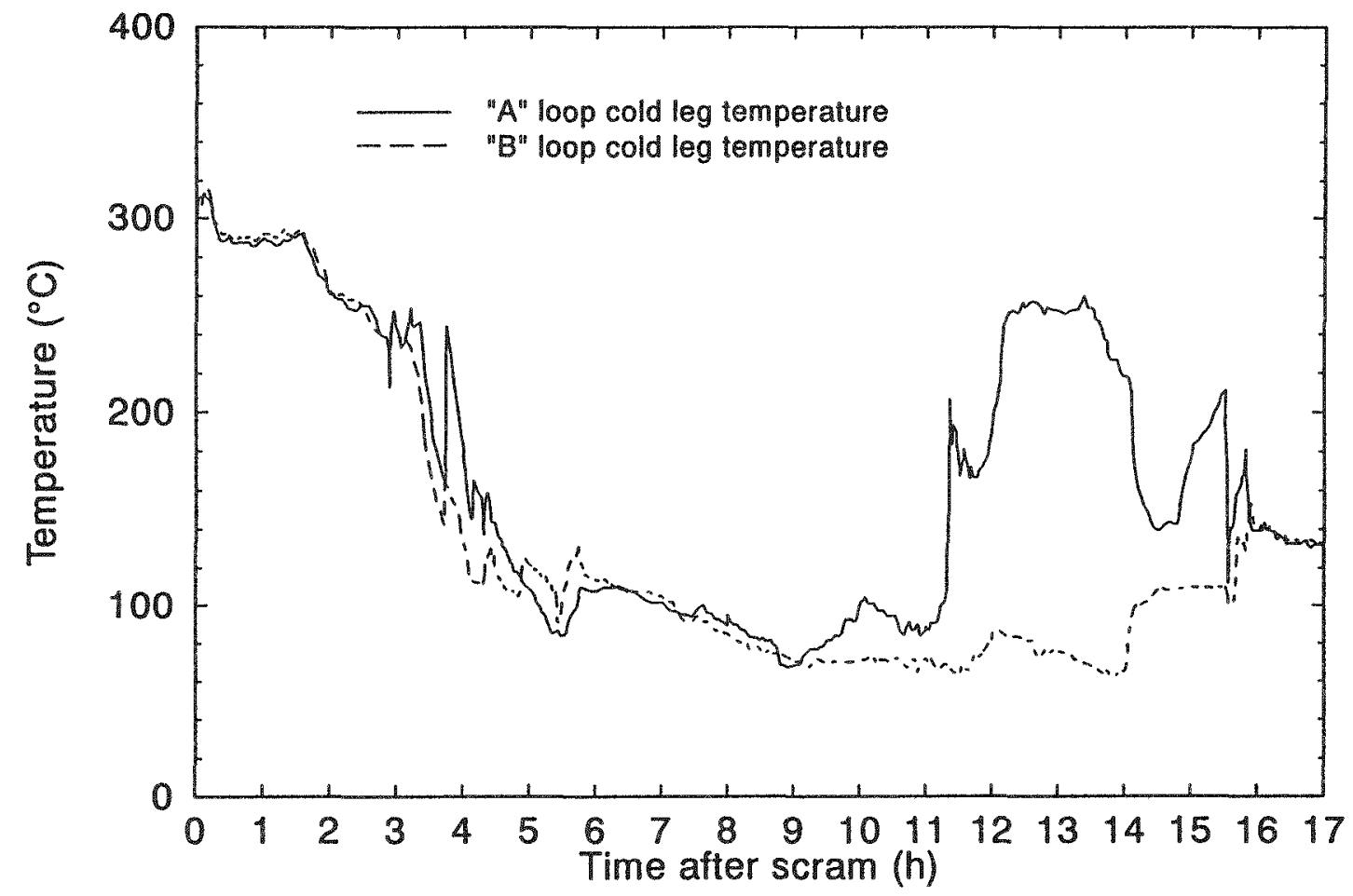

M834 | |r-0393-02

Figure 7-2. Cold-leg temperatures during the TMI-2 accident. 
Metallurgical evidence from TMI-2 examinations also provide background information for weld failure analyses. As discussed in Section 4.1.4, examinations indicated that the Inconel penetration welds did not melt. Stainless steel cladding, which has approximately the same melt temperature as Inconel, showed no signs of melt, even inside the hot spot. ${ }^{7,8}$ Examination of a penetration weld slightly outside the hot spot also revealed no melting of the weld (including the buildup above the vessel surface). ${ }^{9}$

\subsubsection{Preliminary Analyses}

Results from several initial calculations were required as input to the margin-to-failure analyses. These included calculations to determine the distance melt penetrated through the instrumentation nozzles of the TMI-2 pressure vessel, the potential for a debris jet to fragment as it travels through coolant, and the thermal response of the vessel during and after the relocation of molten debris to the lower head.

Figure 7-1 illustrates the manner in which results from these calculations are input to subsequent failure analyses. For example, results from melt penetration calculations provide input for selecting the thermal load from the debris to the tube for an ex-vessel tube rupture analysis. Results from the vessel thermal analysis provide input for analyzing the integrity of the weld holding the lower head penetration tubes to the vessel and the potential for global and localized failures to occur in the vessel.

7.1.4.1 Melt Penetration through TMl-2 Instrumentation Nozzles. Calculations were performed to determine the degree of melt ingress into the instrumentation nozzles of the TMI-2 vessel lower head, specifically to determine if melt contacted ex-vessel tube sections. ${ }^{1}$ Prior to predicting melt penetration distances, nozzles containing melt with known penetration distances were used to select an appropriate model for estimating penetration distances. Results indicate that a modified bulk freezing model, ${ }^{10}$ which considers heat loss from the melt to the tube and the coolant, was more appropriate than a conduction model ${ }^{11,12}$ for estimating the melt penetration distances observed in the TMI-2 nozzles.

Melt penetration distances predicted with the modified bulk freezing model indicate that molten debris containing fuel did not travel through instrument tubes to locations below the lower head. Calculations conservatively bounded possible melt compositions, temperatures, and melt flow areas to maximize penetration distances. Furthermore, it was conservatively assumed that the nozzle stub height was $1.3 \mathrm{~cm}$, which was the smallest height observed in TMI-2 defueling efforts. Although calculations indicate that it is possible for molten debris with highly metallic compositions to flow to ex-vessel tube locations, it is felt that any metallic material was quenched when it relocated to the lower head during the TMI-2 accident. Hence, ex-vessel tube temperatures are not predicted to experience higher temperatures than the reactor coolant system temperatures. Therefore, tube failure calculations were performed assuming the tubes were at the RCS coolant temperature.

7.1.4.2 Jet Impingement and Thermal Response Calculations. Calculations were performed to investigate melt relocation and the subsequent thermal loading to the vessel during the TMI- 2 accident. ${ }^{1}$ The thermal response of the vessel during and after debris relocation was investigated considering lower-bound, upper-bound, and best-estimate (or nominal) values for 
input parameters related to debris decay heat, debris relocation mass, and heat transfer from the debris and the vessel. First, the amount of breakup as one or more jets flowed through the coolant standing in the lower head was calculated assuming appropriate ranges for input parameters. Then, one-dimensional global and localized vessel temperature distributions were obtained to provide input for subsequent structural analysis calculations to determine the margin to failure in the TMI-2 vessel. Input to the thermal analysis was primarily based upon companion sample examination data (debris composition, decay heat levels, and "slow cooling" evidence). Results from the thermal analyses were compared with vessel "boat sample" examination data (peak hot spot and global vessel temperatures, duration of peak hot spot temperatures, and cooling rate of vessel in the hot spot location).

Simulation results from the TEXAS fuel-coolant interaction mode $1^{13-16}$ indicate that insignificant amounts of breakup occurred assuming that the total mass of debris injected into the lower plenum was approximately $10,000 \mathrm{~kg}$ (although it is recognized that approximately $19,000 \mathrm{~kg}$ of material relocated to the lower head, it is not clear that all of this mass relocated during the 224- to 225-minute time frame). Total mass flow rates ranging from 300 to $1,000 \mathrm{~kg} / \mathrm{sec}$ were used to model scenarios in which the debris was assumed to relocate through saturated or subcooled water conditions. Because melt may have drained from more than one of the holes in the elliptical flow distributor plate, analyses considered one- and three-jet cases. Maximum breakup was predicted for cases in which three jets were assumed to impact the lower head. However, even in the cases examining three jets with assumptions that maximized the heat transfer from the jet to the coolant, the total breakup mass was approximately $43 \mathrm{~kg}$. Hence, the breakup predicted by TEXAS for molten jets of debris draining from the elliptical flow distributor plate was relatively insignificant. Therefore, subsequent vessel thermal response calculations assumed that the majority of debris reached the lower plenum in a molten state without significant breakup or quenching.

A total of 15 cases (see Table 7-1) were analyzed to consider the vessel thermal response using various combinations of upper-bound, lower-bound, and best-estimate values for input parameters, such as debris-to-coolant heat transfer, debris decay heat, debris-to-vessel thermal contact, and heat removal from the vessel. Although the quantitative vessel wall surface peak temperatures differed, results from most of these sensitivity studies were qualitatively similar, namely, that the thermal response can be divided into the following three time periods:

- An initial localized temperature spike for the duration and location of jet impingement (typically lasts for about 1 minute)

- A transient vessel heatup (typically lasts for about 1 hour)

- A quasi-steady vessel temperature distribution (typically lasts for several hours).

Only Case 15, which was based upon lower-bound input assumptions, was found to result in global peak temperature predictions consistent with boat sample examination data, namely that peak vessel temperatures remain below values at which the material undergoes a transition from ferritic to austenitic steel. Best-estimate input values that were used for the nominal case (Case 12 in Table 7-1) resulted in global peak temperatures of over $900^{\circ} \mathrm{C}$, which is inconsistent with metallurgical examination data. 
Table 7-1. Vessel thermal response calculation results.

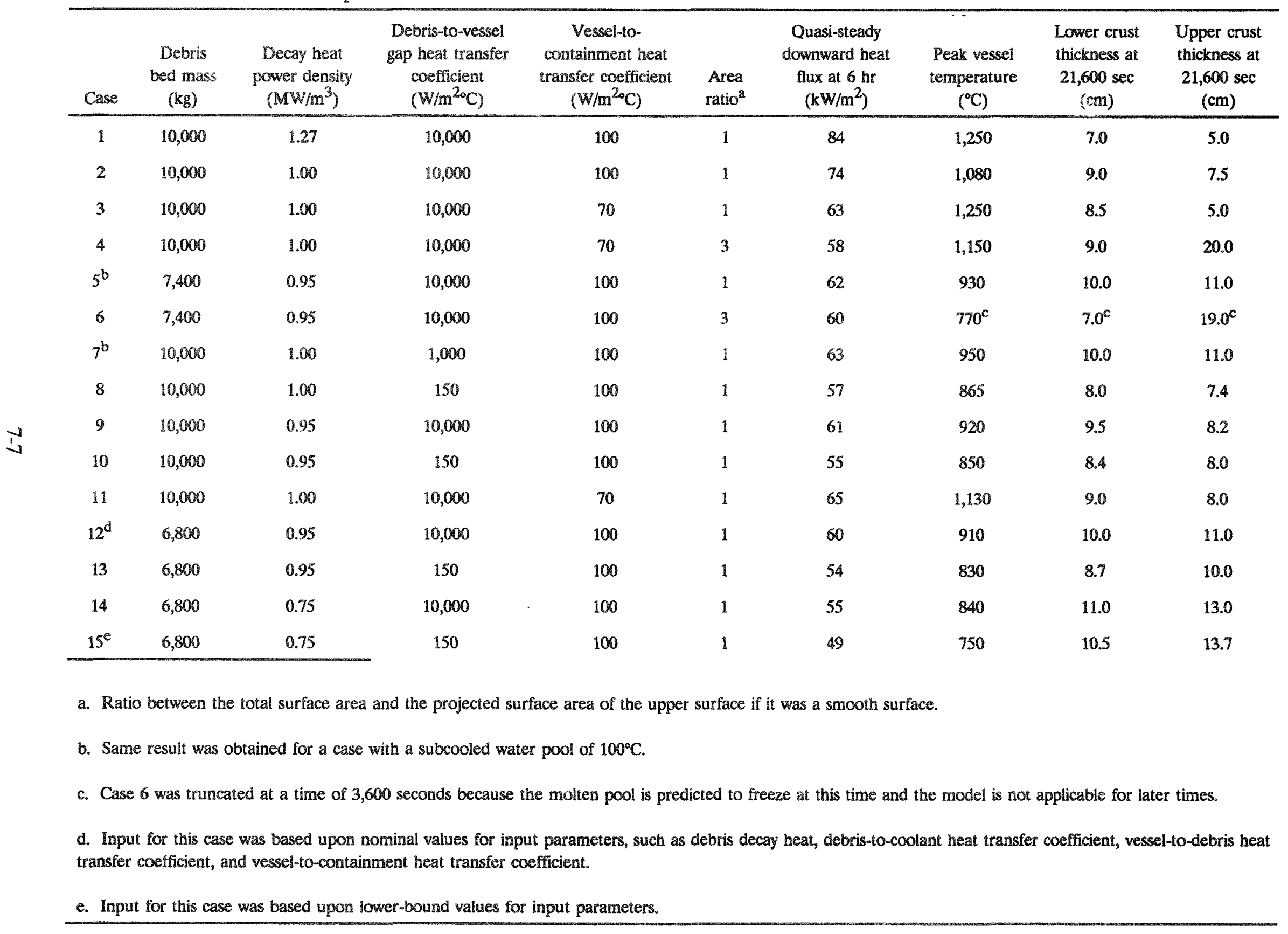


Results from vessel thermal response calculations indicate that the magnitude and duration of the hot spot temperatures estimated in TMI-2 vessel examinations could not have been caused by an impinging jet because peak temperatures during melt relocation are typically not predicted to be sustained for more than a few minutes (instead of the 30-minute duration indicated by vessel examinations). Rather, thermal analyses indicate that hot spot temperatures must have occurred later in the scenario from a sustained heat load due to debris resting on the lower head. The limited area estimated to have experienced hot spot temperatures suggests that this region was subjected to a localized heat source, such as might occur with a nonhomogeneous debris bed or a localized region with better contact between the debris and the vessel.

\subsection{Failure Modes}

Failure of the TMI-2 pressure vessel due to relocation of approximately 19 metric tonnes of molten debris to the lower head could have resulted from one of several mechanisms. These failure mechanisms include tube ejection, tube rupture, localized vessel failure, and global vessel failure. Scoping calculations for each mechanism were performed with the objective of determining for which mode there existed the smallest margin to failure during the accident. ${ }^{1}$

Failure of a penetration tube weld could result from debris melt attack and sustained heating from accumulated debris around the perimeter of a tube. Reactor system pressure could then cause failure via tube ejection. Tube rupture may result from a combination of high pressure and elevated ex-vessel tube temperature due to contact with debris that has traveled within the tube to ex-vessel locations.

Global vessel failure may be caused by elevated system pressure and/or the weight of debris on the lower head, in conjunction with sustained heating from accumulated debris on the lower head. Localized vessel failure may be caused by thermal and mechanical loads on the lower head due to nonuniform heat sources within the debris bed or a coherent jet of debris impinging directly onto the lower head.

The potential for each of the above failure mechanisms to occur was evaluated on the basis of both ultimate strength and creep effects. Failure of an instrument tube or the vessel by exceeding the ultimate strength of the material reflects the instantaneous response of the material to temperature/load combinations over a given time period. Failure by creep, on the other hand, reflects the cumulative damage of the temperature/load combinations over a much longer time period. Creep failure occurs at or before ultimate strength failure; thus, creep produces the lowest margin to failure.

As a basis of comparison between failure mechanisms in most of these scoping calculations (discussed in Section 7.3 and 7.4.2), a stress-based margin to failure for creep failure was defined by the consensus of the Structural Mechanics Peer Review Group. ${ }^{17}$ The procedure includes converting the multi-dimensional stress state to an effective stress, interpolating the time to failure for constant temperature and stress using the Larson-Miller parameter, and predicting time to failure for the actual stress and temperature history using a time damage model. The entire procedure has not been verified experimentally for cases such as the TMI-2 vessel, where temperature and pressure are changing and a temperature gradient exists through the thickness. However, the individual steps (calculation of effective stress, interpolation of time to failure with 
the Larson-Miller parameter and use of the time damage model) have been verified experimentally. ${ }^{18-22}$ Additionally, this procedure has been used in a previous creep analysis of a case very similar to the TMI-2 vessel and penetrations: thick-wall furnace tubes, under internal pressure with a temperature gradient through the thickness. ${ }^{23}$ When results from the initial scoping calculations suggested that a stress-based failure criterion may be too conservative for predicting failure, calculations (discussed in Section 7.4.3) were performed in which failure was defined as the point at which mechanical instability occurred.

\subsection{Analytical Estimates of Vessel Margin to Failure}

Several models, using closed-form analytical or simplified numerical solution techniques, were used to determine the thermal and mechanical response of the lower head to the molten debris. Most of the models used in the margin-to-failure calculations are extensions of models developed and/or applied under the NRC-sponsored Lower Head Failure Analysis Program. ${ }^{10}$ These models were modified according to the geometry of the TMI-2 vessel and operating conditions during the accident. Details of the calculations are outlined in Reference 1.

\subsubsection{Scoping Analysis for TMl-2 Penetration Tube Weld Fallure}

A penetration ejection model was developed in the NRC-sponsored lower head failure program $^{10}$ to predict tube ejection, assuming that the tube weld failed. Prior to using the tube ejection model, it is necessary to establish that weld failure occurs. As discussed in Section 7.1, metallurgical evidence from TMI-2 examinations indicates that the Inconel penetration welds did not melt. 8,9

Based on the maximum predicted temperatures and maximum recorded pressures during the accident, calculations were performed to examine the mechanical behavior of the weld for penetrations inside the hot spot. The purpose was to evaluate the possibility of weld failure by exceeding the ultimate strength of the material or by creep. Creep rupture can occur at high temperatures with relatively low stresses. If weld integrity can be ensured, further penetration ejection analysis is not needed (weld integrity precludes ejection).

Weld failure calculations, which used peak temperature and pressure data, were extremely conservative. Best-estimate calculations indicate that the ultimate-strength margin to failure is $60 \%$, where the margin to failure is defined by

Margin to Failure $=1$ - effective stress/ultimate strength.

Lower- and upper-limit estimates of the ultimate-strength margin to failure were $54 \%$ and $65 \%$, respectively. If the peak hot spot temperature and a $15 \mathrm{MPa}$ system pressure were both maintained constant, the time to creep failure is estimated as 7.2 hours with upper and lower estimates of 4.2 and 16.9 hours, respectively. The large ultimate-strength margin to failure and the long estimated time to creep failure are conservative for several reasons. One reason is that the analysis assumed a constant pressure of $15 \mathrm{MPa}$, whereas the peak temperatures may have occurred at a lower pressure. Furthermore, calculations assumed that the peak temperature remained constant, when in fact, the peak temperature was estimated to last for only 0.5 hours. In addition, the load-bearing weld area was minimized by ignoring the weld buildup material 
above the stainless steel cladding and using a minimum weld depth into the vessel. Finally, the load was assumed to be carried solely by the weld, and none of the load was distributed to the unistrut support.

Ultimate strength failure was not predicted because the applied stress on the weld was very low. For the same reason, the weld was predicted to withstand peak hot spot temperatures and pressures for 7 hours before failing by creep. Although the assumed temperature for the weld was relatively high $\left(1,075-1,100^{\circ} \mathrm{C}\right)$, the low applied stress $(12.32 \mathrm{MPa}, 1.786 \mathrm{ksi})$ presented little challenge to the ultimate strength of the weld, as indicated by the $60 \%$ best-estimate margin to failure and the relatively long, best-estimate creep failure time of 7.2 hours. Because penetration weld integrity during the TMI-2 accident was ensured, penetration ejection was ruled out as a possible failure mode.

\subsubsection{Ex-vessel Instrument Tube Fallure}

Another possible failure mode that is associated with the instrument tube is the tube bursting under accident conditions in a location outside the vessel lower head. This failure would allow melt to travel through the tube and be expelled out of the reactor vessel.

Results from melt penetration calculations indicate that ceramic debris would not penetrate the lower head. Other compositions of debris such as control material, which may travel below the lower head, would not contain sufficient heat capacitance to heat ex-vessel tube sections. Therefore, the tube failure analysis was performed assuming that the tube remains at RCS temperatures. An upper bound on the coolant temperature was taken to be a representative saturation temperature $\left(327^{\circ} \mathrm{C}\right)$ corresponding to system pressures during the first 12 hours after the major relocation of fuel occurred; a lower-bound temperature was based on the minimum temperature $\left(127^{\circ} \mathrm{C}\right)$ measured in the cold legs during the transient (see Figure $7-2$ ). An approach based on force equilibrium, similar to that of the instrument tube weld margin-to-failure analysis, was used to evaluate tube failure. Margins to failure based on creep time to failure and ultimate strength were calculated.

Results from these calculations show the ultimate-strength margin to failure to be $96.0 \%$ for a tube temperature of $127^{\circ} \mathrm{C}$, and $95.8 \%$ for a tube temperature of $327^{\circ} \mathrm{C}$. The small variation in margin to failure is a result of the minor change in the ultimate strength of Inconel 600 over this temperature range. Times to creep rupture at these temperatures are estimated to be on the order of $10^{15}$ and $10^{29}$ hours. Hence, tube failure from tube rupture and from tube ejection (based upon results from Section 7.3.1 weld integrity calculations) can effectively be eliminated as potential failure mechanisms.

\subsubsection{Global Vessel Rupture}

A calculation of margin to failure for global vessel rupture requires consideration of a structural collapse of the lower head under the primary loading of the vessel's internal pressure. Thermal stresses complicate the analysis by causing stress redistribution, some plastic response, and creep relaxation (at higher temperatures and stresses), resulting in further stress redistribution. These stresses tend not to cause ultimate collapse of a structure unless the primary load-carrying capacity is affected by the thermal plasticity and creep damage. 
Structural evaluations of margin to failure for global rupture of the vessel could range from relatively simple to rather complex calculations. In a more straightforward fashion, force equilibrium of the system pressure and the ultimate collapse load of the vessel could be computed. In more complex calculations, stress redistribution from thermal stress and creep relaxation could be performed. Recognizing the need for parameter studies in this analysis and maintaining an approach that was consistent with the scope of the TMI-2 VIP, the scoping calculations for global vessel rupture (see Reference 1) were based on the simpler, force equilibrium method.

Results of the global rupture analyses for the nominal case temperature distribution (Case 12 in Table 7-1) indicate that vessel failure would have occurred 1.7 hours after the start of the major core relocation in the accident. Figure 7-3 summarizes results for the nominal case and illustrates the phasing of vessel wall temperature, system pressure, progression of calculated vessel wall damage, and the calculated margin-to-failure history during the accident. The innermost wall segment temperature history with the time-dependent margin to failure is plotted in Figure 7-3 (top). The history of total wall segment damage is shown in Figure 7-3 (bottom), concurrently with the operating system pressure. Instantaneous margins to failure ranged from over $80 \%$ at the beginning of core relocation to $45 \%$ at 1.5 hours and then dropped sharply to zero at 1.7 hours.

The model calculated failure to occur for the lower-bound temperature case (see Case 15 in Table 7-1) after 2.3 hours. These, results are summarized in the plots of Figure 7-4. For this scenario, the temperature rise was slower, and the vessel was predicted to survive until normal system operating pressure levels were restored and the inner wall temperature reached $727^{\circ} \mathrm{C}$. Major wall damage began after 2.0 hours and very rapidly accelerated to failure at 2.3 hours. Failure margins again started at $80 \%$ and reduced to about $45 \%$ at the 2-hour mark and quickly dropped to zero afterwards.

As discussed in Section 7.1.4.2, temperature distributions used in these failure analyses were based upon companion sample examination results that indicate that the debris underwent relatively slow cooling. Although boat sample examinations indicate that the material in the hot spot region was rapidly cooled, there was no boat sample data about the manner in which the vessel was cooled in regions outside the hot spot. Temperature distributions based upon companion samples resulted in calculations predicting vessel failure, with the nominal temperature distribution case failing at 1.7 hours and the lower-bound case failing at 2.3 hours after core relocation. From these calculations, it appears that global vessel temperatures decreased more rapidly in the actual accident, probably within 1.5 to 2 hours after core relocation.

\subsubsection{Localized Vessel Failure}

This section discusses lower head failure associated with the application of an elevated heat flux over a localized region, resulting in temperatures and temperature gradients consistent with metallurgical observations of the TMI- 2 boat samples. A commercial finite element code ${ }^{24}$ was used to obtain transient, two-dimensional temperature profiles in the lower head. A structural model, ${ }^{10}$ which is a variation of a finite deformation shell theory, calculated thermal, plastic, and creep strains using properties of SA533B steel. 


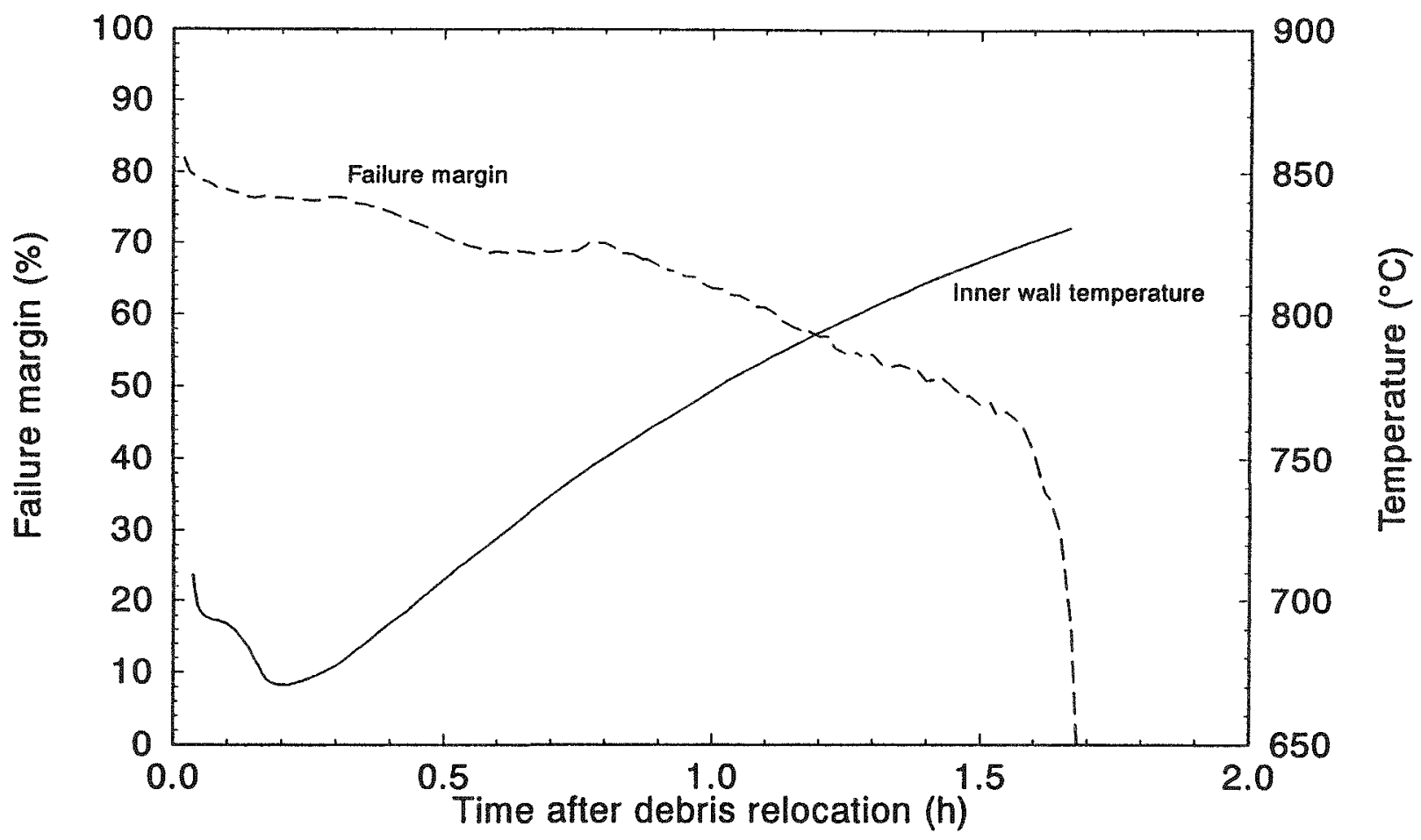

M970 Hr-0893-13

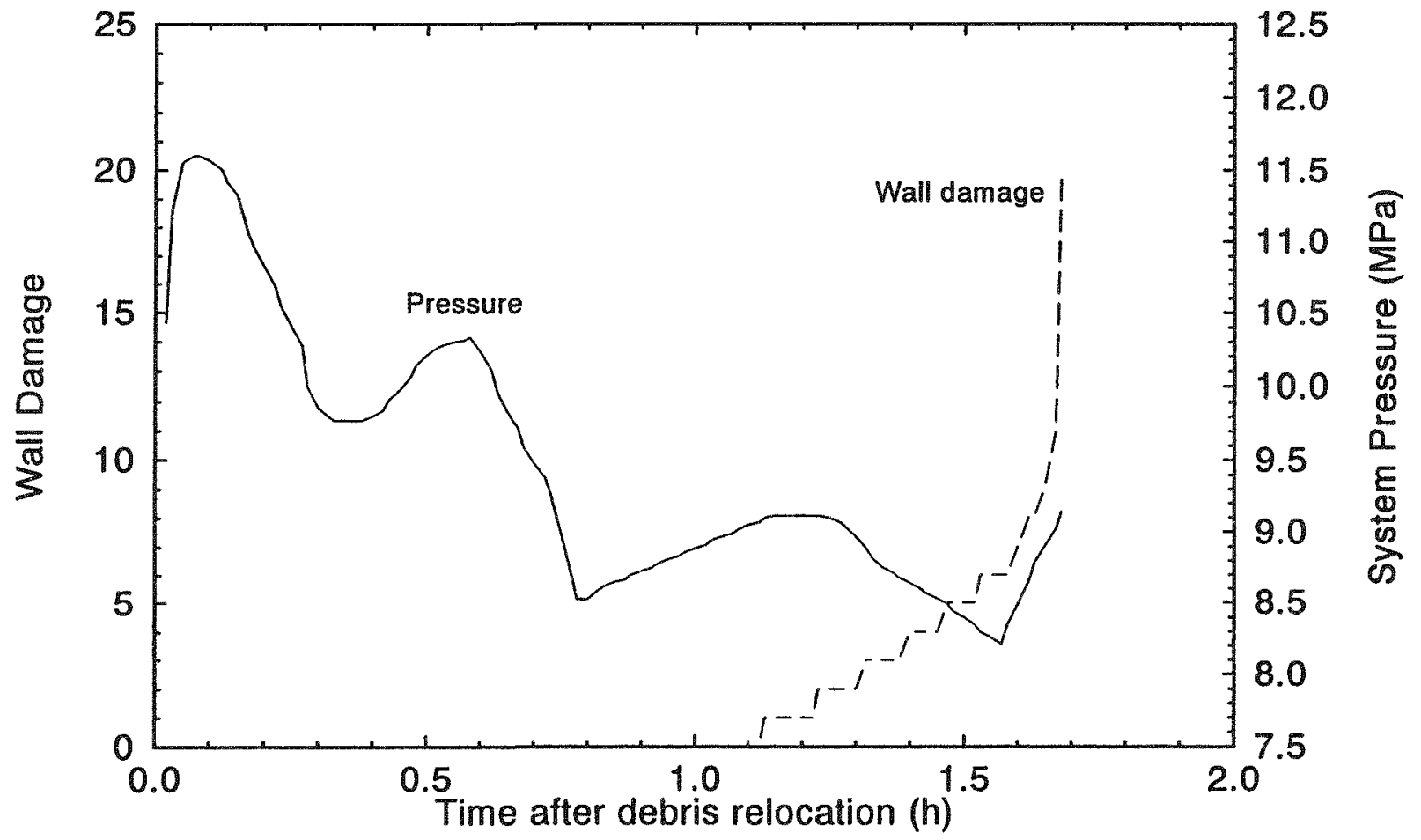

M970 /18-0893-14

Figure 7-3. Nominal case results for global failure. 


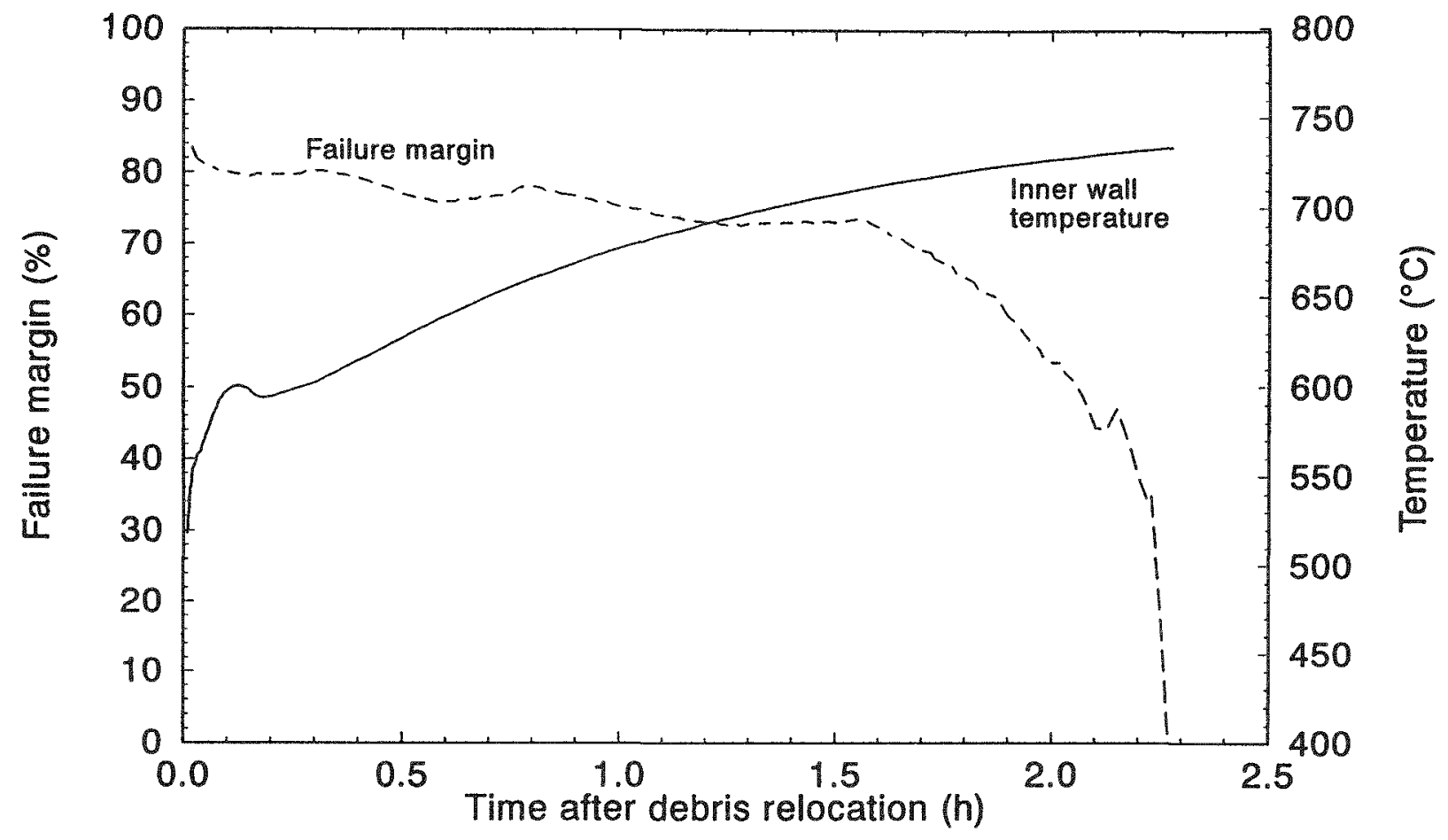

$M 970$ ]16.0893.15

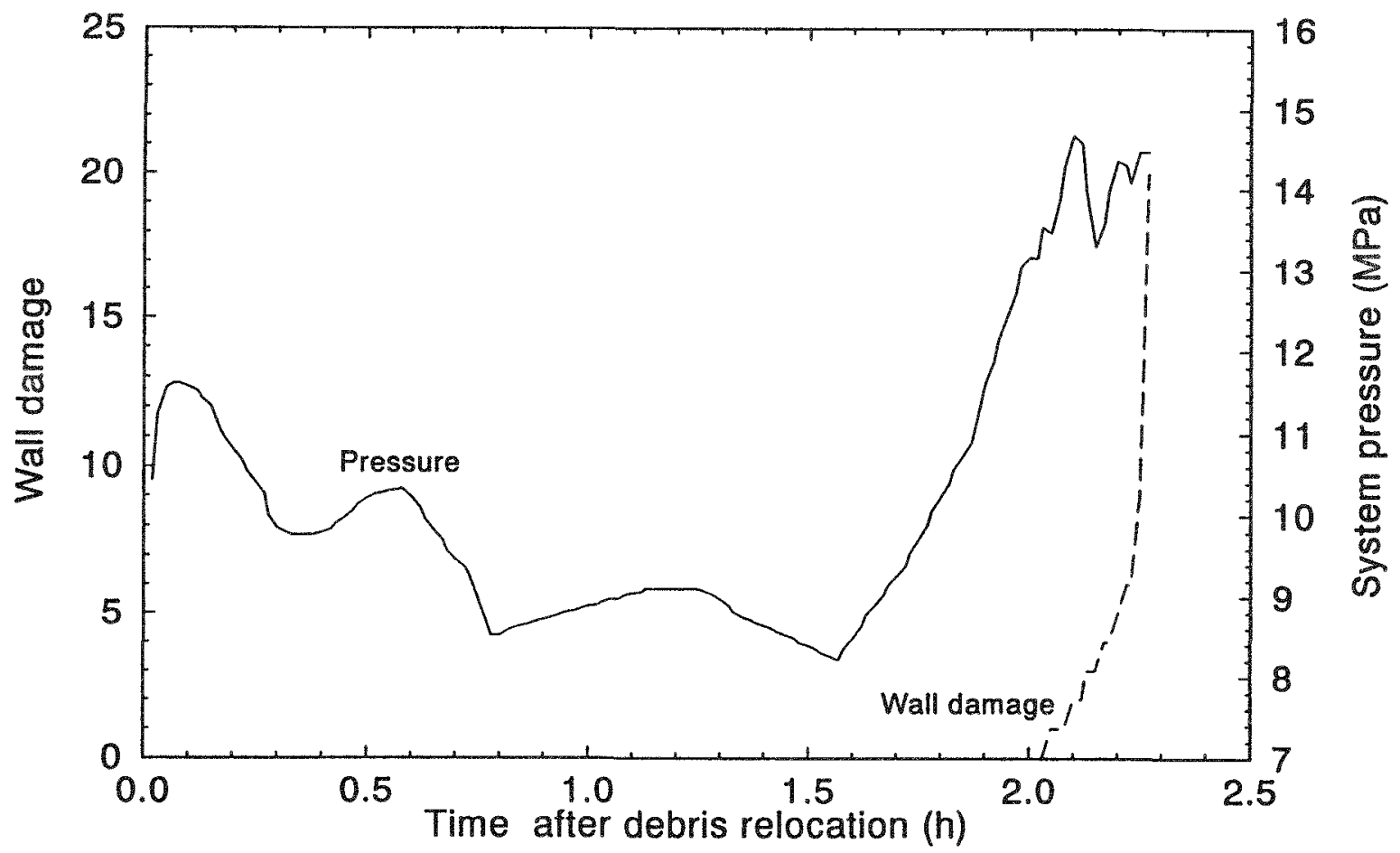

M970 |16r-0693-16

Figure 7-4. Lower-bound case results for global failure. 
In order to understand the relative roles of the background and hot spot temperature distributions, three cases were considered: (a) a lower-bound global temperature distribution without the hot spot (Case 15 of Table 7-1), (b) hot spot temperatures imposed on top of the lower-bound global temperature, and (c) hot spot temperatures imposed on a vessel with cool background temperatures $\left(327^{\circ} \mathrm{C}\right.$ inner surface; $277^{\circ} \mathrm{C}$ outer surface). A complete description of these calculations is found in Reference 1, which explains that failure was predicted to occur in 1.9 hours for Case (a) and in 1.5 hours for Case (b). The vessel was predicted to survive for Case (c), which was considered a hot spot on a vessel with cool background temperatures.

The effect of a hot spot was evaluated for a shell with a cool background [Case (c)] to confirm that the metallurgically estimated hot spot temperatures alone would not result in a localized vessel failure. Since metallographic examinations of vessel specimens outside the hot spot only indicated that the vessel did not reach the ferritic-to-austenitic transition temperature (approximately $727^{\circ} \mathrm{C}$ ), global vessel temperatures could have been considerably lower than this transition temperature. (Note that peak values predicted in the lower-bound temperature distribution were approximately equal to the transition temperature.) To bound possible temperatures in this cooler case, the initial temperature distribution from the lower-bound case (Case 15 of Table 7-1) was used; that is, a linear temperature distribution through the thickness with a $327^{\circ} \mathrm{C}$ inner surface temperature and a $277^{\circ} \mathrm{C}$ outer surface temperature.

The structural response results for Case (c) are shown in Figure 7-5, which shows both damage rate and accumulated damage versus time. There are four distinct peaks in the damage rate. The first, between 3 and 30 seconds, was associated with the thermal shock (i.e., the nodes on the inner surface experienced a relatively severe damage rate as they reached temperatures in excess of $1,027^{\circ} \mathrm{C}$, yielding in compression as they expanded against the cooler shell). This severe damage rate was diminished as the temperature front moved into the interior wall of the vessel.

The second damage rate peak occurred just over 1,000 seconds into the transient and represents the largest rate $\left(0.1 \mathrm{hr}^{-1}\right)$ at any time during the transient. This state occurred when the temperature front had elevated the outer surface temperatures to levels of 527 to $577^{\circ} \mathrm{C}$. The outer surface material was supporting a large tensile stress $(\sim 250 \mathrm{MPa})$, and at this temperature experienced both a high damage rate and creep rate. The damage rate dissipated when the temperature front completely penetrated the shell, pushing the outer surface temperature above $727^{\circ} \mathrm{C}$, reducing the temperature gradient and associated stresses.

At 1.6 hours into the TMI-2 transient, the system was repressurized, and the damage rate experiences a third peak, although of substantially lesser size than the transient heatup peak. The fluctuations in the repressurization peak mirror the fluctuations in the TMI-2 pressure history associated with relief valve opening and reseating. Although the transient pressure fluctuations continued until 260 minutes after relocation, these calculations assumed a constant pressure for time periods greater than 180 minutes after relocation, causing the fluctuations to disappear from the damage rate plot after this time. ${ }^{a}$ Repressurization to $14.5 \mathrm{MPa}$ at 2.1 hours also corresponds to the attainment of maximum temperatures in the shell, so the damage rate decreased shortly after repressurization as the shell cooled.

a.Subsequent sensitivity calculations indicate that failure time predictions did not vary significantly when the actual TMI-2 pressure history was used after 260 minutes. 


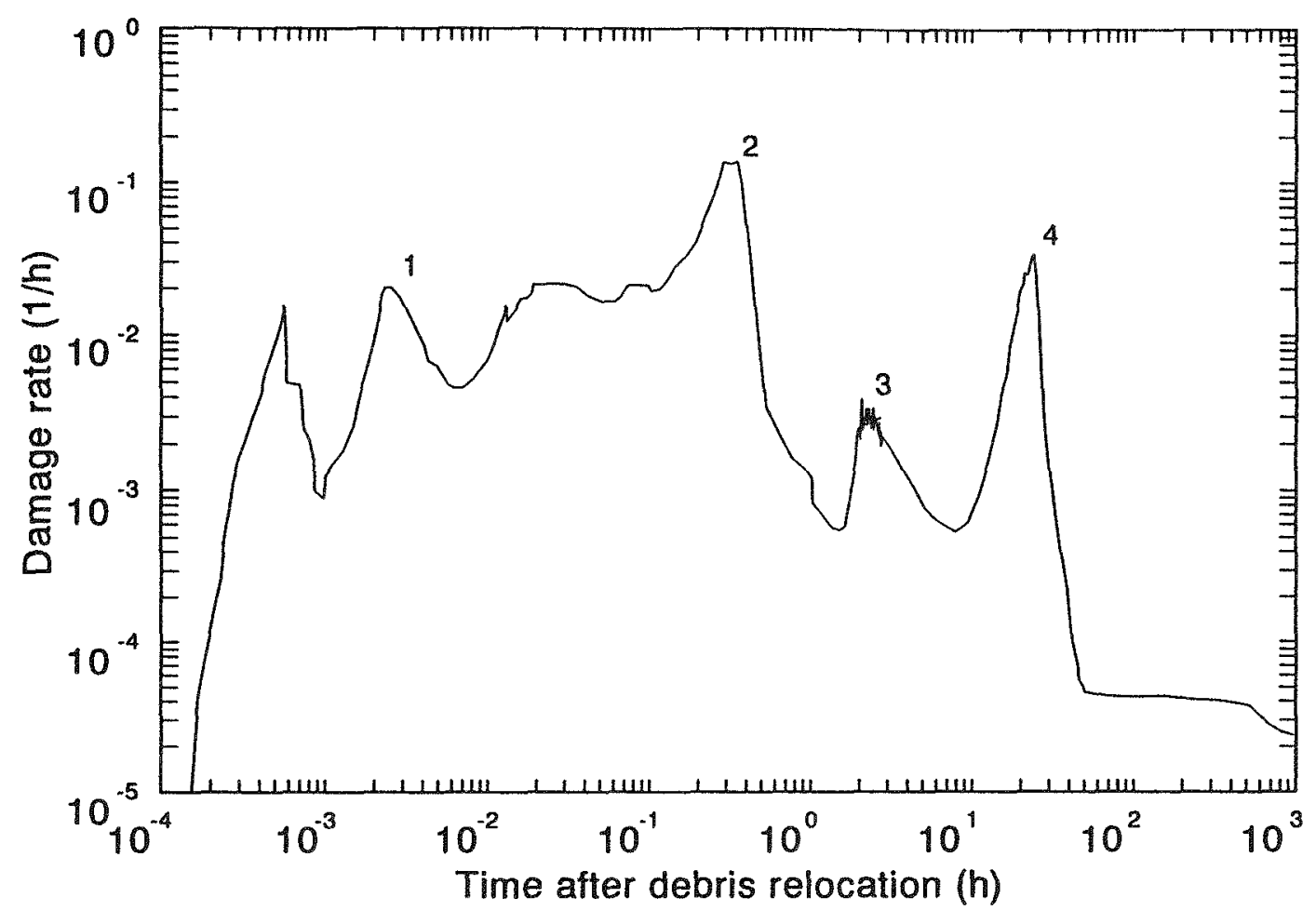

M919 HI. 0793-05

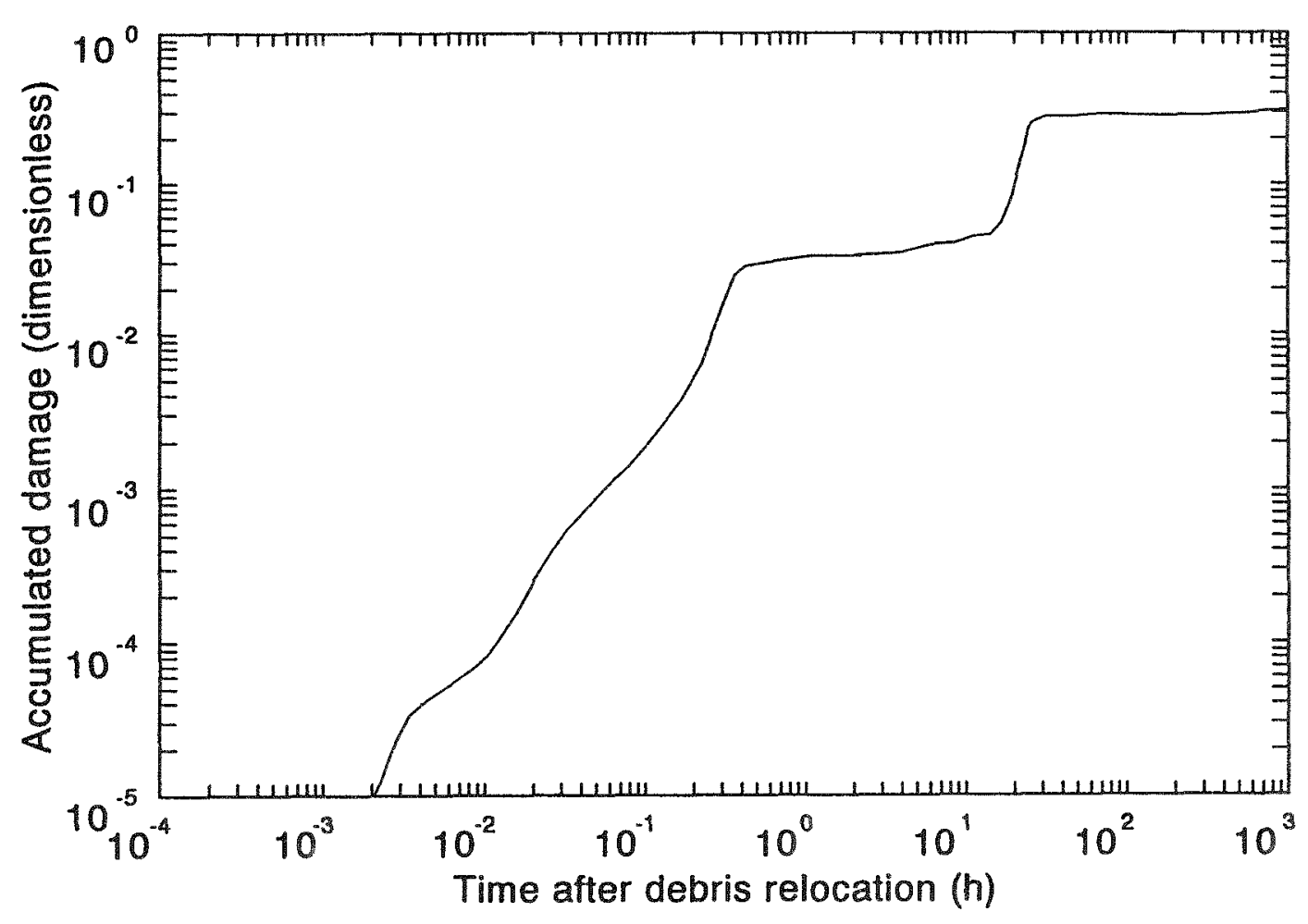

Figure 7-5. Damage rate and accumulated damage versus time in the hot spot case for localized failure. 
The final damage rate peak occurs about 24 hours after the major melt relocation occurred and is associated with cooldown. During the heatup and high temperature periods, material near the inner surface of the vessel at its base experienced compressive stress and underwent negative creep strain under compressive load. As the vessel cooled, this material then contracted and experienced tension. As the material temperature dropped during the cooldown period, tensile stresses on the bottom inner surface reached the $+100 \mathrm{MPa}$ range, causing rapid damage accumulation and the damage rate peak at 24 hours, which is shown in Figure 7-5. Only a few ligaments failed during the heatup and maximum temperature period. Unlike the first case (lower-bound temperature distribution without a hot spot) where outer ligaments failed first, here, the first ligaments to fail were on the interior surface. In both cases, high tensile stresses drove the failures. During the cooldown period, for this case, a substantial number of ligaments failed. The failed ligament distribution is shown in Figure 7-6. An " $\mathrm{x}$ " is plotted at each Gauss point where damage has reached $100 \%$.

For the localized failure analyses, margin to failure was defined by the Structural Mechanics Peer Review Group ${ }^{17}$ to be the difference between time to failure and the time at which pressure and temperature states are frozen at points of maximum damage rate. Hence, the margin to failure for this case was evaluated by assuming constant temperature and pressure conditions for each of the peaks in Figure 7-5. The initial peak associated with the thermal shock (during melt relocation) was not relevant to the margin-to-failure analysis, because only the material on the inner surface experienced elevated temperatures during the first 30 seconds of the transient. Margin to failure is then defined as the minimum of all margin-to-failure calculations evaluated for peaks 2,3 and 4 in the damage rate curve. Of the three margin-to-failure calculations, margin to failure associated with maximum pressure and temperature conditions (corresponding to peak 3 ) imposed the most severe limitations. For this case, the margin to failure is estimated as 8 hours.

The three cases examined in this investigation indicate that vessel background temperatures outside the hot spot region play a pivotal role in determining whether or not the vessel is predicted to survive. The vessel is predicted to fail without any hot spot if heat fluxes corresponding to lower-bound input assumptions (Case 15 of Table 7-1) are applied over a large angular segment of the lower head. However, the vessel is capable of surviving local hot spots in the temperature range and of the duration inferred from TMI-2 metallurgical examinations, but the balance of the shell must remain cool.

\subsection{Sensitivity of Results to Debris Cooling and Failure Criterion}

As discussed in Sections 7.1 and 7.3, initial scoping margin-to-failure calculational results were inconsistent with several observations from VIP metallurgical examinations:?

- Nominal case thermal analysis results, which were obtained using input based upon companion sample examination data, indicate that the vessel temperatures outside the hot spot exceeded $727^{\circ} \mathrm{C}$, which is inconsistent with metallurgical examination data.

- Nominal and lower-bound thermal analysis results indicate that hot spot temperatures occurred for longer than the 30 minutes indicated by metallurgical examinations. 
Time $=1000 \mathrm{~h}$

Clipped ligaments $(x)$, all but three after $10 \mathrm{~h}$

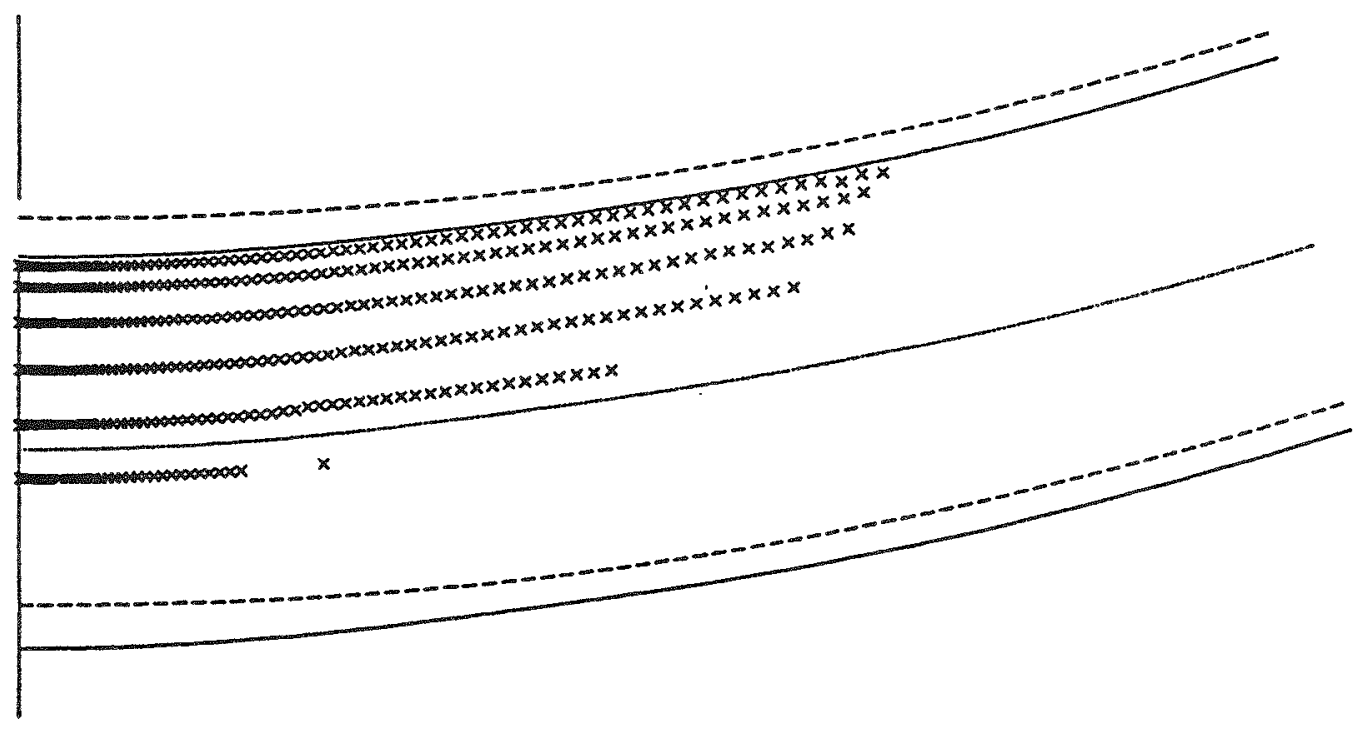

Figure 7-6. Distributions of $100 \%$ damaged ligaments in the hot spot case for localized failure. 
- Nominal case thermal analysis results indicate that the vessel did not cool at the $10-100^{\circ} \mathrm{C} / \mathrm{min}$ rates through the SA533 steel transition temperature as indicated by metallurgical examinations.

- Structural analysis results for the nominal and lower-bound cases indicate that the vessel would fail before it was repressurized to $15 \mathrm{MPa}$.

As noted in Section 7.1, thermal analyses were performed based upon debris properties (decay heat levels, "slow cooling" evidence) from the companion sample examinations. However, thermal and structural calculational results combined with metallurgical examination results suggest that some form of debris cooling occurred that was not evident in the TMI-2 companion samples. In addition, analysis results suggest that a stress-based failure criterion may be too conservative for predicting failure. This section describes analyses performed to investigate the effects of debris cooling and failure criterion on calculational results.

First, scoping calculations were performed to determine if the hypothesis of debris cooling after relocation could be substantiated by evaluating changes in the mass and internal energy of material within the vessel using measured plant data or parameters that were inferred from measured plant data. Second, calculations were performed to quantify the magnitude of cooling required in order for the vessel response to be consistent with metallurgical examination data. Although there are insufficient data to determine the exact mechanisms that caused the debris to cool within the first 2 hours after relocation, two possible forms of cooling were investigated that have the potential to produce this additional cooling:

- In slow cooling, it was assumed that channels or cracks in the debris allowed for infusion of water that cooled the debris near the channels, but left interior portions hot.

- In rapid cooling, it was assumed that gaps or channels between the lower debris crust and the vessel allowed relatively high flow rates of coolant between the debris and the vessel. These high flow rates were postulated to rapidly cool the vessel and outer portions of the debris, but leave interior portions of the debris relatively hot.

Using the two-dimensional finite element thermal analysis code and the finite-difference model applied in Section 7.3.4, calculations were performed to determine cooling rates due to each type of mechanism so that the vessel response would be consistent with metallurgical examination data. Then, scoping calculations were performed to determine if coolant flowing through a reasonable number of channels within the debris and/or gaps between the debris and the vessel could support the estimated cooling rates.

\subsubsection{Changes in Debris Internal Energy after Relocation}

Initial scoping calculation results suggest that some form of debris cooling occurred within the vessel after the time when a major relocation occurred ( -224 minutes) and before the vessel was repressurized ( $\sim 320$ minutes). By applying some simplifying assumptions related to heat transfer within the vessel, an order-of-magnitude estimate of the change in debris internal energy after debris relocation was obtained using thermal-hydraulic parameters that were either directly measured during the accident or inferred from plant data measured during the accident. 
Volume, mass, and energy conservation equations were applied to debris and coolant within the TMI-2 vessel to determine the change in debris internal energy during the time interval of interest (between 224 and 320 minutes after reactor trip). Sources of coolant entering the vessel during this time period include normal RCS makeup and high-pressure injection from the emergency core cooling system. Sources of coolant exiting the vessel during this time period include normal RCS letdown and coolant flowing out the open power-operated relief valve (PORV). These coolant flow rates and associated uncertainties were quantified using results from previous analyses of plant data (References 2, 3, 4, and 5). Upper and lower bounds for debris decay were obtained using information in Reference 25 to account for the reduction due to volatile fission product release.

The energy conservation equation was applied during the time period after relocation. Hence, energy from zircaloy oxidation was neglected because most oxidation is predicted to have occurred during earlier stages of the transient. Because the reactor coolant pumps did not run during this time period, the primary source of heat loss from the system is associated with mass exiting the system through the PORV. Although additional heat may be transferred to upper plenum structures within the vessel via natural circulation, these losses were conservatively neglected to maximize estimates for debris internal energy when the vessel was repressurized. Because of these simplifying assumptions, results from these scoping calculations should be viewed as only order-of-magnitude estimates that indicate the relationship between the debris internal energy at the time of relocation and at the time before the vessel was repressurized.

Calculation results indicate that the debris internal energy decreased between relocation and vessel repressurization. Calculations considered upper and lower bounds for all the input parameters, and results indicate that a negative change in debris internal energy occurred for the time period of interest in all of the cases considered. Although there is considerable uncertainty associated with these results, scoping calculations suggest that the estimated decrease in debris internal energy is sufficient for all of the debris that relocated to the lower head to solidify and experience a decrease in temperature ranging from 420 to $2,250^{\circ} \mathrm{C}$.

\subsubsection{Slow and Rapid Cooling Analysis}

Results summarized in Section 7.3 indicate that the vessel is predicted to fail if a hot spot is imposed on a background temperature distribution obtained with lower-bound debris decay heat input, but is capable of surviving hot spots if the balance of the vessel remains relatively cool. Calculations were performed to quantify the cooling needed to prevent predictions of vessel failure and obtain vessel cooling rates consistent with metallurgical examination data.

In the first type of calculation, the slow cooling needed to ensure that the vessel does not fail was investigated. Calculations were performed to investigate cases with a hot spot temperature distribution superimposed on $25 \%, 33 \%$, and $50 \%$ of the background heat fluxes obtained using nominal values for debris decay heat, debris-to-vessel heat transfer, and ex-vessel heat removal. For these three cases, it is predicted that the vessel survives, fails in 6.5 hours, and fails in 2.8 hours, respectively. Hence, under slow cooling assumptions, the vessel is predicted to survive a hot spot in the presence of a background heat flux somewhere between $25 \%$ and $33 \%$ of the nominal case values. 
In the second type of calculation, analyses were performed to investigate the cooling needed to obtain vessel cooling rates consistent with the values observed in metallurgical examinations of specimens in the hot spot region. As noted in Reference 9, vessel specimens from the hot spot region indicate that the vessel underwent cooling rates between 10 and $100^{\circ} \mathrm{C} / \mathrm{min}$ in the ferriticto-austenitic transition temperature region $\left(727\right.$ to $827^{\circ} \mathrm{C}$ ) at times between 15 to 50 minutes after the hot spot reached $1,047^{\circ} \mathrm{C}$. Under these conditions, the vessel would be capable of surviving a hot spot on a background heat flux higher than the $25 \%$ to $33 \%$ found for the slow cooling analysis.

Calculations were performed to quantify the heat sink needed to obtain these cooling rates and to quantify the background heat flux, as a percentage of nominal values, that the vessel could sustain without failing in the presence of this additional heat sink. Although there are uncertainties in both the timing and the rate of cooling, it was decided to fix the timing so that rapid cooling is initiated at 30 minutes after the vessel reaches $1,050^{\circ} \mathrm{C}$. Two different rapid cooling rates, 10 and $100^{\circ} \mathrm{C} / \mathrm{min}$, were selected to investigate the sensitivity of the response to the cooling rate. Rapid cooling calculations were performed for cases of hot spot temperatures on $33 \%$ and 50\% of nominal background heat fluxes. The heat sinks required to obtain these cooling rates were 25 and $125 \mathrm{~kW} / \mathrm{m}^{2}$, respectively. Simulations were also run for a hot spot on $75 \%$ of the nominal heat flux, but these simulations predict vessel failure in a little over 2 hours. Hence, heat fluxes smaller than $75 \%$ of the nominal case heat fluxes are needed to prevent vessel failure during the 30-minute time interval that hot spot temperatures are sustained and prior to rapid cooling being initiated.

In summary, analyses suggest the hypothesis that both slow and rapid cooling occurred in the debris during the first 2 hours after melt relocation. If only a slow cooling mechanism were present, the vessel temperatures would not experience the rapid cooling rates observed in the metallurgical examinations. Furthermore, results indicate that the vessel is predicted to fail if hot spot temperatures on the nominal case heat fluxes were sustained for the 30 -minute time period estimated in metallurgical examinations. Thus, analyses indicate that both mechanisms must be considered in order to obtain results consistent with TMI-2 VIP examinations.

\subsubsection{Debris Configurations to Obtain Required Cooling Rates}

Results in Section 7.4.2 indicate that the vessel thermal and structural response would be consistent with metallurgical examinations if both rapid and slow cooling mechanisms were present in the debris. Although results are dependent on the time at which rapid cooling is initiated, calculations indicate that the heat load from the debris must be reduced to somewhere between 50 and $75 \%$ of the nominal case values to simulate the required amount of slow cooling and that between 25 and $125 \mathrm{~kW} / \mathrm{m}^{2}$ must be removed from the vessel to simulate the required amount of rapid cooling inferred from metallurgical examinations of vessel steel in the hot spot region. Although there are insufficient data to quantitatively determine the exact mechanisms that caused this amount of cooling, this section documents results from scoping calculations that were performed to investigate some possible mechanisms that could provide this cooling.

Estimating the number and size of debris channels and the size of debris-to-vessel gaps requires many assumptions related to debris properties and heat transfer parameters. A detailed discussion of inputs used in these calculations is found in Reference 1. In general, however, the 
large uncertainty in bulk debris parameters was treated by estimating upper and lower bounds for each parameter and by obtaining results by propagating upper-and lower-bound estimates.

Lower-bound geometric parameters for channels within the debris and between the debris and the vessel were selected to minimize heat transfer capabilities. As discussed above, Section 7.4.2 results indicate that both rapid and slow cooling mechanisms were needed in order to be consistent with metallurgical examination data. Therefore, it is assumed that the simultaneous presence of cracks and gaps within the debris provides multiple pathways for steam release (e.g., water may travel down along the gap and boil up through cracks). Hence, these calculations do not consider steam blockage due to countercurrent flow. There is little, if any, basis for many of the heat transfer parameters. Therefore, calculations were initially performed assuming that the coolant remains in a liquid state. Because single-phase heat transfer from a liquid is lower than subcooled or saturated boiling heat transfer, these initial calculations provide estimates for debris configurations required with conservative heat transfer coefficients. As indicated by results from these calculations, lower-bound channel geometry and conservative heat transfer assumptions indicate that debris configurations required for both slow or rapid cooling mechanisms are reasonable. Hence, additional types of channel geometries or heat transfer conditions, in which cooling would be more efficient, were not investigated.

The number of channels within the debris and the geometry of channels or gaps between the debris and the vessel were estimated by applying conservation of energy between the required amount of heat removal (estimated in Section 7.4.1) and the amount of heat that could be removed. The amount of heat that could be removed is dependent upon the number and/or geometry of channels, the debris temperature, the coolant temperature, and the heat transfer coefficient between the debris and the coolant. Although it is expected that natural convection would dominate heat transfer, correlations for both natural and forced convection were considered. Results were used to determine if the number and geometry of the channels were plausible.

Results indicate that less than 218 channels with a relatively small effective diameter (a value of $5 \mathrm{~mm}$ was assumed, which corresponds to a $2 \times 10 \mathrm{~mm}$ rectangular gap) within the hard layer of debris in the TMI- 2 vessel could preclude vessel failure being predicted. Using this upperbound number, the volume of channels would be less than $8 \times 10^{-6} \mathrm{~m}^{3}$. The volume of the hard layer of debris within the lower head is estimated as between 0.8 and $1.0 \mathrm{~m}^{3}$. Hence, it is estimated that a relatively insignificant volume of channels within the TMI- 2 debris bed could have removed a sufficient amount of heat to preclude vessel failure being predicted. Calculations also indicate that coolant traveling through a relatively small gap (a value of $1 \mathrm{~mm}$ was assumed) between the debris and the vessel could cause the vessel cooling rates estimated by metallurgical examination data. Although companion sample examinations did not substantiate that portions of the debris cooled within the first 2 hours, it should be noted that the mass of the companion samples was small compared to the mass that relocated (less than $7 \mathrm{~kg}$ of the $19,000 \mathrm{~kg}$ that relocated were examined) and that a minimal volume of cooling channels within the debris and a minimal size gap between the debris and the vessel could supply sufficient cooling. Finally, it should be observed that both of these calculations assumed that the coolant remained liquid as it removed heat from the debris. If coolant traveling within the debris channels boiled, heat transfer would be much more efficient and thus would reduce the number and/or size of channels needed to obtain the hypothesized cooling. 
In summary, results indicate that the debris configuration required to obtain calculational results consistent with metallurgical data is plausible. A minimal volume of channels within the debris and a minimal size gap between the debris and the vessel could easily support the rapid and slow cooling hypothesized to exist during the TMI-2 accident.

\subsubsection{Sensitivity of Results to Failure Criteria}

Inspection of plots of vessel deformation and damage distribution in the previous sections illustrates that, in many cases, predicted failure strains are quite small (less than 10\%). Members of the Structural Mechanics Peer Review Group indicated that these results suggest that the stress-based damage failure criterion used for calculations discussed in the previous section is too conservative. ${ }^{26}$ It is therefore desirable to perform a similar set of calculations with a less conservative failure criterion to see how the required reduction in nominal loading is changed when the criterion is modified. Results in the previous sections were also performed with constitutive relations based solely on secondary creep. It has also been suggested that one of the reasons for the low predicted failure strains is the lack of tertiary data in the constitutive relations. ${ }^{26}$ For these reasons, another set of structural simulations were performed. The failure criterion used in the simulations described in this section is one of mechanical instability. Damage is not used, and no ligaments are clipped. As the structure approaches failure, it advances a fixed increment of deformation in progressively shorter time intervals. Three characteristic quantities were used to define the point of failure: the vertical deflection at the bottom of the shell, directly underneath the hot spot; the maximum hoop strain, also directly underneath the hot spot; and the maximum rotation of the shell meridian, located somewhere in the cusped region. When these characteristic deflections and rotations are plotted versus time, a distinct knee appears in the curve which marks the onset of mechanical instability. This defines the point of failure.

Three types of calculations were performed to investigate the influence of failure criterion and the inclusion of tertiary creep. First, calculations were performed using the nominal heat fluxes without a hot spot. Second, calculations were performed to quantify the amount of slow cooling needed to preclude vessel failure. Finally, calculations were performed to determine the amount of rapid cooling needed to obtain cooling rates consistent with the cooling indicated by vessel metallurgical examinations.

To see the influence of the tertiary strains, a calculation was first performed for a case in which the nominal heat fluxes were applied to a sector of the lower head without the hot spot. In one simulation, the constitutive relations included only the secondary creep regime, while in the other, both secondary and tertiary relations were used. The simulation including only the secondary regime failed in just under 3.75 hours. Although the simulation including the tertiary regime was terminated prior to the time of failure, it appeared that failure would have occurred in about 2.75 hours.

Simulations were performed involving the hot spot on background heat flux distributions corresponding to $100 \%, 75 \%, 62.5 \%$, and $50 \%$ of the nominal case. Results indicate that failure times are well defined for the cases of hot spots on $100 \%$ and $75 \%$ of nominal, with failures occurring just under 2 and 3 hours, respectively. However, the response of the $62.5 \%$ and $50 \%$ nominal cases is somewhat different because the rate of change of deformations is more modest with time after a few hours. 
At approximately 4 hours into the transient, the reactor coolant system pressure decreases substantially, resulting in pressures as low as $3 \mathrm{MPa}$ before ascending back to $16 \mathrm{MPa}$ at 11 hours. As indicated in Figure 7-7, the rate of change of deformations drops dramatically once this lower pressure is encountered. In the case of a hot spot on $50 \%$ nominal heat flux, the hot region is still quite restrained before depressurization, with very small tensile normal stress components in the hot spot region. When the system depressurizes, the vessel unloads elastically, and most of the hot spot experiences compression following depressurization. Only the outer two ligaments experience tension at this time. The structure creeps down for a period of time so that the hoop strain actually decreases during depressurization. There is less of this effect for the case of $62.5 \%$ of nominal heat flux, and, after the depressurization is complete (approximately 5.25 hours), values for characteristic deformation parameters (strains, rotations, and displacments) begin to rise again.

The combination of depressurization with the partial propagation of tertiary creep through the vessel results in a few severe stress states, which slow the simulation down significantly. Ligaments were allowed to and did return to the secondary regime, but this did not relieve all points from the tertiary regime. As a result, it was not possible to get the simulation to advance past 6 hours with the actual pressure history. Figure 7.7 illustrates that the case involving $62.5 \%$ nominal heat flux advanced to substantially greater deformations than the case involving $50 \%$ nominal heat flux before the depressurization, and the deformations appear to recover and continue to climb after depressurization. Results involving rapid cooling, discussed below, suggest that a vessel experiencing these deflections, and subject to repressurization to $16 \mathrm{MPa}$, will again experience rapid rates of increasing deformation. Hence, the simulations suggest that the vessel is not able to survive slow cooling of a hot spot on a background heat flux $62.5 \%$ of the nominal level.

Figure 7-8 illustrates the distribution of tertiary ligaments for the hot spot on the $62.5 \%$ nominal heat flux under the actual pressure history. It is clear from this figure that the tertiary regime is unable to propagate all the way through the vessel's thickness before the depressurization. Furthermore, once the depressurization occurs, the through-thickness propagation recedes. The results of these slow cooling analyses are that the vessel is capable of surviving a hot spot on a background heat flux outside the area of the hot spot between $50 \%$ and $62.5 \%$ of nominal; this may be compared with the results from the damage-based criterion, which suggests survival is possible on a background heat flux between $25 \%$ and $33 \%$ of nominal (see Section 7.4 .2 ).

Rapid cooling simulations were performed for hot spots on background heat fluxes equal to $62.5 \%, 75 \%$, and $80 \%$ of the nominal level. Maximum values of characteristic deformation parameters for the $62.5 \%$ case are plotted in Figure 7-9. Rapid cooling in all cases was initiated at 2.16 hours into the transient, at which time the hot spot had been above $1,320 \mathrm{~K}$ for a sufficient period of time to be consistent with metallurgical observations inferred from TMI-2. At the time rapid cooling is initiated for the case of $62.5 \%$ of nominal heat flux, the vessel has experienced only modest deflections, and the hot spot is still well restrained. Initiation of rapid cooling results in a small decrease in all characteristic deformation parameters, and the vessel asymptotically reaches a benign state. The vessel easily survives the case of rapid cooling for $62.5 \%$ of nominal heat flux. In the cases of rapid cooling with $75 \%$ and $80 \%$ of nominal heat flux, the vessel experiences considerably greater deformation before rapid cooling is initiated. 


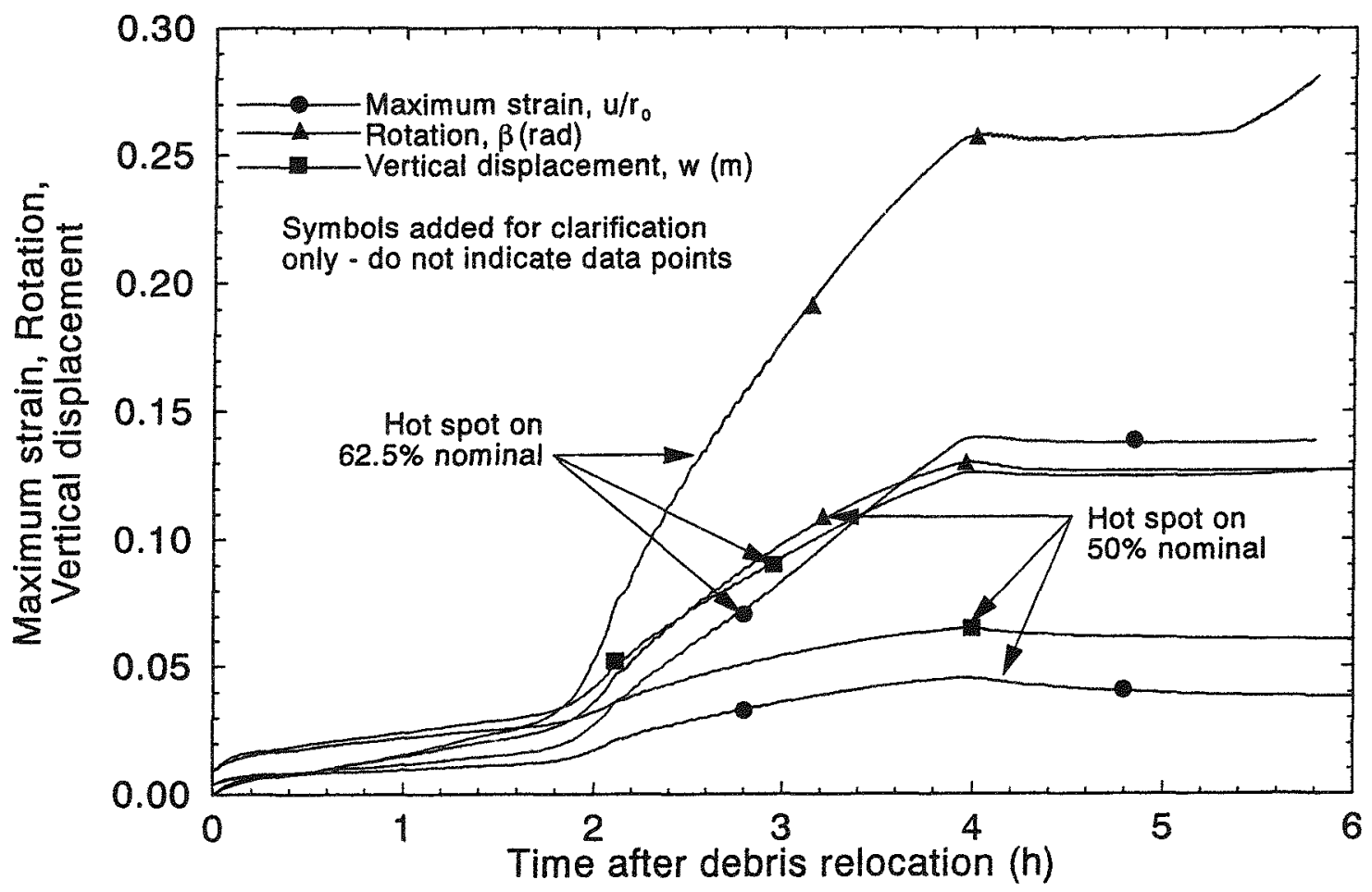

M971 jir-0893-03

Figure 7-7. Comparison of results for cases with a hot spot on $50 \%$ and $62.5 \%$ nominal case heat fluxes. 

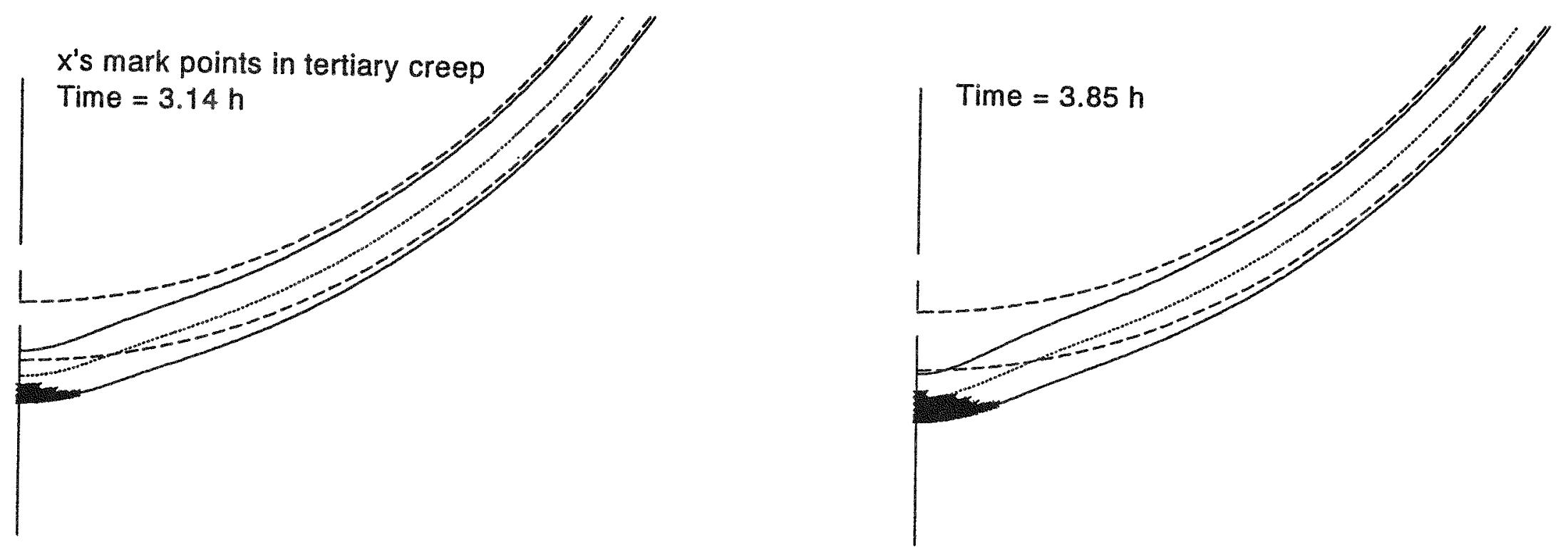

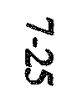

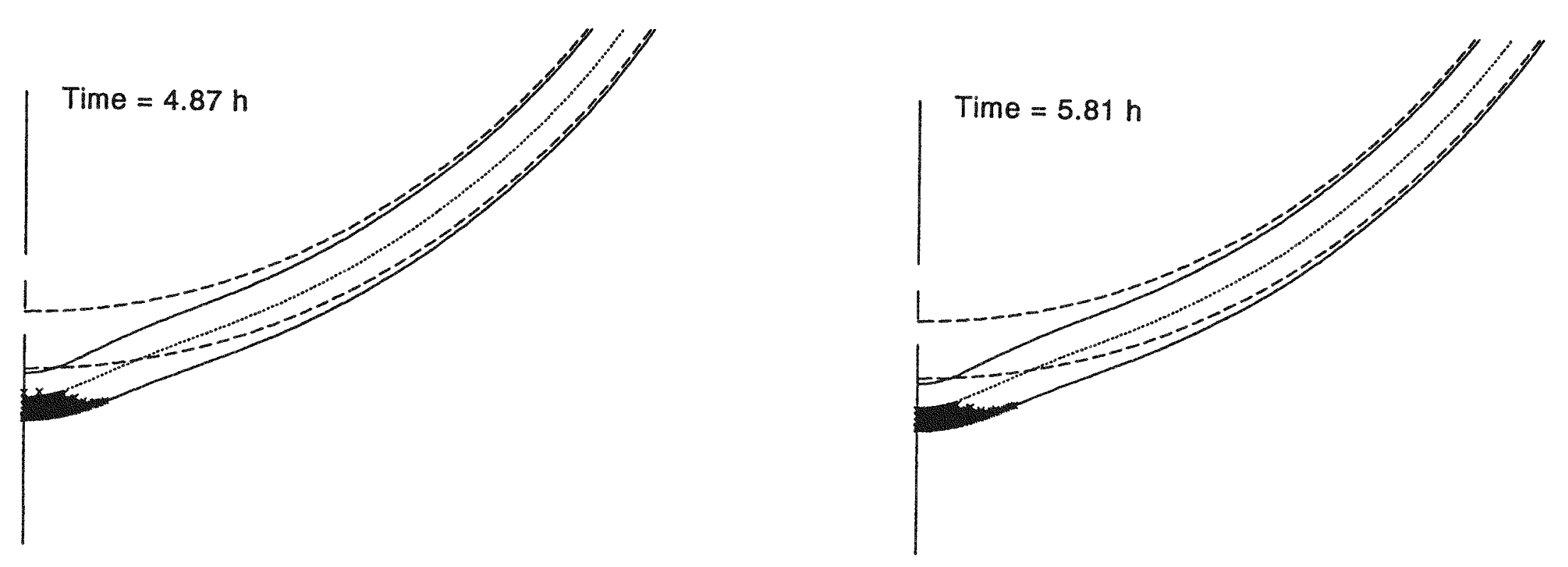

Figure 7-8. Distribution of ligaments experiencing tertiary creep at various times for the $62.5 \%$ nominal case with a hot spot. 


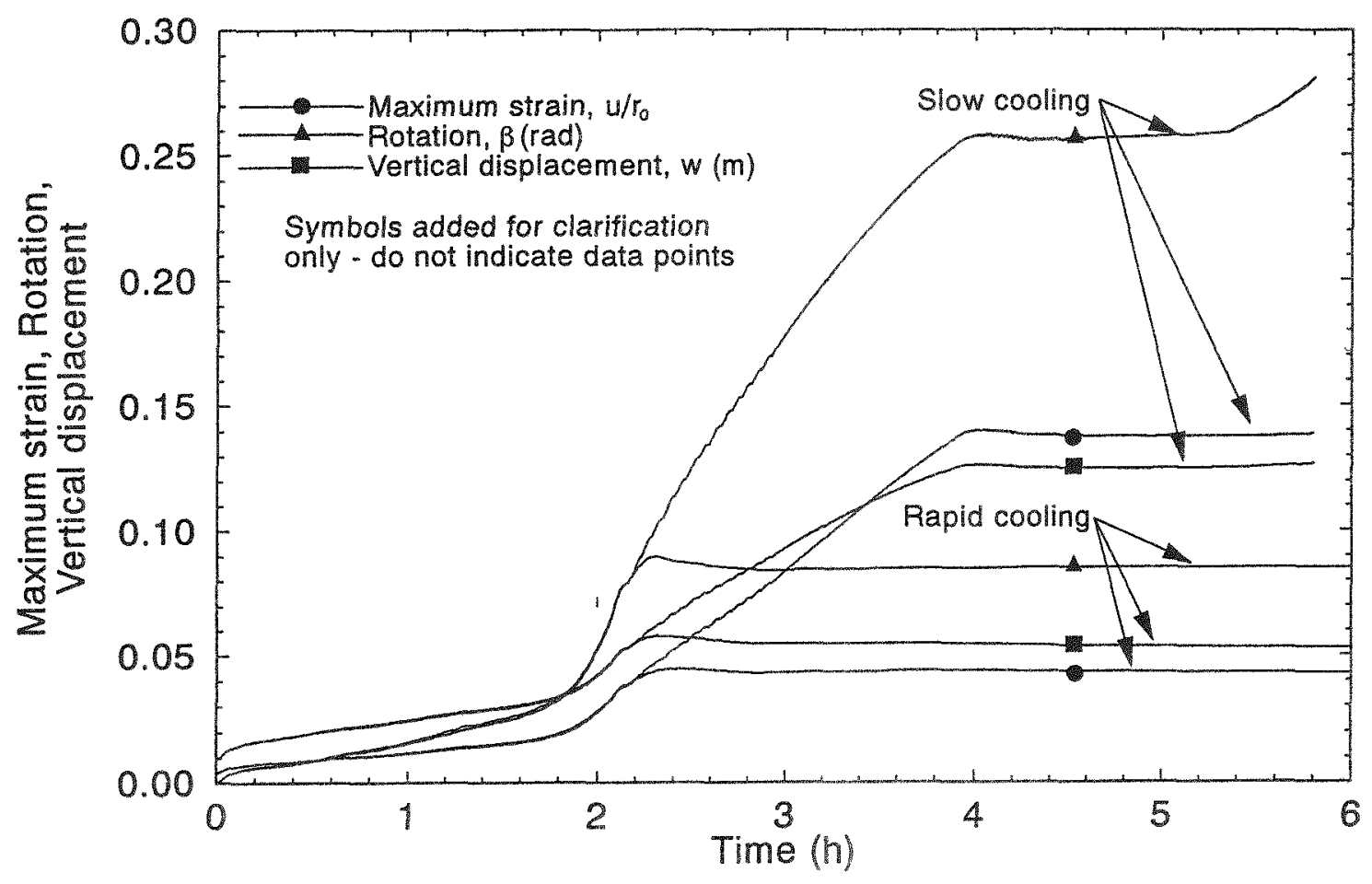

M971 jtr-0893-07

Figure 7-9. Comparison of results with and without rapid cooling for a $6.25 \%$ nominal case with a hot spot.

As indicated in Figure 7-10, the response of characteristic deformation parameters is quite different from the case of $62.5 \%$ of nominal heat flux. During the cooling period itself, there is little change in either the peak strain or vertical deflection, but the maximum meridian rotation decreases. Once the cooldown is completed, all characteristic deformation parameters continue to increase, but at a slower pace than experienced before the initiation of rapid cooling. At 4 hours into the transient, the system depressurizes, and virtually no change in any of the characteristic deformation parameters occurs during this period. Once the system begins to repressurize at 11 hours, however, all characteristic deformation parameters begin to rapidly increase again. Although these latter two cases were not run all the way to failure, it appears from the plots that failure occurs in about 13 and 11 hours, respectively, for the cases of rapid cooling of a hot spot from $75 \%$ and $80 \%$ of the nominal background heat flux.

In summary, it has been found that vessel survival based on a mechanical instability failure criterion is possible for a hot spot on $50 \%$ to $62.5 \%$ of nominal case background heat flux under slow cooling conditions, and between $62.5 \%$ and $75 \%$ of nominal case heat flux in the presence of rapid cooling. Levels of survivable heat flux are substantially larger than in the slow cooling case analyzed using the damage-based failure criterion, but the distinction between slow and rapid cooling survivability is not nearly as great. 


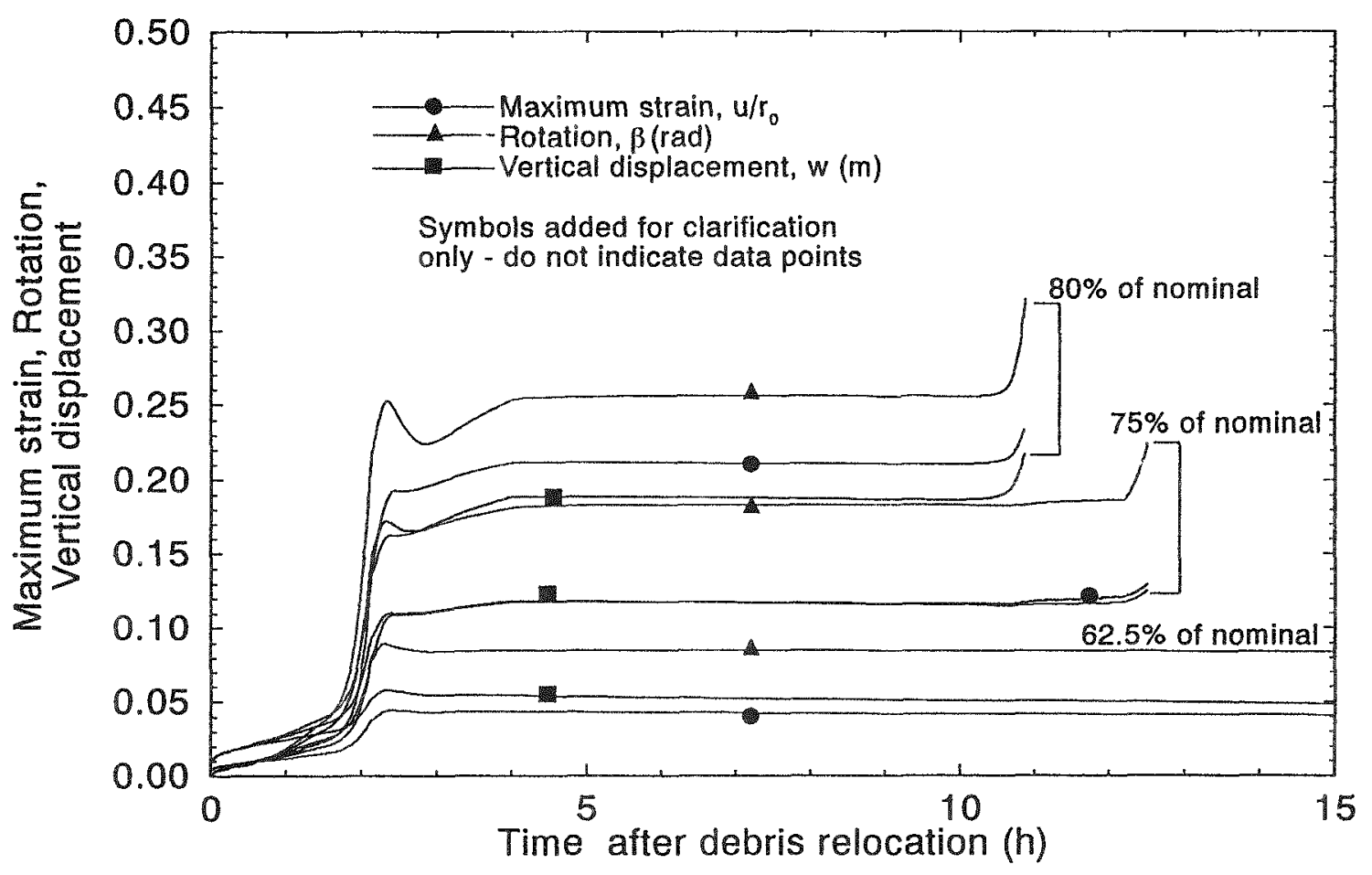

M971 Hr-0893-06

Figure 7-10. Comparison of results for rapid cooling on various nominal heat fluxes with a hot spot.

\subsection{Summary and Conclusions}

As part of the TMI-2 VIP, margin-to-failure calculations for mechanisms having the potential to threaten the integrity of the vessel were performed to improve understanding of events that occurred during the TMI- 2 accident. This section summarizes results from these calculations and major insights gained from the analyses.

Results from melt penetration calculations indicate that molten fuel would not penetrate the lower head, and that other material (such as control rod material), which may penetrate below the vessel head, would not have sufficient heat capacitance to raise ex-vessel tube temperatures.

Hence, ex-vessel tube rupture calculations were performed assuming tube temperatures consistent with the vessel coolant temperatures. Because such temperatures were expected to result in very high margin-to-failure estimates, a constant upper-system pressure of $15 \mathrm{MPa}$ was also applied in the tube failure calculations. Results indicate that the margin to failure for this failure mode was very high.

Jet impingement calculations indicate that the amount of breakup occurring as melt relocated to the lower plenum is insignificant. Impingement calculations also indicate that the magnitude and duration of hot spot temperatures estimated in TMI-2 vessel examinations could not have been caused by an impinging jet. Rather, hot spot temperatures probably occur later in 
the scenario due to a sustained heat load from molten debris on the lower head. The limited area estimated to have experienced hot spot temperatures suggests that this region was subjected to a localized heat source, such as might occur with a nonhomogeneous debris bed or a localized region with enhanced debris-to-vessel contact.

Thermal analysis results indicate that only a case with lower-bound input assumptions for parameters, such as debris decay heat, result in global vessel temperature predictions that are consistent with metallurgical examination data; namely, that global vessel temperatures remain below values at which the material undergoes a transition from ferritic to austenitic steel.

Results from a weld failure analysis indicated that the weld holding the nozzle to the vessel remained intact. Because it was not known if the hot spot temperatures occurred at the same time that the RCS was repressurized to $15 \mathrm{MPa}$, weld failure calculations were conservatively performed assuming that peak temperatures and pressures occurred simultaneously. Results indicated that even for these very conservative assumptions, there was considerable margin in the weld's integrity. Therefore, there was no need for a tube ejection analysis.

The potential for the vessel to fail globally was evaluated for vessel temperature distributions based upon nominal and lower-bound input assumptions. Note that both of these temperature distributions were obtained by assuming that the molten debris experienced relatively slow cooling rates, in order to be consistent with companion sample examination data. Global failure was predicted to occur 1.7 hours after melt relocation for the nominal case, and 2.3 hours after debris relocation for the lower-bound case. Thus, results suggest that additional debris cooling, not evident from companion sample examinations, occurred within the first 2 hours to prevent global vessel failure.

The potential for the vessel to experience a localized failure was evaluated by imposing hot spot temperatures on two background temperature distributions, the lower-bound case temperatures, and a benign case with temperatures remaining at the initial conditions for the lower-bound case (i.e., vessel temperatures below $327^{\circ} \mathrm{C}$ ). These two temperature distributions bounded possible background temperature distributions predicted by metallographic examinations because boat sample examinations indicate that temperatures outside the hot spot remained below the ferritic-to-austenitic transition temperatures, and it is known that vessel temperatures were, at least, at operating conditions. Lower-bound case results indicate that the presence of a hot spot reduces failure time predictions from 1.9 to 1.5 hours. Furthermore, the deformation and damage distribution predicted in the vessel just prior to failure differ because of the hot spot. However, results from the benign case indicate that the vessel is capable of surviving a local hot spot in the temperature range and of the duration inferred from the metallurgical examinations if the regions of the vessel outside the hot spot remain relatively cool.

Because initial scoping calculations based upon debris decay heat values from companion sample examinations indicate that vessel failure would occur, additional scoping calculations were performed to investigate the potential for debris cooling to have occurred after relocation to the lower head. An energy balance considering coolant mass flows entering and leaving the vessel indicate that the debris cooled in the time period between relocation and vessel repressurization (between 224 and 320 minutes). Two forms of cooling were investigated that have the potential to produce the postulated debris cooling: 
- A slow cooling mode in which it is assumed that water slowly removes heat as it travels through channels or "cracks" within the debris.

- A rapid cooling mode in which it is assumed that coolant rapidly removes heat as it travels through channels or "gaps" between the vessel and the debris.

The slow cooling analysis indicates that coolant traveling through a relatively insignificant volume of channels within the debris (i.e., less than $1 \%$ of the debris volume) will remove sufficient heat to preclude vessel failure being predicted. Rapid cooling analysis results indicate that coolant traveling through a debris-to-vessel gap of minimal thickness (i.e., as small as $1 \mathrm{~mm}$ ) will remove sufficient heat to allow the vessel to experience cooling rates consistent with metallurgical examination data.

Although the magnitude of debris cooling required was decreased when the stress-based failure criterion was replaced with a mechanical instability failure criterion, calculational results indicate that a combination of both cooling mechanisms must occur in order for results to be consistent with metallurgical examination data. For example, if only a slow cooling mechanism were present, the vessel temperatures would not be predicted to experience the rapid cooling rates observed in the metallurgical examinations. Furthermore, analyses indicate that the vessel would fail before the hot spot temperatures on the nominal case heat fluxes were sustained for the 30-minute time period estimated in metallurgical examinations. Thus, analyses indicate that both mechanisms must be considered in order to obtain results consistent with TMI-2 VIP examinations.

In summary, major insights from the failure analyses include the following:

- The large margin-to-failure estimates for tube failure mechanisms essentially preclude the potential for tube failure to occur during the TMI-2 event.

- It is possible for the vessel to withstand the hot spot temperatures and durations determined from the vessel metallurgical examinations if the area of the vessel outside the hot spot remains relatively cool. Localized and global vessel failure calculations indicate that the background temperature behavior of the vessel, which is highly dependent upon the heat load from relocated debris in the lower head, is key to predicting failure from either of these mechanisms.

- It is postulated that sufficient debris cooling occurred within the first 2 hours after debris relocation to the lower head in order to prevent predictions of vessel failure when the vessel was repressurized. Although companion sample examination data are insufficient to quantify the timing and rate of debris cooling, additional scoping calculations suggest that the debris cooled in the time interval after relocation and before vessel repressurization.

- Debris cooling may have occurred via coolant traveling in channels within the debris and in gaps between the debris and the vessel. Calculations indicate that the presence of a relatively insignificant volume of channels within the debris in conjunction with a relatively thin gap between the debris and the vessel would have significantly enhanced debris cooling during this time period and allowed margin-to-failure calculation results to be consistent with metallurgical examination data. 


\subsection{References}

1. L. A. Stickler et al., Calculations to Estimate the Margin to Failure in the TMI-2 Vessel, TMI V(93)EG01, OECD-NEA-TMI-2 Vessel Investigation Project, October 1993.

2. J. L. Anderson, Recommended HPI Rates for the TMI-2 Analysis Exercise (0-300 Minutes), EGG-TMI-7833, EG\&G Idaho, Inc., September 1987.

3. P. Kuan and E. L. Tolman, Electromatic Relief Valve Flow and Primary System Hydrogen Storage during the TMI-2 Accident, EGG-TMI-7703, EG\&G Idaho, Inc., May 1987.

4. R. D. McCormick, TMI-2 Data Summary Report, EGG-TMI-7843, EG\&G Idaho, Inc., September 1987.

5. Y. Nomura, PORV Discharge Flow during the TMI-2 Accident, EGG-TMI-7825, EG\&G Idaho, Inc., July 1987.

6. A. P. Kelsey, Lower Head Debris Topography, TMI-2 Technical Bulletin TB-89-02, GPU Nuclear Corporation, Project Planning and Analysis Department, Middletown, PA, February 27, 1989.

7. G. E. Korth, Metallographic and Hardness Examinations of TMI-2 Lower Pressure Vessel Head Samples, TMI V(92)EG01, OECD-NEA-TMI-2 Vessel Investigation Project, January 1992.

8. MPR Associates, Inc., Phase 4 Status Report: Removal of Test Specimens from the TMI-2 Reactor Vessel Bottom Head, Project Summary, MPR-1195, October 1, 1990.

9. D. R. Dierks and L. A. Neimark, Results of Mechanical Tests and Supplementary Metallographic Examinations of the TMI-2 Lower Head Samples, TMI V(93)AL02, OECDNEA-TMI-2 Vessel Investigation Project, Argonne National Laboratory, June 1993.

10. J. L. Rempe et al., Light Water Reactor Lower Head Failure Analysis, NUREG/CR-5642, EGG-2618, EG\&G Idaho, Inc., October 1993.

11. M. Epstein et al., "Transient Freezing of Flowing Ceramic Fuel in a Steel Channel," Nuclear Science and Engineering, 61, 1976, pp. 310-323.

12. M. Epstein, "Heat Conduction in the $\mathrm{UO}_{2}$-Cladding Composite Body with Simultaneous Solidification and Melting," Nuclear Science and Engineering, 51, 1973, pp. 84-87.

13. C. C. Chu and M. L. Corradini, "A Transient Model for Fuel-Coolant Interactions," Proceedings of the Thermal Reactor Safety Meeting, San Diego, CA, February 2-6, 1986, II.2-1 through II.2-10, February 1986. 
14. C. C. Chu, One-Dimensional Transient Fluid Model for Fuel-Coolant Interaction Analysis, Ph.D. dissertation, University of Wisconsin-Madison, Madison, WI, May 1986.

15. C. C. Chu and M. L. Corradini, "One-Dimensional Fuel-Coolant Interaction," Journal of Nuclear Science and Engineering, 101, No. 1, January 1989, p. 48-71.

16. C. C. Chu, M. L. Corradini, J. Murphy, and J. Tang, A Code Manual for TEXAS-II: One Dimensional Transient Fluid Model for Fuel-Coolant Interaction Analysis, UWRSR-39, University of Wisconsin, Madison, WI, July 1992.

17. J. Strosnider, Summary Record of the TMI VIP Structural Mechanics Peer Review Group Meeting, Idaho Falls, Idaho, May 11, 1992, TMI V(92)EG09, OECD-NEA-TMI-2 Vessel Investigation Project, July 20, 1992.

18. R. Huddleston, "An Improved Multiaxial Creep-Rupture Strength Criterion," Journal of Pressure Vessel Technology, 107, November 1985, pp. 421-429.

19. F. R. Larson and J. Miller, "A Time-Temperature Relationship for Rupture and Creep Stresses," Transactions of the ASME, 78, July 1952, pp. 765-775.

20. R. M. Goldoff, "Comparison of Parameter Methods for Extrapolating High-Temperature Data," Journal of Basic Engineering, 81, Series D, Number 4, December 1959, pp. 629-643.

21. E. L. Robinson, "Effect of Temperature Variation on the Creep Strength of Steels," Transactions of the ASME, 60, 1938, pp. 253-259.

22. P. N. Randall, "Cumulative Creep Damage in Creep Rupture Tests of a Carbon Steel," Journal of Basic Engineering, 84-2, June 1962, pp. 239-242.

23. 1. Finnie and M. Patel, "Life-Prediction for Furnace Tubes Operating in the Creep-Rupture Range," Mechanical Behavior of Materials: Proceedings of the 1974 Symposium on Mechanical Behavior of Materials, August 21-24, 1974, Kyoto, Japan, Society of Materials Science, Japan, Vol. 2, 1974, pp. 215-225.

24. PAFEC, Version 6.1, Nottingham, England: PAFEC Ltd., 1984.

25. B. G. Schnitzler, Fission Product Decay Heat Modeling for Disrupted Fuel Regions (FDECAY), EGG-PHYS-5698, EG\&G Idaho, Inc., December 1981.

26. Y. R. Rashid, "Summary of Comments on the Margin-to-Failure Report," Presentation at the 11th Programme Review Meeting of the OECD-NEA-TMI-2 Vessel Investigation Project, TMI V(93)MAN, May 17, 1993. 



\title{
8. DEBRIS RELOCATION SCENARIO
}

\author{
J. R. Wolf and D. W. Akers, Idaho National Engineering Laboratory \\ L. A. Neimark, Argonne National Laboratory
}

\subsection{Introduction}

This section presents one possible scenario describing the relocation of debris to the lower head of the reactor vessel and is based on available plant instrumentation records and postaccident examination results. The scenario presented here is not the only potential debris relocation scenario, but is consistent with information obtained from plant data, VIP examinations, analysis efforts, and other TMI-2 programs.

This scenario addresses debris relocation events chronologically and assesses factors that may have contributed to the end-state condition of the lower head, the damage to the structures in the lower part of the reactor vessel, and the debris on the lower head. Included is the initial movement of molten material from the core, through the reactor vessel core support assembly to the lower internals, and finally onto the lower head. A general description of the accident scenario is presented in Section 2.

\subsection{Initial Events}

The initial event that affected the relocation scenario was the melting of control and fuel rods that occurred between 100 and 174 minutes when the upper half of the core was uncovered. ${ }^{1}$ During this period, both fuel and control rod cladding melted and drained down through the uncovered core leaving intact fuel pellet stacks and rubble. The cladding material flowed down through the core to form a metallic crust 10 to $15 \mathrm{~cm}$ thick at the lower core region. ${ }^{2}$ This lower bound was at the water level that was near the lowest grid spacer and about $20 \mathrm{~cm}$ from the bottom end of the fuel rods. This was the lowest water level during the entire accident and was about $2 \mathrm{~m}$ above the lower head.

At 174 minutes, the $2 \mathrm{~B}$ coolant pump was activated for 19 minutes. However, significant flow through the core only lasted for about 15 seconds before the reactor coolant system repressurized. This repressurization was due to zircaloy oxidation and steam formation in the upper core debris bed caused by injection of relatively cool water by the $2 \mathrm{~B}$ pump. Jets of steam from this event caused damage to the southern and northern portions of the upper fuel assembly grid and transported debris to the top of the upper plenum, ${ }^{3,4}$ onto leadscrew surfaces, ${ }^{5,6}$ and onto several other horizontal surfaces in the reactor vessel. ${ }^{7}$ Examinations of the upper core debris indicated that the control rod materials $(\mathrm{Ag}-\mathrm{In}-\mathrm{Cd})$ were concentrated in particles smaller than $1 \mathrm{~mm}$ and would thus be susceptible to transport as a hydrosol.

As discussed in Reference 6, the overall upper core debris region was composed of about $27,000 \mathrm{~kg}$ of material. Between 3 and $10 \%$ of this debris was less than $1 \mathrm{~mm}$ in diameter. Since particles less than $1 \mathrm{~mm}$ may be transportable as a hydrosol, quantities of loose debris from both control and fuel rods either settled directly in the lower part of reactor vessel during quiescent periods or were transported through the reactor coolant loop by the $2 \mathrm{~B}$ pump transient and settled in areas such as the lower head where there was relatively low flow. Therefore, finding 
intergranular $\mathrm{Ag}$-In-Cd in the surfaces of several nozzles and in the vessel cladding cracks should not be unexpected. Unfortunately, the amount of such material and the depth of the deposition layer on the lower head cannot be definitely determined.

\subsection{Relocation to the Lower Head}

Between 224 and 226 minutes, several almost simultaneous events indicated that a major change in core configuration occurred and that molten material relocated to the lower head in one continuous flow. The count rate of the neutron source-range monitor located on the outside of the reactor vessel increased sharply. Also, the simultaneous alarm of incore self-powered neutron detectors (SPNDs) at all levels on the same instrument stalk suggested that a common point of damage occurred. The molten material in the lower head heated the instrument nozzles sufficiently to produce thermoelectric currents in the SPNDs, which caused the instruments to alarm. Examination of the alarm data ${ }^{8}$ indicated that the first alarms were for SPND stalks that were in instrument tubes on the east side of the lower vessel and then propagated to the center. Post-accident measurements of incore thermocouple loop resistance, as discussed in Reference 8, indicated that new thermocouple junctions were formed in the lower head as the leads were melted by high temperatures caused by the relocated fuel. The new junctions also resulted in alarms of several of the incore thermocouples. The alarms followed a sequence similar to the SPNDs. A primary system pressure pulse (2 MPa) also occurred during this time period. These data are indicative of the time when the relocation occurred and indicate that it initiated in the eastern part of the core and lower head.

\subsubsection{Movement of Molten Material Through The Vessel}

Post-accident examinations of the eastern half of the core region and lower vessel internals confirmed plant instrumentation data and showed that relocation of the fuel debris to the lower head occurred in the eastern half of the vessel. Overall, approximately 19 metric tonnes of material reached the lower head. As discussed in Section 5, the relocated material was primarily a $(\mathrm{U}, \mathrm{Zr}) \mathrm{O}_{2}$ ceramic. Visual examinations of this part of the vessel during defueling indicated that the primary path through the vessel was through a hole melted in the R6 vertical core former wall and then downward through the horizontal baffle plates. Figure 8-1 shows a cross section of the reactor vessel internal structure. Fuel melt was found in the P-5 and R-6 assemblies near the bottom of the fuel assemblies, which indicated that some liquified fuel had drained into these assemblies and solidified during the relocation. However, as no flow path was found through these assemblies to the lower head, the principal relocation path was identified as being through the damaged core former at the R-6/P-5 core locations. Three holes in the core former wall were identified. Dimensions of the holes through the former wall ranged from $23 \times 3 \mathrm{~cm}$ to $20 \times 7 \mathrm{~cm} .9,10$ The damage to the core former wall was about $140 \mathrm{~cm}$ from the bottom of the core or a little below the midpoint of the reactor core. The damage location is indicated in Figure 8-2.

\subsubsection{Movement of Molten Debris Through the Core Support Assembly}

At the bottom of the vertical core former plates, the molten material melted back into the lower core support assembly (CSA). Visual observations indicate a massive hole and damage in the bottom on the vertical core former wall located at core grid locations R-6, R-7, P-4, and P-5. 


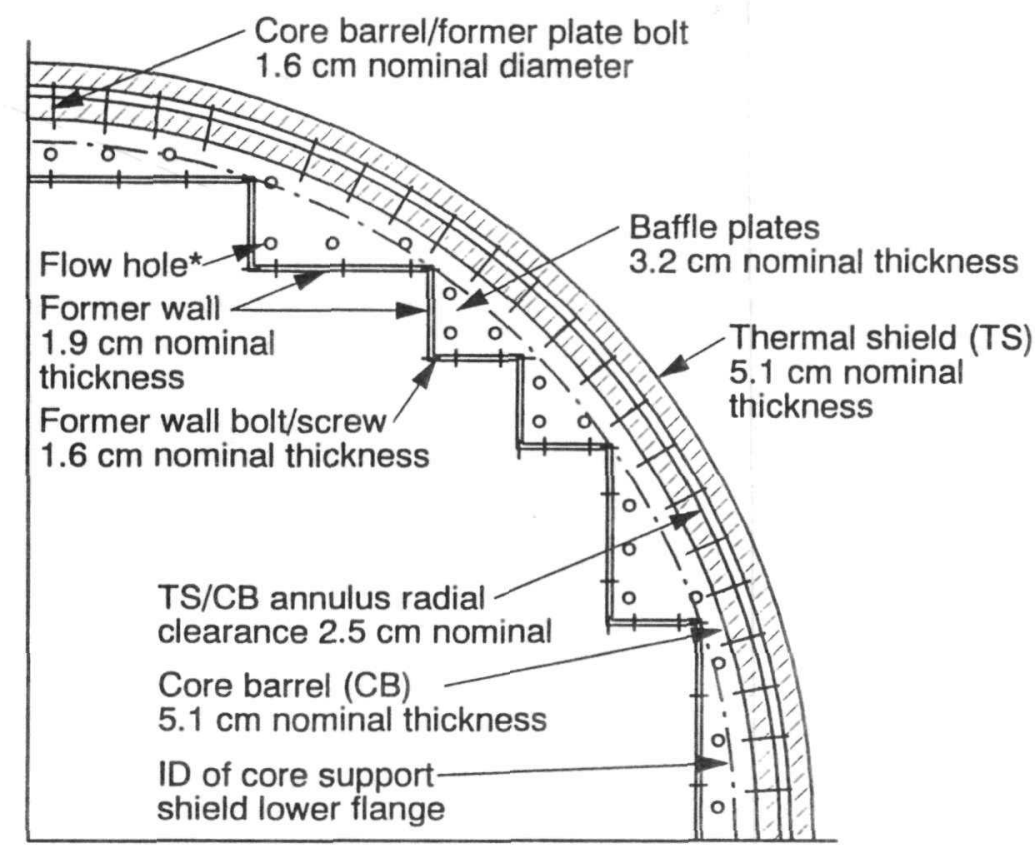

* $3.3 \mathrm{~cm}$ nominal diameter except at the fifth level where the holes are $2.5 \mathrm{~cm}$ diameter (see text)

Figure 8-1. Reactor vessel internal structures.

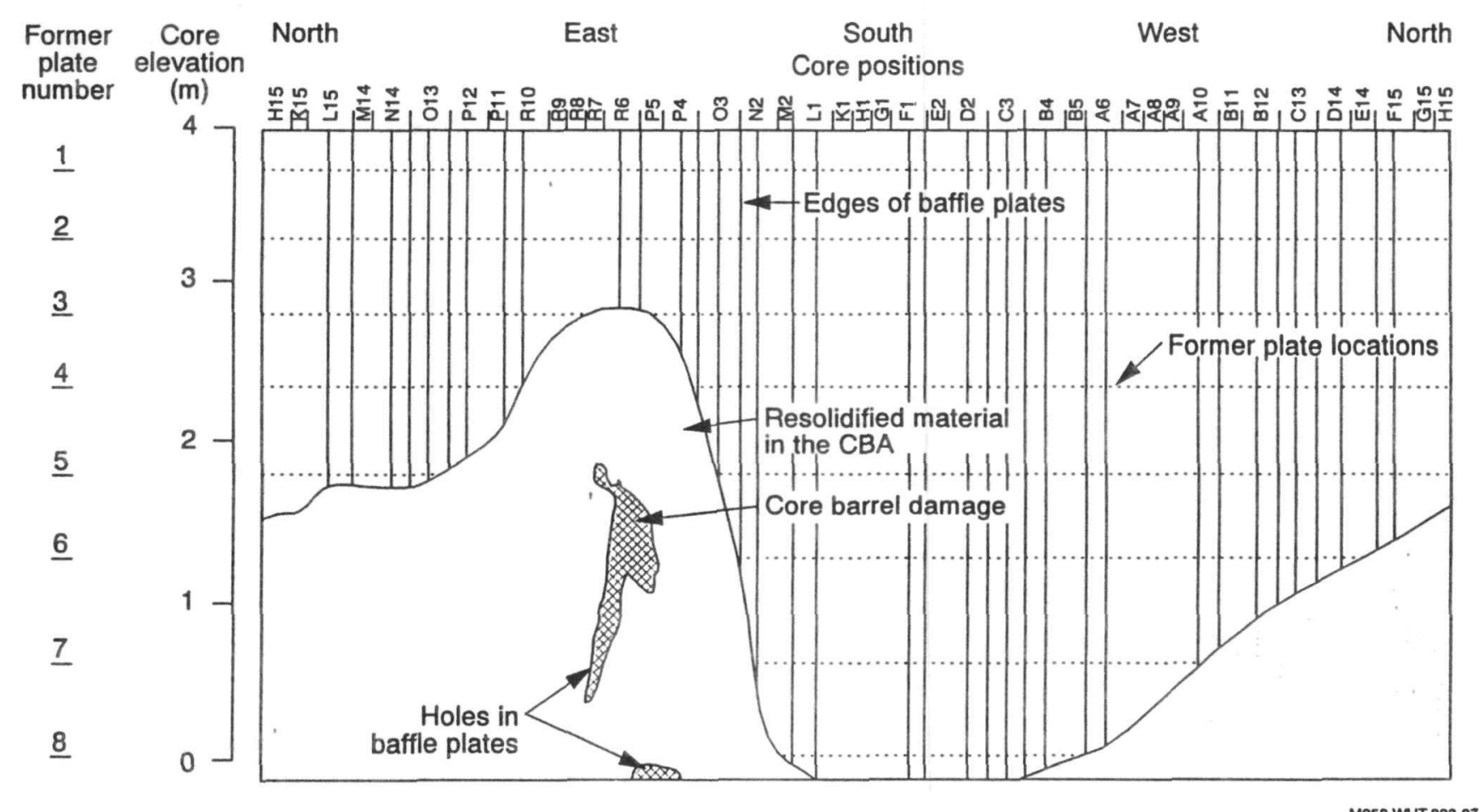

Figure 8-2. Fuel debris profile inside core former (laid flat). 
It is very difficult to trace the exact path the molten material took as it moved through the CSA structures. The flow movement scenario presented here is based on evidence derived from the assumption that the presence of flow holes plugged with solidified material indicates that molten material flowed through these holes or adjacent holes during the relocation. It is likely that once a hole was plugged with solidified material, any subsequent material that flowed in that area was diverted by the plug and flowed downward through an adjacent hole.

The CSA geometry consists of a number of plates and forging and as shown in Figure 8-3. Once in the CSA, the majority of the molten material continued to flow down through the structures on the eastern periphery in the $R-6 / 7$ and $P-4 / 5$ area. However, visual examinations indicated that some of the molten material was found to have flowed around the perimeter of the CSA structures as it penetrated downward towards the lower head. Figure 8-4 shows the location of solidified material at several locations in the flow holes of the lower grid, the area between the lower grid and the flow distributor plate, and between the flow distributor plate and the grid forging. The presence of solidified material is assumed to indicate that molten material flowed through or adjacent to these locations.

\subsubsection{Molten Debris Movement on the Elliptical Flow Distributor}

Based on the locations of solidified material in the CSA as shown in Figure 8-4, it is postulated that the molten material flowed onto the elliptical flow distributor (EFD) from the same areas where plugged flow holes existed in the CSA. Figure 8-5 indicates the locations in the EFD where solidified material was observed in or above a flow hole. ${ }^{11,12}$ As can be seen in the figure, these locations are in general agreement with the locations in Figure 8-4, where solidified material was observed in the CSA. As seen in Figures 8-4 and 8-5, many of the plugged flow holes line up quite well, which indicates that the flow moved vertically downward and covered much of the periphery of the CSA structure as it followed the flow hole alignment pattern onto the EFD. For example, the plugged holes near locations H-15, K-15, and L-15 shown in Figure 8-4 are near plugged locations $\mathrm{H}-15, \mathrm{~K}-15$, and $\mathrm{K}-14$ shown in Figure 8-5. Also, the plugged holes in location C-14 shown in Figure 8-4 are near the plugged holes in locations D-13 and D-14 shown in Figure 8-5.

The minimal amount of damage on the EFD suggests that the first material that reached the EFD, and subsequently the lower head, was probably relatively cool. The exact temperature depends on both the amount of heat given up by the molten flow before it reached the EFD and the exact composition of the molten flow. As the flow moved downward towards the EFD and eventually the lower head, heat was lost to the melting of core former structures and to water that filled the lower plenum region. If lower-temperature phases were present in the molten material, especially in the initial portion of the flow that would tend to incorporate melted structural material, it would be possible for this material to be mobile at temperatures below the solidus temperature of $(\mathrm{U}, \mathrm{Zr}) \mathrm{O}_{2}$. Microstructural and microchemical examinations of portions of the loose debris that were removed from the lower head prior to the VIP ${ }^{13,14}$ indicate that eutectic structures present in grain boundary phases could have had a solidus temperature that was considerably lower than that of the bulk $(\mathrm{U}, \mathrm{Zr}) \mathrm{O}_{2}$ material. This low melting point compared to the bulk material suggests that the grain boundaries may have remained liquid after the grains themselves had solidified. This would have allowed portions of the molten relocation flow to remain mobile at temperatures below the bulk $(\mathrm{U}, \mathrm{Zr}) \mathrm{O}_{2}$ solidus temperature. 


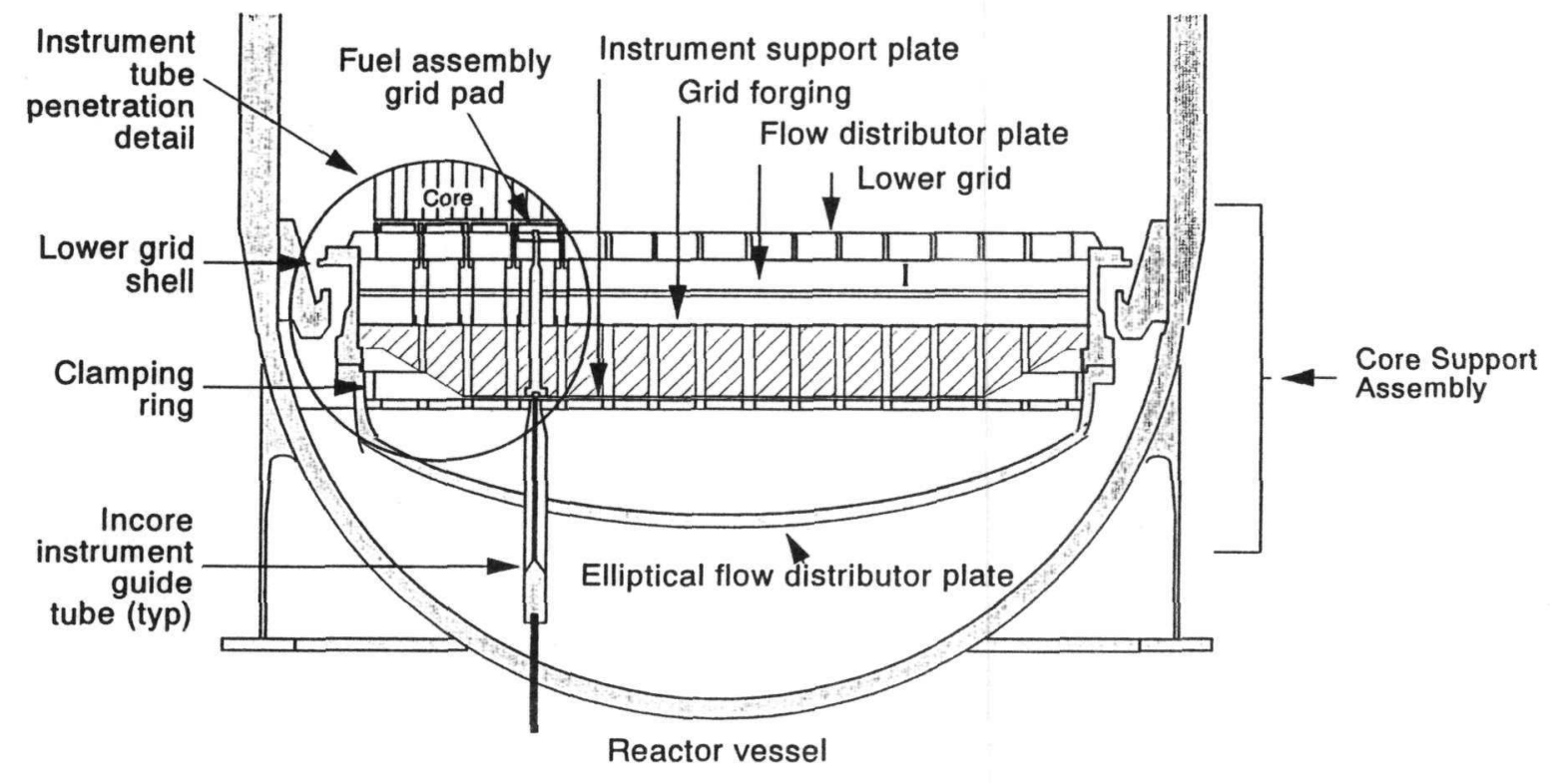

M958 jrw-0893-08

Figure 8-3. TMI-2 core support assembly.

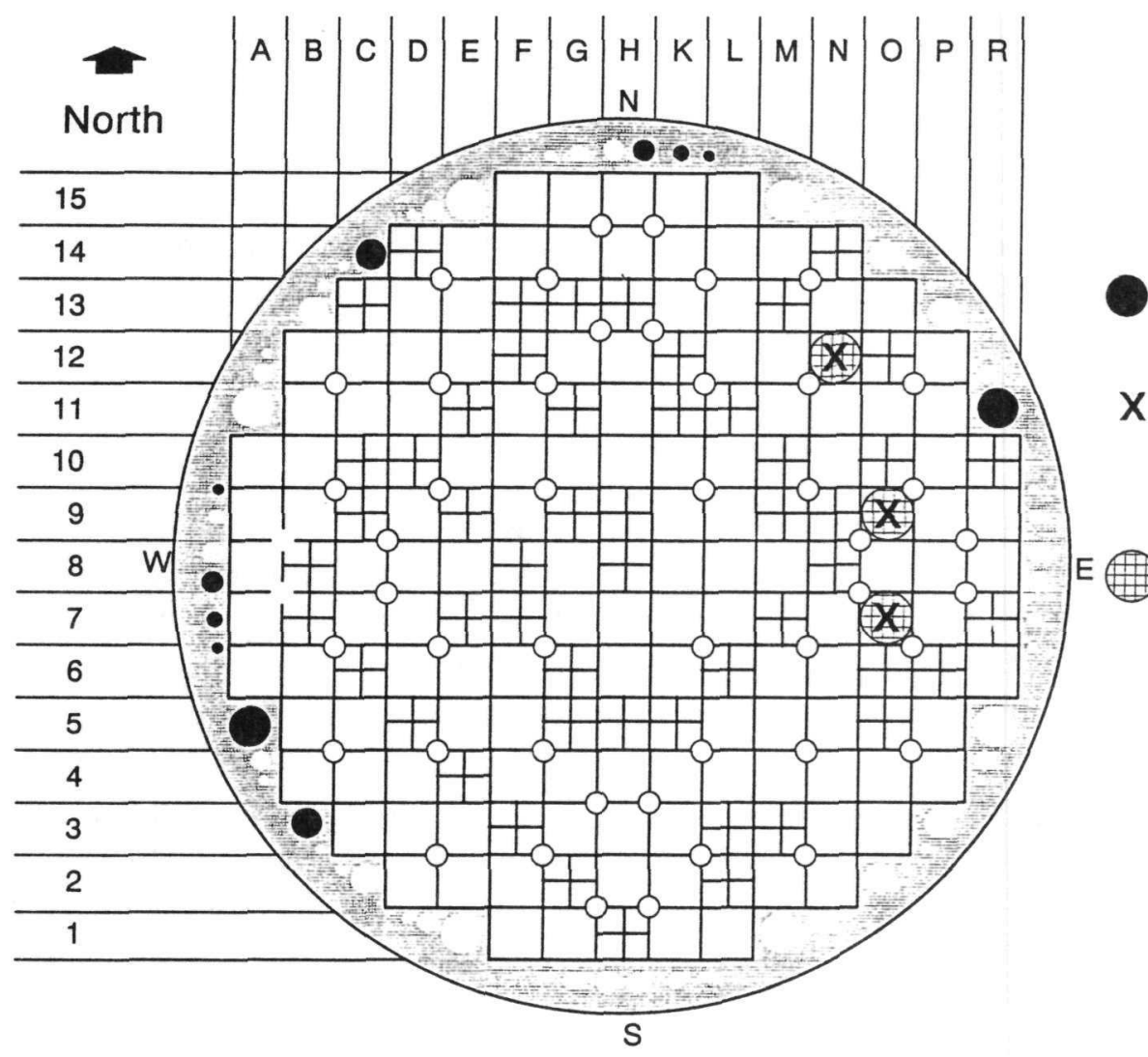

Resolidified material flowed through the shaded holes in the grid forging

$\mathrm{X}$ Location of resolidified material between the lower grid and the flow distributor plate

\section{Location of resolidified} material between distributor plate and the grid forging

Figure 8-4. Solidified material in core support assembly. 


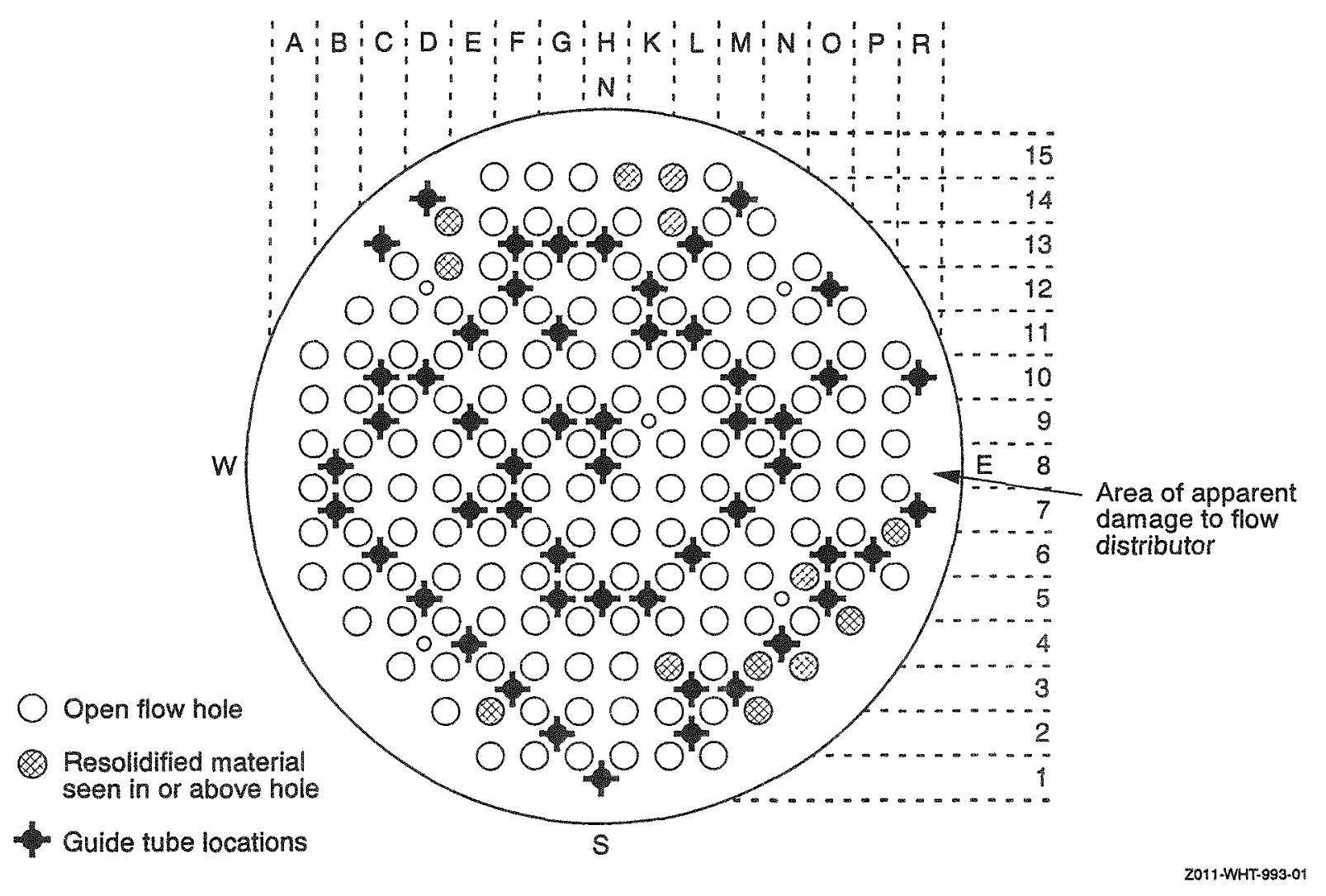

Figure 8-5. Solidified material in the elliptical flow distributor.

Some of the molten material solidified on the EFD and formed plugs in the flow holes at locations shown in Figure 8-5. The subsequent flow of material was probably diverted by the plugged holes and dropped onto the lower head from several different locations around the periphery of the EFD.

\subsubsection{Movement of Molten Debris on the Lower Head}

One of the most puzzling questions of the VIP program has been why the molten material that relocated to the lower head did not do more damage to the vessel itself and why some nozzles were completely buried in solidified debris but showed absolutely no damage while others were almost totally destroyed. It is postulated that when the initial portion of the continuous relocation flow reached the lower head, the combination of the heat sink provided by the nozzles " and the vessel lower head itself, along with insufficient thermal energy in the molten flow, cooled and rapidly froze the initial portion of molten material that reached the lower head. This made it possible for the rapid formation of a thick ceramic crust, regardless of the temperature of the molten material. The rapid buildup of this crust resulted in the formation of an insulating ceramic layer that covered much of the lower head and also formed around many nozzles. Wherever the lower head and nozzles were covered by this insulating debris layer, they were protected from thermal damage. 
As the initially cooler material fell onto the lower head from several different locations around the periphery of the EFD, the material effectively formed a cup-shaped basal crust structure that served to insulate the lower head structures in these areas. Then, hotter material flowed downward across the top of this basal crust and caused the nozzle damage pattern described in Section 6. The pattern of nozzle damage indicates that multiple flow paths existed and that the movement of molten material onto and across the lower head was not one massive unified flow.

The pattern of nozzle degradation observed at elevated levels for several nozzles is shown in Figure 8-6 and indicates the extent of the insulating ceramic debris layer that formed in the lower head and protected many of the nozzles and the lower head from extensive thermal damage. As the flow moved on top of the initial insulating debris layer, newly exposed molten fuel came in contact with the nozzles at elevated levels. These nozzles were melted at an elevation that is thought to be representative of the bottom of the molten fuel flow. Since the molten material flowed on top of the initial debris layer, this height is also representative of the thickness of insulating material that protected the lower head and the lower portions of many nozzles. As an example, examinations showed that the nozzle damage at M-9 was at about $25 \mathrm{~cm}$ above the lower head, and the damage to H-5 was about $15 \mathrm{~cm}$ above the head. Damage to nozzles around the M-9 and H-5 core locations, which have damage at elevations above the base of the nozzles, suggests that the insulating layer was approximately $25 \mathrm{~cm}$ thick at the M-9 location and $15 \mathrm{~cm}$ thick at H-5.

As the hotter molten material flowed across the top of the insulating ceramic debris layer, the cup-shaped structure that had initially formed on the lower head began to be filled. In the end, this resulted in what is known as the "hard debris layer," which is shown in Figure 8-7. ${ }^{15}$ The debris depths shown in this figure were determined from mechanical probing of the hard layer during the defueling operation.

The last material to flow onto the lower head was what is known as the "loose debris layer." The depths of the loose debris layer are shown in Figure 8-8 and were determined before the defueling effort began. ${ }^{16,17}$ The depths were determined by probing examinations and by analysis of video tapes taken of the lower head debris. Figures 8-9, 8-10, and 8-11 show cross sections of the hard debris layer thickness at several representative locations. As shown in these figures, there are relatively steep cliff-like areas along the periphery of the debris bed, and both full length and damaged nozzles are embedded in the debris.

\subsubsection{Formation of the Hot Spot}

In addition to damaging the nozzles on the lower head, the flow of the hotter molten material may have also resulted in the formation of the localized lower head hot spot. It is postulated that as the hotter material flowed down the sides of the cup-like shape that was formed by the initial insulating crust towards the bottom of the vessel, the insulating layer crust became progressively thinner. Eventually, the flow of hotter material reached an area where the basal crust thickness was insufficient to adequately insulate the lower head, and a localized hot spot formed. The location of the hot spot on the lower head is shown in Figure 8-12. 


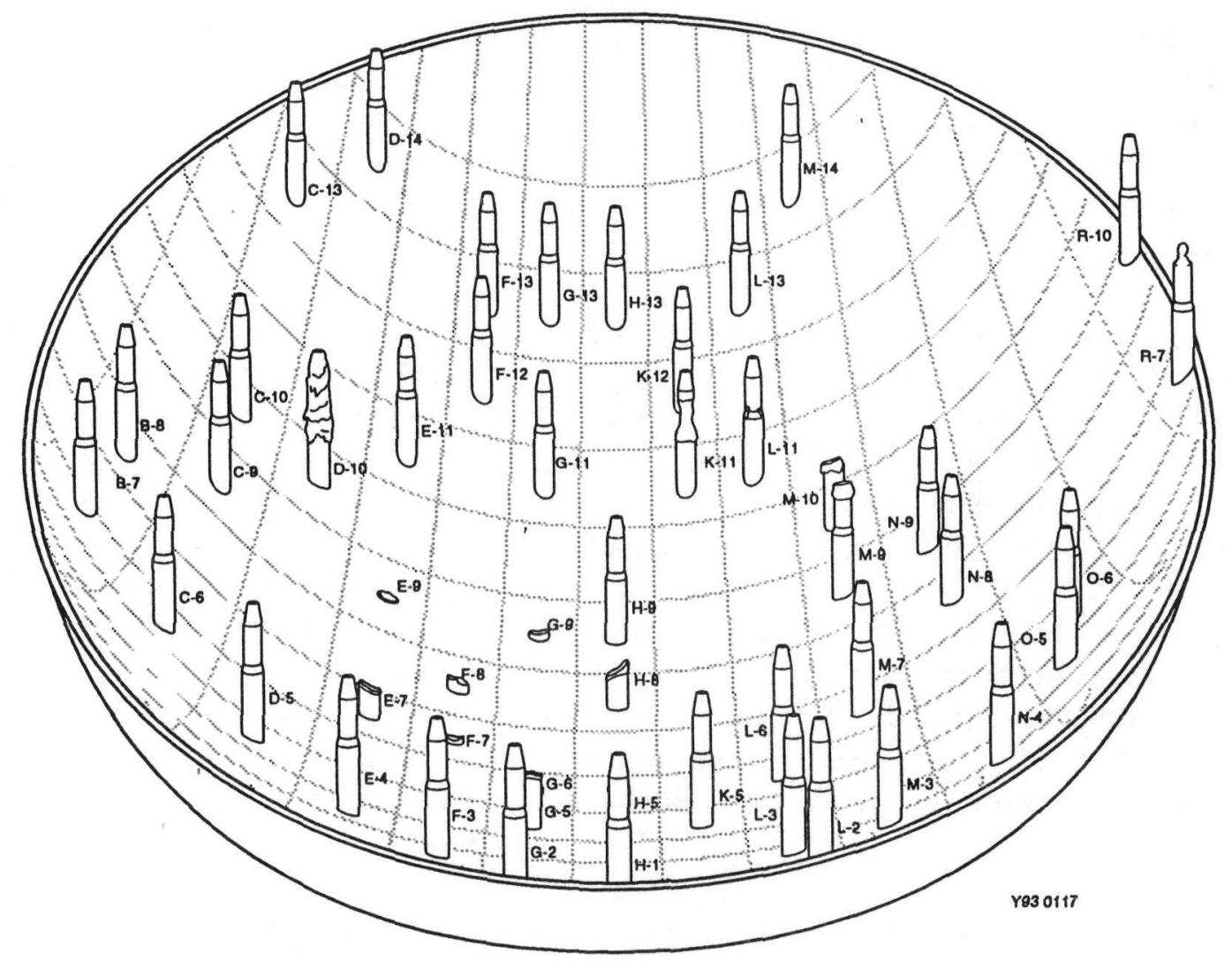

Figure 8-6. Nozzle damage profile.

The hypothesis that the hot spot was occurred beneath a crust that was of insufficient initial thickness to protect the lower head is consistent with the observation that the deepest debris was found in other locations of the vessel rather than over the hot spot. A progressively thinner crust was also indicated by data from the nozzle examinations, which showed that more of the nozzle length was melted in the vicinity of the hot spot. The region where the most severe nozzle damage occurred was consistent with the location of the hot spot and indicated that the insulating layer was thinnest in this area.

\subsection{Lower Head Cooling}

As was discussed in Section 7, thermal calculations that were based on coolant mass flow entering and exiting the reactor coolant system support the hypothesis that more lower head debris cooling occurred than would be expected, based on data from companion sample examinations. Metallurgical examinations presented in Section 4 indicated that at the hot spot location, the lower head was heated to peak temperatures of about $1,100^{\circ} \mathrm{C}$ and indicated that the temperature was maintained at that level for approximately 30 minutes before cooling rapidly $\left(50^{\circ} \mathrm{C} / \mathrm{min}\right) .{ }^{18}$ 
$\mathrm{N}$

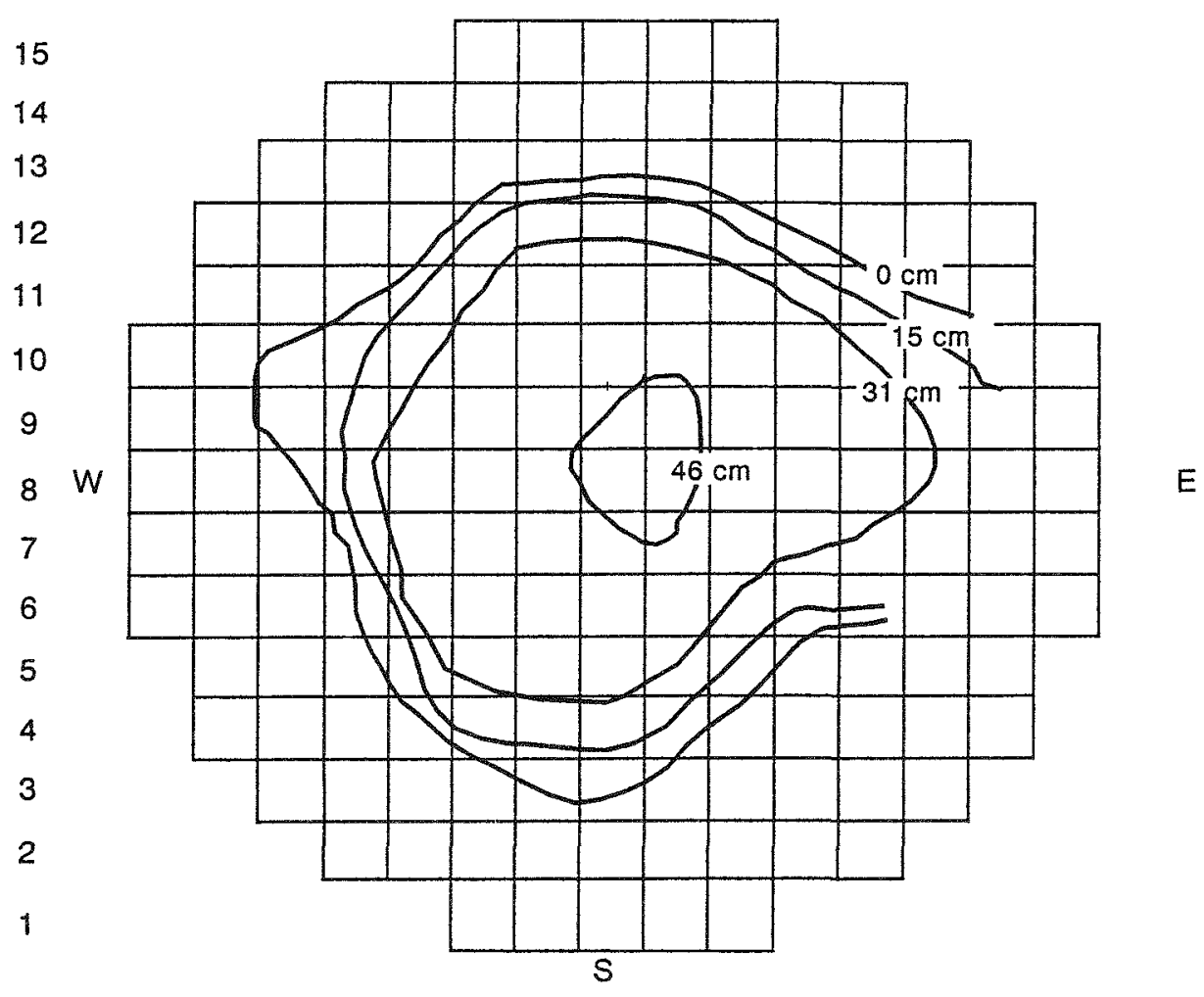

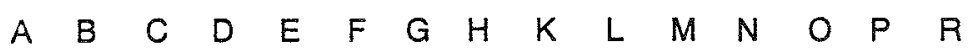

M919 jir 0793 \{3

Figure 8-7. Hard layer debris depth. (Contour lines represent incremental increases, with the outside line equal to $0 \mathrm{~cm}$ and the inside equal to $46 \mathrm{~cm}$.)

\begin{tabular}{|l|l|l|l|l|l|l|l|l|l|l|l|l|l|l|}
\hline$A$ & $B$ & $C$ & $D$ & $E$ & $F$ & $G$ & $H$ & $K$ & $L$ & $M$ & $N$ & $O$ & $P$ & $R$ \\
\hline
\end{tabular}

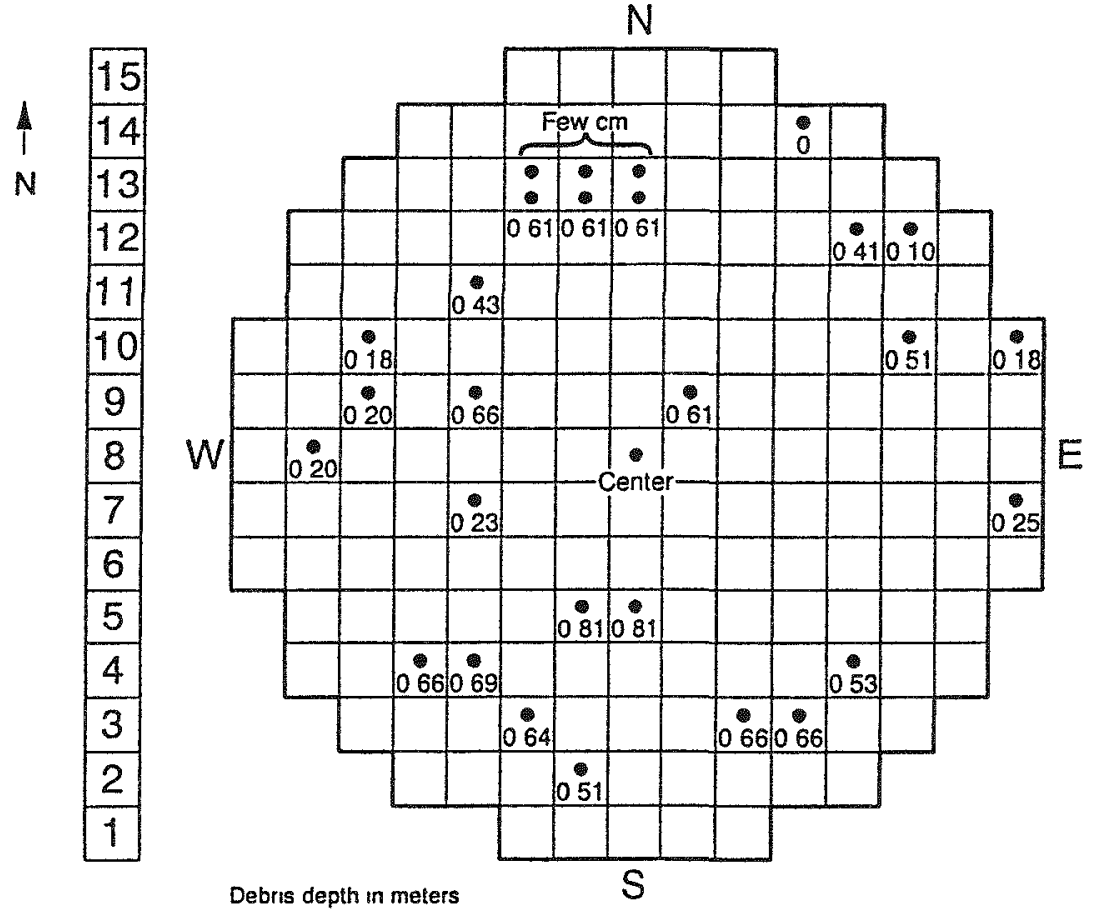

Figure 8-8. End state hard and loose layer debris configuration. 

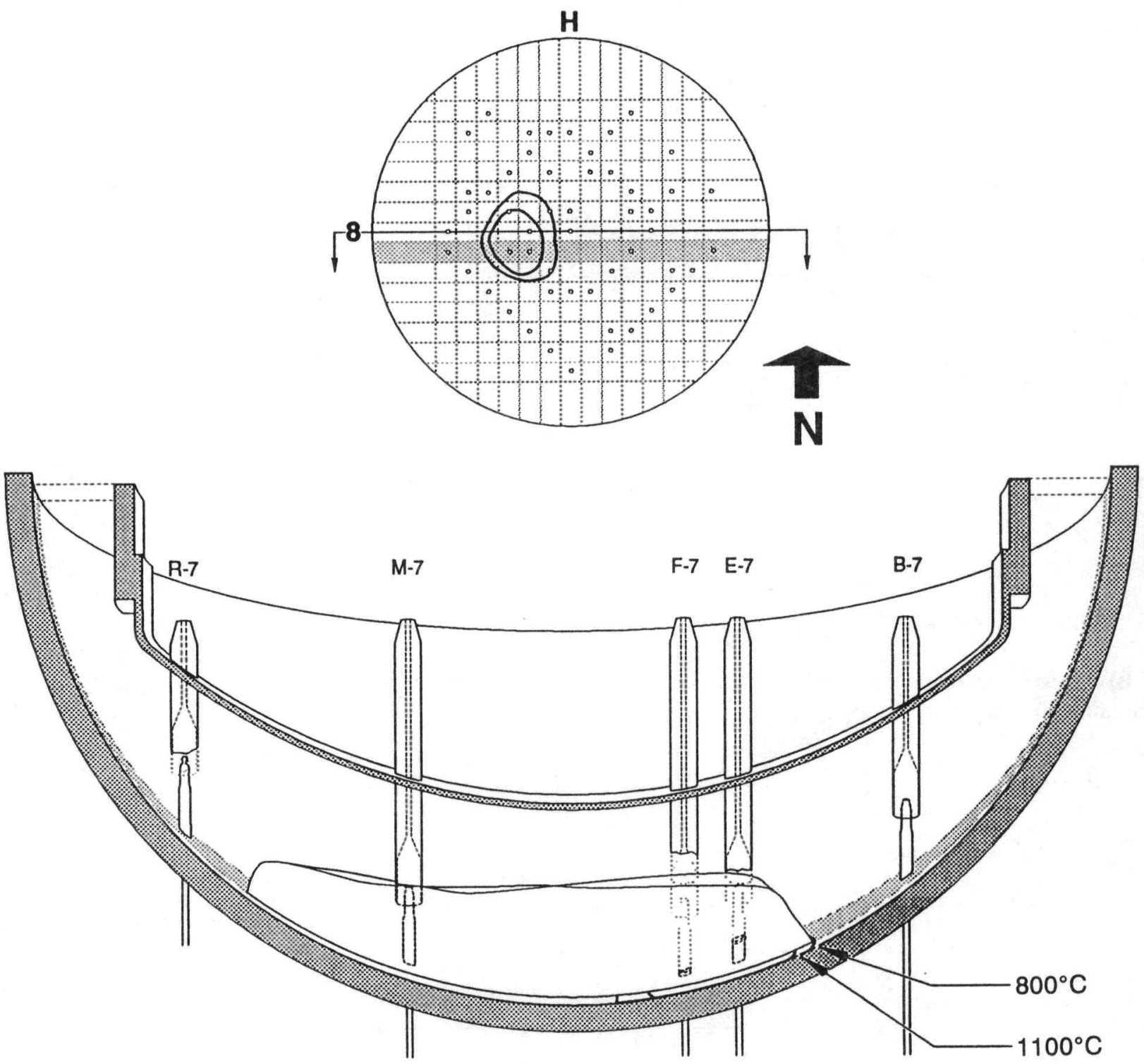

Figure 8-9. TMI-2 lower head cross section of hard debris, row 7. 

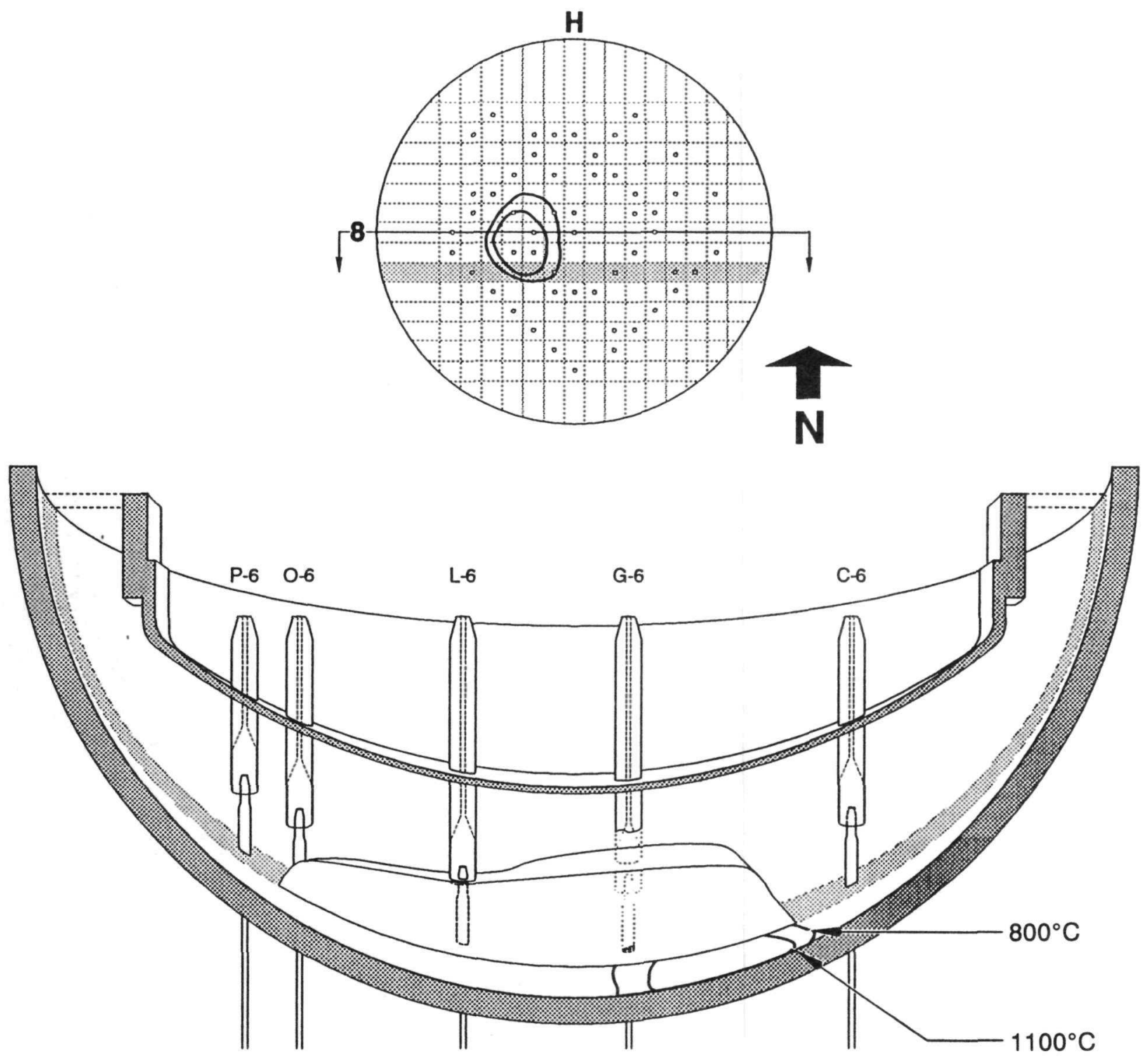

Y930413

Figure 8-10. TMI-2 lower head cross section of hard debris, row 6. 

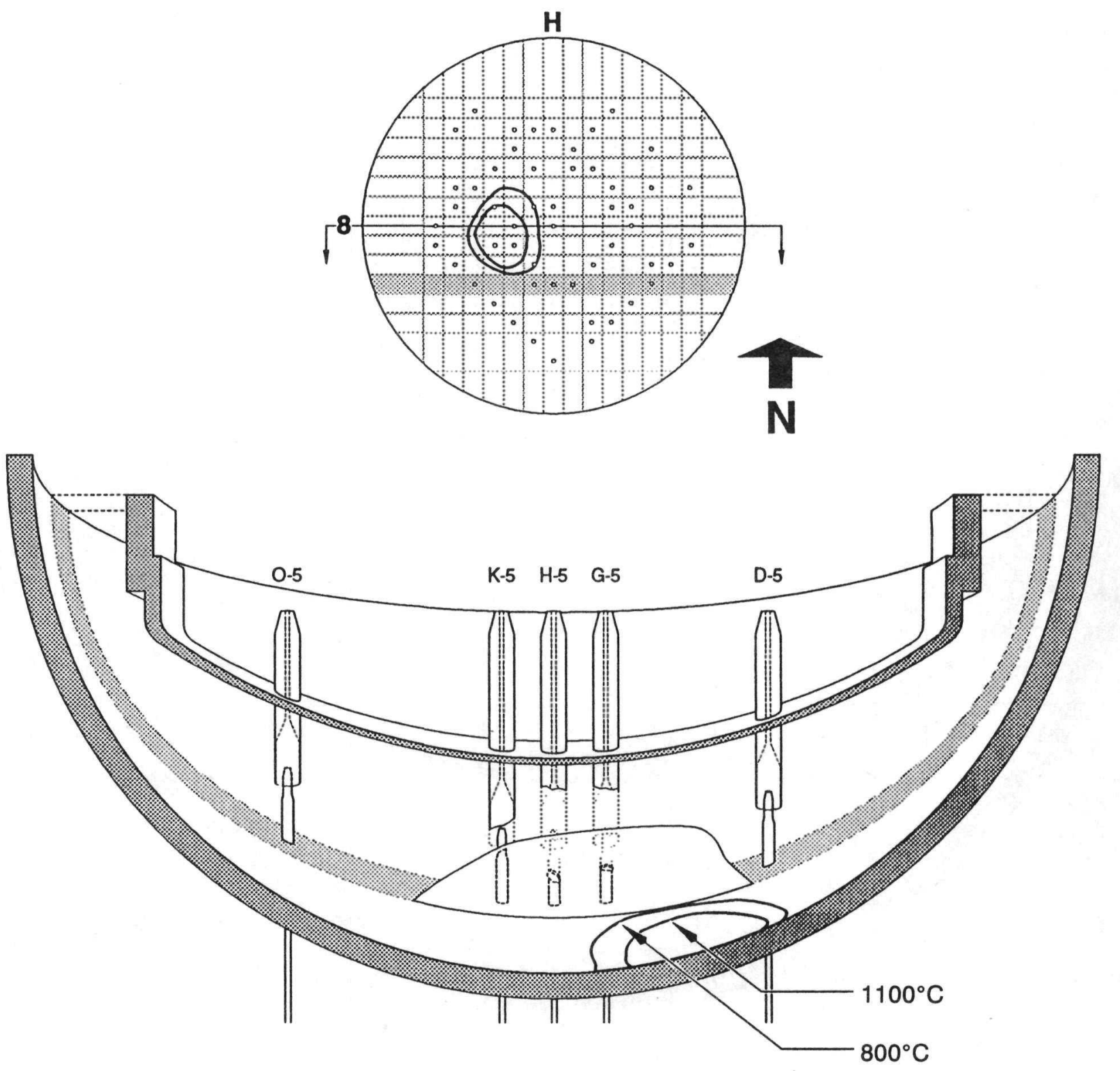

Figure 8-11. TMI-2 lower head cross section of hard debris, row 5. 


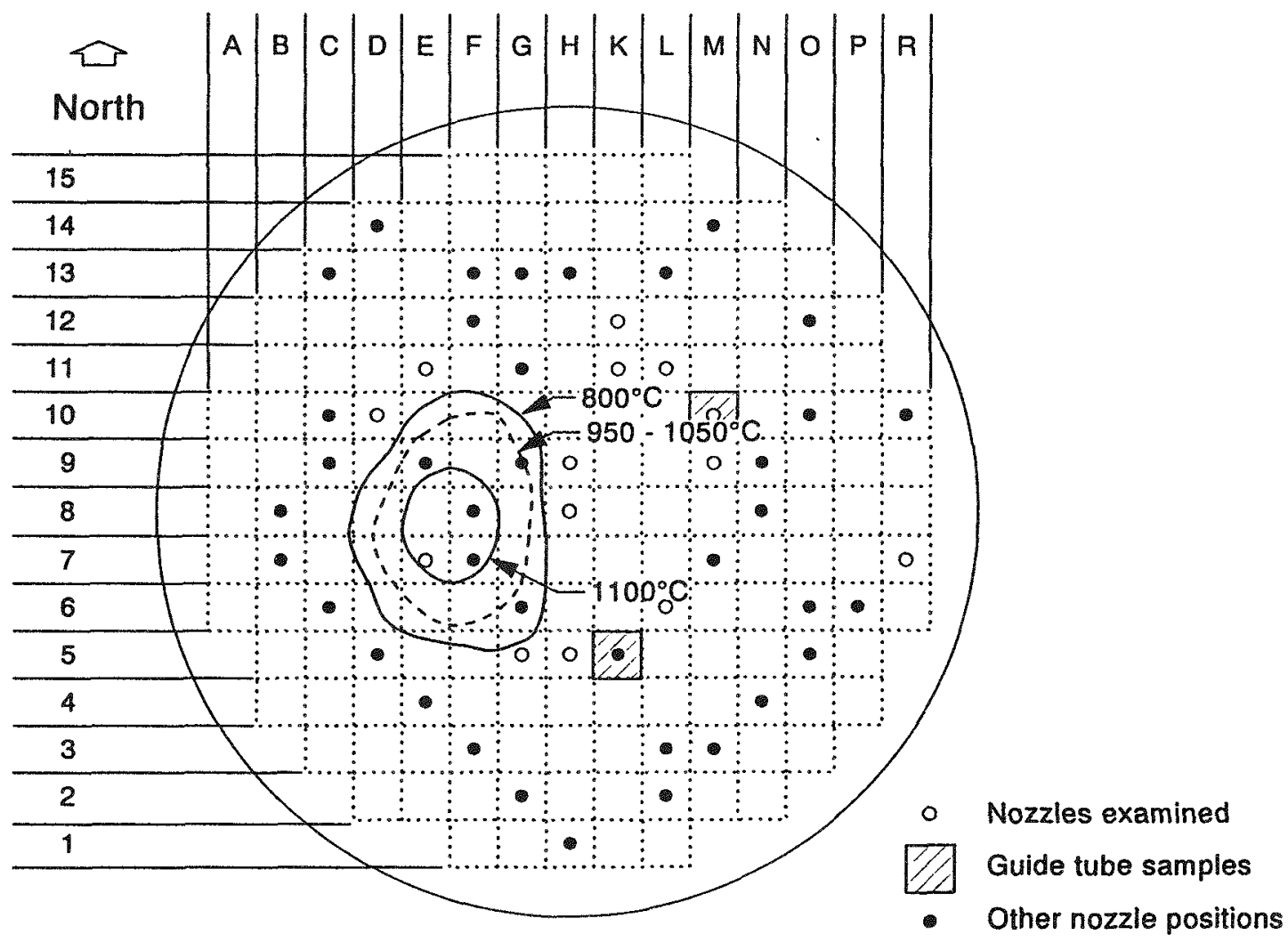

nowse now-0083 os

Figure 8-12. Lower head hot spot and nozzle/guide tube locations. 
The mechanism that was responsible for the postulated rapid cooling of the lower head after 30 minutes has not been adequately explained. One proposed mechanism for this rapid cooling is the presence of interconnected flow channels within the debris and between the vessel and the debris layer. A considerable period of time (up to 30 minutes) would be required to adequately cool the peripheral portions of the debris before water could penetrate through to the hot spot location. Upon penetration of water through gaps between the debris and the vessel wall, the vessel steel could have cooled rapidly as indicated by the metallurgical examinations.

\subsection{Relocation Scenario Conclusions}

A scenario has been postulated based upon available plant instrumentation records and postaccident examination results. Although it is recognized that this scenario is not the only potential relocation scenario, it is consistent with information from plant data, VIP examinations, and analysis efforts. Key points of the scenario discussed in this section are summarized below:

- Relocating molten fuel flowed down through the core support assembly and onto the eliptical flow distributor plate.

- The initial molten fuel flow plugged holes around the periphery of the eliptical flow distributor plate, causing molten material to relocate from this plate to the lower head at several locations.

- The initial molten debris on the lower head cooled rapidly and formed an insulating layer of variable thickness that protected the lower head and many of the nozzles from damage.

- The pattern of molten material deposition on the lower head resulted in most of the vessel being insulated and protected from thermal damage. However, in the area just to the west of center (E-7, E-8, and F-8), the insulating layer was not sufficiently thick to protect the lower head, producing a localized hot spot.

- Effects, such as porosity in the insulating debris bed and cracking that occurred as the basal crust was formed, allowed water to penetrate into the debris bed to maintain some cooling.

- The hot spot remained hot for 30 minutes until water penetrated to the lower head between the crust and the vessel wall and caused rapid cooling of the vessel steel.

\subsection{References}

1. J. M. Broughton, P. Kuan, D. A. Petti, and E. L. Tolman, "A Scenario of the Three Mile Island Unit 2 Accident," Nuclear Technology, 87, No. 1, August 1989, p. 34.

2. D. W. Akers and R. K. McCardell, "Core Materials Inventory and Behavior," Nuclear Technology, 87, No. 1, August 1989. 
3. Quick Look Inspection: Report on the Insertion of a Camera Into the TMI-2 Reactor Vessel Through a Leadscrew Opening, GEND-030, EG\&G Idaho, Inc., Vol. 1 and 2, March/April 1983.

4. M. L. Russell, TMI-2 Core Cavity Sides and Floor Examinations, GEND-INF-074, EG\&G Idaho, Inc., December 1985 and January 1986.

5. K. Vinjamuri, D. W. Akers, and R. R. Hobbins, Examination of H8 and B8 Leadscrews from Three Mile Island Unit 2, GEND-INF-052, EG\&G Idaho, Inc., September 1985.

6. D. W. Akers et al., TMI-2 Core Debris Grab Samples-Examination and Analysis, GEND-INF-075, EG\&G Idaho, Inc., September 1986.

7. V. R. Fricke, Quick-Look Inspection Results, GPU Technical Report TPO/TMI-026, Rev. 0, December 1982.

8. P. Kuan, Core Relocation in the TMI-2 Accident, EGG-TMI-7402, EG\&G Idaho, Inc., November 1986.

9. S. Bokharee, Fuel Debris in Region Between Core Former Baffle Plates and Core Barrell, TMI-2 Technical Bulletin TB 87-9, May 12, 1987.

10. S. Bokharee, Fuel Debris in Region Between Core Former Baffle Plates and Core Barrel, TMI-2 Technical Bulletin TB 87-9, Rev. 1, July 9, 1987.

11. GPU Nuclear, Inc., "Color Inspection of E/SE Core Former Region After Defueling Former Plates 6, 7, 8, LGRS," VHS video, October 26, 1987.

12. G. R. Eidam et al., "TMI-2 Defueling Conditions and Summary of Research Findings," Proceedings of the International Symposium on Severe Accidents in Nuclear Power Plants, Sorrento Italy, March 21-25, 1988.

13. P. Hofmann et al., "Reactor Core Material Interactions at Very High Temperatures," Nuclear Technology, 87, No. 1, August 1989.

14. R. V. Strain, L. A. Neimark, and J. E. Sanacki, "Fuel Relocation Mechanisms Based on Microstructures of Debris," Nuclear Technology, 87, No. 1, August 1989, p. 214.

15. V. R. Fricke, Reactor Lower Head Video Inspection - Phase II, TMI-2 Technical Bulletin TB86-3, January 8, 1986.

16. J. Adams and R. Smith, TMI-2 Lower Plenum Video Data Summary, EGG-TMI-7429, EG\&G Idaho, Inc., July 1987.

17. M. L. Russell and R. K. McCardell, "Three Mile Island Unit 2 Core Geometry," Nuclear Technology, 87, No. 4, December 1989.

18. G. E. Korth, Metallographic and Hardness Examinations of TMI-2 Lower Pressure Vessel Head Samples, TMI V(92)EG01, OECD-NEA-TMI-2 Vessel Investigation Project, EG\&G Idaho, Inc., January 1992. 



\section{CONCLUSIONS}

Through the efforts of the VIP Signatories who supported the project, numerous significant contributions were made that dramatically increased the understanding of both the extent of damage to the vessel lower head and the margin of structural integrity that remained in the vessel. The principal results and conclusions from this project are discussed below.

- Vessel steel examinations indicated that a localized hot spot developed in the region of samples E-6, E-8, F-10, and G-8. In this region, the maximum temperature of the ferritic steel base metal near the interface with the stainless steel cladding was approximately $1,100^{\circ} \mathrm{C}$. The steel may have remained at this temperature for as long as 30 minutes before cooling occurred. Temperatures $5 \mathrm{~cm}$ into the $14.2-\mathrm{cm}$-thick vessel wall (the thickness includes the cladding) were estimated to be $100 \pm 50^{\circ} \mathrm{C}$ lower than the peak surface temperatures. Away from the vicinity of the hot spot, lower head temperatures did not exceed the $727^{\circ} \mathrm{C}$ transformation temperature.

- Even though a definitive scenario describing the movement of molten fuel and the formation of a localized hot spot during the lower head relocation process cannot be determined, there is evidence based on nozzle damage patterns to suggest that the initial flow onto the lower head formed an insulating layer that protected the lower head itself and several of the nozzles from extensive damage. Nozzle damage occurred in locations where the molten lava-like flow moved across the top of the insulating debris layer and contacted the nozzles in the areas where damage was found. The hot spot formed in a location where this debris layer had insufficient thickness to effectively insulate the lower head from the molten lava-like flow.

- Large margins to failure existed throughout the TMI-2 event for the failure mechanisms of tube rupture. Melt penetration calculations indicated that ceramic melt would not penetrate below the vessel head, which resulted in the margin to failure for this failure mechanism being extremely high. This effectively eliminated the possibility of an ex-vessel tube rupture.

- Lower head penetration weld failure calculations were performed, and results indicated that there was a considerable margin in the weld's integrity. Hence, the need for any tube ejection analysis was precluded, and the possibility of a tube ejection was eliminated.

- Jet impingement calculations indicated that the magnitude of the hot spot temperatures estimated in the metallurgical examinations were due to a longer-term heatup of the debris rather than from a jet impinging directly on the lower head.

- Analyses indicated that for a TMI-2 type accident, a localized effect such as a hot spot will shorten the overall global vessel failure time but is unlikely to cause vessel failure by itself as long as the background lower head temperatures (outside the area of the hot spot) remain cool. 
- Using simplified models of debris cooling, the margin-to-failure analysis for the lower head indicated that the calculated vessel temperature distribution would have resulted in vessel failure when the reactor system was repressurized. Additional debris cooling by water flowing through gaps between the debris and the lower head or by water flowing through cracks in the debris was postulated to have occurred within the first 2 hours after debris relocation to the lower head to prevent the calculated vessel failure.

The potential for the vessel to experience a global failure was evaluated for vessel temperature distributions based upon nominal and lower-bound input assumptions for parameters such as debris decay heat, outer vessel heat transfer coefficients, and debris to gap heat transfer resistance. It was also assumed that the debris experienced relatively slow cooling rates in order to be consistent with companion sample examinations and incore thermocouple data. Global failure was predicted to occur 1.7 hours after relocation of debris to the lower head for the nominal case and 2.3 hours after relocation for the lower-bound case.

- Analyses were performed to quantify the magnitude of additional cooling needed in order to obtain results consistent with metallurgical examination data. Results indicated that additional cooling from coolant flowing through channels within the debris bed and from coolant flowing between the debris and the vessel needed to be modeled in order for the vessel thermal response to be consistent with metallurgical examination data. Calculations indicated that coolant traveling within a negligible volume of channels within the debris bed (i.e., much less than $1 \%$ of the debris bed volume) and that a very small gap thickness (e.g., as small as $1 \mathrm{~mm}$ ) would provide sufficient cooling. 
NAC FOAM 335

(2-89!

NACM 1102.

3201,3202

2. TITLE AND SUBTITLE

TMI-2 Vessel Investigation Project Integration Report

BIBLIOGRAPHIC DATA SHEET

(Se instructions on the reverse)

5. AUTHOR(S)

J. R. Wolf, J. L. Rempe, L. A. Stickler, G. E. Korth, D. R. Diercks, L. A. Neimark, D. W. Akers, B. K. Schuetz, T. L. Shearer, S. A. Chd vez, G. L. Thinnes,

R. J. Witt, M. L. Corradini, J. A. Kos
U.S. NUCLEAR REGULATOAY COMMISSION 1. REPORT NUMBEA

(Asslgne bY NRC, Add Vot., Supp., Plev.

NUREG/CR-6197

TMI V(93)EG10

EGG-2734

3. DATE REPORT PUBLISHEO

MONTH

March

1994

4. FINOA GRANT NUMBER

A6899

6. TYPE OF REPORT

Technical

7. PERIOD COVERED UnCLUSUE DaTes

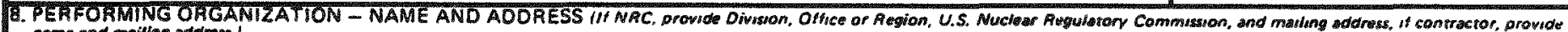
navne and mailling addusas,

EG\&G Idaho, Inc.

Idaho Falls, ID 83415

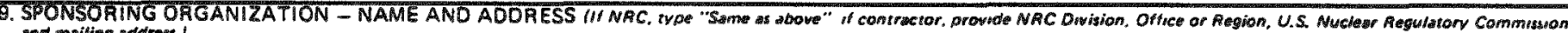
end matiting oddress.

Division of Systems Research

Office of Nuclear Regulatory Research

U.S. Nuclear Regulatory Commission

Washington, D.C. $20555-0001$

10. SUPPLEMENTARY NOTES

11. ABSTRACT 1200 words or lass

The Three Mile Island Unit 2 (TMI-2) Vessel Investigation Project (VIP) was an international effort that was sponsored by the Nuclear Energy Agency of the Organization for Economic Cooperation and Development. The primary objectives of the VIP were to extract and examine samples from the lower head and to evaluate the potential modes of failure and the margin of structural integrity that remained in the TMI-2 reactor vessel during the accident.

This report presents a summary of the major findings and conclusions that were developed from research during the VIP. Results from the various elements of the project are integrated to form a cohesive understanding of the vessel's condition after the accident.

12. KEY WORDS/DESCR! PTORS /List words or phrowest thet will assist researehers in locating the report. I

TMI-2, Metallography, Hardness, Thermal Damage, Accident Temperatures, Nuclear Material, Radionuclide Behavior, Core Debris, Nuclear Material, Core Materials Behavior, Reactor Material Interactions, Vessel Thermal Response, Vessel Structural Response, Melt-water Interactions, Tube Failure, Melt Penetration in Tubes

13. AVAILABILITY STATEMENT
Unlimited
14. SECUAITY CLASSIFICATION
TThis PageI
Unclassified
Trma REPOn!
Unclassified
15. NUMBER OF PAGES
16. PRICE


